LBL -28271

DE9 $0 \quad 008494$

Reaction of Tris(cyclopentadienyl)uranium Compounds with Amines, Azides, and Related Ligands

\author{
Robert Keith Rosen \\ Materials and Chemical Sciences Division \\ Lawrence Berkeley Loboratory \\ 1 Cyclotron Rond \\ Berkeley, California 94720
}

\title{
DISSERTATION
}

Submitted in partial satisfaction of the requirements for the degree of DOCTOR OF PHILOSOPHY

\author{
in \\ CHEMISTRY \\ in the \\ GRADUATE DIVISION \\ of the \\ UNIVERSITY OF CALIFORNIA at Berkeley
}

December 1989

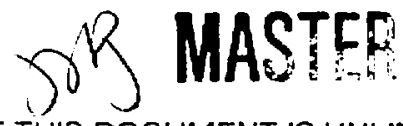




\section{Reaction of Tris(cyclopentadienyl)uranium Compounds with Amines, Azides, and Related Ligands}

Robert Keith Rosen

\section{Abetract}

The trivalent uranium compound, (McC5 $\left.\mathrm{H}_{4}\right)_{3} \mathrm{U}($ tht), serves as a one- or two-electron reducing agent towarcis azides, $\mathrm{RN}_{3}$. These reactions produce either the uranium(IV) azide, $\left(\mathrm{MCC}_{3} \mathrm{H}_{4}\right)_{3} \mathrm{UN}_{3}$ or uranium(V) imides, $\left(\mathrm{MeC}_{5} \mathrm{H}_{4}\right)_{3} \mathrm{UNR}$. The role of steric and electronic effects upon this reaction has been investigated using several series of azides. For $\mathrm{Me}_{3} \mathrm{XN}_{3}$, the imides are produced when $X=C$ or $S i$, both products are formed when $X=G e$, and the azide is produced when $X=\mathrm{Sn}$. For $\mathrm{Ph}_{3} \mathrm{XN}_{3}$, the azide is produced when $\mathrm{X}=\mathrm{C}$ or $\mathrm{Sn}$. For $\mathrm{Ph}_{3-x} \mathrm{CH}_{x} \mathrm{~N}_{3}$, the imide is produced when $\mathrm{x}=2$ and both compounds are produced when $x=1$. For substituted phenylazides, $R_{6} \mathrm{H}_{4} \mathrm{~N}_{3}$, only the imides are produced.

$\left(\mathrm{MeC}_{5} \mathrm{H}_{4}\right)_{3} \mathrm{UN}_{3}$ forms an adduct with the Lewis acid $\mathrm{AlMe}_{3}$. $\left(\mathrm{RC}_{5} \mathrm{H}_{4}\right)_{3} \mathrm{UN}_{3}$ also forms an adduct with $\left(\mathrm{RC}_{5} \mathrm{H}_{4}\right)_{3} \mathrm{U}(\mathrm{R}=\mathrm{Me} \text { or SiMe})_{3}$. The azide ligand is displaced upon reaction with $\mathrm{CO}_{2}(\mathrm{CO})_{8}$ to form $\left(\mathrm{MeC}_{5} \mathrm{H}_{4}\right)_{3} \mathrm{U}-\mu-\mathrm{OC}\left[\mathrm{CO}_{3}(\mathrm{CO})_{9}\right]$.

The magnetic moments of the imides were measured to be $\mu_{\mathrm{e} f f}=1.2$ 1.6 B.M. (5-40 K), and $\mu_{\text {eff }}=1.8-2.3$ B.M. (ca. $\left.140-280 \mathrm{~K}\right) .\left(\mathrm{MeC}_{5} \mathrm{H}_{4}\right.$ ) UNAr (AI = p-tolyl) acts as an oxidizing agent; $a$ mixture of this imide and the uranium(II) amine $\left(\mathrm{MeC}_{5} \mathrm{H}_{4}\right)_{3} \mathrm{U}\left(\mathrm{NH}_{2} \mathrm{Ar}\right)$ yields the uranium(IV) amide, $\left(\mathrm{MeC}_{5} \mathrm{H}_{4}\right)_{3} \mathrm{UNHAr}$. $\left(\mathrm{MeC}_{5} \mathrm{H}_{4}\right)_{3} \mathrm{UNPh}$ inserts $\mathrm{CO}$ to give the bridged phenylisocyanate compound $\left[\left(\mathrm{MeC}_{5} \mathrm{H}_{4}\right)_{3} \mathrm{U}\right]_{2}-\mu-\mathrm{PhNCO}$. The imides also are 
reduced by azides to give $\left(\mathrm{MeC} \mathrm{C}_{5} \mathrm{H}_{3} \mathrm{UN}_{3}\right.$, by $\mathrm{CO}_{2}(\mathrm{CO})_{8}$ to give $\left(\mathrm{MeC}_{5} \mathrm{H}_{4}\right)_{3} \mathrm{U}-\mu-\mathrm{OC}\left[\mathrm{CO}_{3}(\mathrm{CO})_{9}\right]$, and by alcohols to give $\left(\mathrm{MeC} \mathrm{C}_{5} \mathrm{H}_{4}\right)_{3} \mathrm{UOR}$.

The magnetic properties of uranium diimides, $\left[\left(\mathrm{MeC}_{5} \mathrm{H}_{4}\right)_{3} \mathrm{U}\right]_{2}(\mu-N R N)$, were investigated. When $\mathrm{NRN}=1,4-\mathrm{N}_{2} \mathrm{C}_{6} \mathrm{H}_{4}$ the compound is antiferromagnetic $\left(T_{N}=c a .18 \mathrm{~K} ; \mathrm{J}=c a .-19 \mathrm{~cm}^{-1}\right)$. For $1,3-\mathrm{N}_{2} \mathrm{C}_{6} \mathrm{H}_{4}$, as well as stilbene and nupthalene diimides, no magnetic exchange is observed.

Several uranium(III) amines, $\left(\mathrm{MeC}_{5} \mathrm{H}_{4}\right)_{3} \mathrm{U}\left(\mathrm{NH}_{2} \mathrm{R}\right)$, were produced from $\left(\mathrm{MeC}_{5} \mathrm{H}_{4}\right)_{3} \mathrm{U}\left(\right.$ thf and $\mathrm{RNH}_{2}$, and $\mathrm{NH}_{3} \mathrm{w}, \mathrm{s}$ und to be : better ligand towards $\left(\mathrm{MeC}_{3} \mathrm{H}_{4}\right)_{3} \mathrm{U}$ then is $\mathrm{PMe}_{3}$. $\left[\left(\mathrm{MeC}_{5} \mathrm{H}_{4}\right)_{3} \mathrm{U}\right]_{2}\left[\mu-1, A,\left(\mathrm{~A}_{2} i^{2} \cdot{ }_{2} \mathrm{C}_{6} \mathrm{H}_{4}\right]\right.$ was prepared and does not exhibit electronic exchange between the metal centers. The amines may be oxidized to $\left(\mathrm{MeC}_{5} \mathrm{H}_{4}\right)_{3} \mathrm{UNH}$ thermally or chemically; the rate of thermolysis was found to be first-order in $\left(\mathrm{MeC}_{5} \mathrm{H}_{4}\right)_{3} \mathrm{U}\left(\mathrm{NH}_{2} \mathrm{R}\right)$.

$\left(\mathrm{MeC}_{5} \mathrm{H}_{4}\right)_{3} \mathrm{UMe}$ is formed from $\left(\mathrm{MeC}_{5} \mathrm{H}_{4}\right)_{3} \mathrm{UNH}_{2}$ and $\mathrm{AlMe}_{3}$. $\left(\mathrm{MeC}_{5} \mathrm{H}_{4}\right)_{3} \mathrm{UN}\left(\mathrm{NH}_{2}\right) \mathrm{Ph}$ is produced from either $\left(\mathrm{MeC}_{5} \mathrm{H}_{4}\right)_{3} \mathrm{U}$ (ihf), $\left(M e C_{5} H_{4}\right)_{3} \mathrm{UR}\left(\mathrm{R}=\mathrm{Me},{ }^{\mathrm{Bu}}\right)$, or $\left(\mathrm{MeC}_{5} \mathrm{H}_{4}\right)_{4} \mathrm{U}$ and phenylhydrazine; this phenylhydrazido(1-) complex may be thermolyzed to the amide, $\left(\mathrm{M} \mathrm{EC}_{5} \mathrm{H}_{4}\right)_{3} \mathrm{UNHPh}$.
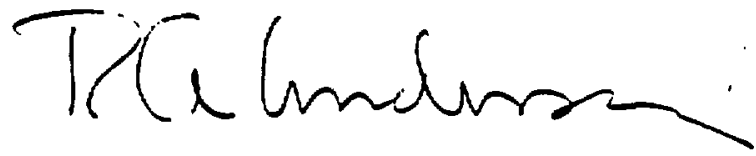


\section{Acknowledgements}

Whew. Well, the hell of the last four weeks or so is winding to a close, and finally I get a chance to forget chemistry for awhile and ramble about those who helped me get this thing done. Those reading this who know me well realize how I love having an audience to babble to, whether it be aloud or on paper. This entire document reflect that. I, as you know, am not the unemotional type; I tell those whom I feel strongly about exactly how I feel. Thus, these acknowledgments will take awhile. Not that I have more people to thank than anyone else, I just like doing it more, and this is my chance.

In the spring of 1984, 1 visited Berkeley on a rainy day. While walking from Latimer to the Faculty Club for lunch, Dick Andersen told me that he had become hooked on synthetic organometallic chemistry the first time he made an emeraid green compound. Dick, I truly believe you about that, and never has a single comment and the way in which it was spoken had such an influence on my life. Right there, I decided on Berkeley, on working with you, and on organometallics, and it is a decision I will never regret for a moment. I don't expect to ever meet anyone with such a passion for chemistry. I have learned to think about molecules, to stand up for my ideas... the list of what you have taught is endless. I hope I've made you a tiny bit more famous in my time in the center of tho universe; at the very least i hope you're pleased with what you got, because I certainly got so much from you. I will deeply miss talking science, baseball, and life with you, and hope we'll still get the chance. Every once in awhile you'll want to revoke this thing; do me a favor and resist the temptation.

I have never regretted working up on the hill at LBL rather than on campus, primarily because of the very special people who made it a superb 
work environment. George, I thank you for all the help, the many quips, the spider web for N.E.'s office, and the use of the magnetometer room (it's one hot pickup spot). Norm, LIGHTEN UP. You drive me completely crazy, but, believe it or not, I have tremendous respect for you and you're not bad at taking a joke (usually). "Unde" Jerry (because that is truly how I think of you), I'll really mise you. Don't clean it up; you wouldn't be the same without piles. Thanks for gyerything. You were responsible for helping me get a lot accompllahed in this theais work by providing what was needed and keeping it running (even if I had to push a little). I'll miss 8 a.m. coffee and computers a lot, even if we usually just grunted at one another anyway. To Alan, Dave P., Glen, and the reat....thanks.

Because, as most of you know, l've stuck around a tad longer than most, there have been a lot of members of the Andersen group, so I can't get too detailed here. John and Steve got me going and put up with me daily; Dave , Carol, Nikki, and Joanne made it lots of fun in the early years. Later, it was Mikey and Sharon. And most recently, Phil, Wayne, Marc, Mike, and Wing (the pseudo-groupmember). I want to thank you five especially; the last year and a half has been fantastic. Wing, you've been a great help in many things and given good advice. Don't let Norm be abusive for too much longer. To my two most recent hillmates, Marc and Wayne: thanks for listening, suggesting, joking, machine-hitting, taking phone calls, and generally keeping me in line and sane. You're a great pair to work with, and III really miss you. ("Is that right, Chief?")

Finally, there have been several truly special friends without whom I had no chance of survival.

Mary and Evan (soon to be Mr. and Mrs.), you are wonderful roomies and friends. I can't count how many times I've turned to you, and you've 
never let me down. I wish you the best things in your life together, and I hope you keep having great memories of our time on Stockton Ave. $M$, thanks for listening so much, even when you didn't want to, and giving advice that almost always turned out right. I'll miss getting tickled or whacked with pillows - watching TV will be no challenge anymore.

Sarah (ee?), the last five months of my time here has been made very special and unforgettable by your love and friendship. You've calmed me down when it all got to be too much for me, and you've pushed me when it was badly needed. Keep asking queations even if it annoys people; you truly kept me on my toes. I'll deeply miss having you around for all our discussions, friendly disagreements, or just to be with someone who cares, understands, and listens. There are too many good memories to list, so just ke:p them warm and close to your heart, and when things get tough here, think of me, call me, and remember how fun it sometimes can be.

Steve, my roomie, labmate, officemate, and big brother: well, I finally made it, too. You've been there through it all, so what can I say that you don't already know? We've shored more than I can start to list; we've gone through our prelims, helped each other with relationship problems, cooked huge birds, won softball championships...well, you know. Thank you for picking me up whenever I stumbled along the way. You're the greatest and I'll really miss you and C.P.

Jenny, you were there for so much of what has gone in here. I will always consider your love and support a huge part of any success I had here, and having a non-chemist to talk to helped me put things in perspective sometimes. No matter where we end up. I'm proud of all you've accomplished, and I know you'll make it big. Thank you for all the great times, for showing me California and making me love it so much, and for 
always being there when things hit their lowest. We sure kept things feisty a lot, but we've never let one another down. Your love and friendship and the thoughts of all we've been through together is something I'll always cherish.

Finally, one group of people has seen me through not only this work, but my whole life as well. Mom, Dad, and Steve, I can't thank you enough for your support and love through all of this. It's been hard to be a continent away from you when times got tough, but you've never been too busy to listen and help, or even to kt me plck up and fly home when I needed a break. I hope l've made you proud, because you are so much a part of all of this; your encouragement to dream my wildest dreams, your confidence in me to go out and attain those dreams, and your support when I sometimes failed for awhile were the forces that have guided me through all of my achievements thus far. No one could ask for a better family, and I value your love and friendship above anything in life. Thank you so much. 
Table of Contents

Introduction

Chapter 1 Preparation and Reactions of Tria(cyclopentadienyl)uranium Azide and Imide Compounds

Section 1.1 Results of Reactions of Trivalent Uranium Metallocenes

with Axides

Section 1.2 Discussion of Reactions of Trivalent Uranium Metallocenes with Aaides

Section 1.3 Properties and Reactions of $\left(\mathrm{RC}_{5} \mathrm{H}_{4}\right)_{3} \mathrm{UN}_{3}\left(\mathrm{R}=\mathrm{Me}, \mathrm{SiMe}_{3}\right) \ldots$

Section 1.4 Properties and Reactions of $\left(\mathrm{MeC}_{5} \mathrm{H}_{4}\right)_{3} \mathrm{UNR}$............................. 59

References

Chapter 2 Reactions of $\left(\mathrm{MeC}_{5} \mathrm{H}_{4}\right)_{3} \mathrm{U}(\mathrm{thf})$ with Diazides ............................ 104

Section 21 Preparation and Properties of $\left[\left(\mathrm{MeC}_{5} \mathrm{H}_{4}\right)_{3} \mathrm{U}_{2}\left(1,4-\mathrm{N}_{2} \mathrm{C}_{6} \mathrm{H}_{4}\right) \cdots \cdots 114\right.$

Section 22 Preparation and Properties of $\left[\left(\mathrm{MeC}_{5} \mathrm{H}_{4}\right)_{3} \mathrm{U}_{2}\left(1,3-\mathrm{N}_{2} \mathrm{C}_{6} \mathrm{H}_{4}\right) \ldots \ldots . .125\right.$

Section 2.3 Two Other Diimides of Uranium(V) ............................................ 138

Section 24 Reaction of $\left(\mathrm{MeC}_{5} \mathrm{H}_{4}\right)_{3} \mathrm{U}(\mathrm{th})$ with $\mathrm{Me}_{2} \mathrm{Si}\left(\mathrm{N}_{3}\right)_{2} \ldots \ldots \ldots \ldots . . . . . . . . . . . . . . .152$

Section 25 Model for the Interpretation of the Antiferromagnetism of the Para-diimide

References 158

Chapter 3 Tris(cyclopentadienyl)uranium Amine, Amide, and Hydrazide Compounds 
Section 3.1 Preparation and Properties of $\left(\mathrm{MeC}_{5} \mathrm{H}_{4}\right)_{3} \mathrm{U}\left(\mathrm{NH}_{2} \mathrm{R}\right)$

Compounds

Section 3.2 Preparation and Properties of $\left(\mathrm{MeC}_{5} \mathrm{H}_{4}\right)_{3} \mathrm{UNHR}$ Compounds 181

Section 3.3 Preparation and Properties of $\left(\mathrm{MeC}_{5} \mathrm{H}_{4}\right)_{3} \mathrm{UN}(\mathrm{R}) \mathrm{NH}_{2}$

Compounds

Section 3.4 Preparation of a Dinuclear Uranium Amine ........................... 205

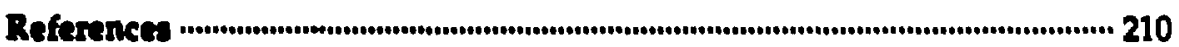

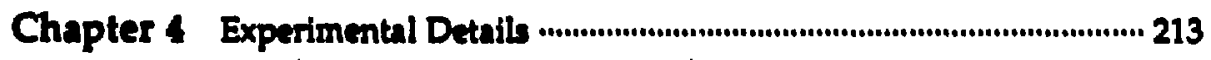

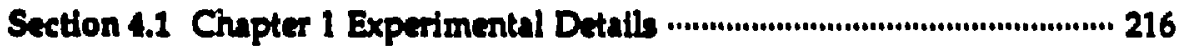

Section 4.2 Chapter 2 Experimental Details …….............................................. 236

Section 4.3 Chapter 3 Experimental Details ……............................................. 240

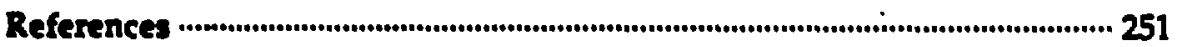




\section{to my parents}

\section{for supporting and loving me}

and

to Dick

for teaching me 


\section{Introduction}

The field of organoactinide chemistry was established with the synthesis of $\mathrm{C}_{\mathrm{P}_{3}} \mathrm{UCl}$ and $\mathrm{C}_{\mathrm{P}_{3}} \mathrm{ThCl}$ by Reynolds and Wilkinson in 1956. ${ }^{1}$

However, it was the proposal by R. D. Fischer that f-orbitals could properly overlap with the cyclooctatetraene dianion ${ }^{2}$ and the subsequent synthesis of uranocene, $\left(\mathrm{C}_{8} \mathrm{H}_{2}\right)_{2} \mathrm{U}$, by Streitwiear and Müller-Westerhoff in $1968^{3}$ that sparked the interest in the organometallic chemistry of the f-metals.

There are a number of reasons for choosing an actinide rather than a lanthanide to study the synthesis and reactivity of f-metal complexes. In the lanthanide series, the if elections are, due to inefficient nuclear shielding, essentially core electrons; their energies are below those of the 5 s and $5 p$ electrons. Thus, these 4f-orbitals do not possess the spatial extent necessary for interaction with the ligand orbitals, and the bonding in lanthanide complexes is considered to be essentially ionic. Additionally, the oxidation states of the lanthanides are rather limited. All of the ions exhibit stable +3 states, $\mathrm{Yb}, \mathrm{Sm}, \mathrm{Tm}$, and Eu have stable +2 oxidation states, and $\mathrm{Ce}, \mathrm{Tb}, \mathrm{Nd}$, and $\operatorname{Pr}$ have stable +4 states. This, of course, limits the potential redox chemistry of these metals.

These factors, however, are different in the $5 f$ series. In the early actinides, the $5 f$-orbitals are of similar energy to the $65-$ and $6 \mathrm{p}$-orbitals. This results in a greater radial extension of these f-orbitals, and allows the $5 f$ and $6 \mathrm{~d}$ eiectrons to participate in more covalent bonding interactions. ${ }^{4}$ Recent results by Stults and Brennan have dramatically shown this by demonstrating the effect of r.-backbonding interactions in uranium(III) complexes. ${ }^{3}$ Although only uranium and thorium are available for the study of large scale 
synthetic chemistry of the actinides, the wide variety of oxidation states available for uranium makes it an attractive element. While thorium has only a stable +4 oxidation state (and a much less stable +3 ), oxidation states in uranium range from +3 to +6.4 The bulk of the organometallic chemistry of uranium to date has utilized the tetravalent oxidation state, although in recent years study of the trivalent compounds has been undertaken in more detail.6

In 1985, Brennan and Andersen initiated the study of pentavalent organouranium compounds with the syntheses of the cyclopentadienyl uranium imide complexes ( $\left.\mathrm{RC}_{5} \mathrm{H}_{4}\right)_{3} \mathrm{UNR}{ }^{7}$ Because no other organometallic compounds of uranium in the +5 state exist, we set out in work described in this thesis to study the syntheses of these materials and to elucidate their physical and chemical properties in more detail. Chapter 1 concentrates on these investigations. Transition metal imido complexes have been extensively investigated over the last 20-30 years," and comparisons of the properties and reactivity of our f-metal imide compounds with the d-metal materials will be discussed. As a consequence of the synthetic route into these uranium(V) imides, we synthesized tetravalent uranium azides, $\left(\mathrm{RC}_{5} \mathrm{H}_{4}\right)_{3} \mathrm{UN}_{3}$. Although $\mathrm{CP}_{3} \mathrm{UN}_{3}$ has been reported previously, information concerning this compound is available, and thus we felt it would be interesting to study the properties and the chemical reactions of the uranium azides. Azide compounds of main group and transition metals have been the subject of a great deal of study,' and once again we would like to compare the differences and similarities between these compounds and our f-metal species. These azides are also discussed in Chapter 1.

Because of the core-like behavior of the 4 electrons, magnetic susceptibility measurements on compounds of the lanthanide series generally 
yield magnetic moments close to that calculated for the free ion." Conversely, the magnetic moments of the actinide ions are complicated by spin-orbit coupling. The $5 f^{1}$ system found in the pentavalent uranium complexes should be somewhat easier to interpret, and we therefore have investigated the magnetic behavior of several of the uranium imides, and these data are presented in Chapter 1.

One of the consequences of working with these $5 f^{1}$ systems is the possibility of observing magnetic interactions between two pentavalent uranium atoms. This would require the synthesis of a compound containing an appropriate bridging ligand between the metal centers. This possibility is of particular interest in these systems because it has been proposed that $5 \mathrm{f}^{\mathrm{n}}$ systems with half-integer values of $\mathrm{J}$ are most likely to exhibit magnetic ordering, ${ }^{10}$ and for $5 f^{l}, J=5 / 2$. Only in the extended lattice systems in the halides of uranium(III) and plutonium(III) $\left(\mathrm{UCl}_{3}, \mathrm{UBr}_{3}, \mathrm{UI}_{3}, \mathrm{PuCl}_{3}\right)$ has antiferromagnetic coupling been observed; 11 no discrete, molecular compound of the actinides has ever been found to exhibit this phenomenon. Very few compounds in the $4 f$ series have been found in which the lanthanide atoms show evidence of magnetic exchange; the only published example is $C p_{4} D y_{2}(\mu-B r)_{2},{ }^{11}$ although several ytterbium compounds prepared by J. Boncella and D. Berg also exhibit this behavior. ${ }^{12}$ Chapter 2 discusses the synthesis and properties of several dinuclear uranium diimide complexes, with a particular focus upon the magnetic behavior of these materials. Included among these compounds is one which exhibits the first example of antiferromagnetic coupling seen in a molecular actinide system.

The results we obtained using the imido ligand led us to study other nitrogen-containing materials. Nitrogen ligands are often reasonably good Lew:s bases and thus should be reactive towards the actinide metal center; in 
addition the presence of the lone pair on the nitrogen could give rise to further interesting reactivity and the formation of other novel uranium compounds. Many interesting types of nitrogen compounds exist, such as azides (used in the synthesis of the uranium imide and azide compounds), amines, and hydrazines, and these are known to be quite reactive. In particular, we were interested in synthesizing and studying families of related uranium compounds with the metal in different oxidation states, such as the series shown below:

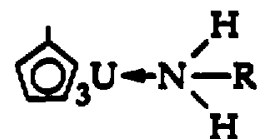

U(III)<smiles></smiles>

U(IV)

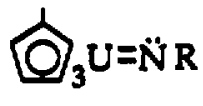

$U(V)$

Chapter 3 discusses the synthesis of uranium(III) primary amine complexes, as well as the oxidation of these materials to the corresponding uranium(IV) amides. No compounds of this type had been previously prepared in the f-metal series. A dinuclear diamine complex of uranium was also prepared, and the magnetism investigated in search of interactions such as those seen in the uranium( $V$ ) compounds discussed in Chapter 2. In addition, Chapter 3 will also report several reactions forming uranium(IV) hydrazide compounds, and the unusual thermolysis reaction of these materials resulting in the cleavage of the $\mathrm{N}-\mathrm{N}$ bond. 


\section{References}

1 Reynolds, L. T.; Wilkinson, G. J. Inorg. Nucl. Chem. 1956, 2, 246.

2 Fischer, R. D.; Theoret. Chim. Acta 1963, 1, 418.

3 Streitwieser Jr., A.; Müller-Westerhoff, U. J. Am. Chem. Soc. 1968, 90, 7364.

- Cotton, F. A.; Wilkinson, G. Adounced Inorganic Chemistry, Fifth Edition John Wiley and Sons, New York, 1988, pp. 955-1017.

S Brennan, J. G.; Stults, S. D.; Andersen, R. A.; Zalkin, A. Organometallics $1988,7,1329$.

- In addition to reference 4, see, for example, the following : (a) Kannellakopulos, B. in Marks, T. J.; Fischer, R. D.; eds. Organometallics of the f-Elements D. Reidel Publishing Company, Dordrechet, Holland, 1978, pp. 1-35. (b) Marks, T. J.; Emst, R. D. in Wilkinson, G.; Stone, F. G. A.; Abel, E. W.; eds. Comprehensive Organometallic Chemistry Pergamon Press, Oxford, England, 1982, Chapter 21. (c) Takats, J. in Marks, T. J.; Fragala, I. L.; eds. Fundamental and Technological Aspects of Organo-f-Element Chemistry D. Reidel, New York, 1985, pp. 159-193. (d) Weigel, F. in Katz, J. J.; Morss, L. R.; Seaborg, G. T.; eds. The Chemistry of the Actinide Elements Chapman and Hall, London, England, 1986, Chapter 5. (e) Tatsumi, K; Nakamura, A. J. Am. Chem. Soc. 1987, 109, 3195, and references therein. (f) Brennan, J. G. Ph.D. Thesis, University of California, Berkeley 1985. (g) Stewart, J. L. Ph.D. Thesis, Unioersity of California, Berkeley 1988 (h) Stults, S. D. Ph. D. Thesis, University of California, Berkeley 1988.

7 Brennan, J. G.; Andersen, R. A. J. Am. Chem. Soc. 1985, 107, 514. 
- See, for example: Nugent, W. A.; Haymore, B. L. Coord. Chem. Reo. $1980,31,123$.

- See, for example: (2) Thayer, J. S. Organomet. Chem. Rev. 1966, Z, 157. (b) Dori, Z.; Ziolo, R. F. Chem. Reo. 1973, 73, 247. (c) Patai, S., ed. The Chemistry of the Azido Group Interscience Publishers, London, 1971. (d) Fair, H. D.; Walker, R. F. Energetic Materials, Volume 1: Physics and Chemistry of the Inorganic Azides, Volume 2: Technology of the Inorganic Azides Plenum Press, New York, 1977.

10 Lea, K. R.; Leask, M. J. M.; Wolf, W. P. J. Phys. Chem. Solids 1962, 23, 1381.

11 Lueken, H.; Lamberts, W.; Hannibal, P. Inorg. Chim. Acta 1987, 132, 111. 12 (a) Boncella, J. Ph.D. Thesis, University of California, Berkeley 1984. (b) Berg, D. B. Ph.D. Thesis, University of California, Berkeley 1987. 


\section{Chapter 1}

\section{Preparation and Reactions of Tris(cyclopentadienyl)uranium Azide and Imide Compounds}

While a great deal of attention has been paid in recent years to organouranium chemistry in the +3 and +4 oxidation states, pentavalent uranium compounds have remained relatively rare. Indeed, the only compounds known of $U(V)$ as of the mid-1980's were the pentavalent halides, $\mathrm{UX}_{5}$ (and related compounds such as $\mathrm{UF}_{6}$ and $\mathrm{Na}_{3} \mathrm{UF}_{2}$ ), the cationic oxide, $\mathrm{UO}_{2}^{+}$, and the oxychloride, $\mathrm{UOCl}_{3}{ }^{1}$ In 1984, Brennan and Andersen reported the two-electron oxidation of $\left(\mathrm{MeC}_{5} \mathrm{H}_{4}\right)_{3} \mathrm{U}($ thr) by phenylazide to give the stable pentavalent imido complex $\left(\mathrm{MeC}_{5} \mathrm{H}_{\varphi_{3}} \mathrm{UNPh}\right.$ and dinitrogen (Scheme 1-1).2

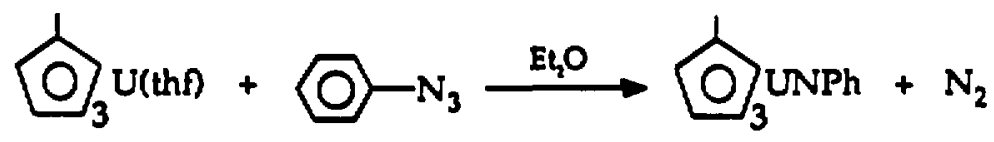

Scheme 1-1: Prepartion of pentayalent uranism imide:

This was the first organometallic derivative of uranium(V). In addition to the crystal structure, the evidence for the presence of the unusual oxidation state of the metal center is supported by the relatively broad linewidths in the ${ }^{2} \mathrm{H} \mathrm{NMR}$ spectrum, giving $\mathrm{MeC}_{5} \mathrm{H}_{4}$ ring resonances with widths of $v_{1 / 2}=40$ $60 \mathrm{~Hz}$. It has been noted that uranium(III) and uranium(V) compounds 
generally exhibit linewidths an order of magnitude greater than similar uranium(IV) compounds. ${ }^{3}$ In addition, Berg obtained magnetic susceptibility data on the related compound, $\mathrm{Cp}_{3} \mathrm{UNSiMe}_{3}$, which indicated that the uranium is pentavalent.

Due to an interest in further examining the properties añis izactivitiy of these pentavalent uranium complexes, we undertook the study of the reactions of trivalent uranium with a wide variety of azides. Early in this work, we came upon a reaction which demonstrated a second possible pathway by which these reactions could proceed. When a solution of trityl azide $\left(\mathrm{Ph}_{3} \mathrm{CN}_{3}\right)$ in diethylether was added to $\left(\mathrm{MeC}_{5} \mathrm{H}_{4}\right)_{3} \mathrm{U}($ thf), a light green precipitate was obtained immediately. This is in marked contrast with the products that had previously been isolated from analogous reactions: there was no noticeable evolution of gas, and the pentavalent complexes $\left(\mathrm{MeC}_{5} \mathrm{H}_{4}\right)_{3} \mathrm{UNPh}$ and $\left(\mathrm{MeC}_{5} \mathrm{H}_{4}\right)_{3} \mathrm{UNSiMe}_{3}$ are quite soluble in ether as well as being very intensely solored. The pale green material could be recrystallized from either toluene or dichloromethane to yield green misrocrystals. The ${ }^{1} \mathrm{H}$ NMR spectrum of this material showed narrow line widths for the ring protons on the cyclopentadiene $\left(v_{1 / 2}=<10 \mathrm{~Hz}\right)$, and the infrared spectrum exhibited a strong, broad stretch at $2115 \mathrm{~cm}^{-1}$.

This evidence suggested that the trivalent uranium had simply undergone a one-electron oxidation, with transfer of the azide group from the trityl group to the uranium, as shown below (Scheme 1-2).

$$
\mathrm{O}_{3} \mathrm{U}(\mathrm{th})+\mathrm{Ph}_{3} \mathrm{CN}_{3} \stackrel{\mathrm{E}, \mathrm{O}}{\longrightarrow} \mathrm{O}_{3} \mathrm{UN}_{3}+" \mathrm{Ph}_{3} \mathrm{C} "
$$

Scheme 1-2: Formation of a uranium(IV) azide from trivalent uranium and tritylazide 
It would then follow that the by-product from the reaction would be the relatively stable trityl radical, which would presumably then dimerize to form the well studied (and well debated) trityl dimer, or "hexaphenylethane."5 This was confirmed by performing the reaction of $\left(\mathrm{MeC}_{5} \mathrm{H}_{4}\right)_{3} \mathrm{U}($ thr) with tritylazide in an NMR tube in deuterated benzene, and observing the ${ }^{{ }^{2}} \mathrm{H}$ NMR spectrum of the priducts. Several distinctive peaks can be easily seen in this spectrum, as shown in Figure 1-1. These include:

1. The three peaks from the tetravalent uranium complex

$\left(\mathrm{MeC}_{5} \mathrm{H}_{4}\right)_{3} \mathrm{UN}_{3}$ located at $8=11.3 \mathrm{ppm},-3.2 \mathrm{ppm}$, and $-17.8 \mathrm{ppm}$.

2. The peaks resulting from tetrahydrofuran, seen as multiplets at $\delta=$ $3.55 \mathrm{ppm}$ and $1.40 \mathrm{ppm}$.

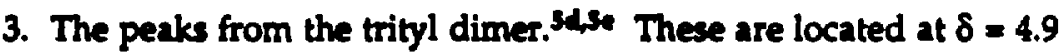
ppm ( $\mathrm{H}_{A}$, singlet), $5.95 \mathrm{ppm}\left(\mathrm{H}_{b}\right.$, doublet of doublets), and $6.45 \mathrm{ppm}$ ( $H_{c}$, doublet). There are also several resonances from the phenyl ring protons seen between $\delta=7.0$ and $7.3 \mathrm{ppm}$.

The diagram below (Figure 1-2) of the currently accepted structure for this dimer $^{\text {se }}$ shows the designations of the protons:

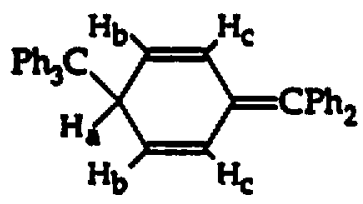

Figure 1-2: The structure of the trityl dimer.

Reactions in which an organoazide functions as an azide transfer reagent are not without precedent, either in organic, inorganic, or transition metal chemistry, although these reactions generally involve replacement of 


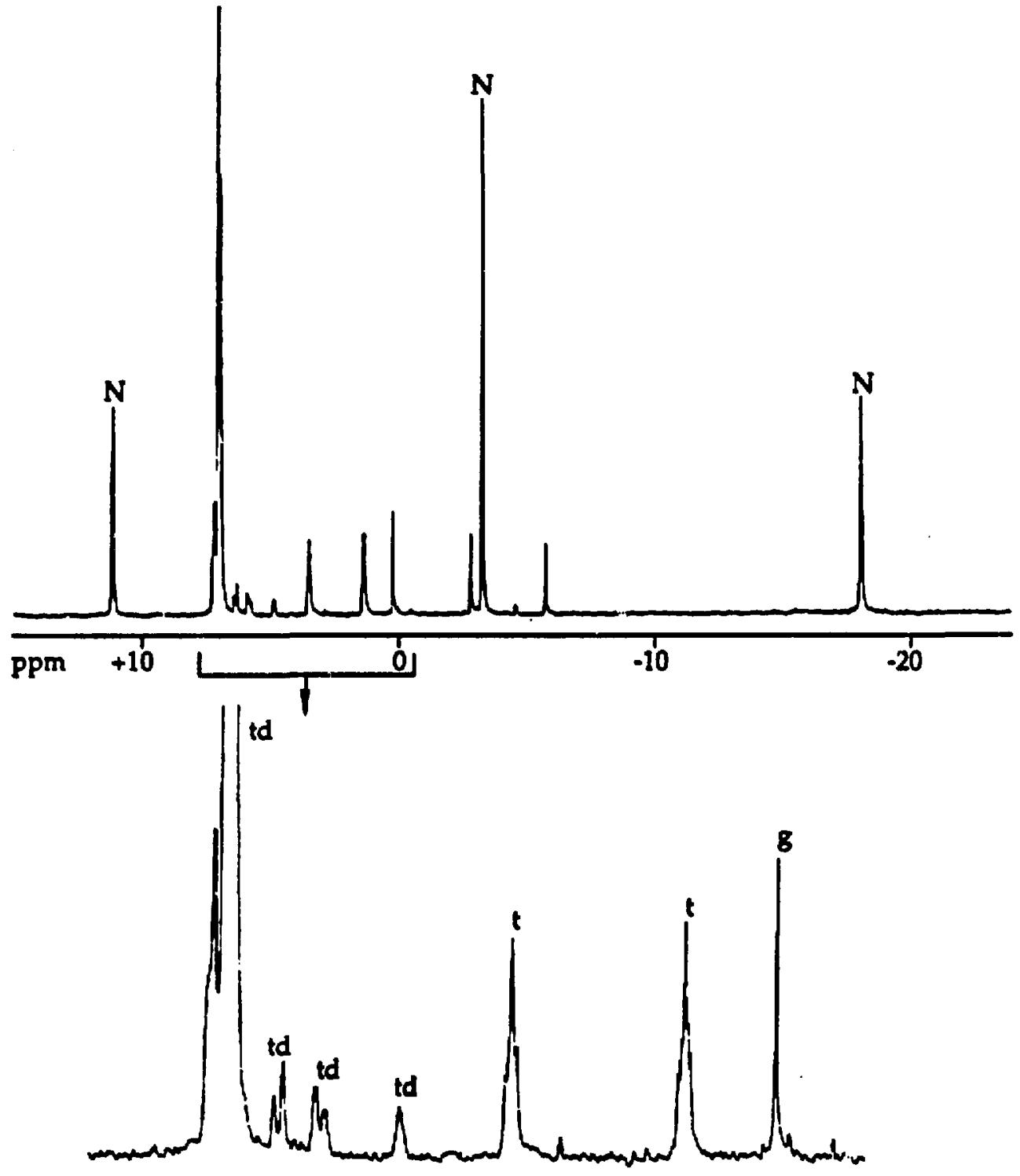

Figure 1-1: 'H NMR spectrum from the NMR tube reaction of $\left(\mathrm{MeC}_{5} \mathrm{H}_{4}\right)_{3} \mathrm{U}$ (th) with $\mathrm{Ph}_{3} \mathrm{CN}_{3}$. The symbols represent the following: N: $\left(\mathrm{MeC}_{5} \mathrm{H}_{4} \mathrm{UN}_{3}\right.$; t thf; td: trityl dimer; 8: stopcock grease. 
some other group with the azide rather than a simple addition as described here. Perhaps the best azide for this purpose is trimethylsilylazide, which is used extensively in organic chemistry to put azide groups on organic molecules.ce Azide transfer reactions are also known for transition metal complexes, although our use of trityl azide for this purpose seems to be rather unusual. One other example has been reported in the literature; this is the oxidation of $\mathrm{CP}_{2} \mathrm{~V}$ with $\mathrm{Ph}_{3} \mathrm{CN}_{3}$ to produce a vanadium(III) azide ${ }^{\text {6d }}$ (Scheme 1-3).

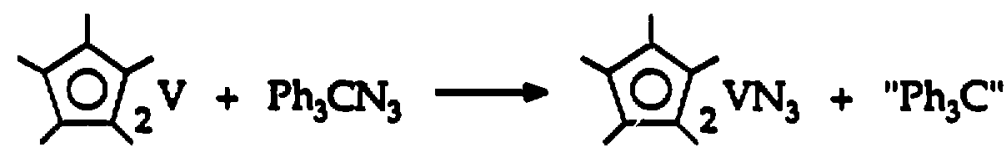

Scheme 1-3: Oxidation of vandocene by tritylazide.

In fact, we have found that a variety of $\mathrm{Ph}_{3} \mathrm{CX}$ compounds may be used as one-electron oxidizing agents towards trivalent uranium. Examples of this are shown below (Scheme 1-4): 


$$
\begin{aligned}
& +\mathrm{Ph}_{3} \mathrm{CCl} \underset{\mathrm{R}=\text { SiMe, }}{\longrightarrow} \stackrel{\mathrm{O}_{3}}{\mathrm{RCl}}
\end{aligned}
$$

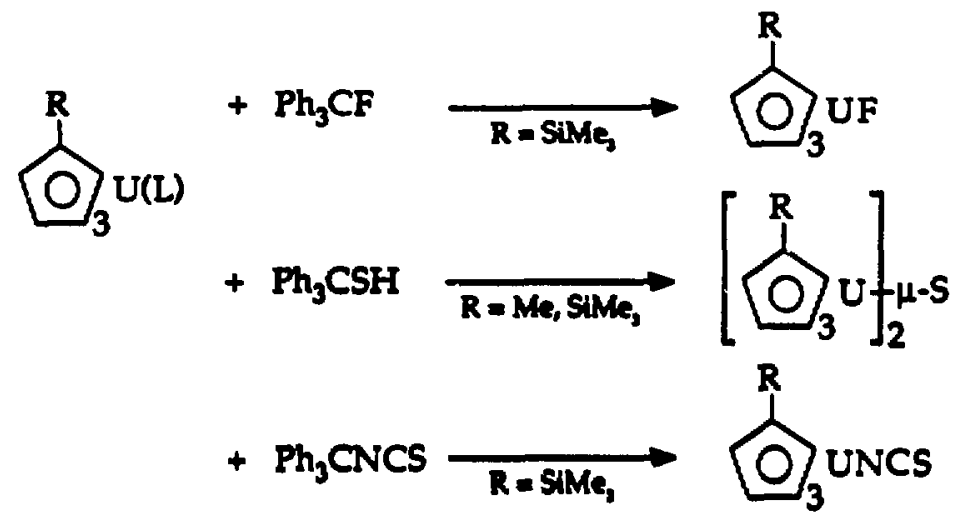

Scherne 1-4: Reaction of trivalent uranium with trityl compounds. Note that when $R=M e, L=$ the, and when $R=$ SiMes, the compound is base-free.

Each of the products shown below has been previously characterized, with the exception of ( $\left.\mathrm{Me}_{3} \mathrm{SiC}_{5} \mathrm{H}_{4}\right)_{3} \mathrm{UNCS}$. ( $\left.\mathrm{Me}_{3} \mathrm{SiC}_{5} \mathrm{H}_{4}\right)_{3} \mathrm{UCl}$ was originally reported by Dormond and Duval, ${ }^{7}\left(\mathrm{Me}_{3} \mathrm{SiC}_{5} \mathrm{H}_{4}\right)_{3} \mathrm{UF}$ has been prepared by Stults, and [( $\left.\left(\mathrm{RC}_{5} \mathrm{H}_{4}\right)_{3} \mathrm{U}\right]_{2}-\mu-\mathrm{S}$ by Brennan.' It should be noted that $\mathrm{Ph}_{3} \mathrm{CNH}_{2}$ and $\mathrm{Ph}_{3} \mathrm{CH}$ did not react with $\left(\mathrm{RC}_{5} \mathrm{H}_{\varphi_{3}} \mathrm{U}\right.$, and $\mathrm{Ph}_{3} \mathrm{COH}$ gave a complex mixture of products.

The compound $\left(\mathrm{MeC} \mathrm{CH}_{5} \mathrm{H}_{3} \mathrm{UN}_{3}\right.$ is not the first reported uranium(IV) azide; $\mathrm{Cp}_{3} \mathrm{UN}_{3}$ was reported as unpublished resuits by Kanellakopulos et. al. in a review article published in 1979.10 The properties of this material appear to resemble that of the methylcyclopentadienyl compound: both are formed in high yield and both are green.

$\left(\mathrm{MeC} \mathrm{H}_{4} \mathrm{H}_{3} \mathrm{UN}_{3}\right.$ was also prepared by an independent method in order to completely confirm its synthesis in the tritylazide reaction. Although the detailed synthesis for $\mathrm{CP}_{3} \mathrm{UN}_{3}$ has not appeared in the literature, reactions 
producing similar $\mathrm{Cp}_{3} \mathrm{UX}$ materials are availatle. These syntheses frequently utilize a reaction first discovered by Reynclds and Wilkinson in 1956, ${ }^{11}$ proceeding oia formation of the aquated cation $\mathrm{Cp}_{3} \mathrm{U}^{+}$from $\mathrm{CP}_{3} \mathrm{UCl}$ in thorougiily deoxygenated water solution. The cation may then be reacted with a variety of $\mathrm{Na}-\mathrm{X}$ or $\mathrm{K}-\mathrm{X}$ salts to yield $\mathrm{C} \mathrm{p}_{3} \mathrm{UX}$ complexes in very good yield ${ }^{12}$ (Schome 1-5):

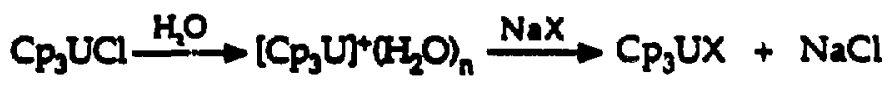

Seheme 1.5. Preparation of unanlum cyelopentadienyls in aqueous solution.

This reaction scheme proved quite successful for the synthesis of the uranium azide. When $\left(\mathrm{MeC}_{5} \mathrm{H}_{4} \mathrm{UCl}_{3} \mathrm{Uas}\right.$ suspended in deoxygenated water, a light green color indicative of the uranium cation developed in the solution, with a great deal of the uranium chioride remaining as a brown solid. Addition of a solution of sodium azide in water resulted in an instant light green precipitate. The $\left(\mathrm{MeC}_{5} \mathrm{H}_{4}\right)_{3} \mathrm{UN}_{3}$ was recovered by filtering off the water, thoroughly drying the solid under reduced pressure, and recrystallizing the material from dichloromethane. This procedure typically provides greater than $80 \%$ yield of the uranium azide.

It is interesting to note that this procedure was unsuccessful in the aftempted preparation of $\left(\mathrm{Me}_{3} \mathrm{SiC}_{5} \mathrm{H}_{4}\right)_{3} \mathrm{UN}_{3}$. When $\left(\mathrm{Me}_{3} \mathrm{SiC}_{5} \mathrm{H}_{4}\right)_{3} \mathrm{UCl}$ was suspended in deoxygenated $\mathrm{H}_{2} \mathrm{O}$, there was no noticeable coloring of the solution to the distinctive pale green of the aquated cation. Addition of a solution of sodium azide in water gave no immediate precipitate, however after several days a green precipitate was slowly formed. After a week of stirring, there seemed to be a great deal of this green solid, but after removing 
the water and drying the exceedingly air-sensitive material, it could not be redissolved in hexane, ether, $\alpha$ toluene. This is in direct contrast with the solubility of a pure sample of $\left(\mathrm{Me}_{3} \mathrm{SiC}_{5} \mathrm{H}_{4} \mathrm{UNN}_{3}\right.$ obtained by oxidation of $\left(\mathrm{Me}_{3} \mathrm{SiC}_{5} \mathrm{H}_{4} \mathrm{U}_{3} \mathrm{U}\right.$ by trimethyltinazide, which is quite hexane soluble (Scheme 1-6).

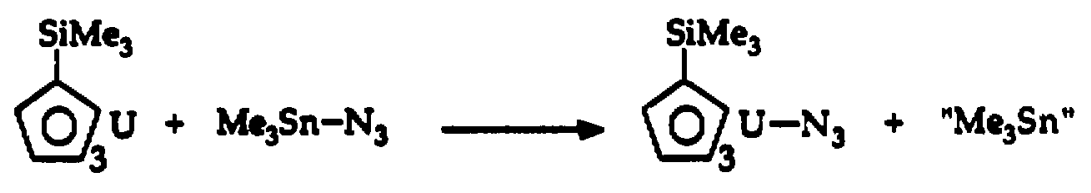

Scheme 1-A Prepantion of $\left(\mathrm{Me}_{3} \mathrm{SCC}_{5} \mathrm{H}_{4}\right)_{3} \mathrm{UN}_{3}$.

A detailed discussion concerning reactions such as the one above as well as of the properties and reactivity of the uranium azide complexes will appear later in this chapter.

The discovery that organic azides could function either as one- or twoelectron oxidizing agents towards uranium(III) led us to undertake a study of a larger group of azides. The goal of this study was to see how variations in the steric and electronic environment of the azide could change the reactivity towards uranium. Of particular interest was seeing whether electronic effects alone could play a significant role. The reason for this was that, as noted above, the one example we had found of an azide acting as an azide transfer reagent involved the very bulky triphenylmethyl group. Could we keep size relatively constant and still see changes in the reactivity? The azides chosen for study can be subdivided into several groups:

1. Trimethyl Group IVA Azides. These include t-butylazide, trimethylsilylazide, trimethylgermylazide, and trimethyltinazide. This 
group should kexp steric effects relatively minimal while greatly altering the electronic environment of the azide.

2. Triphenyl Group IVA Azides. These included tritylazide and triphenyltinazide.

3. Phenylmethylazides. These inciuded tritylazide, diphenylmethylazide (benzhydrylazide), and phenylmethylazide (benzylazide). The behavior of this group should greatly reflect steric differences.

4. Subetituted Fhenylanides. This group allowed us to change electronic effects usine, para substituents, and steric sffects nsing ortho substituents.

A brief mention should be made here on the synthesis and handling of these azides. It should be noted that azides are often unstable, exothermically decoinposing with evolution of $\mathrm{N}_{2}{ }^{13}$ This is particularly true in the presence of heavy metals or at high temperatures. All azide syntheses were carried out with care on reiatively small scales (cr. 10-20 mMol) at room temperattres or below, unless it wa quite certain that the azide was stable to elevated temperatures.

There were two primary synthetic methods used for the preparation of the azides. The first method involves replacement of a halide using sodium azide (Scheme 1-7). Solvent and reaction conditions vary depending on thic particular azide involved.

$$
\mathrm{R}-\mathrm{X}+\mathrm{NaN}_{3} \longrightarrow \mathrm{R}-\mathrm{N}_{3}+\mathrm{NaX}
$$

Schene 1-7: Formation of axides from halides. 
This method is successful for the preparation of $R N_{3}$ when $R=t-B u,{ }^{14 a}$ $\mathrm{GeMe}_{3}{ }^{146} \mathrm{SnMe}_{3}{ }^{146} \mathrm{Ph}_{2} \mathrm{CH},{ }^{14 c}$ and $\mathrm{Ph}_{3} \mathrm{Sn} .{ }^{14 d}$

The second technique for producing azides, used for all the substituted phenyl azides, is by diazotization reactions starting from substituted anilines. ${ }^{13}$ These reactions are typically done at between $0^{\circ} \mathrm{C}$ and $-10^{\circ} \mathrm{C}$ to stabilize the diazonium salt. Once the dirzonium salt has been made, it is allowed to react with $\mathrm{NaN}_{3}$, resulting in lows of $\mathrm{N}_{2}$ and production of the azide (Scheme 1-8).

$$
\mathrm{ArNH}_{2} \stackrel{\mathrm{HCl} / \mathrm{NaNO}_{1}}{\longrightarrow}\left[\mathrm{ArN}_{2}\right]^{+}[\mathrm{C}]^{\cdot} \stackrel{\mathrm{NaN}_{2}}{\longrightarrow} \mathrm{ArN}_{3}+\mathrm{N}_{2}+\mathrm{NaCl}
$$

Scheme 1-4: Formution of azjdes by diazotization of amines.

These azides are isolated by ether extraction, and purified by vacuum distillation or recrystallization. When the azides were liquids, we found that reduced pressure, low temperature distillations greatly reduced decomposition and increased product yield (as well as improving the safety factor).

Table 1-1 shows a summary of the products of the reactions of trivalent uranium, $\left(\mathrm{MeC}_{5} \mathrm{H}_{4}\right)_{3} \mathrm{U}(\mathrm{th})$, with these azides. Further detail on these reactions is discussed below. 
$\widehat{\bigcirc}_{3} \mathrm{Uthe}+\mathrm{RN}=-\longrightarrow \widehat{\bigcirc}_{3}^{\mathrm{UNR}+\mathrm{N}_{2}}$

\begin{tabular}{|c|c|c|c|}
\hline $\mathbf{R}$ & $\hat{0}_{3}^{\text {Prod }}$ & $\begin{array}{l}\text { tages } \\
\hat{O}_{3} \mathrm{U}-\mathrm{N}\end{array}$ & Byproduct \\
\hline $\mathrm{Me}_{3} \mathrm{C}$ & 100 & 0 & $\mathbf{N}_{2}$ \\
\hline $\mathrm{Me}_{3} \mathrm{Si}$ & 100 & 0 & $\mathbf{N}_{2}$ \\
\hline $\mathrm{Me}_{3} \mathrm{Ge}$ & $70-80$ & $30-20$ & $\mathrm{~N}_{2}+\left(\mathrm{Me}_{3} \mathrm{Ge}\right)_{2}$ \\
\hline $\mathrm{Me}_{3} \mathrm{Sn}$ & 0 & 100 & $\left(\mathrm{Me}_{3} \mathrm{Sn}\right)_{2}$ \\
\hline $\mathrm{Ph}_{3} \mathrm{C}$ & 0 & 100 & $\left(\mathrm{Ph}_{3} \mathrm{C}\right)_{2}$ \\
\hline $\mathrm{Ph}_{3} \mathrm{Sn}$ & 0 & 100 & $\left(\mathrm{Ph}_{3} \mathrm{Sn}\right)_{2}$ \\
\hline $\mathrm{Ph}_{2} \mathrm{CH}$ & $85-90$ & $15 \cdot 10$ & $\mathrm{~N}_{2}+\left(\mathrm{Ph}_{2} \mathrm{CH}\right)_{2}$ \\
\hline $\mathrm{PhCH}_{2}$ & 100 & 0 & $\mathrm{~N}_{2}$ \\
\hline $\mathrm{Ph}$ & 100 & 0 & $\mathrm{~N}_{2}$ \\
\hline $\mathrm{p}-\mathrm{Me} \mathrm{C}_{6} \mathrm{H}_{4}$ & 100 & 0 & $\mathrm{~N}_{2}$ \\
\hline $\mathrm{p}-\mathrm{MeOC}_{6} \mathrm{H}_{4}$ & 100 & 0 & $\mathbf{N}_{2}$ \\
\hline $\mathrm{p}-\mathrm{Me}_{2} \mathrm{NC}_{6} \mathrm{H}_{4}$ & 100 & 0 & $\mathrm{~N}_{2}$ \\
\hline $0-\mathrm{MeC}_{6} \mathrm{H}_{4}$ & 100 & 0 & $\mathrm{~N}_{2}$ \\
\hline $0^{-} \mathrm{P}_{\mathrm{T}} \mathrm{C}_{6} \mathrm{H}_{4}$ & 100 & 0 & $\mathrm{~N}_{2}$ \\
\hline $2,6-\mathrm{Me}_{2} \mathrm{C}_{6} \mathrm{H}_{3}$ & 100 & 0 & $\mathrm{~N}_{2}$ \\
\hline
\end{tabular}

Table 1-1: Summary of product distribution in reactions of $\left(\mathrm{MeC}_{5} \mathrm{H}_{4}\right)_{3} \mathrm{U}(\mathrm{th} f)$ with azides. 


\section{Section 1.1: Results of Reactions of Trivalent Uranium Metallocenes with Azides}

\subsection{A: Results of Reactions Using Trimethyl Group IVA Azides}

t-Butyl- and trimethylsilylazides reacted instantly with trivalent uranium metallocenes in diethyl ether, with evolution of gas. The products were extracted with hexane to give deep red solutions, and crystallization from hexane yielded brown/black needles. The ${ }^{1} H$ NMR spectra of these materials showed very broad resonances, particularly for the cyclopentadienyl ring protons $\left(v_{1 / 2}=130-150 \mathrm{~Hz}\right.$ in the t-butyl and $v_{1 / 2}=50-55 \mathrm{~Hz}$ in the trimethylsilyl). The spectra strongly suggest the presence of pentavalent uranium, and integration is consistent with the uranium(V) imides, $\left(\mathrm{MeC}_{5} \mathrm{H}_{4}\right)_{3} \mathrm{UNR}\left(\mathrm{R}={ }^{\mathrm{B}} \mathrm{Bu}, \mathrm{SiMe}_{3}\right)$. The identity of these materials is confirmed by the parent ion in the electron impact mass spectrum.

When trimethylgermylazide $\left(\mathrm{Me}_{3} \mathrm{GeN}_{3}\right)$ was added to an ether solution of $\left(\mathrm{MeC}_{5} \mathrm{H}_{4}\right)_{3} \mathrm{U}$ (th), there was no immediate gas evolution nor an obvious darkening of the solution color. The reaction mixture was stirred for three days, and the ether removed to give a red/brown residue. Some of this residue was found to be hexane soluble, and brown crystals could be obtained from this solution. This material appeared to be the uranium imide, $\left(\mathrm{MeC}_{5} \mathrm{H}_{4}\right)_{3} \mathrm{UNGeMe}_{3}$, by ${ }^{{ }^{2} \mathrm{H}} \mathrm{NMR}$ spectroscopy. The hexane-insoluble solid dissolved in dichlormethane, and subsequent analysis by ${ }^{1} \mathrm{H}$ NMR spectroscopy showed it to be identical with $\left(\mathrm{MeC}_{5} \mathrm{H}_{4}\right)_{3} \mathrm{UN}_{3}$ obtained from the tritylazide or $\mathrm{NaN}_{3} / \mathrm{H}_{2} \mathrm{O}$ preparations.

Thus, we had found the first example in which one azide, $\mathrm{Me}_{3} \mathrm{GeN}_{3}$, could function as either a one-electron azide transfer reagent or a twoelectron imide transfer reagent, although the reaction strongly favored the 
production of the imide( $>70 \%$ imide and $<30 \%$ azide). Interestingly, even though a great deal of imide was formed, there was no instantaneous bubbling of the ether solution as is normally observed when imides were formed and $\mathrm{N}_{2}$ produced. Perhaps this reaction proceeds far more slowly, with either a slow coordination step of the germanium azide or a slow step in which electron transfer occures with loss of either $\mathrm{N}_{2}$ or (presumably) the trimethylgermyl radical.

It seemed likely that as we proceeded down group IVA in the periodic table, the reaction may proceed further towards the uranium(IV) azide complex. Indeed, when trimethyltinazide was allowed to react with $\left(\mathrm{MeC}_{5} \mathrm{H}_{4}\right)_{3} \mathrm{U}\left(\right.$ thr), the only product isolated was $\left(\mathrm{MeC}_{5} \mathrm{H}_{4}\right)_{3} \mathrm{UN}_{3}$.

Trimethyltinazide was also used to prepare the more soluble uranium azide complex, $\left(\mathrm{Me}_{3} \mathrm{SiC}_{5} \mathrm{H}_{4}\right)_{3} \mathrm{UN}_{3}$. Reaction of $\mathrm{Me}_{3} \mathrm{SnN}_{3}$ with the trivalent uranium species $\left(\mathrm{Me}_{3} \mathrm{SiC}_{5} \mathrm{H}_{4}\right)_{3} \mathrm{U}$ gave the azide in good yield.

\subsection{B: Results of Reactions Using Triphenyl Group IVA Azides}

Other than trityl azide, the only additional azide from this category that was utilized was triphenyltinazide, $\mathrm{Ph}_{3} \mathrm{SnN}_{3}$. When ether was added to a mixture of $\left(\mathrm{MeC}_{5} \mathrm{H}_{4}\right)_{3} \mathrm{U}($ thf $)$ and $\mathrm{Ph}_{3} \mathrm{SnN}_{3}$ an immediate green precipitate was obtained. The ether was removed after stirring for one day, and ${ }^{1} \mathrm{H}$ NMR spectroscopy indicated that the product was $\left(\mathrm{MeC}_{5} \mathrm{H}_{4}\right)_{3} \mathrm{UN}_{3}$. Peaks were also seen in the phenyl region of the spectrum. Heating the material in a Schlenk tube to approximately $100^{\circ} \mathrm{C}$ under vacuum resulted in the sublimation of a white solid, which was removed from the tube and analyzed by mass spectroscopy. The spectrum showed a cluster at the correct masses for $\mathrm{Ph}_{3} \mathrm{Sn}$, indicating that the byproduct in this reaction was probably $\mathrm{Ph}_{3} \mathrm{SnSnPh}_{3}$. Presumably, the tin-tin bond is extremely weak, and the material dissociates 
into the "monomeric" form in the mass spectrometer. Simulation of the isotopic cluster for $\mathrm{C}_{18} \mathrm{H}_{15} \mathrm{Sn}$ showed excellent good agreement with the obtained spectrum, and both the actual and simulated spectra are shown in Figure 1-3.

This batter reaction was aiso performed using the more soluble trivalent uranium metallocene $\left(\mathrm{Me}_{3} \mathrm{SiC}_{5} \mathrm{H}_{4}\right)_{3} \mathrm{U}$. This was done in order to attempt to better observe the byproduct of the reaction. After $\left(\mathrm{Me}_{3} \mathrm{SiC}_{5} \mathrm{H}_{4} \mathrm{~J}_{3} \mathrm{U}\right.$ was allowed to react for a day with $\mathrm{Ph}_{3} \mathrm{SnN}_{3}$ and the ether removed, the solid material was washed with hexane to remove the soluble complex $\left(\mathrm{Me}_{3} \mathrm{SiC}_{5} \mathrm{H}_{4}\right)_{3} \mathrm{UN}_{3}$. This left an off-white solid, which was dissolved in deuterated benzene and examined by ${ }^{119} \mathrm{Sn}$ NMR spectroscopy at $33.34 \mathrm{MHz}$. The spectrum showed a single peak at approximately $\delta=-138 \mathrm{ppm},{ }^{16}$ and is shown in Figure 1-4. This strongly suggested that the tin-containing product is indeed hexaphenylditin, whose reported ${ }^{119}$ Sn NMR shift is $\delta=$ CR. -144 ppm. ${ }^{17}$ Please note that the ${ }^{119} \mathrm{Sn} \mathrm{NMR}$ of $\mathrm{Ph}_{3} \mathrm{SnN}_{3}$ is also shown in Figure 14 to show that we did not simply observe excess azide in the spectrum rather than a true by-product.

\subsection{C: Results of Reactions Using Phenylmethyl Azides}

As mentioned earlier, the reason for sequentially removing phenyl groups from tritylazide was to observe what effect changing the steric environment of the azide had upon its reactivity towards trivalent uranium. Benzhydrylazide, $\mathrm{Ph}_{2} \mathrm{CHN}_{3}$ is easily prepared from the corresponding chloride. When this azide was added to an ether solution of $\left(\mathrm{MeC}_{5} \mathrm{H}_{4}\right)_{3} \mathrm{U}(\mathrm{thf})$, gas evolution was immediately observed, and the solution color darkened. Removal of the ether followed by extraction and crystallization from hexane 

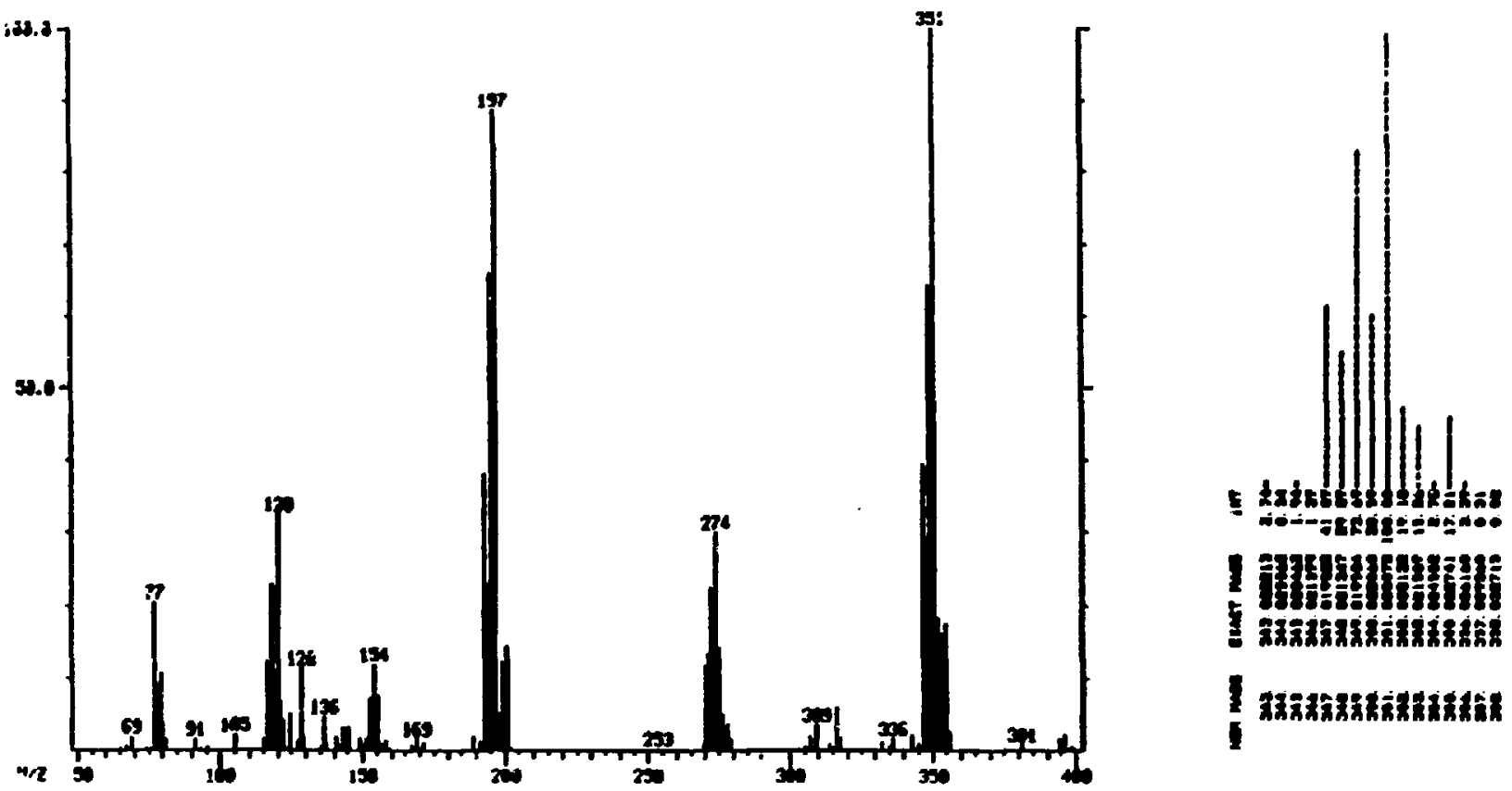

Figure 1-3: The mass spectrum of the sublimed white solid from the reaction of $\left(\mathrm{MeC}_{5} \mathrm{H}_{4}\right)_{3} \mathrm{U}(\mathrm{th})$ with $\mathrm{Ph}_{3} \mathrm{SnN}_{3}$; presumably this material is $\mathrm{Ph}_{3} \mathrm{SnSnPh}_{3}$. The highest observed mass is for $\mathrm{Ph}_{3} \mathrm{Sn}$, and the simulation of the isotopic cluster for this unit is shown on the right. 

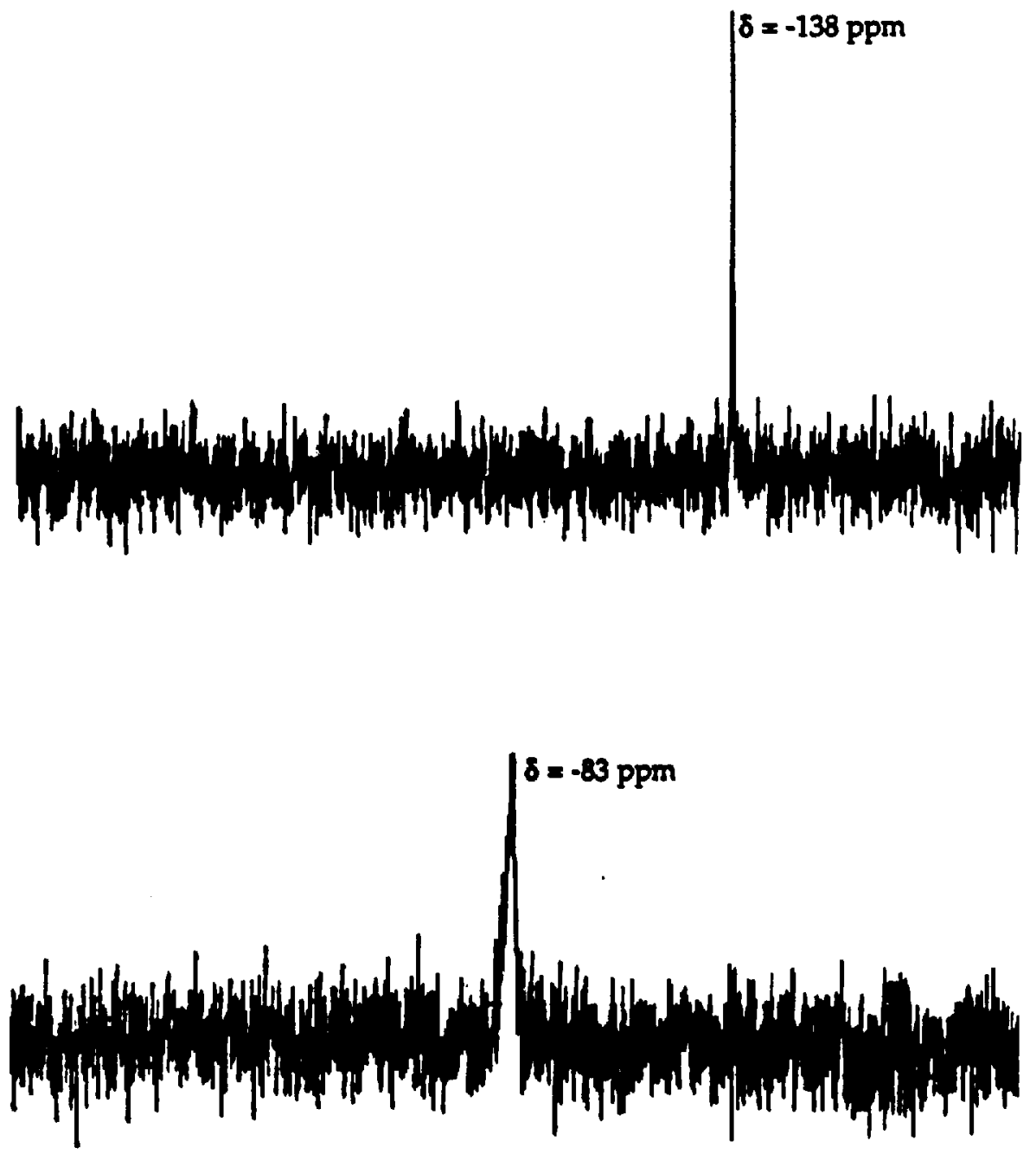

Figure 1-4: ${ }^{119} \mathrm{Sn} \mathrm{NMR} \mathrm{spectra} \mathrm{of} \mathrm{Ph}_{3} \mathrm{SnN}_{3}$ (bottom) and the white, hexane-insoluble solid from the reaction of $\left(\mathrm{Me}_{3} \mathrm{SiC}_{5} \mathrm{H}_{4}\right)_{3} \mathrm{U}$ with $\mathrm{Ph}_{3} \mathrm{SnN}_{3}$ (top; believed to be $\mathrm{Ph}_{3} \mathrm{SnSnPh}_{3}$ ). 
gave brown crystals of the uranium(V) imide, $\left(\mathrm{MeC}_{5} \mathrm{H}_{4}\right)_{3} \mathrm{UNCHPh}_{2}$, although ${ }^{1} \mathbf{H}$ NMR spectroscopy indicated that these cystals were slightly contaminated with $\left(\mathrm{MeC}_{5} \mathrm{H}_{4}\right)_{3} \mathrm{UN}_{3}$. The hexane insoluble material was extracted with dichloromethane, and this extract yielded a small amount of the uranium(IV) azide.

To try to gauge the product distribution in this reaction more sccurately, the procedure was repeated in an NMR tube. Note that this involved a change of solvent from $\mathrm{Et}_{2} \mathrm{O}$ to $\mathrm{C}_{6} \mathrm{D}_{6}$, which may or may not affect the chemistry. When the reactants were mixed and the ${ }^{1} H$ NMR spectrum obtained, it indicated that ca. 85 - 90\% of the product was the pentavalent uranium imide, while only $10-15 \%$ was the tetravalent azide.

The reaction was also repeated on a preparative scale with ether as solvent. In this case, after one hour of stirring, the volatile materials were removed, and the residue directly analyzed by ${ }^{1} \mathrm{H}$ NMR spectroscopy (Figure 1-5). The spectrum once again indicated a predominance of the uranium(V) product, and the approximate percentages are 85 - 95\% $\left(\mathrm{MeC}_{5} \mathrm{H}_{4}\right)_{3} \mathrm{UNCHPh}$ and 5 - 15\% $\left(\mathrm{MeC}_{5} \mathrm{H}_{4}\right)_{3} \mathrm{UN}_{3}$.

It should be noted that the brond peak widths obtained in the spectra of these uranium( $V$ ) imides makes accurate integration difficult. The numbers are meant to convey a fairly rough idea of whether one product or the other is the dominant product, but it would be incorrect to make conclusions based on small differences in product percentages obtained by these techniques. It is, however, comforting to see that the NMR experiments and the isolated products reflect roughly similar product distributions.

When a second phenyl ring was removed and benzylazide, $\mathrm{PhCH}_{2} \mathrm{~N}_{3}$, was used, the favored product was the uranium imide, $\left(\mathrm{MeC}_{5} \mathrm{H}_{4}\right)_{3} \mathrm{UNCH} \mathrm{Hh}_{2}$, and no evidence was seen for the formation of the uranium azide. The 


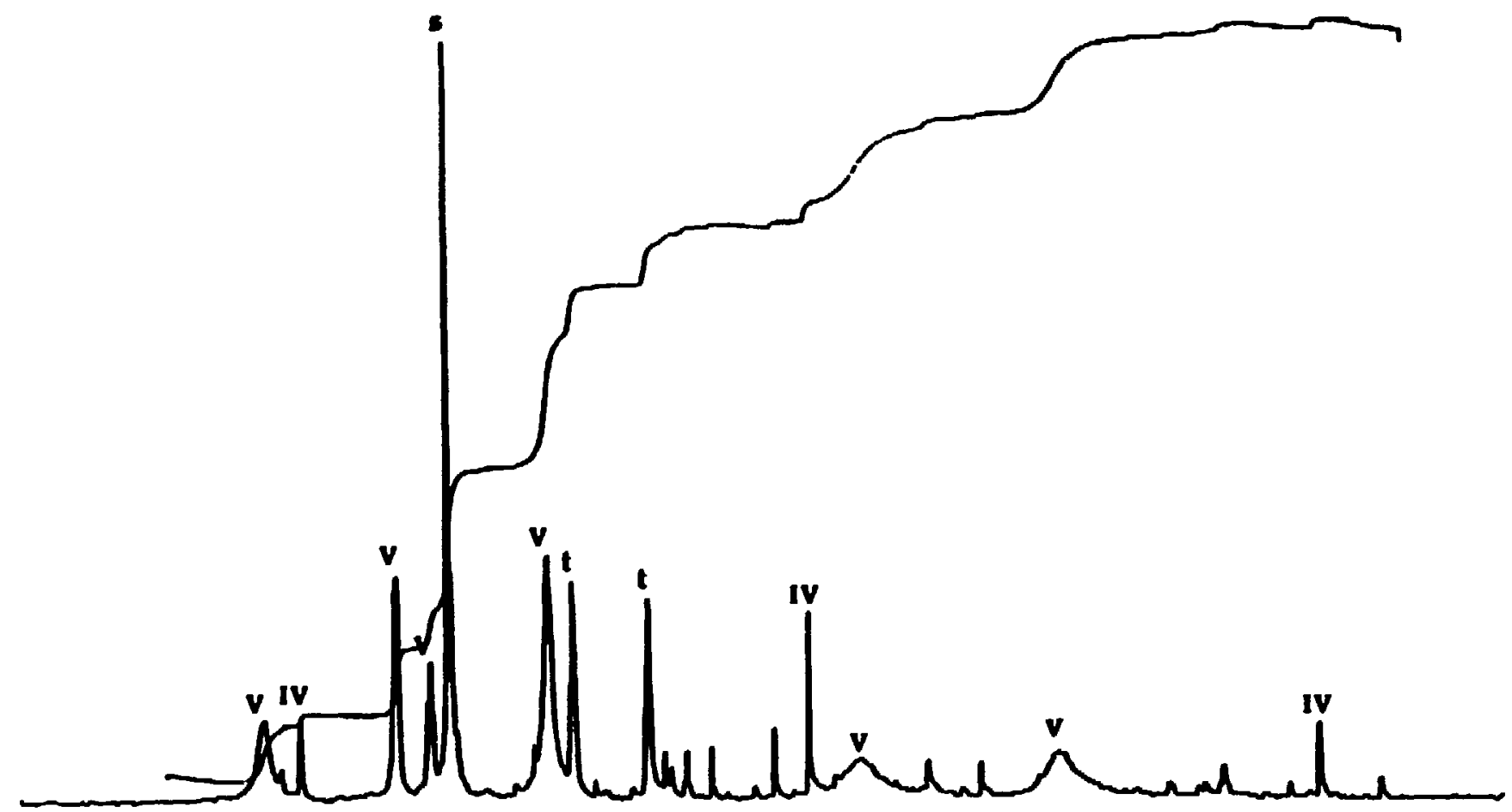

Figure 1-5: The ${ }^{1} \mathrm{H}$ NMR spectrum from the NMR tube reaction of $\left(\mathrm{MeC}_{5} \mathrm{H}_{4}\right)_{3} \mathrm{U}(\mathrm{th})$ with $\mathrm{Ph}_{2} \mathrm{CHN}_{3}$. The symbols represent the following: $\mathrm{V}$ : $\left(\mathrm{MeC}_{5} \mathrm{H}_{4}\right)_{3} \mathrm{UNCHPh}$; IV: $\left(\mathrm{MeC}_{5} \mathrm{H}_{4}\right)_{3} \mathrm{UN}_{3}$; s: solvent; t: thf. 
benzyl $\mathrm{CH}_{2}$ group shows an highly unusual chemical shift in the ${ }^{1} \mathrm{H}$ NMR ( $\delta$ $=$ ca. $+123 \mathrm{ppm}$ ); this is discussed in the later section on properties of the uranium imides.

The results obtained from these experiments suggest a strong steric effect in the reaction of $\left(\mathrm{MeC}_{5} \mathrm{H}_{4}\right)_{3} \mathrm{U}(\mathrm{thf})$ with phenylmethylazides. This will be discussed in further detail in Section 1.2.

\subsection{D: Results of Reactions Uaing Subattuted Phenylaxides}

In all cases in which $\left(\mathrm{MeC}_{3} \mathrm{H}_{4}\right)_{3} \mathrm{U}$ (th) was allowed to react with a substituted phenyl axide, only the uranium( $V$ imides have been obtained. Substitiuents include the following: p-methyl, o-methyl, 2,6-dimethyl, p-methoxy, p-dimethylamino, o-isopropyl, and p-trifluoromethyl. 


\section{Section 1.2: Discussion of Reactions of Trivalent Uranium Metallocenes with Azides}

The obvious question that must be addressed as a result of the data presented thus far is, "Why do some azides behave as one-electron oxidizing agents while come behave as two-electron oxddants?" It is important for this discussion to recognize the two accepted resonance structures by which azides may be represented (Figure 1-6):

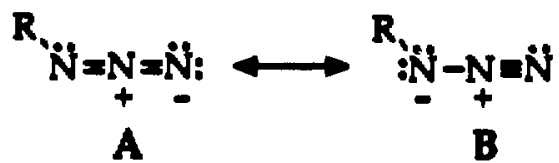

Figure 1-4. Resonance structures of azides.

It seems reasonable to assume that resonance structure $B$ is the one that is more likely to produce an imide upon reaction with a metal center. The reasons for this are twofold: firstly, the structure has an N-N triple bond, allowing easy loss of $\mathrm{N}_{2}$ from the compound, and secondly, the concentration of electron density on the $\alpha$-nitrogen would seem to allow for a very strong interaction with an electropositive metal center. On the other hand, structure $A$ contains a considerably stronger bond between the $\alpha$-nitrogen and the $\beta$-nitrogen, making it more difficult to break the $\mathrm{N}-\mathrm{N}$ bond and form the uranium imide species.

Of course, the distribution of the products is certainly going to be dependent upon what form is taken by the reaction intermediate. Presumably, the reaction must go through a transition state in which either the $\alpha$ - or $\psi$-nitrogen is coordinated to the uranium center. The $\beta$-nitrogen 
can be eliminated as a possible coordination site due to the partial positive charge which all plausible resonance structures place upon this atom. It also seems most likely that the $\alpha$-nitrogen must coordinate when the imide is formed, to keep the NR unit intact. A labelling study has been done to attempt to substantiate this, which will be presented shortly. The major question then becomes one of which possible intermediate leads to the formation of the uranium azide. The most reasonable possibilities would seem to be as follows (see Figure 1-7):

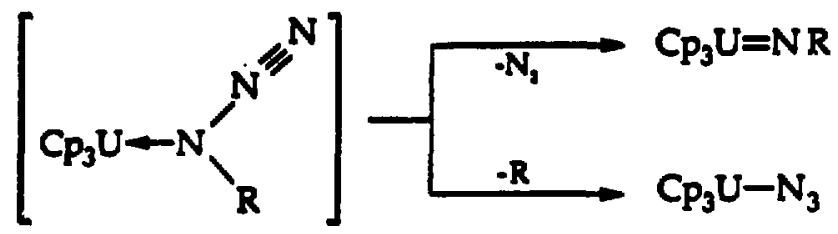

Posalble mechanisan a1: $\alpha-\mathrm{N}$ coordination in all cases.

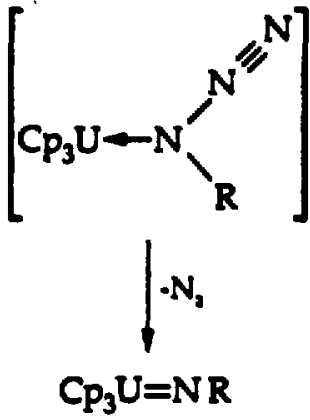

$$
\begin{gathered}
{\left[\mathrm{CP}_{3} \mathrm{U}-\mathrm{N}=\mathrm{N}=\mathrm{N}-\mathrm{R}\right]} \\
\left.\right|_{\mathrm{P}_{3} \mathrm{U}-\mathrm{N}_{3}} ^{-\mathrm{R}}
\end{gathered}
$$

Pousible mechanism 12: a-N coordination leads to uranium imide, Y $N$ coordination leads to uranium azide.

Figure 1-7: Prissible mechanisms for reaction of uranium(III) with azides.

1. Coordination occurs at the $\alpha$-nibuzen in all cases. Once the azide has coordinated, either electronic or steric effects could cause loss 
of either $\mathrm{N}_{2}$ or $\mathrm{R}$. Electronic effects would involve the strength of the N-R bond as well as the stability of the resultant radical, while steric effects could dominate in how close the $\alpha$-nitrogen could get to the metal center, resulting in either one or two electron transfer.

2. Coordination occurs at the $\alpha$-nitrogen in the formation of the uranium imide, but at the rnitrogen in the formation of the uranium saide. In this case, the major electronic effect involves how much electron density is at the $\alpha$ - or $\gamma$-nitrogens to allow coordination with the uranium. Steric effects would suggest that the bulkier the $R$ group of the azide, the more likely y-coordination is to occur.

One way to gain partial understanding of the mechanism of this reaction is through labelling studies. $\alpha-{ }^{15} \mathrm{~N}$ labelled phenylazide is easily prepared from the labelled aniline, by diazotization and subsequent reaction with sodium azide. 13 The percentage of ${ }^{15} \mathrm{~N}$ in the azide was determined by mass spectroscopy, and was found to be $>99 \%$ (see Figure 1-8). When this material was reacted with $\left(\mathrm{MCC}_{5} \mathrm{H}_{4}\right)_{3} \mathrm{U}$ (th), the resulting uranium imide showed essentially complete incorporation of the label. The mass spectra of both $\left(\mathrm{MeC}_{5} \mathrm{H}_{4}\right)_{3} \mathrm{UNPh}$ and $\left(\mathrm{MeC}_{5} \mathrm{H}_{4}\right)_{3} \mathrm{U}^{15} \mathrm{NPh}$ are shown in Figure 1-8. Analysis of the spectra show $>98 \%{ }^{15} \mathrm{~N}$ in the product from the labelling experiment.

The infrared spectra of the labelled and unlabelled imides are shown in Figure 1-9. Trogler et. al. have synthesized the compound $C_{p}$ "VNPh (by reaction of $\mathrm{Cp}^{\circ} \mathrm{V}$ and $\mathrm{PhN}_{3}$ ), and the infrared spectra of the labelled and unlabelled compounds have been analyzed in order to determine the positions of the $\mathrm{C}-\mathrm{N}$ and $\mathrm{V}-\mathrm{N}$ stretches. ${ }^{19}$ They report that the $\mathrm{C}-\mathrm{N}$ stretch occurs at $1330 \mathrm{~cm}^{-1}$ in $\mathrm{Cp}^{*} \mathrm{VNPh}$ and at $1307 \mathrm{~cm}^{-1}$ in $\mathrm{Cp}^{*} \mathrm{~V}^{15} \mathrm{NPh}$, while the $V-N$ stretch is observed at $934 \mathrm{~cm}^{-1}$ in $C_{p}$ VNPh and at $923 \mathrm{~cm}^{-1}$ in 

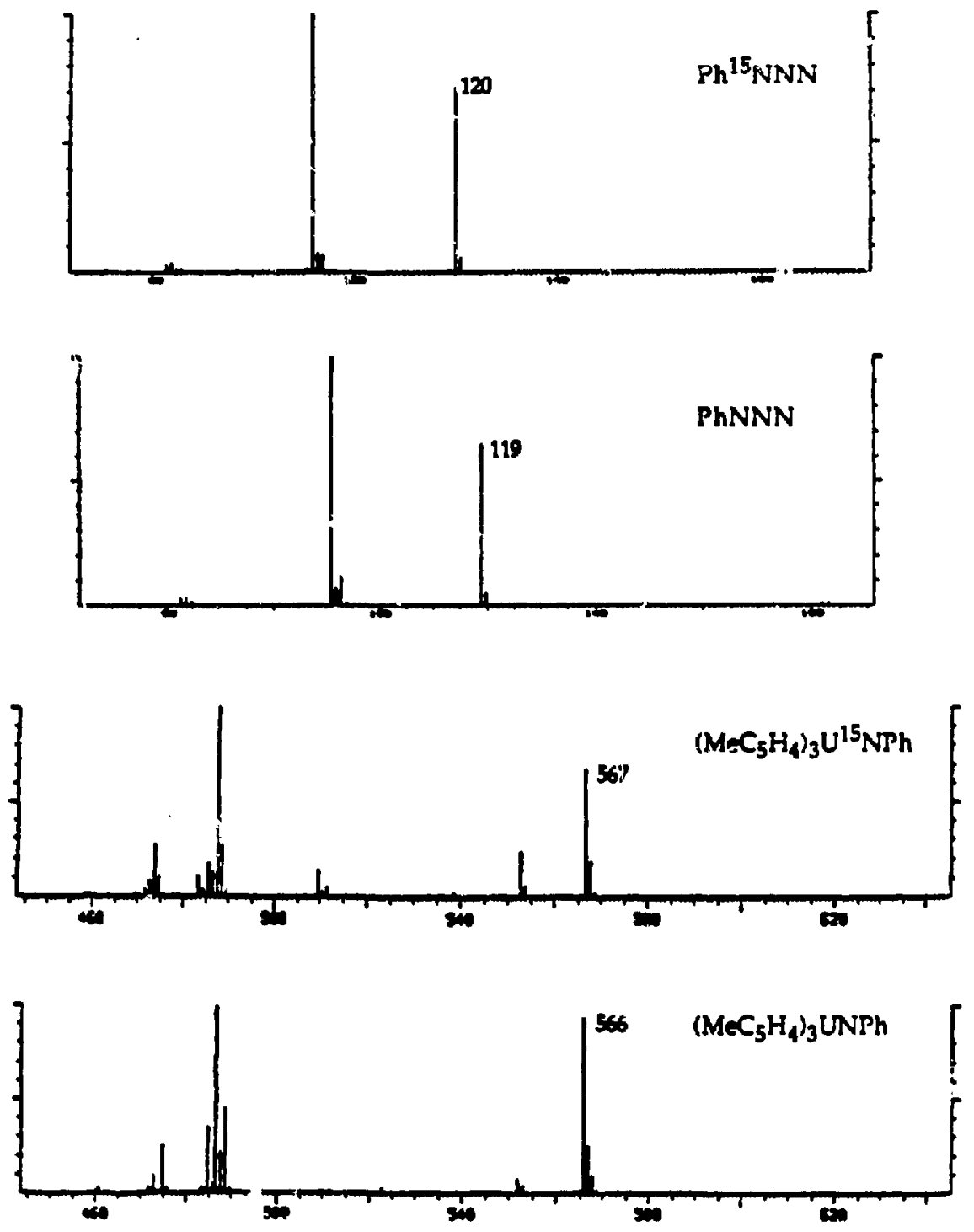

Figure 108: Mass spectra of the labelled and unlabelled phenylazide and the labelled and urlabolled uranium(V) phenylimide. 

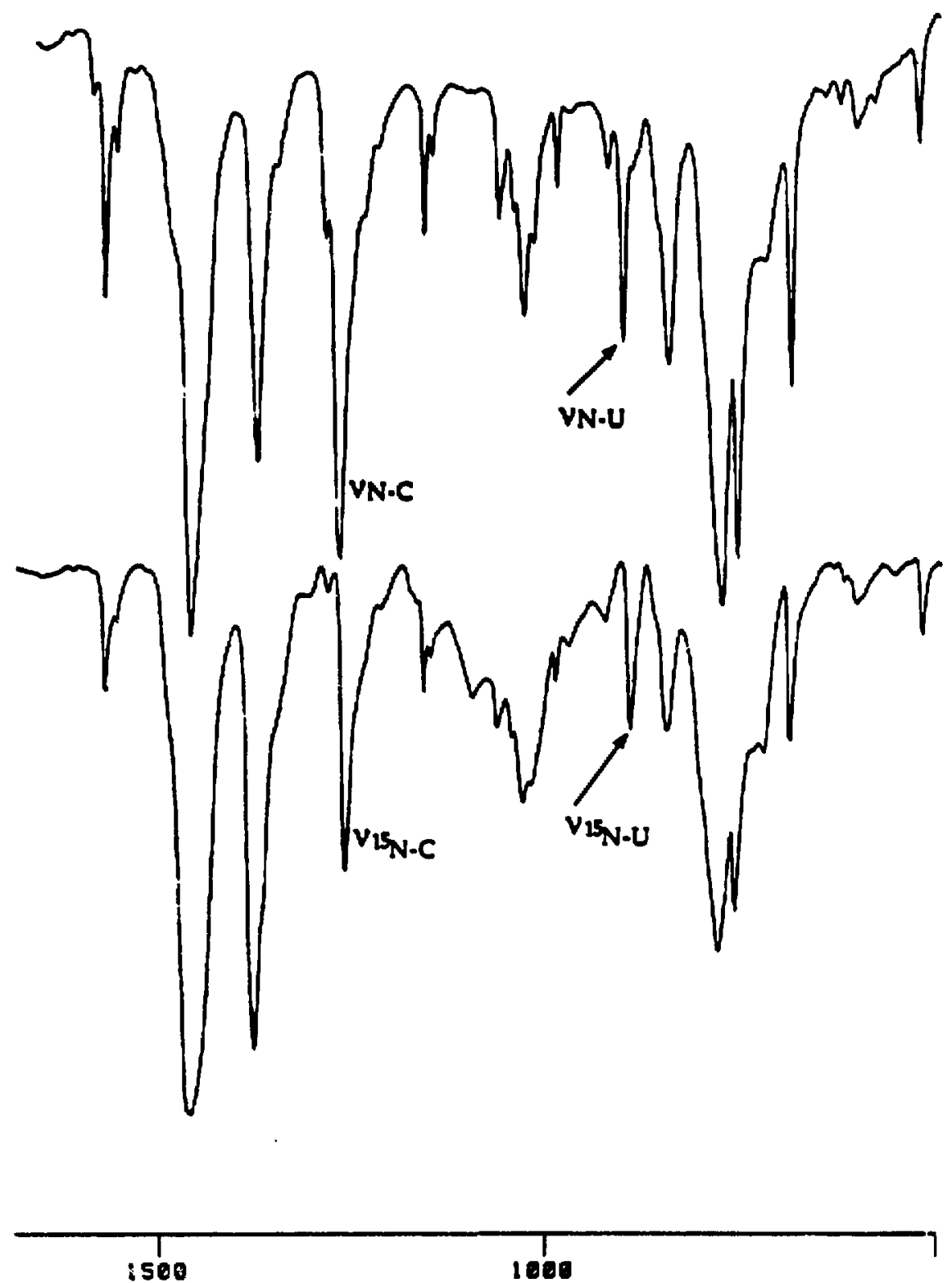

Figure 1-9: Infrared spectra of $\left(\mathrm{MeC}_{5} \mathrm{H}_{4}\right)_{3} \mathrm{UNPh}$ (top) and $\left(\mathrm{MeC}_{5} \mathrm{H}_{4}\right)_{3} \mathrm{U}^{15} \mathrm{NPh}$ (bottom). 
$\mathrm{Cp} \mathrm{V}^{15} \mathrm{NPh}$. In the spectra of the uranium molecules, we observe a strong stretch at $1271 \mathrm{~cm}^{-1}$ for $\left(\mathrm{MeC}_{5} \mathrm{H}_{4}\right)_{3} \mathrm{UNPh}$, which shifts to $1260 \mathrm{~cm}^{-1}$ in $\left(\mathrm{MeC}_{5} \mathrm{H}_{4}\right)_{3} \mathrm{U}^{15} \mathrm{NPh}$. This is assigned as the $\mathrm{C}-\mathrm{N}$ stretch. The only other absorbtion which is observed to shift significantly is a medium strength stretch which occurs at $909 \mathrm{~cm}^{-1}$ in $\left(\mathrm{MeC}_{5} \mathrm{H}_{4} \mathrm{~J}_{3} \mathrm{LNPh}\right.$ and at $895 \mathrm{~cm}^{-1}$ in $\left(\mathrm{MeC}_{5} \mathrm{H}_{4}\right)_{3} \mathrm{U}^{15} \mathrm{NPh}$. This is assigned as the U-N stretch.

The infrared data and the mass spectroscopy indicate that the ${ }^{15} \mathrm{~N}$ from $\alpha$-labelled phenylazide was completedly incorporated in the final uranium imide product. What conclusions regarding the mechanism of azide reaction with trivalent uranium can we draw from this result? Certainly it shows that no unusual rearrangement of the azide occurs on coordination to the metal center. The nitrogen originally bonded to the aryl group remains bonded to it in the product. This strongly suggests an $\alpha$-coordinated intermediate at the transition state of the reaction.

A more informative labelling study would be one in which a labelled azide was used to form the uranium(IV) azide compound, rather than the imide. In this case, we could examine where in the uranium product the $15 \mathrm{~N}$ is found, and possibly draw further conclusions concerning the mechanism (Scheme 1-9);

$$
\begin{aligned}
\mathrm{CP}_{3} \mathrm{U}+\mathrm{R}^{15} \mathrm{NNN} \longrightarrow & \mathrm{C}_{3} \mathrm{U}^{15} \mathrm{NNN} \\
& \alpha \cdot \text {-labelled }
\end{aligned} \text { and/or } \begin{gathered}
\mathrm{C}_{\mathrm{P}_{3}} \mathrm{UNN}^{15} \mathrm{~N} \\
\boldsymbol{\gamma} \text {-labelled }
\end{gathered}
$$

Scheme 1-9. Proposed reaction to produce an ${ }^{15} \mathrm{~N}$ - labelled uranium azide.

$15 \mathrm{~N}$ in the alpha position (directly bonded to the uranium) would suggest an intermediate in which the $\alpha$-nitrogen on the organic azide coordinates to the 
metal center. However, ${ }^{15} \mathrm{~N}$ in the position gamma to the uranium would suggest an intermediate in which the $\gamma$-nitrogen on the organic azide coordinates to the metal center. Unfortunately, we have been unable to investigate these possibilities. The reason for this is that we are unable to generate a preferentially labelled azide starting material which forms the uranium(IV) product. Azides specifically labelled in the $\alpha-\beta-$, or $\gamma$-positions can be made by diszotzation reactions of amines. Unfortunately, all azides made by diszotization form the uranium( $V$ imide. To make an azide which forms the uranium(IV) azide product, we must use the synthesis discussed earlier in which a halide is exchanged for the $\mathrm{N}_{3}^{*}$ unit. This reaction cannot be controlled to give pure products which are ${ }^{15} \mathrm{~N}$ labelled in the $\alpha$ - or rpositions ( $\beta$-labelling is not useful in our mechanistic study).

Thus, to briefly summarize the results of our labelling attempts, the one labelling experiment we have been able to perform strongly hints at coordination of the $\alpha$-nitrogen of the vaide to the uranium center in a reaction which results in formation of the uranium(V) imide product. However, the more interesting question of whether $\alpha$-or $\gamma$-coordination is responsible for the uranium(IV) azide formation remains unanswered.

Despite the problems with the labelling reactions, we can still at least advance some theories as to why the reactions of trivalent uranium with azides proceed by two different routes. I will discuss these ideas in the following sections, taking into account both the electronic and steric properties of the $\mathrm{R}$ group in $\mathrm{RN}_{3}$ and how these properties might affect the reaction intermediate and therefore the final product. 
This group of azides gives us perhaps the most interesting series in which we can look at electronic effects of the $\mathrm{R}$ group in $\mathrm{RN}_{3}$ upon the reactivity towards trivalent uranium. The reactions showed that as we proceed down the periodic table in $\mathrm{Me}_{3} \mathrm{XN}_{3}(X=$ group IVA element), the products formed move from the uranium(V) imide $\left(M e C_{5} H_{4}\right)_{3} \mathrm{UNR}$ to the uranium(IV) azide $\left(\mathrm{MeC}_{5} \mathrm{H}_{4}\right)_{3} \mathrm{UN}_{3}$, with $\mathrm{Me}_{3} \mathrm{GeN}_{3}$ forming both products. This trend should be explairable predominantly by electronic effects, since the steric bulk of the $\mathrm{Me}_{3} \mathrm{X}$ groups are probably relatively similar.

We will assume for this discussion that the intermediate in the reaction of $\left(\mathrm{RC}_{5} \mathrm{H}_{4}\right)_{3} \mathrm{U}$ with these group $\mathrm{NA}$ azides involves $\alpha$-coordination of the azide. Thus, at the transition state, cleavage of either the $\mathrm{Me}_{3} \mathrm{X}-\mathrm{N}$ bond (giving the uranium azide product), or the $\alpha \mathrm{N}-\beta \mathrm{N}$ bond (giving the uranium imide product) can occur (see Figure 1-7). Assuming we observe the thermodynamically preferred product in these reactions and not a kinetic product, we can predict the following:

1. When the $\mathrm{N}-\mathrm{N}$ bond strength of the azide is greater than the $\mathrm{N}-\mathrm{XMe}_{3}$ bond strength, uranium(IV) azide formation is preferred.

2. When the $\mathrm{N}-\mathrm{XMe}_{3}$ strength of the azide is greater than the $\mathrm{N}-\mathrm{N}$ bond strength, uranium(V) imide formation is preferred.

3. When the $\mathrm{N}-\mathrm{XMe}$ and $\mathrm{N}-\mathrm{N}$ bond strengths are of the same order, both products will be formed.

We can therefore look at the trends in bond strengths for group IVA nitrogen compounds to attempt to rationalize our observations. The values reported for several dimethylamides of group IVA are shown in Table 1-2 below: 


\begin{tabular}{|c|c|c|}
\hline Compound & $\begin{array}{c}\text { X-N Bond Strength } \\
\text { (kcal mol } \text {-1 }^{\text {) }}\end{array}$ & Reference \\
\hline $\mathrm{H}_{3} \mathrm{CNMe}_{2}$ & 76 & 20 \\
$\mathrm{Me}_{3} \mathrm{SiNMe}_{2}$ & 79 & 21 \\
$\mathrm{Me}_{3} \mathrm{GeNMe}_{2}$ & 55 & 22 \\
$\mathrm{Me}_{3} \mathrm{SnNMe}_{2}$ & 41 & 22 \\
\hline
\end{tabular}

Trble 1-2: Group IVA $X-N$ bond strength values.

These values may be contrasted with the energy required to break the $\alpha N-\beta N$ bond. Some values of bond strengths of N-N single bonds can be obtained from hydrazines; in $\mathrm{H}_{2} \mathrm{NNH}_{2}, 66 \mathrm{kcal} \mathrm{mol}^{-1}$, and in $\mathrm{Me}_{2} \mathrm{NNH}_{2}, 59 \mathrm{kcal}$ mol $^{-1}{ }^{20}$ Thus, we see that $\mathrm{C}-\mathrm{N}$ and Si-N bonds are considerably stronger than the $\mathrm{N}-\mathrm{N}$ bond, and only the uranium(V) product is observed from the silicon and carbon azides of this group. The Ge-N bond strength, on the other hand, is of the same order as an N-N single bond, and indeed we observe both the uranium(IV) and uranium(V) products in the reaction of $\mathrm{Me}_{3} \mathrm{GeN}_{3}$ with $\left(\mathrm{MeC}_{5} \mathrm{H}_{4}\right)_{3} \mathrm{U}(\mathrm{th})$. The much weaker $\mathrm{Sn}-\mathrm{N}$ bond allows formation of only the uranium(IV) product.

\section{B: Discussion of Reactions Using Triphenyl Group IVA Azides}

As discussed earlier, both $\mathrm{Ph}_{3} \mathrm{CN}_{3}$ and $\mathrm{Ph}_{3} \mathrm{SnN}_{3}$ yield only $\left(\mathrm{MeC}_{5} \mathrm{H}_{4}\right)_{3} \mathrm{UN}_{3}$ as the uranium containing product when allowed to react with $\left(\mathrm{MeC}_{5} \mathrm{H}_{4}\right)_{3} \mathrm{U}$ (th) . It is presumed that this product comes about primarily for steric reasons; the three phenyl rings would create an enormously bulky transition state if the azide coordinated at the $\alpha$-nitrogen, and the uranium imide product would therefore be sterically disfavored. Because of this, it seems that initial coordination of the azide through the $\gamma$-nitrogen is the most 
likely possibility for the intermediate in this reaction. Experimental evidence for this is desireable, but as noted previously, a meaningful labelling study on systems of these sorts has, thus far, proven impossible.

As noted earlier in this chapter, results similar to those obtained for $\left(\mathrm{MeC}_{5} \mathrm{H}_{4}\right)_{3} \mathrm{U}$ were obtained in reactions of vanadium metallocenes with bulky azides. ${ }^{\text {ad }}$ Both $\mathrm{Ph}_{3} \mathrm{CN}_{3}$ and $\mathrm{Ph}_{3} \mathrm{SiN}_{3}$ react with $\mathrm{Cp}_{2}^{*} \mathrm{~V}$ to yield the azide, $\mathrm{Cp}_{2} \mathrm{VN}_{3}$. The authors also propose a rnitrogen coordination. Interestingly, $\mathrm{Me}_{3} \mathrm{SiN}_{3}$ also reacts with $\mathrm{Cp}_{2}^{*} \mathrm{~V}$ to give $\mathrm{Cp}_{2}^{*} \mathrm{VN}_{3}$, rather than the imide. This is again attributed to steric interactions, although this seems odd in light of our observations with uranium.

\subsection{C: Discussion of Reactions Using Phenylmethyl Azides}

This series of azides, utilizing $\mathrm{Ph}_{3} \mathrm{CN}_{3}, \mathrm{Ph}_{2} \mathrm{CHN}_{3}$ and $\mathrm{PhCH}_{2} \mathrm{~N}_{3}$, demonstrates primarily the results of changing the steric effects of the azides. The product of the reaction of these azides with $\left(\mathrm{MeC}_{5} \mathrm{H}_{4}\right)_{3} \mathrm{U}(\mathrm{th})$ proceeds from only the uranium azide, $\left(\mathrm{MeC}_{5} \mathrm{H}_{4}\right)_{3} \mathrm{UN}_{3}$, in the case of the bulky trityl azide, to a mixture of azide and imide for benzhydryl azide $\left(\mathrm{Ph}_{2} \mathrm{CHN}_{3}\right)$, to only the imide, $\left(\mathrm{MeC}_{5} \mathrm{H}_{4}\right)_{3} \mathrm{UNCH}_{2} \mathrm{Ph}$, for benzyl azide.

We can see that these changes in product distribution are caused only by steric effects if we look briefly at the electronic nature of this series of azides. Replacing the hydrogens on methylazide $\left(\mathrm{H}_{3} \mathrm{CN}_{3}\right)$ with electron withdrawing phenyl rings should make the central carbon more electronegative. This will cause the $\mathrm{C}-\mathrm{N}$ bond in the azide to become less polarized, and therefore would tend to stabilize the $B$ resonance structure of the azide. Following this argument, the B resonance structure would be more favored in $\mathrm{Ph}_{3} \mathrm{CN}_{3}$ than in $\mathrm{PhCH}_{2} \mathrm{~N}_{3}$. However, if the the $\mathrm{B}$ structure is indeed, as we have assumed, the one that is more likely to produce a 
uranium(V) imide, then some other effect must be dominating the electronic changes. This is, presumably, the steric effect.

We can then 2sk why the product distribution changes so dramatically in moving from trityl azide to benzhydryl azide. The reaction of trityl azide with trivalent uranium gives $100 \%$ uranium(IV) azide product; the reaction of benzhydryl azide with trivalent uranium gives $c a .85 \%$ uranium(V) imide and 15\% uranium(IV) azide. The steric interactions at the proposed transition states holp explain this observation. Let's once again assume, as previously proposed, that coordination at the c-nitrogen of the zzide is required for production of the uranium(V) imide product. Trityl azide, with the three-large aryl rings on the carbon bound to this $\alpha$-nitrogen, should have enormous steric problems getting this ritrogen close enough to the metal center for reaction to occur. Presumably, the azide then coordinates through the rnitrogen, producing the uranium(IV) azide. However, if we replace just one aryl ring with a hydrogen, we can easily picture a much less bulky transition state in which $\alpha$-coordination would be somewhat more favorable. Two of the phenyl rings could point away from the metal, minimizing their steric interactions with the methylcyclopentadienyl rings, while the single hydrogen would point inward. Removing a second aryl ring should further reduce the crowding in the transition state, and indeed we see no uranium(IV) azide when benzylazide is used.

The bond strength arguments used in section 1.2.A can also be applied to these azides. The $\mathrm{C}-\mathrm{N}$ bond in $\mathrm{PhCH}_{2} \mathrm{NMe}_{2}$ has a bond strength of $62 \mathrm{kcal}$ mol $^{-1}{ }^{20}$ Although a value for the $\mathrm{C}-\mathrm{N}$ bond in $\mathrm{Ph}_{2} \mathrm{CHNMN_{2 }}$ has not been reported, we can estimate that it is on the order of $4 \mathrm{kcal} \mathrm{mol}^{-1}$ less. We make this estimate by comparison of the $\mathrm{C}-\mathrm{H}$ bond strengths in $\mathrm{PhCH}_{3}$ and $\mathrm{Ph}_{2} \mathrm{CH}_{2}$; these are $-4 \mathrm{kcal} \mathrm{mol}^{-1}$ different. ${ }^{20}$ The important point is that these values 
are very close to the value for an $\mathrm{N}-\mathrm{N}$ single bond, and we thus observe both the uranium( $V$ ) and uranium(IV) products in the case of $\mathrm{Ph}_{2} \mathrm{CHN}_{3}$, although the uranium( $V$ product is strongly favored. The small gain in C-N bond energy in going from $\mathrm{Ph}_{2} \mathrm{CHIN}_{3}$ to $\mathrm{PhCH}_{2} \mathrm{~N}_{3}$ may be sufficient to cause only production of the uranium(V) imide product.

\section{D: Discussion of Reactions Using Subettuted Phenylazides}

Unfortunately, attempts to utilize substituents on phenyl rings to electronically "tune" the azides were unsuccessful. The reactions of all of the substituted phenylazides we tried yielded only the uranium(V) imide products, with certain special exceptions that will be mentioned at the end of this section.

The basis for these attempts was relatively simple. Electron donating substituents on the phenyl ring should make the carbon bonded to the $\mathrm{N}_{3}^{-}$ ligand less electronegative. This increases the polarity of the of the $\mathrm{C}-\mathrm{N}$ bond, destabilizing the B resonance structure which we believe produces the uranium( $V$ ) product. Donating groups were tried at the para- and orthopositions, and included p-methyl, o-methyl, p-methoxy, p-dimethylamino, o-isopropyl, and 2,6-dimethyl. It is interesting to note that the ortho substitution should have a significant steric effect in addition to the electronic changes, but even a bulky group such as isopropyl did not apparently destabilize the $\alpha$-coordinated intermediate significantly to cause production of any $\left(\mathrm{MeC}_{5} \mathrm{H}_{4}\right)_{3} \mathrm{UN}_{3}$.

Why did attempts at tuning the electronics of aryl arides fail so greatly, especially since para-substitution of this nature has been studied extensively in organic chemistry and found to have a strong influence on reaction rates? ${ }^{23}$ The reason is probably related to results summarized by Kaftory 
involving $X$-ray diffraction data on arides. 24 He found that $s p^{2}$ hybridized carbon azides show a slightly greater difference in their $\mathrm{N}-\mathrm{N}$ bond lengths when compared to $\mathrm{sp}^{3}$ azides, demonstrating a favoritism for the B resonance structure over the $A$ isomer. This is explained by the greater electronegativity of the $\mathrm{sp}^{2}$ carbon, which causes a less polar $\mathrm{C}-\mathrm{N}$ bond and therefore stabilization of electron density and negative charge on the $\alpha$-nitrogen. In addition, there is a sacond important electronic situation in these azides, the possible $\pi$-bonding interaction between the $\mathrm{N}_{3}^{-}$and the aryl $\pi$-system. This interaction would tend to strengthen the $\mathrm{C} \cdot \mathrm{N}$ bond, and would again favor the $B$ resonance structure by delocalization of electron density from the Q-nitrogen into the aryl $\pi$-orbitals.

Apparently, these two effects so strongly favor the B resonance form, and, concurrently, the production of uranium( $V$ imides, that they cannot be reversed by simple substitution on the ring. Although it seems intuitive that electron-donating groups will change the electronic properties of the azide in the direction we desire, it seems that we simply cannot put enough $e^{-}$- density into the aryl ring to reverse the trend in reactivity. Altering the steric properties of these compounds is more likely to produce the uranium(IV) azide (perhaps 2,6-diisopropyl, although this is not a known compound), but this is far less interesting to us, as this type of "steric tuning" was already easily accomplished in the phenylmethyl azide series.

I mentioned earlier that there were several special cases in these aryl substitution reactions; this involved azides in which $e^{-}-$withdrawing groups were used on the ring. When para-nitrophenylazide, $\mathrm{p}-\mathrm{O}_{2} \mathrm{NC}_{6} \mathrm{H}_{4} \mathrm{~N}_{3}$, was allowed to react with $\left(\mathrm{MeC}_{5} \mathrm{H}_{4}\right)_{3} \mathrm{U}($ thr), only a dark, insoluble precipitate was obtained. It seems quite likely that the uranium coordinated to the nitro- 
oxygen rather than the azido ligand; this is consistent with the insoluble materials formed by accidental air oxidation of these types of compounds.

Reaction of para-trifluoromethylphenylazide, $\mathrm{p}-\mathrm{F}_{3} \mathrm{CC}_{6} \mathrm{H}_{4} \mathrm{~N}_{3}$, with $\left(\mathrm{MeC}_{5} \mathrm{H}_{4}\right)_{3} \mathrm{U}$ (thf), produced a cystalline product whose ${ }^{1} \mathrm{H}$ NMR is certainly consistent with the formulation $\left(\mathrm{MeC}_{5} \mathrm{H}_{4}\right)_{3} \mathrm{UN}\left(\mathrm{p}-\mathrm{F}_{3} \mathrm{CC}_{6} \mathrm{H}_{4}\right)$. However, this compound was impure, the impurity being the tetravalent uranium fluoride, $\left(\mathrm{MeC}_{5} \mathrm{H}_{4}\right)_{3}$ UF. Recrystallization failed to seperate these two materials despite what appears to be a large solubility difference (the fluoride is quite insoluble in hexane), and it is possible that the imide slowly decomposes to the fluoride. When the ortho-substituted trifluoromethylphenylazide was used, the dominant product was $\left(\mathrm{MeC}_{5} \mathrm{H}_{4}\right)_{3} \mathrm{UF}$. Very small resonances that are probably due to $\left(\mathrm{MeC}_{5} \mathrm{H}_{4} \mathrm{UNN}_{3}\left(0-\mathrm{F}_{3} \mathrm{CC}_{6} \mathrm{H}_{4}\right)\right.$ are also observed in the spectrum (by comparison with spectra of other ortho-substituted imides). These reactions were not pursued further. 


\section{Section 1.3: Properties and Reactions of $\left(\mathrm{RC}_{5} \mathrm{H}_{4}\right)_{3} \mathrm{UN}_{3}$ \\ $\left(\mathrm{R}=\mathrm{Me}\right.$ or $\left.\mathrm{SiMe}_{3}\right)$}

\subsection{A: Properties of $\left(\mathrm{MeC}_{5} \mathrm{H}_{4}\right)_{3} \mathrm{UN}_{3}$ and $\left(\mathrm{Me}_{3} \mathrm{SiC}_{5} \mathrm{H}_{4}\right)_{3} \mathrm{UN}_{3}$}

As reported earlier in this chapter, these compounds are synthesized by several different methods. For the $\mathrm{MeC}_{5} \mathrm{H}_{4}$ compound, two techniques were commonly used to produce clean material in high yield: replacement of the chloride of $\left(\mathrm{MCC} \mathrm{C}_{5}\right)_{3} \mathrm{UCl}$ in aqueous solution or oxidation of the trivalent compound $\left(\mathrm{MeC}_{5} \mathrm{H}_{4}\right)_{3} \mathrm{U}($ thf $)$ with trityl axdde. Either reaction can be performed on relatively large scales (ca. $3 \mathrm{~g}$ ). The aqueous process typically gives an $80-90 \%$ yield of $\left(\mathrm{MeC}_{5} \mathrm{H}_{4}\right)_{3} \mathrm{UN}_{3}$, while the trityl azide preparation gives yields of ca. 50\%. The trityl azide reaction is, though, easier to perform; $\left(\mathrm{MeC}_{5} \mathrm{H}_{4}\right)_{3} \mathrm{U}(\mathrm{th} f)$ and $\mathrm{Ph}_{3} \mathrm{CN}_{3}$ are simply mixed as solids in a 1:1 molar ratio, diethyl ether added to give an immediate green precipitate, and, after stirring for one hour, the ether is filtered off to give a very pure green powder of $\left(\mathrm{MeC}_{3} \mathrm{H}_{4}\right)_{3} \mathrm{UN}_{3}$. The compound instantly turns brown/black in the presence of oxygen, and in fact will smoke and spark on exposure as a finely divided powder to $\mathrm{O}_{2}$.

One other reaction in which $\left(\mathrm{MeC}_{5} \mathrm{H}_{4}\right)_{3} \mathrm{UN}_{3}$ was produced was carried out. This is the oxidation of $\left(\mathrm{MeC}_{5} \mathrm{H}_{4}\right)_{3} \mathrm{U}($ thf $)$ to the azide using hydrazoic acid, $\mathrm{HN}_{3}$ (Figure 1-10):

$$
\mathrm{O}_{3} \mathrm{U}(\mathrm{th})+\mathrm{HN}_{3} \stackrel{\mathrm{E}_{2} \mathrm{O}}{\longrightarrow} \mathrm{O}_{3} \mathrm{UN}_{3}+1 / 2 \mathrm{H}_{2}
$$

Figure 1-10: Oxidation of $\left(\mathrm{MeC}_{5} \mathrm{H}_{4}\right)_{3} \mathrm{U}(\mathrm{th})$ by hydrazoic acid. 
An ethereal solution of $\mathrm{HN}_{3}$ is easily prepared by combining $\mathrm{NaN}_{3}$ and $\mathrm{H}_{2} \mathrm{SO}_{4}$ in an ether/water mixture, followed by careful distillation of the ether layer. ${ }^{25}$ Because hydrazoic acid is explosive, all manipulations were carried out behind a shield. The $\mathrm{HN}_{3}$ /ether solution was then titrated and used. Adding one molar equivalent of $\mathrm{HN}_{3}$ to a solution of $\left(\mathrm{MeC}_{5} \mathrm{H}_{4}\right)_{3} \mathrm{U}($ thf $)$ in ether yielded a green precipitate and pale solution. After removal of the volatile materials, the green solid was sublimed at $120-130^{\circ} \mathrm{C}$ to give pure $\left(\mathrm{MeC}_{5} \mathrm{H}_{4}\right)_{3} \mathrm{UN}_{3}$ in fairly low yield. Some of the reaidue from the sublimation dissolved in dichloromethane and a small additional amount of the uranium azide was crystallized. It appears that $\mathrm{HN}_{3}$ simply acts like the other ionic azides in its reactivity towards trivalent uranium, not a very surprising result. The low yields obtained from this reaction are probably due to protonation of the $\mathrm{MeC}_{5} \mathrm{H}_{4}$ rings by the acid, resulting in decomposition of the uranium species. This is not unexpected due to the highly acidic nature of $\mathrm{HN}_{3}\left[\mathrm{pKa}\left(\mathrm{H}_{2} \mathrm{O}\right)=4.8\right]^{26}$.

The compound $\left(\mathrm{Me}_{3} \mathrm{SiC}_{5} \mathrm{H}_{4} \mathrm{UNN}_{3}\right.$ as described earlier, cannot be prepared by the aqueous technique mentioned above. Instead, it must be made by oxidation of $\left(\mathrm{Me}_{3} \mathrm{SiC}_{5} \mathrm{H}_{4}\right)_{3} \mathrm{U}$ using $\mathrm{Me}_{3} \mathrm{SnN}_{3}$. The compound is isolated as brown crystals from either hexane or hexamethyldisiloxane $\left[\left(\mathrm{Me}_{3} \mathrm{Si}\right)_{2} \mathrm{O}\right]$ in yields of $\mathrm{ca} .40 \%$. This compound is also exceedingly oxygen sensitive.

There are marked differences in the solubilities of the methylcyclopentadienyl and trimethylsilylcyclopentadienyl uranium azides. $\left(\mathrm{Me}_{3} \mathrm{SiC}_{5} \mathrm{H}_{4}\right)_{3} \mathrm{UN}_{3}$ is extremely soluble in common organic solvents such as hexane, ether, thf, and toluene, giving brown solutions with a green tint. This certair.ly suggests that the compound is monomeric, not a very surprising result considering the bulk of the $\mathrm{Me}_{3} \mathrm{Si}$ groups. $\left(\mathrm{MeC}_{5} \mathrm{H}_{4}\right)_{3} \mathrm{UN}_{3}$, 
on the other hand, is far less soluble. The compound is completely insoluble in hexane, very slightly soluble in ether, and somewhat more soluble in toluene, thf, and $\mathrm{CH}_{2} \mathrm{Cl}_{2}$.

There are two primary reasons for the extreme solubility difference between these two compounds. First, the sire of the $\mathrm{Me}_{3} \mathrm{Si}$ group compared with a Me group decreases the ability of the molecule to pack tightly in the crystal. This makes it easier for a leas polar solvent to break up the lattice. Secondly, the rather narrow azide unit may be capable of interacting with a second metal center in $\left(\mathrm{MeC}_{5} \mathrm{H}_{4}\right)_{3} \mathrm{UN}_{3}$, yielding an oligomeric material such as shown below (Figure 1-11):

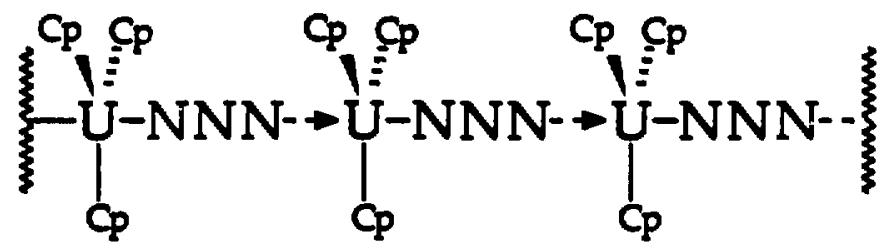

Figure 1-11: Possible oligomeric structure of $\left(\mathrm{MeC}_{5} \mathrm{H}_{4}\right)_{3} \mathrm{UN}_{3}$.

This type of structure is not unknown; $\mathrm{Cp}_{3} \mathrm{UCN}^{27}, \mathrm{Cp}_{3} \mathrm{UC}(\mathrm{CN})_{3}{ }^{28}$, and $\left[\mathrm{Cp}_{3} \mathrm{U}\right]_{2}\left[\mathrm{PH}(\mathrm{CN})_{4}\right]^{29}$ are examples of compounds believed to be oligomeric. In addition, the trigonal bipyramidal structure such an oligumer would require has been observed previously in triscyclopentadienyl uranium compounds, such as $\mathrm{CP}_{3} \mathrm{U}(\mathrm{NCS})(\mathrm{MeCN}) .^{30}$ It is also interesting to note that a similarly insoluble azide was produced recently using ytterbium. ${ }^{31}$ This azide, $\left(\mathrm{Me}_{5} \mathrm{C}_{5}\right)_{2} \mathrm{YbN}_{3}$, appears to be oligomeric, and, in fact, the azide stretches in the infrared spectra of these materials are alike both in position and shape. Presumably, $\left(\mathrm{Me}_{3} \mathrm{SiC}_{5} \mathrm{H}_{4}\right)_{3} \mathrm{CN}_{3}$ cannot have intermolecular interactions of this sort due to the steric requirements of the cyclopentadienyl ligands. 
$\left(\mathrm{Me}_{3} \mathrm{SiC}_{3} \mathrm{H}_{4}\right)_{3} \mathrm{UN}_{3}$ exhibits a relatively low melting point of $103-105^{\circ} \mathrm{C}$. This value can be compared with similar ( $\left.\mathrm{Me}_{3} \mathrm{SiC}_{5} \mathrm{H}_{4}\right)_{3} \mathrm{UX}$ compounds; for $X$ $=\mathrm{Cl}$, the m.p. is $101-102^{\circ} \mathrm{C}$, and for $\mathrm{X}=\mathrm{F}$, the m.p. is $73-75^{\circ} \mathrm{C}$. The compound appears to melt without a color change or any other evidence of decompostion. Converseiy, $\left(\mathrm{MeC}_{5} \mathrm{H}_{4}\right)_{3} \mathrm{UN}_{3}$ melts from $152-160^{\circ} \mathrm{C}$ with apparent decompsstion; the material changes from a bright green to deep brown while slowly melting over this temperature range. More about the thermolysis behavior of these compourds will be discussed in the following section.

The ' ${ }^{2} H$ NMR spectra of these two compounds are shown in Figure 112. Neither of these spectra is remarkable; both show the typical patterns and linewidths of tetravalent $\left(\mathrm{RC}_{5} \mathrm{H}_{4}\right)_{3} \mathrm{UX}$ compounds. The dominant feature of the infrared spectra of these materiais is the extremely strong asymmetric azide stretch above $2000 \mathrm{~cm}^{-1}$ (Figure 1-13). In $\left(\mathrm{Me}_{3} \mathrm{SiC}_{5} \mathrm{H}_{4}\right)_{3} \mathrm{UN}_{3}$, this stretch is observed at $2082 \mathrm{~cm}^{-1}$, and is relatively sharp. The stretch is considerably broader and at higher energy in $\left(\mathrm{MeC}_{5} \mathrm{H}_{4} \mathrm{CNN}_{3}\right.$ occurring at $2115 \mathrm{~cm}^{-1}$. The broadness of this stretch may be indicative of the type of structure depicted earlier in Figure 1-11, and, as mentioned above, the shape of this stretch is very similar to that of bis(pentamethylcyclopentadienyl)ytterbium azide. The higher energy of the stretch in $\left(\mathrm{MeC}_{5} \mathrm{H}_{4}\right)_{3} \mathrm{UN}_{3}$ may be best explained by considering this oligomeric arrangement as a Lewis acid coordination adduct of the azide, with each $\left(\mathrm{MeC}_{5} \mathrm{H}_{4}\right)_{3} \mathrm{UN}_{3}$ unit acting both as the acid and the donor base. Adducts of this sort have been shown to exhibit asymmetric azide stretches at higher frequencies than that of the uncoordinated azide, as Thayer and others found for nitrogen-bound Lewis acid adducts of inurganic azides. $^{32}$ 

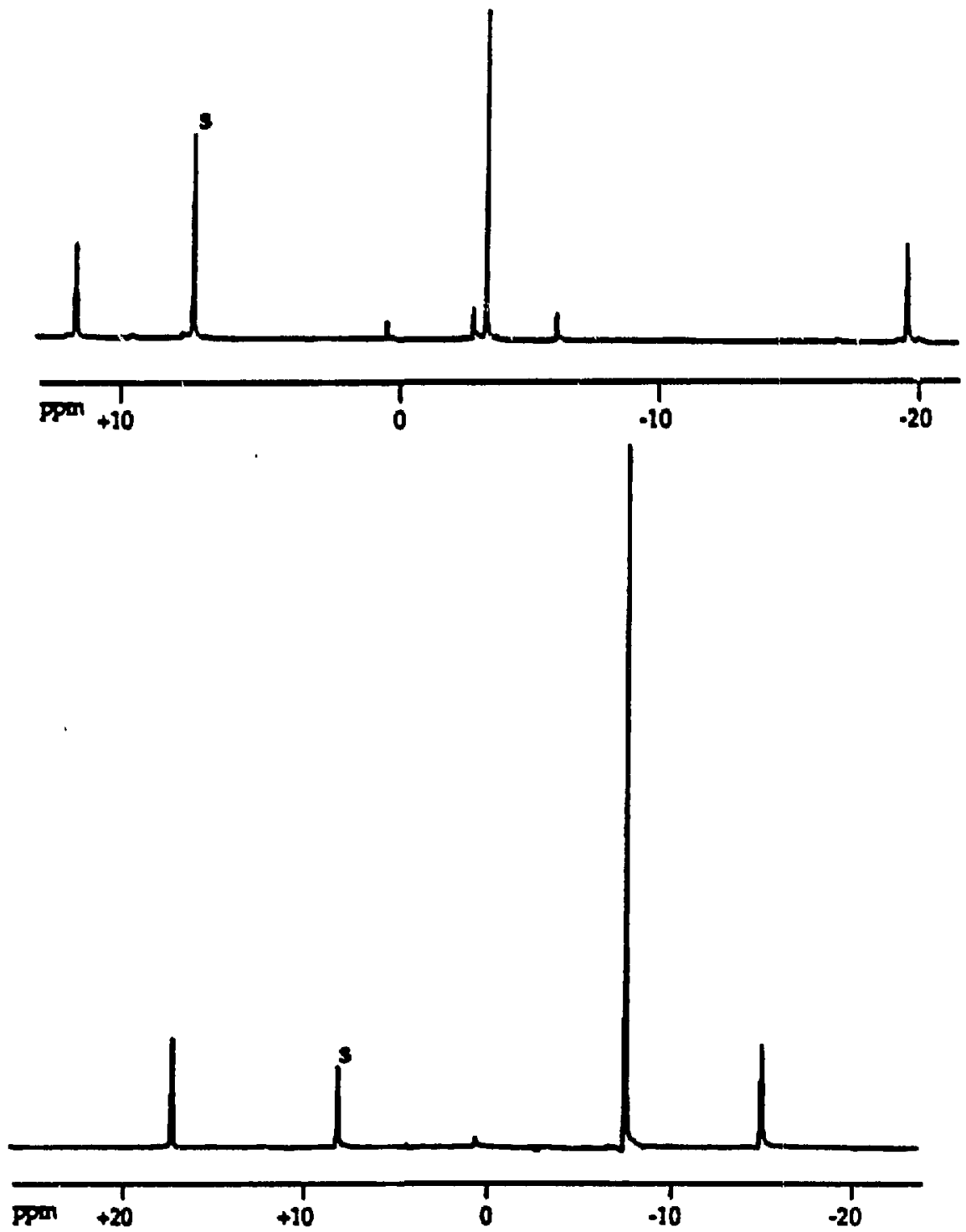

Figure 1-12: ${ }^{1} \mathrm{H}$ NMR spectra of $\left(\mathrm{MeC}_{5} \mathrm{H}_{4}\right)_{3} \mathrm{UN}_{3}$ (top) and $\left(\mathrm{Me}_{3} \mathrm{SiC}_{5} \mathrm{H}_{4}\right)_{3} \mathrm{UN}_{3}$ (bottom) [s: solvent]. 

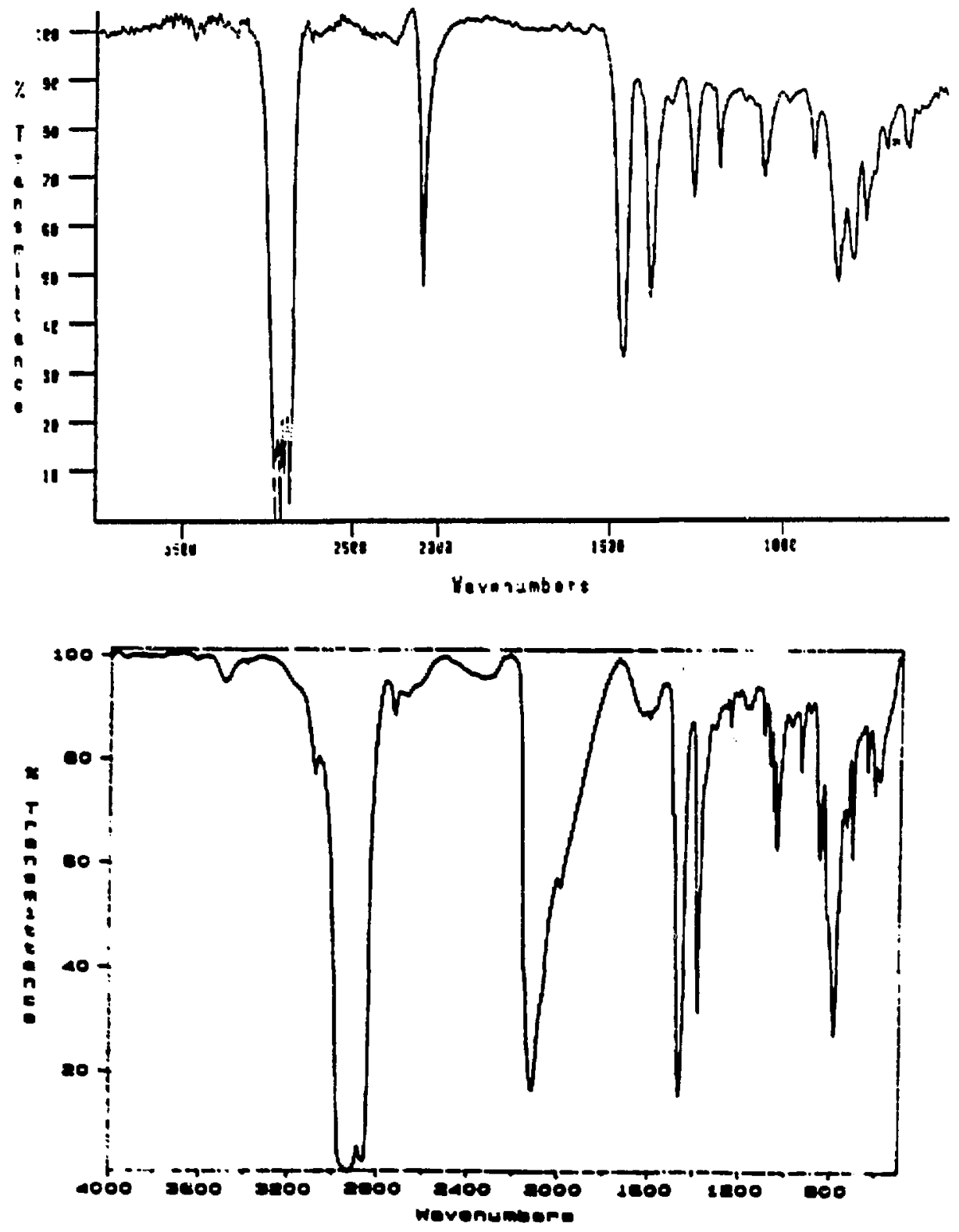

Figure 1-13: Infrared spectra (Nujol mulls) of $\left(\mathrm{Me}_{3} \mathrm{SiC}_{5} \mathrm{H}_{4}\right)_{3} \mathrm{LN}_{3}$ (top) and $\left(\mathrm{MeC}_{3} \mathrm{H}_{4}\right)_{3} \mathrm{UN}_{3}$ (bottom). 
Both compounds exhibit molecular jons in the electron impact mass spectrum, and the simulated spectra agree well with those determined experimentally.

\subsection{B: Reactions of $\left(\mathrm{Me}_{3} \mathrm{SiC}_{3} \mathrm{H}_{4}\right)_{3} \mathrm{UN}_{3}$ and $\left(\mathrm{MeC}_{3} \mathrm{H}_{4}\right)_{3} \mathrm{UN}_{3}$}

Our earliest attempts at exploring the chemistry of these azides involved pyrolysis reactions. The goal of thees experiments was to eliminate dinitrogen from the azide to produce a uranium nitride, $\left(\mathrm{RC}_{5} \mathrm{H}_{4}\right)_{3} \mathrm{UN}$, formally a uranium(VI) species. 33 When $\left(\mathrm{MeC}_{5} \mathrm{H}_{4}\right)_{3} \mathrm{UN}_{3}$ was heated to $\mathrm{ca}$. $200^{\circ} \mathrm{C}$ under one atmosphere of nitrogen or argon, the green solid slowly turned black. There was no obvious evidence of gas evolution, and the black srlid was completely insoluble in organic solvents. Similar results were obtained when the material was thermolyzed in refluxing decane (b.p. $174^{\circ} \mathrm{C}$ ). A black precipitate formed which would not redissolve. When this azide was heated under vacuum (ca. $10^{-4}$ torr), the bright green solid was found to sublime unchanged at $90-100^{\circ} \mathrm{C}$.

It appears from these results that the $\mathrm{N}-\mathrm{N}$ bonds in this azide are relatively strong, and that the two-lectron oxidation to the uranium nitride is not favorable. If the nitride is being formed in the solid phase pyrolysis or in the solution reaction, it is a polymeric material that we cannot characterize. It is quite possible, however, that at these temperatures reactions involving the cyclopentadienyl rings may also occur, and the material may simply decompose completely.

Several attempts were made to thermolyze $\left(\mathrm{Me}_{3} \mathrm{SiC}_{5} \mathrm{H}_{4}\right)_{3} \mathrm{UN}_{3}$ in the solid phase. These reactions were done under an argon atmosphere in sealed ampoules. When the material was heated for two hours at $200^{\circ} \mathrm{C}$, only unreacted starting material was recovered. This indicates a considerably 
greater thermal stability for this azide relative to $\left(\mathrm{MeC}_{5} \mathrm{H}_{4}\right)_{3} \mathrm{UN}_{3}$. However, when the azide was heated to $250^{\circ} \mathrm{C}$ for $1 \frac{1}{4}$ hours, a yellow material sublimed up the sides of the tube, and a brown residue remained at the bottom. The ${ }^{1} \mathrm{H}$ NMR spectra of both materials were uninterpretable. The material at the base of the tube was quite insoluble and showed very few peaks in the NMR, while the sublimed material gave a complex spectrum. When the azide was heated to his ter temperatures, even more complex spectra resulted. It is quite obvious that this resction is not clean or straightforward, and it seems likely that a large number of products are formed. No further work on pyrolysis of the arides was performed.

A second attempt to explore the reactivity of this compound involved the use of a good Lewis acid, trimethylaluminum, to see whether the lone pairs on the azide were accessible for coordination. When a solution of AlMe, in hexane was added to $\left(\mathrm{MeC}_{5} \mathrm{H}_{4}\right)_{3} \mathrm{UN}_{3}$ dissolved in toluene, no color change was observed. Subsequent work-up of the reaction mixture yielded only the unreacted uranium azide. However, when trimethylaluminum in hexane was added to $\left(\mathrm{MeC}_{5} \mathrm{H}_{4}\right)_{3} \mathrm{UN}_{3}$ dissolved in dichloromethane, an instant color change from light greer./brown to darker brown was observed. Removal of the volatile materials followed by extraction and crystallization from toluene yielded brown crystals. These crystals, when treated with diethyl ether, immediately turned bright green, and $\left(\mathrm{MeC}_{5} \mathrm{H}_{4} \nu_{3} \mathrm{UN}_{3}\right.$ could once again be isolated from the solution. This result suggested that the compound formed is a weak coordination complex of the formula $\left(\mathrm{MeC}_{5} \mathrm{H}_{4}{ }_{3} \mathrm{UN}_{3} \cdot \mathrm{AlMe}_{3}\right.$. Further evidence for a relatively weak coordination was given by studying the ${ }^{1} H$ NMR spectrum of the complex. The spectrum of a mixture of the trimethylaluminum adduct and additional $\left(\mathrm{MeC}_{5} \mathrm{H}_{4}\right)_{3} \mathrm{UN}_{3}$ showed only one set of shifted resonances, with a greatly reduced resonance at 
$\delta=-7.7 \mathrm{ppm}$ attributed to the $\mathrm{AlMe}_{3}$ protons. Spectra of the pure materials and the mixture are shown in Figure 1-14.

Additional evidence of a weak coordination was seen in the fact that it proved difficult to isolate the 1:1 adduct in pure form. Even when $\left(\mathrm{MeC}_{5} \mathrm{H}_{4} \mathrm{UN}_{3}\right.$ was allowed to react with ca. 15 molar equivalents of $\mathrm{AlMe}_{3}$ the product showed an AlMe, resonance in the ${ }^{1} \mathrm{H}$ NMR spectrum with an intensity of approximately 50-80\% of the expected value. It is possible that trimethylaluminum dissociates when the crystals are dried under vacuum or during cystallization from toluene. The adduct does not give a parent ion in the E.L-M.S., instead showing only the uncoordinated uranium azide. The asymmetric $\mathrm{N}_{3}$ stretch in the infrared spectrum of this complex occurs at 2110 $\mathrm{cm}^{-1}$. This is not significantly shifted from the uncoordinated azide, consistent with the idea that the starting material may be oligomeric.

Another piece of evidence suggesting that $\left(\mathrm{MeC}_{5} \mathrm{H}_{4}\right)_{3} \mathrm{CN}_{3}$ may be oligomeric comes from the fact that the $\mathrm{AlMe}_{3}$ adduct was formed in dichloromethane but not in toluene solution. We would expect that the more polar solvent would be more effective at breaking up the interactions between the azide units, allowing coordination of the Lewis acid.

There are, of course, two possible sites for coordination of the trimethylaluminum to the azide: the $\alpha$-or the $r$ nitrogens. No definitive statement concerning which coordination exists in $\left(\mathrm{MeC}_{5} \mathrm{H}_{4}\right)_{3} \mathrm{CN}_{3} \cdot \mathrm{AlMe}_{3}$ may be made, but it should be noted that $\alpha$-coordination is proposed in the compounds $\mathrm{Me}_{3} \mathrm{SiN}_{3} \cdot \mathrm{BBr}_{3}{ }^{34}, \mathrm{Ph}_{3} \mathrm{SiN}_{3} \cdot \mathrm{PPh}_{3}{ }^{35}$, and $\mathrm{MeN}_{3} \cdot \mathrm{SbCl}_{5}{ }^{36}$, while rcoordination has been suggested fo $\mathrm{Ph}_{3} \mathrm{CN}_{3} \cdot \mathrm{PPh}_{3}{ }^{37}$

Several reactions that have been observed with organic and inorganic azides were also attempted with the uranium azides, $\left(\mathrm{RC}_{5} \mathrm{H}_{4}\right)_{3} \mathrm{UN}_{3}$. For 


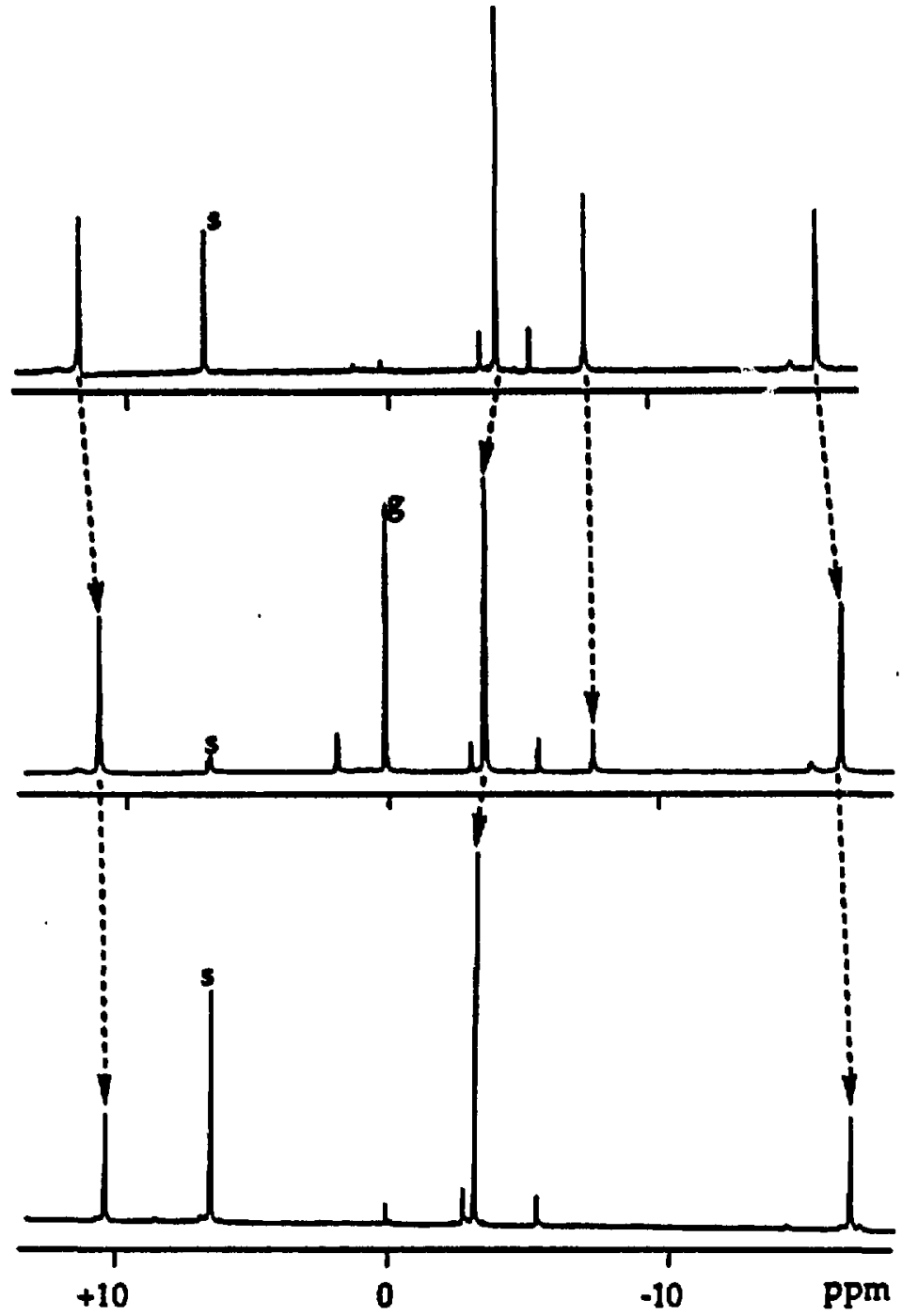

Figure 1-14: ' $\mathrm{H} N \mathrm{NMR}$ spectra of $\left(\mathrm{MeC} \mathrm{C}_{5} \mathrm{H}_{3} \mathrm{UN}_{3} \cdot \mathrm{AlMe}_{3}\right.$ (top), $\left(\mathrm{MeC}_{5} \mathrm{H}_{4} \mathrm{UN}_{3} \cdot \mathrm{AlMe}_{3}+\left(\mathrm{MeC} \mathrm{CH}_{3} \mathrm{UN}_{3}\right.\right.$ (center), and $\left(\mathrm{MeC}_{5} \mathrm{H}_{3} \mathrm{UN}_{3}\right.$ (bottom) [s: solvent; g: stopcock grease]. 
example, most organic azides react with tertiary phosphines, eliminating $\mathrm{N}_{2}$ and forming phosphineimines as shown is Scheme 1-10 below: $:^{38,39}$

$$
\mathrm{RN}_{3}+\mathrm{PR}_{3}^{\prime} \longrightarrow \mathrm{RNPR}_{3}^{\prime}+\mathbf{N}_{2}
$$

Scheme 1-10. Reaction of azides with phosphines to produce a phosphineimine.

This reaction has also been found to procsed with some inorganic azides, such as $\mathrm{R}_{3} \mathrm{SiN}_{3}(\mathrm{R}=\mathrm{Ph}, \mathrm{Me})$. ${ }^{14 \mathrm{~A}} \mathrm{w}$ However, an attempt at a similar reaction of $\left(\mathrm{Me}_{3} \mathrm{SiC}_{5} \mathrm{H}_{4}\right)_{3} \mathrm{UN}_{3}$ with $\mathrm{PMe}_{3}$ yielded only recovered starting material. It should be noted, however, that this reaction was attempted at roum temperature, while many of the known cases require higher temperatures.

Another type of reaction known for organic azides is 1,3-dipolar cycloaddition. ${ }^{11}$ In the case of alkynes, such reactions have also been observed for silicon and tin azides (Scheme 1-11):42

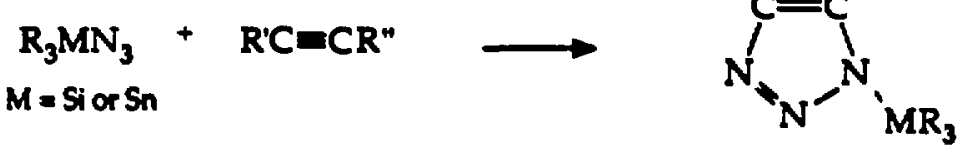

Scheme 1-11: Cyelosddition of azides with alkynes.

Another cycloaddition of this type is reaction of an azide with $\mathrm{CS}_{2}$. This reaction has been observed with a copper azide, $\mathrm{Cu}\left(\mathrm{PPh}_{3}\right)_{2} \mathrm{~N}_{3}$, eventually yielding $\mathrm{Cu}\left(\mathrm{PPh}_{3}\right)_{2} \mathrm{NCS}$, but believed to proceed through an addition product like those shown in Figure 1-15 below: ${ }^{3}$ 

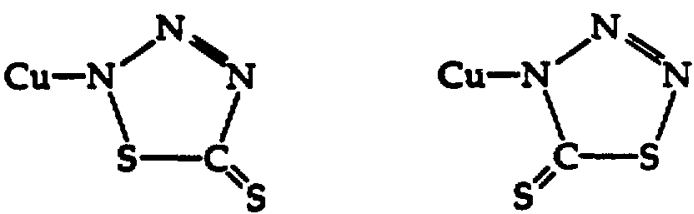

Figure 1-15: Postulated addition product of a copper azide with $\mathrm{CS}_{2}$.

Unfortunately, mixing $\left(\mathrm{MeC} \mathrm{C}_{5} \mathrm{H}_{3} \mathrm{LN}_{3}\right.$ with either diphenylacetylene or carbon disulfide afforded no reaction and only starting material was recovered. Again, these rastions were performed at room temperature and high temperature reactions were not pursued.

Because of an interest in our research group in reactions of transition metal carbonyls with uranium compounds, the azide $\left(\mathrm{MeC} \mathrm{CH}_{4} \mathrm{UN}_{3}\right.$ was also reacted with $\mathrm{Co}_{2}(\mathrm{CO})_{9}$. Interestingly, when $\left(\mathrm{MeC}_{5} \mathrm{H}_{4}\right)_{3} \mathrm{LN}_{3}$ was stirred overnight with $\mathrm{CO}_{2}(\mathrm{CO})_{8}$ in dichloromethane, red crystals were obtained. The infrared spectrum of these crystals showed strong, broad stretches in the area of $2000 \mathrm{~cm}^{-1}$. The ${ }^{1} \mathrm{H}$ NMR showed only one very simple 3:2:2 pattern for the $\mathrm{MeC}_{5} \mathrm{H}_{4}$ resonances and indicated uranium(IV) by the narrow linewidths. The IR and NMR spectra were identical to spectra obtained by Brennan of red crystals from the reaction of $\left(\mathrm{MeC}_{5} \mathrm{H}_{4}\right)_{3} \mathrm{U}\left(\right.$ the) with $\mathrm{Co}_{2}(\mathrm{CO})_{8}$. th the compound was identified as $\left(\mathrm{MeC}_{5} \mathrm{H}_{4}\right)_{3} \mathrm{U}-\mu-\mathrm{OC}\left[\mathrm{Co}_{3}(\mathrm{CO})_{9}\right]$. The identification was performed as follows: First, it was found that $\left(\mathrm{MeC}_{5} \mathrm{H}_{4}\right)_{3} \mathrm{UNR}$, when allowed to react with $\mathrm{CO}_{2}(\mathrm{CO})_{8}$ produced an identical product (this reaction will be discussed in more detail later in this chapter). Then, $C p_{3}$ UNR was reacted with $\mathrm{CO}_{2}(\mathrm{CO})_{2}$ to produce the analogous unsubstituted cyclopentadienyl product. The compound obtained in this way was found to be identical in IR and NMR properties with those reported in the literature 
for $\mathrm{Cp}_{3} \mathrm{U}-\mu-\mathrm{OC}\left[\mathrm{Co}_{3}(\mathrm{CO})_{9}\right]$, made by Stutte and Schmid by the following reaction (Scheme 1-12):4

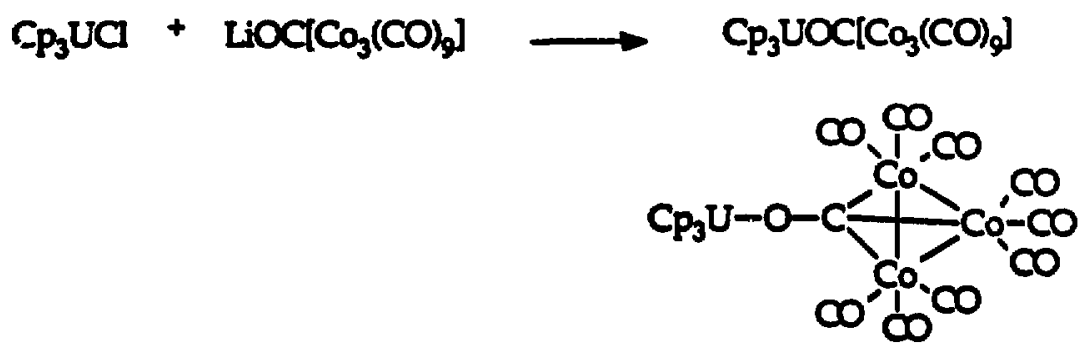

Scheme 1-12; Stutte and Schmid preparation of the uranium-cobalt eartonyl complex.

It is interesting to note that, in the reaction of $\left(\mathrm{MeC}_{5} \mathrm{H}_{4}\right)_{3} \mathrm{UN}_{3}$ with $\mathrm{CO}_{2}(\mathrm{CO})_{8}$ a second product was obtained whose IR spectrum suggested that it contains both azide and carbonyl units. This compound gave no ${ }^{\mathbf{H}} \mathrm{H}$ NMR spectrum, and was isolated in very low yield and its characterization was not pursued.

One final set of reactions will be discussed in this section. These were reactions to see whether the azide group could bridge between two uranium centers to form a mixed-valence uranium complex (Scheme 1-13):

$$
\left(\mathrm{RC}_{5} \mathrm{H}_{4}\right)_{3} \mathrm{U}+\left(\mathrm{R}^{\prime} \mathrm{C}_{5} \mathrm{H}_{4}\right)_{3} \mathrm{UN}_{3} \longrightarrow\left(\mathrm{RC}_{5} \mathrm{H}_{4}\right)_{3} \mathrm{U}-\mathrm{NNN}-\mathrm{U}\left(\mathrm{R}^{\prime} \mathrm{C}_{5} \mathrm{H}_{4}\right)_{3}
$$

Schease 1-13: Preparation of a mixed-valence bridged uranium azide.

A large number of examples of complexes in which the azide group bridges two metal centers are known. These can involve 1,1-bridging, in which both metals are coordinated to the same nitrogen, or, more rarely, 1,3-bridging, in which the $\alpha$ - and $\gamma$-nitrogens are each coordinated to one metal, as shown below (Figure 1-16): 


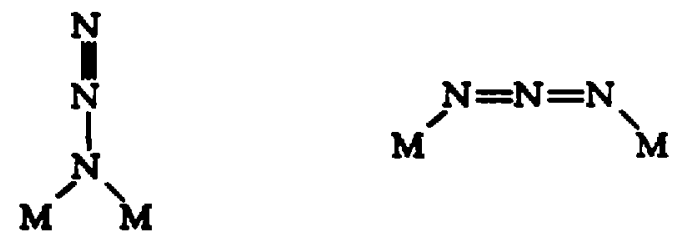

A $\quad$ B

Frare 1-16. Modes of bonding in bridying azide complexes.

Examples of structure $A$ include $\left(\mathrm{Pd}_{2}\left(\mathrm{~N}_{3}\right)_{4}\right]^{2-45}$ and $\left[(\mathrm{CO})_{3} \mathrm{Mn}\left(\mathrm{N}_{3}\right)_{3} \mathrm{Mn}(\mathrm{CO})_{3}\right]^{-46}$, while structure $\mathrm{B}$ is seen in $\left[\mathrm{Cu}\left(\mathrm{PPh}_{3}\right)_{2} \mathrm{~N}_{3}\right]_{2}{ }^{47}$

Attempts at producing this type of compound were made in two ways: either on a preparative scale with attempted isolation of a crystalline product, or by mixing the two uranium species in an NMR tube and observing the resulting spectrum.

Two different NMR experiments were done (Scheme 1-14):

$$
\begin{aligned}
& \left(\mathrm{MeC}_{5} \mathrm{H}_{4}\right)_{3} \mathrm{UN}_{3}+\left(\mathrm{MeC}, \mathrm{I}_{4} \mathrm{U}(\text { thr }) \stackrel{\text { do toluene }}{\longrightarrow}\right. \\
& \left(\mathrm{Me}_{3} \mathrm{SiC}_{5} \mathrm{H}_{4}\right)_{3} \mathrm{UN}_{3}+\left(\mathrm{Me}_{3} \mathrm{SiC}_{5} \mathrm{H}_{4}\right)_{3} \mathrm{U} \stackrel{\mathrm{d}^{*} \text {-toluene }}{\longrightarrow}
\end{aligned}
$$

Seheme 1-14: NMR tube reactions of uranium(IV) arides with uranium(III) complexes.

In the case of the $\mathrm{MeC}_{5} \mathrm{H}_{4}$ compounds, the experiment was quite crude, since the azide is quite insoluble at low temperatures. At room temperature, there appeared to be four fairly broad peaks in the spectrum (in addition to the solvent). However, wheri the temperature was decreased to $-30^{\circ} \mathrm{C}$, the spectrum sharpened and there seemed to be a recognizable pattern, viz., the 3:2:2 pattern typical of $\left(\mathrm{MeC}_{5} \mathrm{H}_{\downarrow_{3}} \mathrm{U}\right.$ compounds was observed at $\delta=-0.57$, 
-27.42 , and $+16.07 \mathrm{ppm}$. In addition, two peaks in the diamagnetic region of the spectrum at $\delta=3.47$ and $1.36 \mathrm{ppm}$ are assigned to uncoordinated thr. This spectrum remained relatively unchanged (except for shifts in the paramagnetic peaks) at $-74^{\circ} \mathrm{C}$. Although this was certainly not definitive evidence of a bridged aride complex, the presence of the free thf was encouraging, and seemed to suggest that the $\mathrm{Cp}_{3} \mathrm{UN}_{3}$ unit is capable of interacting to some extent with a second metal center.

When the $\mathrm{Me}_{3} \mathrm{SiC}_{5} \mathrm{H}_{4}$ compounds were uned, again only resonances due to one species were obeerved in solution. At room temperature, the typical 9:2:2 pattern of these compounds was seen, although one of the ring resonances was quite broad $\left(v_{1 / 2}=39 \mathrm{~Hz}\right.$; see Figure 1-17). This mixture was then examined by variable temperature NMR spectroscopy. At higher temperatures (up to $80^{\circ} \mathrm{C}$ ), the spectrum shifted but remained essentially similar to the room temperature spectrum. The position of the resonances at various temperatures are given in Table 1-3 below:

\begin{tabular}{|cccc|}
\hline $\begin{array}{c}\text { Temperature } \\
\left({ }^{\circ} \mathrm{C}\right)\end{array}$ & $\begin{array}{c}\delta\left(\mathrm{Me}_{3} \mathrm{Si}\right) \\
(\mathrm{ppm})\end{array}$ & $\begin{array}{c}\left.\delta \text { (Ring } \mathrm{H}_{1}\right) \\
(\text { ppin) }\end{array}$ & $\begin{array}{c}\delta\left(\text { Ring } \mathrm{H}_{2}\right) \\
(\mathrm{ppm})\end{array}$ \\
\hline 31 & -8.75 & +1.2 & -16.68 \\
59 & -7.68 & +2.45 & -14.53 \\
70 & -7.44 & +3.00 & -13.79 \\
80 & -7.05 & +4.5 & -12.92 \\
\hline
\end{tabular}

Table 1-3: ' $\mathrm{H}$ NMR chemical shifts in NMR reaction of $\left(\mathrm{MegSi}_{5} \mathrm{H}_{4}\right)_{3} \mathrm{U}$ and $\left(\mathrm{Me}_{3} \mathrm{SKC}_{5} \mathrm{H}_{4} \mathrm{H}_{3} \mathrm{CN}_{3}\right.$.

The broad ring resonance did not sharpen significantly as the temperature was raised, and the other resonances did not seem to change shape greatly, 


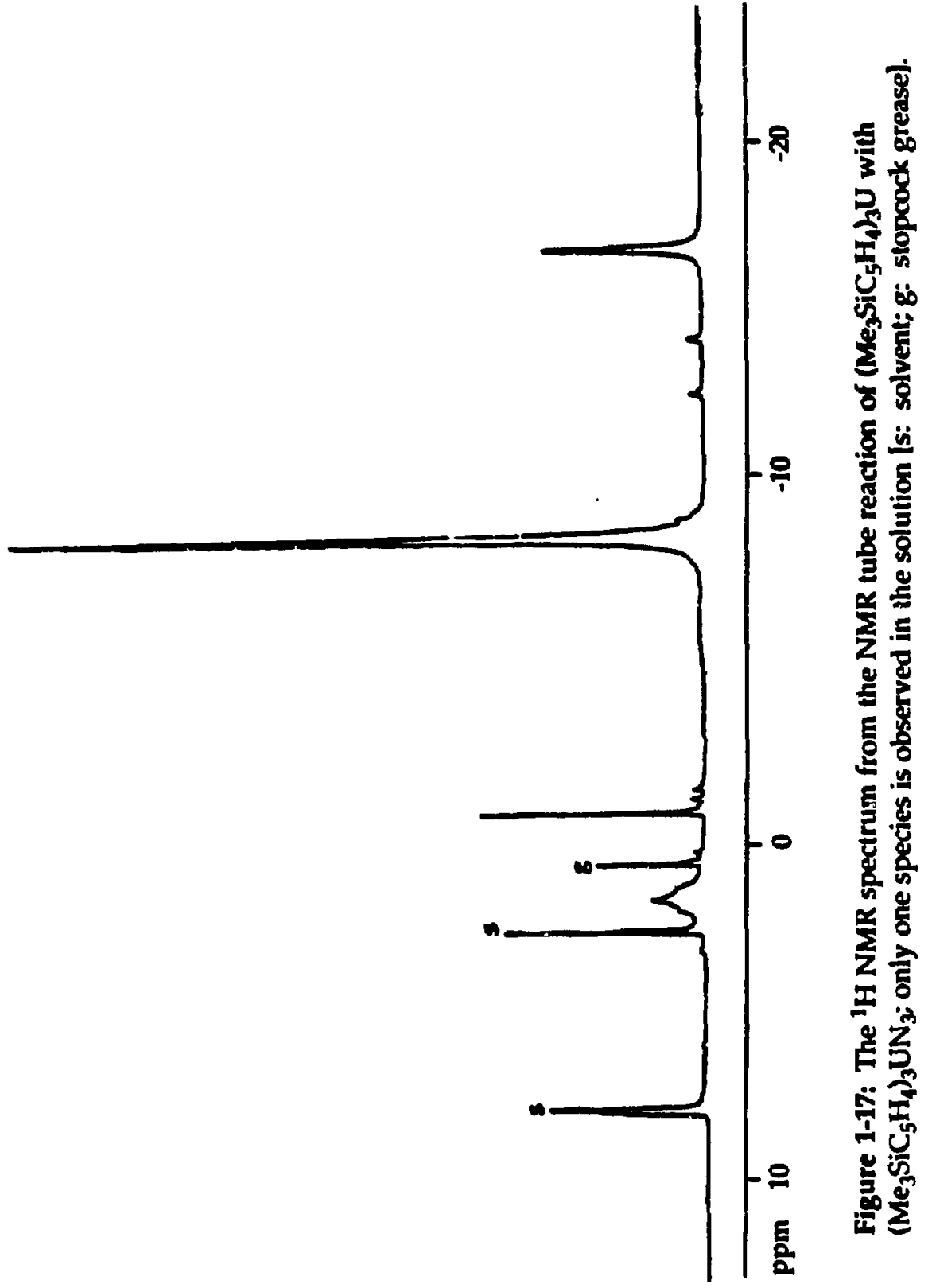


either. At higher temperatures, other small peaks were observed in the spectrum, but these are probably due to decomposition products from either small amounts of air oxidation or thermal decomposition. The spectra at low temperatures were somewhat more complex; several unexplained peaks appeared to grow in. However, there remained only one $\mathrm{Me}_{3} \mathrm{Si}$ resonance with little broadening throughout the experiment (down to $-88^{\circ} \mathrm{C}$ ). The important part of these experiments is that there is only one predominant species present in these solution, a bridged azide that has equivalent $\left(\mathrm{RC}_{5} \mathrm{H}_{4}\right)_{3} \mathrm{U}$ groups on the ${ }^{\mathrm{H}} \mathrm{H}$ NMR time scale.

The most interesting of the experiments done on a preparative scale involved the trimethylsilylcyclopentadienyl derivatives. When $\left(\mathrm{Me}_{3} \mathrm{SiC}_{5} \mathrm{H}_{4}\right)_{3} \mathrm{UN}_{3}$ (pale green/brown) and $\left(\mathrm{Me}_{3} \mathrm{SiC}_{5} \mathrm{H}_{4}\right)_{3} \mathrm{U}$ (dark green) were mixed in hexane, the solution immediately turned a very deep brown, and brown crystals could be obtained from hexane. The room temperature ${ }^{1} \mathrm{H}$ NMR of this material was clean, and showed the identical spectrum to the room temperature spectrum obtained in the NMR tube experiment described above. The material exhibited a sharp melting point of $83-86^{\circ} \mathrm{C}$ $\left[\left(\mathrm{Me}_{3} \mathrm{SiC}_{5} \mathrm{H}_{4}\right)_{3} \mathrm{U}\right.$ melts at $76-77^{\circ} \mathrm{C}^{\text {st }}\left(\mathrm{Me}_{3} \mathrm{SiC}_{5} \mathrm{H}_{4}\right)_{3} \mathrm{UN}_{3}$ melts at $\left.103-105^{\circ} \mathrm{C}\right]$, but the most interesting feature was the infrared spectrum: two assymmetric azide stretches were observed, at 2122 and $2081 \mathrm{~cm}^{-1}$ [the stretch in $\left(\mathrm{Me}_{3} \mathrm{SiC}_{5} \mathrm{H}_{4}\right)_{3} \mathrm{UN}_{3}$ is at $\left.2082 \mathrm{~cm}^{-1}\right]$.

The similar reaction iyas also done with the mixed cyclopentadienes as shown below (Scheme 1-15):

$$
\left(\mathrm{MeC}_{5} \mathrm{H}_{4}\right)_{3} \mathrm{UN}_{3}+\left(\mathrm{Me}_{3} \mathrm{SiC}_{5} \mathrm{H}_{4}\right)_{3} \mathrm{U} \stackrel{\text { toluene }}{\longrightarrow}
$$

Scheme 1-15: Mixed cyclpentadienyl reaction or uranium(IV) azide with trivalent uranium. 
This reaction was done in toluene, and again the solution turned deep brown. Brown cystals were obtained from hexane, and once again two azide stretches were observed in the infrared spectrum, at 2128 and $2079 \mathrm{~cm}^{-1}$. The ${ }^{1} \mathrm{H} N M R$ spectrum of this material was quite complex, and looking at the mass spectrum helped explain why. While some higher masses that may contain two uraniums were seen, the interesting peaks are the monomeric compounds. These show mixing of the cyclopentadienyl groups; the species $\left(\mathrm{Me}_{3} \mathrm{SiC}_{5} \mathrm{H}_{4}\right)_{3} \mathrm{UN}_{3}\left(\mathrm{Me}_{3} \mathrm{SiC}_{5} \mathrm{H}_{4}\right)_{2}\left(\mathrm{MeC}_{5} \mathrm{H}_{4}\right) \mathrm{UN}_{3},\left(\mathrm{Me}_{3} \mathrm{SiC}_{5} \mathrm{H}_{4}\right)\left(\mathrm{MeC}_{5} \mathrm{H}_{4}\right)_{2} \mathrm{UN}_{3}$ and $\left(\mathrm{MeC}_{5} \mathrm{H}_{4}\right)_{3} \mathrm{UN}_{3}$ were all observed in the spectrum. If this swapping of rings occurred in solution as well, it would make the NMR spectrum complex since resonances due to all of the individual species would be observed.

In summary, although unequivocable proof of formation of an azide bridged species was not obtained, it certainly appears likely that one was formed. Particularly in the case of the proposed $\left[\left(\mathrm{Me}_{3} \mathrm{SiC}_{5} \mathrm{H}_{4}\right)_{3} \mathrm{U}\right]_{2}-\mu-\mathrm{N}_{3}$, the evidence is reasonably compelling; the dramatic color change, the very simple and clean ${ }^{1} \mathrm{H} N M R$, and the sharp melting point all lead towards the idea that some interaction has occurred. The presence of two stretches in the infrared spectrum may be explained by assuming that the bridged complex contains two different uranium centers on the infrared timescale. This can be drawn as shown below (Figure 1-18):

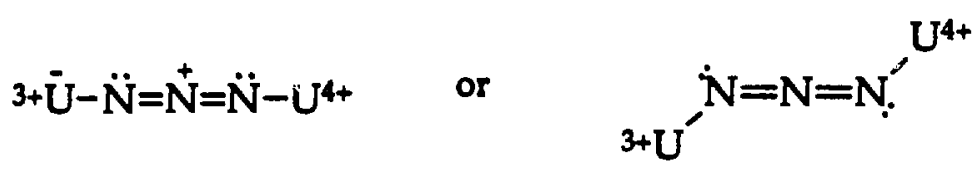

Figure 1-18: A uranium $\mu$-azide complex with localized oxidation states. 
In this case, we can observe two stretches: one stretch is the $V_{N_{3}}$ of $U\left(\right.$ III) $-N_{3} U(I V)$ and one is the $V_{N_{3}}$ stretch of $U(T V)-N_{3} U(I I)$. On the much longer NMR tiriescale, however, we see averaged uranium centers, presumably due to some type of exchange mecharism. 


\section{Section 1.4: Properties and Reactions of $\left(\mathrm{MeC}_{5} \mathrm{H}_{4}\right)_{3} \mathrm{UNR}$}

\subsection{A: Properties of $\left(\mathrm{MeC}_{3} \mathrm{H}_{4}\right)_{3} \mathrm{UNR}$}

As discussed earlier, a large number of pentavalent uranium imides have been synthesized. These are summarized in Table 14 below, showing the various $R$ groups as well as melting points and colors:

\begin{tabular}{|c|c|c|c|}
\hline & $\mathbf{R}$ & Color & M.P. $\left({ }^{\circ} \mathrm{C}\right)$ \\
\hline $\mathbf{I}$ & $\mathrm{CMe}_{3}$ & red & 232-237 \\
\hline II & $\mathrm{SiMe}_{3}$ & red & $132-140^{96}$ \\
\hline $\mathbf{m}$ & $\mathrm{GeMe}_{3}$ & red & $187-189$ \\
\hline IV & $\mathbf{P h}$ & red & $109-112^{2,9 b}$ \\
\hline $\mathbf{v}$ & $\mathrm{p}-\mathrm{MeC}_{6} \mathrm{H}_{4}$ & red & $89-92$ \\
\hline $\mathbf{V I}$ & $\mathrm{p}-\mathrm{Me}_{2} \mathrm{NC}_{6} \mathrm{H}_{4}$ & red & $147-148$ \\
\hline VII & $\mathrm{p}-\mathrm{MeOC}_{6} \mathrm{H}_{4}$ & red & 97.99 \\
\hline VII & $\mathrm{p}-\mathrm{CF}_{3} \mathrm{C}_{6} \mathrm{H}_{4}$ & red & - \\
\hline $\boldsymbol{\alpha}$ & $0-\mathrm{MeC}_{6} \mathrm{H}_{4}$ & red & $118-120$ \\
\hline$x$ & o-iPr. $\mathrm{C}_{6} \mathrm{H}_{4}$ & red & $77-83$ \\
\hline $\mathbf{x I}$ & $2,6-\mathrm{Me}_{2} \mathrm{C}_{6} \mathrm{H}_{3}$ & red & $154-156$ \\
\hline $\mathbf{x I I}$ & $\mathrm{CH}_{2} \mathrm{Ph}$ & red & $57-59$ \\
\hline xill & $\mathrm{CHPh}_{2}$ & red & $89-91$ \\
\hline
\end{tabular}

Table 1-4: Summary of (MeC5 $\mathrm{H}_{4} \mathrm{t}_{3} \mathrm{UNR}$ compounds.

Each of the imides was synthesized by reaction of the appropriate azide, $\mathrm{RN}_{3}$, with $\left(\mathrm{MeC}_{5} \mathrm{H}_{4}\right)_{3} \mathrm{U}(\mathrm{th})$ in ether. In $\mathrm{C} s$ where a mixture of the imide and the uranium(IV) azide was produced $\left(\mathrm{R}=\mathrm{GeMe}_{3}, \mathrm{CHPh}_{2}\right.$ ), the 
compounds were separated by fractional recrystallization. While the azide is insoluble in hexane, all of the imides are readily hexane soluble. Some of the phenylimide complexes are slightly less soluble, presumably due to the ability of the phenyl rings to pack efficiently in the crystal.

The 'H NMR spectra of the materials showed patterns and linewidths similar to those found by Brennan ${ }^{2,56}$ in $\left(\mathrm{MeC}_{5} \mathrm{H}_{4}\right)_{3} \mathrm{LNPh}$ and $\left(\mathrm{MeC}_{5} \mathrm{H}_{4}\right)_{3} \mathrm{UNSiMe}_{3}$ and which we have now found to be typical for these pentavalent uranium complexes. A collection of the linewidth of the cyclopentadienyl ligands are shown below (Table 1-5), to demonstrate the consistently brond lines that have been observed in these compounds.

\begin{tabular}{|c|c|c|c|}
\hline & \multicolumn{3}{|c|}{$V_{1 / 2}(\mathrm{~Hz})$} \\
\hline I & Ring Me & Ring $H$ & Ring H \\
II & 30 & 150 & 135 \\
IV & 15 & 54 & 51 \\
V & 20 & 60 & 49 \\
VI & 20 & 50 & 50 \\
VII & 25 & 70 & 74 \\
VII & 18 & 75 & 60 \\
XX & 16 & 43 & 37 \\
X & 23 & 64 & 67 \\
XI & 25 & 78 & 78 \\
XII & 23 & 76 & 87 \\
XII & 24 & 94 & 78 \\
\hline
\end{tabular}

Table 1-5: ${ }^{1} H$ NMR linewidths in uranium(V) imides. 
The ${ }^{1} \mathrm{H}$ NMR chemical shifts for the compounds I - III are shown in Table I- 6 below:

\begin{tabular}{|c|c|c|c|c|c|}
\hline & & \multicolumn{4}{|c|}{ Chemical Shift (ppm) } \\
& X & Ring Me & Ring H & Ring H & XMe $_{3}$ \\
\hline I & C & +4.2 & -4.2 & -9.9 & +13.6 \\
I & Si & +3.0 & -2.0 & -10.8 & +6.9 \\
III & Ge & +2.9 & -1.5 & -11.1 & +6.5 \\
\hline
\end{tabular}

Table 1- 4 Chemical shifts in (MeC $\left.\mathrm{C}_{5} \mathrm{H}_{4}\right)_{3} \mathrm{UNXMe}$ compounds.

The spectra are all quite similar and unremarkable. The linewidths of the resonances due to the $\mathrm{XMe}_{3}$ groups are similar to that observed for the cyclopentadienyl ring methyl groups. Note that the resonance for the $\mathrm{XMe}_{3}$ group ( $\mathrm{X}=\mathrm{C}, \mathrm{Si}$, or $\mathrm{Ge}$ ) shifts uptield as we progress down the group IVA elements. This suggests that these methyl protons are becoming more shielded, a trend which follows the decreasing electronegativities as we move down the column (moving down the column, the bond between the methyl carbon and the central atom $X$ becomes more polarized towards the methyl carbon due to the electronegativity difference, thus more negative charge on the methyl groups and an upfield shift).

The chemical shifts for the various uranium phenylimides, compounds IV - XI, are shown in Table 1-7. The spectrum of $\left(\mathrm{MeC}_{5} \mathrm{H}_{4}\right)_{3} \mathrm{UNPh}$, which is typical of these uranium(V) imides, is shown in Figure 1-19. The spectrum is presented at two different temperatures, because the resonance for the ortho protons on the phenyl ring overlaps with the 
Table 1-7: 'H NMR Chemlcal Shifts in Tris(melhylcyclopentadienyl) Uranlum Phenylimides, $30^{\circ} \mathrm{C}$.

\begin{tabular}{|c|c|c|c|c|c|c|c|c|}
\hline & \multirow[b]{2}{*}{ Inide } & \multicolumn{3}{|c|}{$\mathrm{MeC}_{5} \mathrm{H}_{4}$} & \multicolumn{4}{|c|}{ Phenyl } \\
\hline & & Me & $\operatorname{Ring} 1$ & Ring 2 & ortho & meta & para & subatituent \\
\hline IV & $\mathrm{C}_{6} \mathrm{H}_{5}$ & +3.67 & -3.32 & -10.92 & -+3.5 & +18.67 & -2.40 & \\
\hline $\mathbf{v}$ & p-MeC_Hy & +3.68 & -3.48 & -10.96 & +3.37 & +18.05 & & +19.01 \\
\hline vI & $\mathrm{p}-\mathrm{Me}_{2} \mathrm{NC}_{6} \mathrm{H}_{4}$ & +3.66 & -4.01 & -10.92 & +2.60 & +17.85 & & +10.20 \\
\hline VII & $\mathrm{p}-\mathrm{MeOC}_{6} \mathrm{H}_{4}$ & +3.68 & -3.66 & -10.92 & +2.94 & +17.98 & & +7.04 \\
\hline Vil & 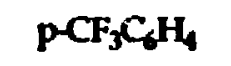 & +3.59 & -3.12 & -11.18 & +3.16 & +18.25 & & \\
\hline $\mathbf{x}$ & $0-\mathrm{MeC}_{6} \mathrm{H}_{4}$ & +4.73 & -7.52 & -8.67 & +5.14 & $+19.95,+19.29$ & -3.15 & +15.27 \\
\hline $\mathbf{x}$ & $0^{-i} \operatorname{PrC}_{6} \mathrm{H}_{4}$ & +4.71 & -8.18 & -8.18 & -+5.04 & $+20.16,+19.27$ & -2.75 & +1.81 \\
\hline $\mathbf{x}$ & $2,6-\mathrm{Me}_{2} \mathrm{C}_{6} \mathrm{H}_{3}$ & +5.67 & -4.60 & -14.23 & & +20.58 & -5.49 & +19.79 \\
\hline
\end{tabular}




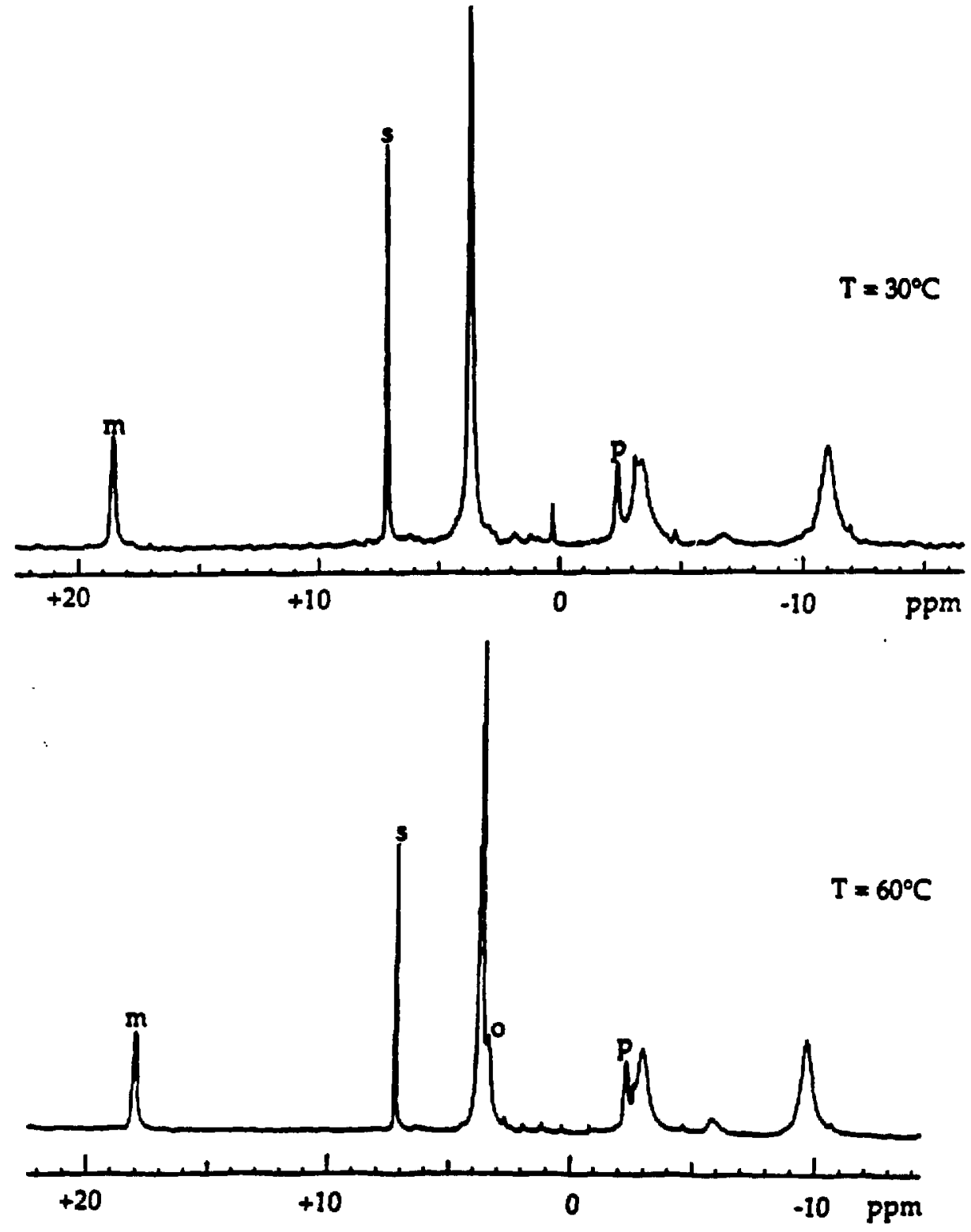

Figure 1-19: ${ }^{1} \mathrm{H}$ NMR spectra of $\left(\mathrm{MeC}_{5} \mathrm{H}_{4} \mathrm{UNNPh}_{3} \mathrm{Ut} 30^{\circ} \mathrm{C}\right.$ (top) and $60^{\circ} \mathrm{C}$ (bottom). The phenyl ring resonances are markes as follows: o: ortho; m: meta; p: para [s: soivent]. 
$\mathrm{MeC}_{5} \mathrm{H}_{4}$ methyl group resonance at room temperature. Note that all of the chemical shifts shown in the table are fairly similar; the spectra of these phenylimides are qualitatively the same in appearance. The assignments of the phenyl ring resonances were made both by the integration and by lcoking at which resonances remained when substituents on the ring were varied.

The 'HNMR spectra of compounds XII and XIII, the phenylmethylimides, are also fairly similar to one another. For compond XII, $\left(\mathrm{MeC}_{3} \mathrm{H}_{4} \mathrm{UNCH}_{2} \mathrm{Ph}\right.$, the $\mathrm{MeC}_{5} \mathrm{H}_{4}$ reconances oceur at $\delta=3.42 \mathrm{ppm}$ (ring $\mathrm{Me}$ ), $\delta=-2.81 \mathrm{ppm}$ (ring $\mathrm{H}$ ), and $\delta=-11.33 \mathrm{ppm}$ (ring $\mathrm{H}$ ), while the phenyl ring resonances occur at $\delta=+8.60 \mathrm{ppm}$ (ortho), $\delta=+12.73 \mathrm{ppm}$ (meta), and $\delta=$ +7.63 ppm (para). Compound XIII shows resonances shifted only slightly from these values. The particularly interesting feature of the spectrum of the benzylimide [( $\left.\left.\mathrm{MeC}_{5} \mathrm{H}_{4}\right)_{3} \mathrm{UNCH}_{2} \mathrm{Ph}\right]$, however, is the resonance for the benzy] $\mathrm{CH}_{2}$ protons. This resonance is seen at $\delta=\mathrm{ca} .+123 \mathrm{ppm}$, and has $\mathrm{v}_{1 / 2}=\mathrm{ca} .450$ $500 \mathrm{~Hz}$. The reasons for the severe deshielding of these protons are not entirely clear. The best suggestion seems to be simply that this $\mathrm{CH}_{2}$ group is surrounded by two electron withdrawing groups; the phenyl ring on one side and the $N=U$ unit on the other. If the sitrogen lone pairs are being pulled towards the uranium as expected, this nitrogen would become even more electronegative and therefore further remove electron density from the $\mathrm{CH}_{2}$ group. Note that this resonance was not observed for the benzhydryl proton in compound XIII, ( $\left.\mathrm{MeC}_{5} \mathrm{H}_{4}\right)_{3} \mathrm{UNCF}_{2} \mathrm{Ph}_{2}$ it may simply be too broad to observe at room temperature.

The electron impact mass spectra of these compounds all demonstrate parent molecular ions for the intact $\left(\mathrm{MeC}_{5} \mathrm{H}_{4}\right)_{3} \mathrm{UNR}$ species. The spectra all agree well with the simulated spectra (for more details, see Chapter 4). A typical spectrum, that of $\left(\mathrm{MeC}_{5} \mathrm{H}_{4} \mathrm{UNPh}\right.$, was presented earlier in this 
chapter (Figure 1-8). Note in this sample that the first fragmentation of the molecule involves loss of a $\mathrm{MeC}_{5} \mathrm{H}_{4}$ ring, rather than dissociation of the $\mathrm{NPh}$ group. This is a trend observed in almost all of these imides, suggesting that the uranium-nitrogen interaction is stronger than the U-Cp interaction.

The infrared spectra of $\left(\mathrm{MeC} \mathrm{C}_{5} \mathrm{H}_{3} \mathrm{UNPh}\right.$ and $\left(\mathrm{MeC}_{5} \mathrm{H}_{4} \mathrm{~J}_{3} \mathrm{U}^{15} \mathrm{NPh}\right.$ were also shown earlier in this chapter (Figure 1-9). From comparison of these compounds, the C-N stretch was assigned at $1271 \mathrm{~cm}^{-1}$, and the U-N stretch at $909 \mathrm{~cm}^{-1}$. Similar stretches are obeerved in the other uranium(V) phenylimides, but it is very difficult to assign the U-N stretches in the other molecules without labelling studies. Presumably the nature of the $R$ group bonded to the nitrogen will have a reasonably large effect on this $U-N$ stretch.

Only two reports of the magnetic susceptibility of a pentavalent uranium complex have appeared, and both of these reports involved the halide $\mathrm{UCl}_{5}$ (tcac) (tcac = trichloriacrylylchloride, $\mathrm{Cl}_{2} \mathrm{CCClCOCl}$ ). The first report, by Selbin et. al., only gave a magnetic moment measured at $300 \mathrm{~K}$.4 This value was reported to be $\mu_{\text {eff }}=1.54$ B.M. The second report, by Fuji et. al., showed a plot of $\chi_{i n}$ vs. T, but gave no values for $\mu_{e f f}{ }^{49}$

The susceptibility of $\mathrm{Cp}_{3} \mathrm{UNSiMe}_{3}$, prepared by Brennan, ${ }^{96}$ was measured previously by D. Berg. The plot of $1 / \chi_{M}$ vs. T for this compound showed two linear regions, one at low temperatures (below ca. $30 \mathrm{~K}$ ), and one at high temperatures (above cr. $100 \mathrm{~K}$ ). From this plot, values of $\mu_{\text {eff }}=1.19$ B.M. for the low temperature data and: $1 . .83$ B.M. for the high temperature data were obtained.

J. Stewart has synthesized several pentavalent uranium imides and measured their moments. ${ }^{\text {so }}$ She observed the same qualitative shape for the plots of inverse susceptibility versus temperature (two linear regions), as well as obtaining similar quantatative values. For the compound 
$\mathrm{U}\left[\mathrm{N}\left(\mathrm{SiMe}_{3}\right)_{2}\right]_{3}\left[\mathrm{~N}\left(\mathrm{p}-\mathrm{MeC}_{6} \mathrm{H}_{4}\right)\right]$, linear least squares fitting of the data gave $\mu_{\text {eff }}=$ 1.49 B.M. at low temperature $(5-40 \mathrm{~K})$ and $\mu_{\text {aff }}=2.26$ B.M. at high temperature $(140-240 \mathrm{~K})$. For the compound $\mathrm{U}\left[\mathrm{N}\left(\mathrm{SiMe}_{3}\right)_{2}\right]_{3}\left(\mathrm{NSiMe}_{3}\right)$, the values were $\mu_{\text {eff }}=$ 1.61 B.M. $(5-40 \mathrm{~K})$ and $\mu_{\text {aff }}=2.04$ B.M. $(140-280 \mathrm{~K})$. As Stewart points out, the magnetic measurements on these compounds seems to provide useful oxidation state information, in contrast with uranium(III) and (IV) complexes, which often yield similar values of $\mu_{\text {aff }}$ In fact, when one uses the Van Vleck equation ${ }^{31}$ to calculate the fres ion moments for uranium(III), (IV), and (V), similar values are obtained for uranium(III) and (IV), while a much lower value is found for uranium(V) (Table 1-8):

\begin{tabular}{|c|c|c|}
\hline $\begin{array}{c}\text { Uranium } \\
\text { Oxidation State }\end{array}$ & Electron Configuration & $\begin{array}{c}\text { Calculated Free Ion } \\
\text { Magnetic Moment }\end{array}$ \\
\hline III & {$[R n] 5 P$} & 3.62 B.M. \\
IV & {$[R n] 5 R$} & 3.58 B.M. \\
V & {$[R n] 5 \AA$} & 2.54 B.M. \\
\hline
\end{tabular}

Table 1-s: Cakculated free ion magnetic moments for various uranium oxidation states.

The magnetic susceptibility of two of the $\left(\mathrm{MeC}_{5} \mathrm{H}_{4}\right)_{3} \mathrm{UNR}$ compounds discussed here has been measured. These were compounds IV and VI, $\left(\mathrm{MeC}_{5} \mathrm{H}_{4}\right)_{3} \mathrm{UNPh}$ and $\left(\mathrm{MeC}_{5} \mathrm{H}_{4}\right)_{3} \mathrm{UN}\left(\mathrm{p}-\mathrm{Me}_{2} \mathrm{NC}_{6} \mathrm{H}_{4}\right)$. The measurements were made over a temperature range of 5-300 K, and at magnetic fields of $5 \mathrm{kG}$ and $40 \mathrm{kG}$. Both compounds exhibited susceptibility vs. temperature curves that had similar appearences to those measured by Berg and Stewart. For compound IV, the plots of $x_{M}$ vs. $T$ and $1 / \chi_{M}$ vs. $T$ are shown in Figures 1-20 and 1-21. Linear regression performed on the $1 / \chi_{M}$ plot yielded a value of $\mu_{\text {eff }}$ $=1.25$ B.M. in the low temperature region $(7-40 \mathrm{~K})$ and $\mu_{\mathrm{eff}}=1.96 \mathrm{~B} . \mathrm{M}$. in the 
Fig. 1-20: Chi vs $T$ plot for $\left(\mathrm{MeC}_{5} \mathrm{H}_{4}\right)_{3} \mathrm{UNPh}$.

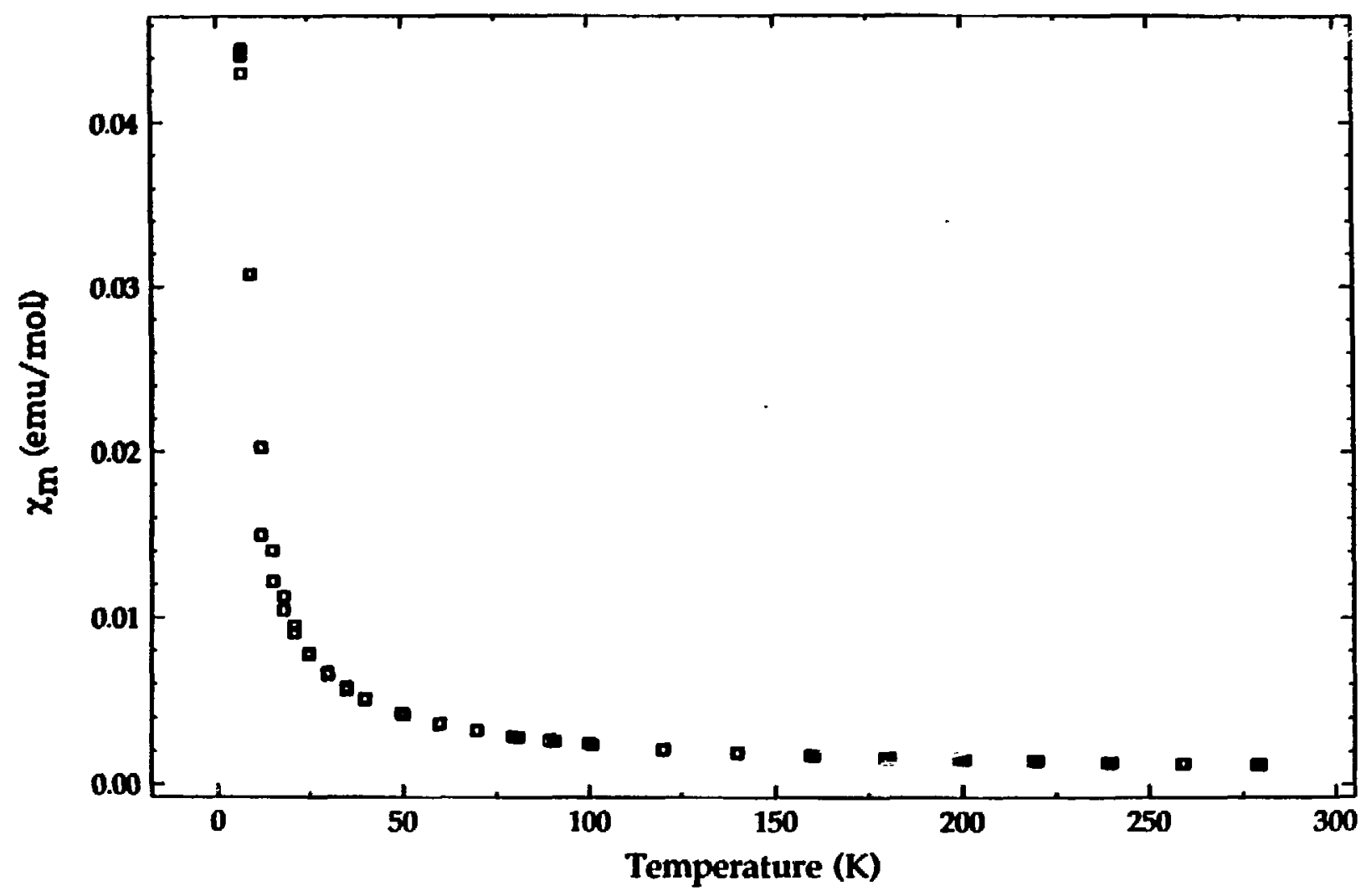


Fig. 1-21: 1/Chi vs $T$ plot for $\left(\mathrm{MeC}_{5} \mathrm{H}_{4}\right)_{3} \mathrm{UNPh}$.

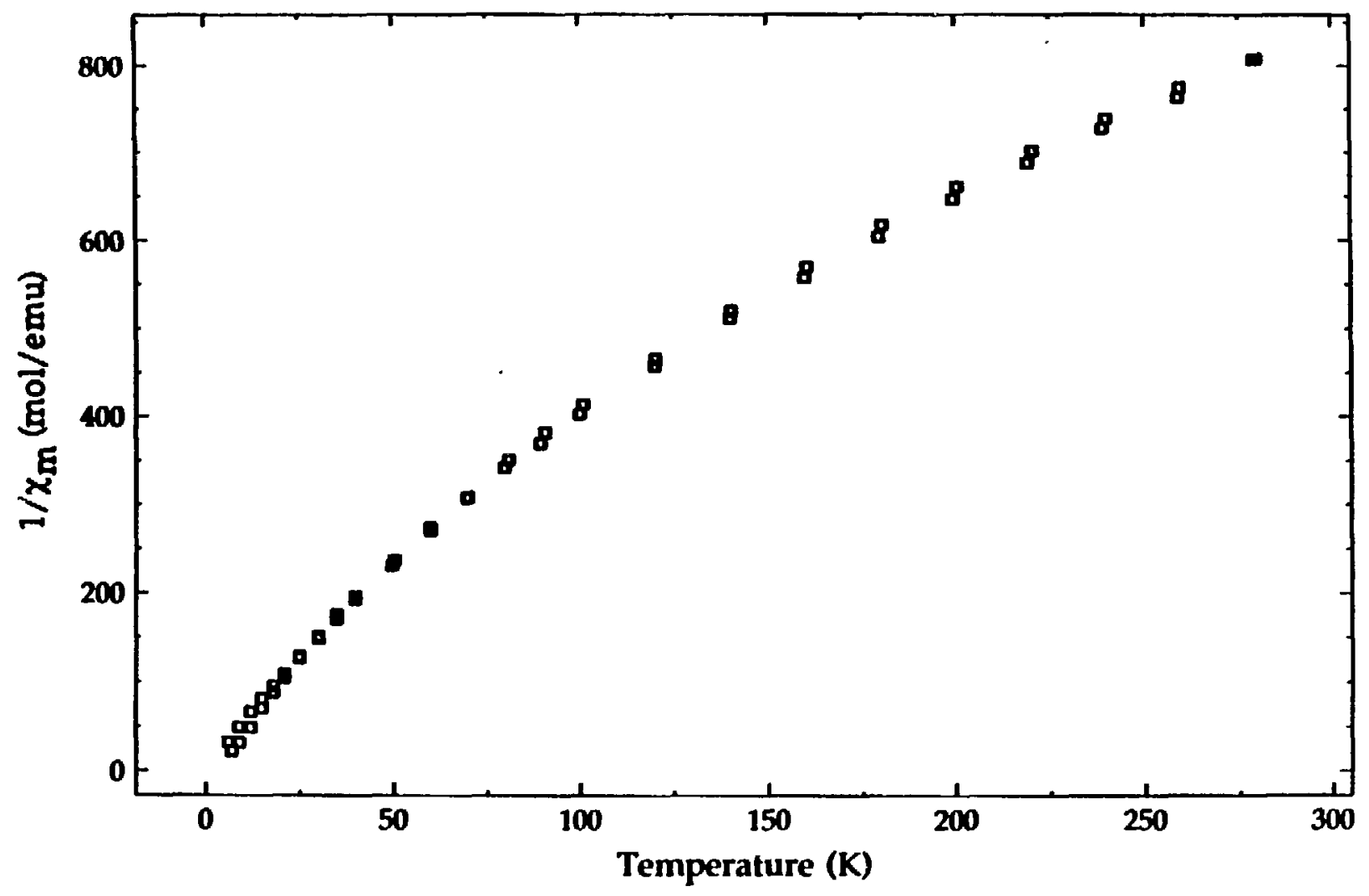


high temperature region (140-280 K). These values are quite similar to those obtained by Berg for the closely related $\mathrm{Cp}_{3} \mathrm{UNSiMe}_{3}$ system, and reasonably close to the values found by Stewart.

The data for compound VI is shown in Figure 1-22 ( $\chi_{M}$ vs. T) and Figure 1-23 $\left(1 / x_{m}\right.$ vs. $\left.T\right)$. The linear regreasion yielded values of $\mu_{\text {eff }}=1.40$ B.M. (5-40 K) and $H_{\text {eff }}=2.21$ B.M. (120-220 K). The magnetic moments for all the uranium( $V$ imides that have been measured thus far are shown in Table 1-9 below:

\begin{tabular}{|c|c|c|c|}
\hline Compound & $\begin{array}{l}H_{\text {eff }} \text { (B.M.) } \\
\text { (Low Temp.) }\end{array}$ & $\begin{array}{l}\mu_{\text {eft }} \text { (B.M.) } \\
\text { (Hileh Temp.) }\end{array}$ & Ref. \\
\hline $\mathrm{Cp}_{3} \mathrm{UNSTM} \mathrm{Ne}_{3}$ & $\begin{array}{c}1.19 \\
(5-30 \mathrm{~K})\end{array}$ & $\begin{array}{c}1.83 \\
(100-300 \mathrm{~K})\end{array}$ & 4 \\
\hline$U\left(N\left(\operatorname{SiMe}_{3}\right)_{2}\right]_{3}[N(p-t o l y)]$ & $\begin{array}{c}1.49 \\
(5-40 \mathrm{~K})\end{array}$ & $\begin{array}{c}2.26 \\
(140-240 \mathrm{~K})\end{array}$ & 50 \\
\hline $\mathrm{U}\left[\mathrm{N}\left(\mathrm{SiMe}_{3}\right)_{2}\right]_{3}(\mathrm{NSiMe})$ & $\begin{array}{c}1.61 \\
(5-40 \mathrm{~K})\end{array}$ & $\begin{array}{c}2.04 \\
(140-280 \mathrm{~K})\end{array}$ & 50 \\
\hline$\left(\mathrm{MeC}_{5} \mathrm{H}_{4}\right)_{3} \mathrm{UNPh}$ & $\begin{array}{c}1.25 \\
(7-10 \mathrm{~K})\end{array}$ & $\begin{array}{c}1.96 \\
(140-280 \mathrm{~K})\end{array}$ & \\
\hline$\left(\mathrm{MeC}_{5} \mathrm{H}_{4}\right)_{3} \mathrm{UN}\left(\mathrm{p}-\mathrm{Me}_{2} \mathrm{NC}_{6} \mathrm{H}_{4}\right)$ & $\begin{array}{c}1.40 \\
(5-40 \mathrm{~K})\end{array}$ & $\begin{array}{c}2.21 \\
(120-220 \mathrm{~K})\end{array}$ & \\
\hline
\end{tabular}

Table 1-s: Magnetic moments of uranium(V) imides.

\subsection{B: Reactions of $\left(\mathrm{MeC}_{5} \mathrm{H}_{4}\right)_{3} \mathrm{UNR}$}

One of the questions we hoped to answer in studying the chemistry of these uranium imides was whether the lone pair on the nitrogen was accessible, and if so, would chemical reactions result? The crystal structure of $\left(\mathrm{MeC}_{5} \mathrm{H}_{4}\right)_{3} \mathrm{UNPh}^{2}$ seemed to suggest that this lone pair is not accessible to 
Fig. 1-22: Chi vs $\mathrm{T}$ plot for $\left(\mathrm{MeC}_{5} \mathrm{H}_{4}\right)_{3} \mathrm{UNp}-\mathrm{Me}_{2} \mathrm{NC}_{6} \mathrm{H}_{4}$

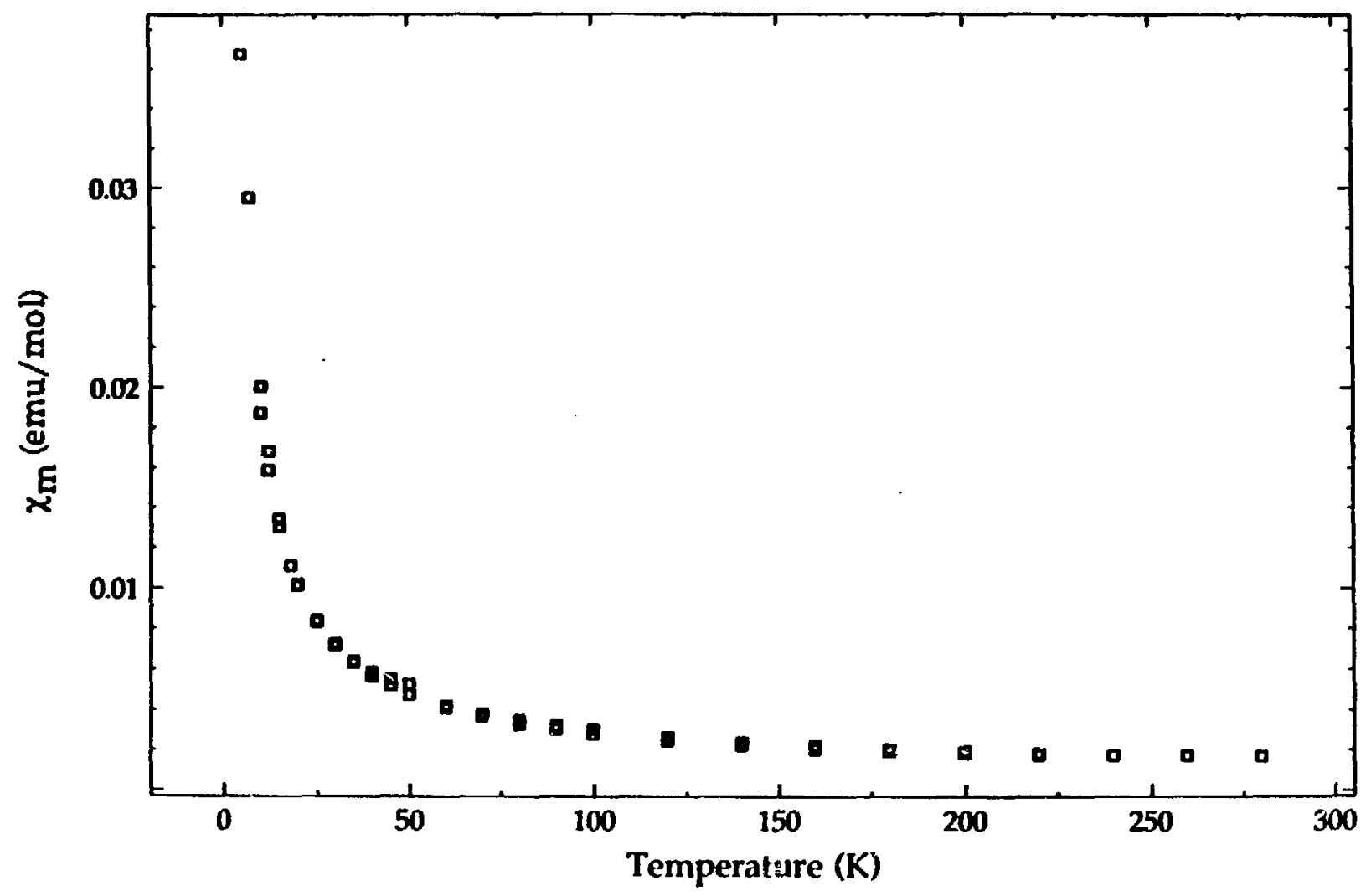

১ั 
Fig. 1-23: 1/Chi vs $\mathrm{T}$ plot for $\left(\mathrm{MeC}_{5} \mathrm{H}_{4}\right)_{3} \mathrm{UNp}-\mathrm{Me}_{2} \mathrm{NC}_{6} \mathrm{H}_{4}$

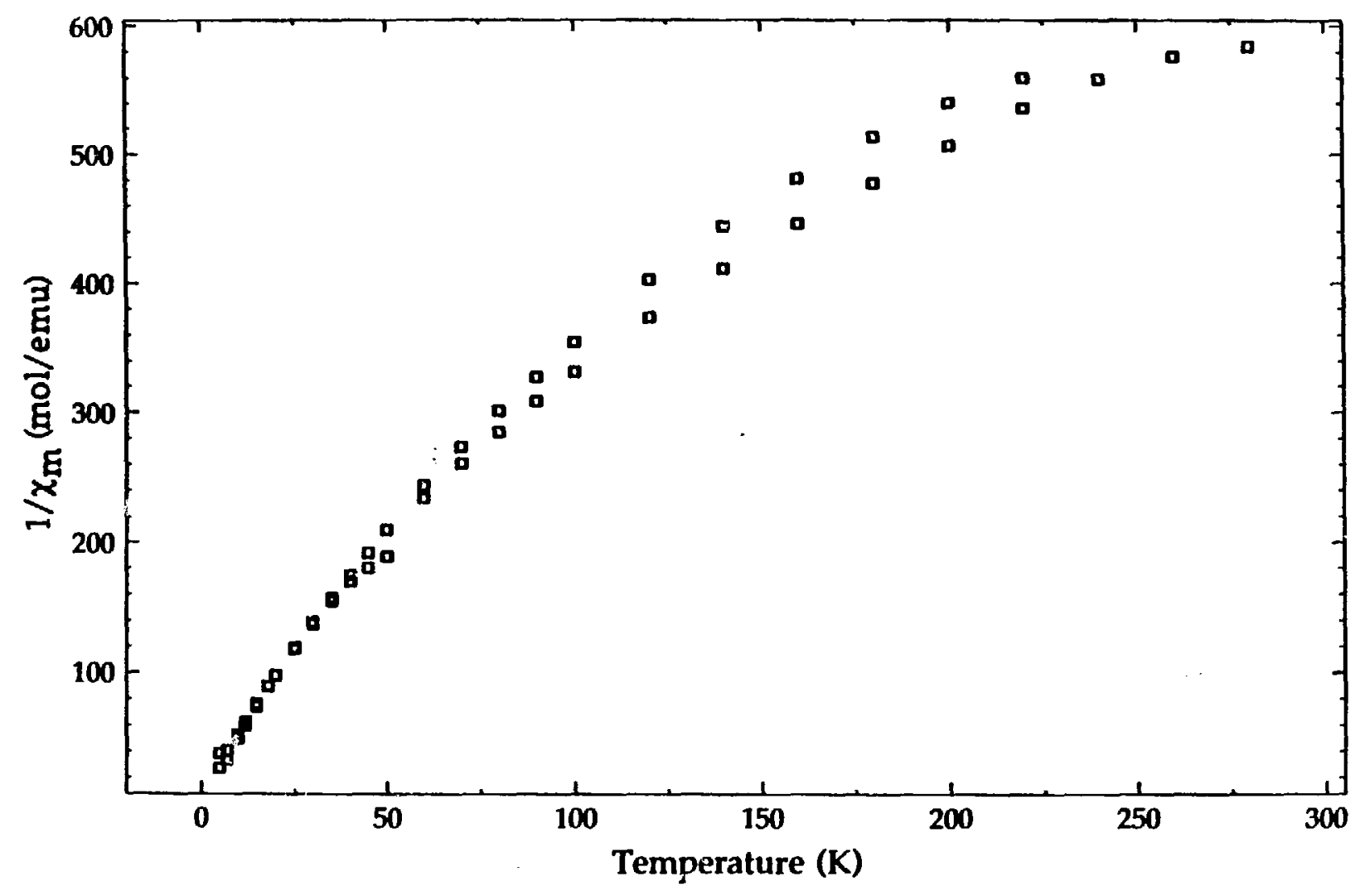


acids. Thi: was inferrred from the U-N-C bond angle, which is nearly linear at $163^{\circ}$, suggesting that the nitrogen lone pair is interacting with the uranium to make a formal triple bond. The extremely short U-N distance of $2.06 \AA$ seers to help support this argument.

Brennan attempted to whe whether the lone pair was accessible by reaction of the imiises with a good Lewis acid, AlMeg. He found that no adduct was formed $v$,ing either (MeC5H ${ }_{3} \mathrm{UNPh}$ or $\mathrm{Cp}_{3} \mathrm{UNSiMe}_{3} .{ }^{\circ 6}$ However, in the UNSiMe, case, it is pousible that the electrons are involved in backbonding with a vacant silicon d-orbital, and in the UNPh case, the lone pair may be interacting with the phenyl $x$-system. Either of these effects could render these electrons inaccessible. For these reasons, the complex $\left(\mathrm{MeC}_{5} \mathrm{H}_{4}\right)_{3} \mathrm{UNCMe}_{3}$ was reacted with $\mathrm{AM}_{3}$. Again, no adduct was isolated, and only unreacted starting material was recovered. We conclude from this that the nitrogen lone pair is probably interacting with the highly positively charged metal center, although we cannot discount the possibility of steric effects precluding the $\mathrm{AlMe}_{3}$ from getting close enough to the nitrogen for interaction to occur.

Brennan made several attempts at reaction of $\left(\mathrm{RC}_{5} \mathrm{H}_{4}\right)_{3} \mathrm{LNSiMe}$ with relatively small molecules. ${ }^{.6}$ The reactions shown below yielded only the unreacted silylimide complex (Scheme 1-16):

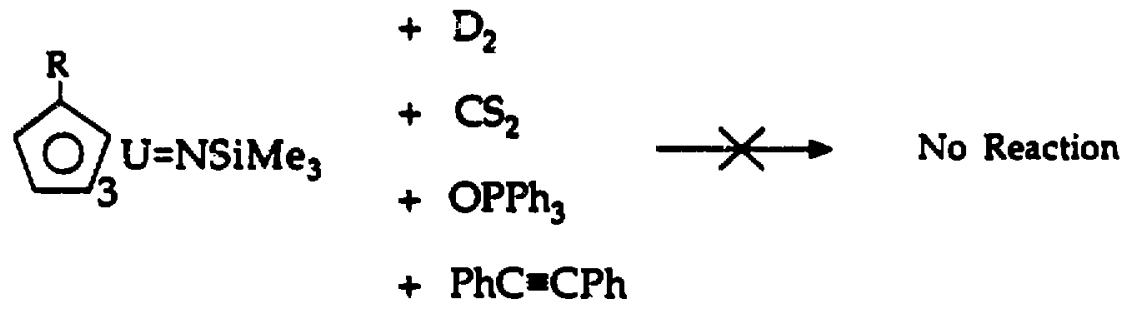

Scheme 1-16: Brennan's attempted reactions of the uranium silylimide complex. 
Perhaps the most interesting reaction of this group was the failure of the material to reduce under several atmospheres of deuterium gas. The aqueous uranium( $V$ /uranium(IV) reduction potential is ca. $+0.58 \mathrm{~V}, 1$ and although there is no reported value for uranium(V) organometallic compounds, we still might expect the imide to reduce to the more favored +4 state.

A similiar reduction was also attempted using the phenylimide, $\left(\mathrm{MeC}_{3} \mathrm{H}_{4}\right)_{3} \mathrm{UNPh}$. When this compound was placed under 220 psi of $\mathrm{H}_{2}$ for 2 days, only the unreacted starting material was recovered. The failure of any reduction to occur may raflect the fact that the hydrogen may be unable to coordinate to the sterically crowded and quite small uranium(V) metal center.

Interestingly, the compound may be reduced to uranium(IV) using a different technique. If the driving force of going from uranium(V) to uranium(IV) is not strong enough to cause reduction with hydrogen, perhaps combining this process with one that also causes a second uranium complex to be oxidized from uranium(II) to uranium(IV) will enable us to reduce the imide. This turrs out to be the case. Uranium(III) complexes of the type $\left(\mathrm{MeC}_{5} \mathrm{H}_{4}\right)_{3} \mathrm{U}\left(\mathrm{NH}_{2} \mathrm{R}\right)$ are easily synthesized from $\left(\mathrm{MeC} \mathrm{C}_{5} \mathrm{H}_{4} \mathrm{U}(\mathrm{th})\right.$ and primary amines. These syntheses and the properties of the complexes will be discussed in detail in Chapter 3. When the amine complex is allowed to react with a uranium(V) imide, two equivalents of the corresponding uranium(IV) amide are formed (Scheme 1-17): 


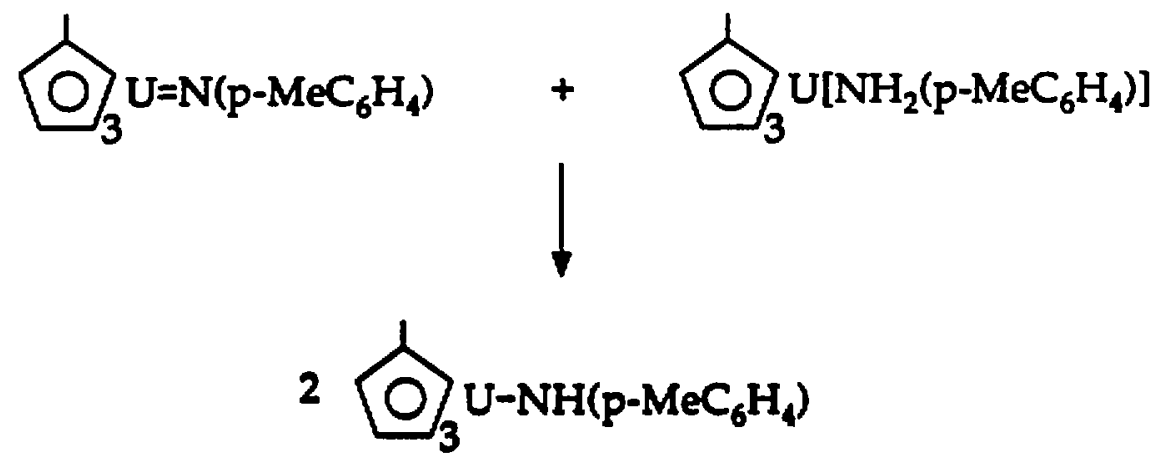

Scheme 1-17: Reaction of a uranium(III) amine with a uranium(V) imide.

An attempt with was also made to see whether unsaturated hydrocarbons could insert into the U-N bond. This, as mentioned above, was tried unsuccessfully by Brennan utilizing the UNSiMe $\mathrm{UN}_{3}$ complex and diphenylacetylene. We found that the phenylimide, $\left(\mathrm{MeC}_{5} \mathrm{H}_{4}\right)_{3} \mathrm{CNPh}$, also did nol react with either diphenylacetylene (1:1 molar ratio in toluene solution) or ethylene (200 p.s.i. for 24 hours in toluene solution).

One interesting set of reactions involving these compounds was performed using the series of molecules shown below (Figure 1-24):

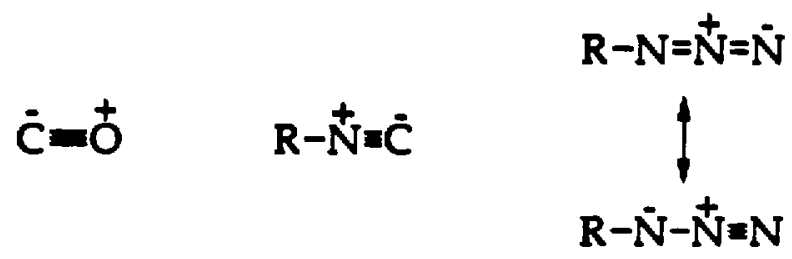

Figure 1-24: Smali o-donating molecules used in reactions with uranium imides.

The common features of these materials is that they are all small, $\sigma$-donating molecules with partial negative charge on the donating atom. This should 
enable them to coordinate very effectively with the highly positively charged metal center.

Brennan performed several of these reactions using both the silylimide, $\left(\mathrm{MeC}_{5} \mathrm{H}_{4}\right)_{3} \mathrm{UNSiMe}_{3}$ and the phenylinide, $\left(\mathrm{MeC}_{5} \mathrm{H}_{4}\right)_{3} \mathrm{UNPh} .96$ When $\left(\mathrm{MeC}_{5} \mathrm{H}_{4}\right)_{3} \mathrm{UNSiMe} \mathrm{N}_{3}$ was placed under an atmosphere of carbon monoxide, a light green precipitate was formed. This material was found to be insoluble in common organic solvents, including dichloromethane. This rules out the formulation of the product as $\left(\mathrm{MeC} \mathrm{C}_{3} \mathrm{H}_{4}\right)_{3} \mathrm{UNCO}$, a compound I have prepared by an aqueous route analogous to that described earlier for the preparation of $\left(\mathrm{MeC}_{5} \mathrm{H}_{4} \mathrm{UN}_{3}\right.$ (Scheme 1-18).
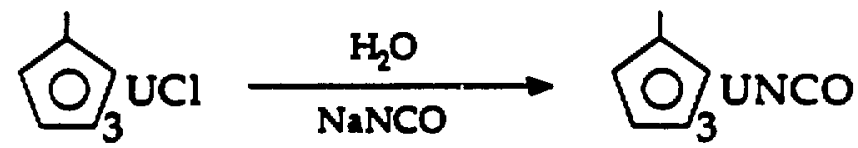

Schere 1-16: Preparation of the uranium isocyanate in aqueous medium.

The isocyanate complex can be recrystallized from dichloromethane to give pale green microcrystals in high yield. The material shows a strong stretch in the infrared spectrum at $2180 \mathrm{~cm}^{-1}$, in contrast with the material Brennan isolated, which exhibited a stretch at $2060 \mathrm{~cm}^{-1}$. It is possible that one of these materials is a U-NCO complex, while the other is U-OCN, but these two compounds cannot be distinguished by their infrared spectra. ${ }^{32}$ No conclusive identification of the compound obtained from the reaction of $\left(\mathrm{MeC}_{5} \mathrm{H}_{4}\right)_{3} \mathrm{UNSiMe}_{3}$ with $\mathrm{CO}$ was ever obtained.

When the uranium phenylimide, $\left(\mathrm{MeC}_{5} \mathrm{H}_{4}\right)_{3} \mathrm{UNPh}$, was placed under Cr. 185 p.s.i. of $\mathrm{CO}$ in ether solution, an insertion product was obtained. A pale orange material formed, and this compound was found by ${ }^{1} \mathrm{H}$ NMR to be 
identical to one obtained by Brennan from reaction of $\left(\mathrm{MeC}_{5} \mathrm{H}_{4}\right)_{3} \mathrm{U}($ thf $)$ with PhNCO. The material is the phenylisocyanate dimer, $\left[\left(\mathrm{MeC}_{5} \mathrm{H}_{4}\right)_{3} \mathrm{U}\right]_{2}-\mu-$ PhNCO, which has been structurally characterized ${ }^{2}$ (Scheme 1-19).
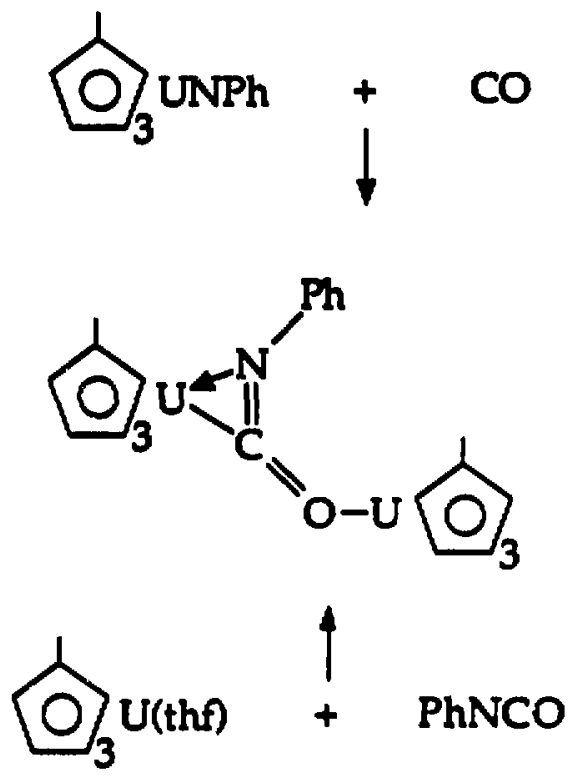

Scheme 1-19: Preparations of $\left(\left(M \mathrm{MC}_{5} \mathrm{H}_{4}\right)_{3} \mathrm{U}\right)_{2}-\mu-\mathrm{PhNCO}$.

Since Brennan had completely characterized this molecule, no characterization other than the ${ }^{1} H$ NMR was carried out. A plausible mechanism for this insertion reaction is shown in Scheme 1-20. 


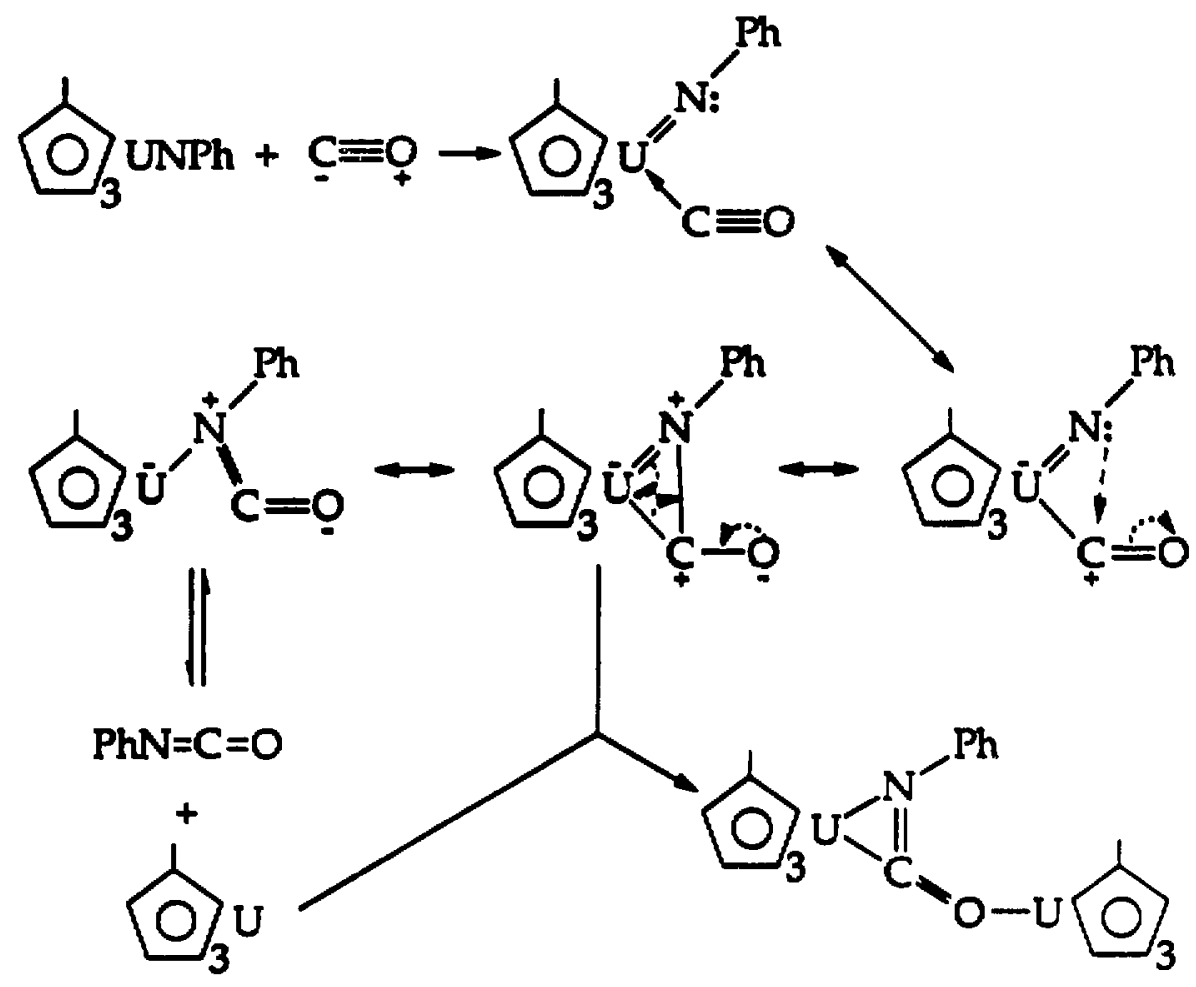

Scheave 1-20: Possible mechanism for formation of an isocyanate complex from $\left(\mathrm{MeC}_{5} \mathrm{H}_{4}\right)_{3} \mathrm{LNTh}$ and $\mathrm{CO}$.

Relatively few examples exist of similar insertions into metal-imido bonds to form isocyanates. This is despite the fact that this reaction is believed to be involved in catalytic carbonylation of organoazides and nitronromatic mmpounds, proceeding through imide intermediates. ${ }^{53}$ Recently, two ex.amples of $\mathrm{CO}$ insertion into an $\mathrm{N}$ - $\mathrm{Ar}\left(\mathrm{Ar}=\mathrm{Ph}\right.$ or $\left.\mathrm{p}-\mathrm{MeC}_{6} \mathrm{H}_{4}\right)$ of a ruthenium trimer have appeared. In the first example, the isocyanatemetal comple $x$ is not isolated, but free isocyanate is formed (Scheme 1-21): ${ }^{34}$ 


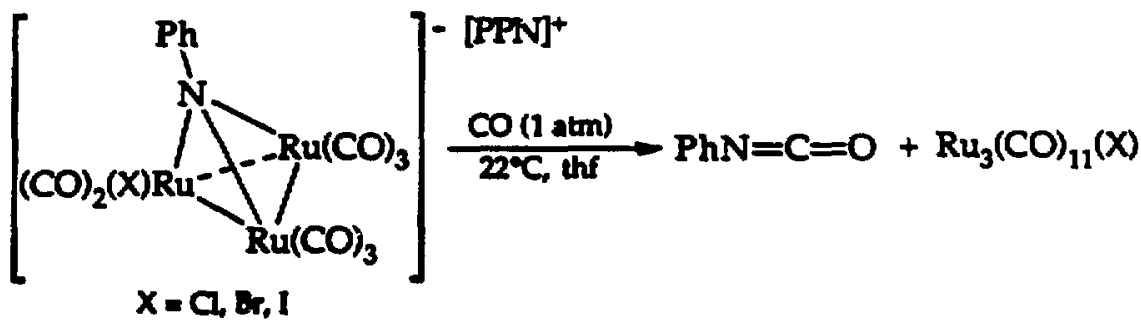

Schene 1-22: Formation of phenylicocganate from a ruthenium-1h-NTh complex.

In the second example, a tautomeric mixture of $\mathrm{Rh}_{2}(\mu-\mathrm{NHR})(\mathrm{CO})_{2}(\mu-\mathrm{dppm}$ $\mathrm{H})(\mu-d \mathrm{ppm})$ and $\mathrm{Rh}_{2}(\mu-\mathrm{NR})(\mathrm{CO})_{2}(\mu-d p p m)_{2}\left[\mathrm{R}=\right.$ Ph or $\mathrm{p}-\mathrm{MeC}_{6} \mathrm{H}_{4}$ dppm = bis(diphenylphosphino)methane] was treated with one atmosphere of $\mathrm{CO}$ to yield a bridged isocyanate complex, $\mathrm{Rh}_{2}\left(\mu-\eta^{2}-\mathrm{RNCO}\right)(\mathrm{CO})_{2}(\mathrm{~m}-\mathrm{dppm})_{2}{ }^{33}$ In addition, an insertion into an imidoiridium complex has been reported (Scheme I-22):56

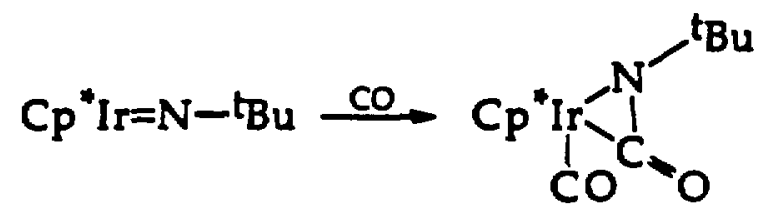

Schere 1-22: $\mathrm{CO}$ insetion into en imide-iridium bond.

Several other reports of isocyanate formation from imides have appeared. ${ }^{37}$ Brennan also reacted $\left(\mathrm{RC}_{3} \mathrm{H}_{4}\right)_{3} \mathrm{CNSiMe}_{3}(\mathrm{R}=\mathrm{H}, \mathrm{Me})$ with both ethylisocyanide (EtNC) and 2,6-xylylisocyanide. ${ }^{96}$ From the EtNC reactions he obtained light green crystalline materials with an infrared stretch at $2080 \mathrm{~cm}^{-1}$. From various data, he formulated the compounds as $\left(\mathrm{RC}_{5} \mathrm{H}\right)_{3} \mathrm{UNCNEt}$, but firm characterization was not obtained. The reactions with ethylisocyanide gave a mixture of products and was not pursued. 
When Brennan reacted (MeCs $\left.\mathrm{H}_{4}\right)_{3} \mathrm{UNPh}$ with ethylisocyanide, a different product was obtained. This light red material was found to be the uranium amide, $\left(\mathrm{MeC} \mathrm{H}_{4}\right)_{3} \mathrm{UNHPh}$. This compound has been synthesized by several other methods which will be discused in Chapter 3. Because it was difficult to imagine a mechanism by which an $\mathrm{H}$. could be transferred, this reaction was repeated in my work, and it was found to be correct. It is especially interesting that this reduction from uranium(V) to uranium(IV) occurs in this reaction, but not under $\mathrm{Ca} .15$ atmospheres of $\mathrm{H}_{2}$ or $\mathrm{D}_{2}$. Presumably, it is the ability of the isocyanide to coordinate to the metal center that facilitates the reaction, a coordination unlikely to occur with hydrogen. Using the idea that the isocyanide is able to coordinate, we can imagine a mechanism where an $\alpha$-hydrogen on the isocyanide is transferred to the imido group (Scheme 1-23):

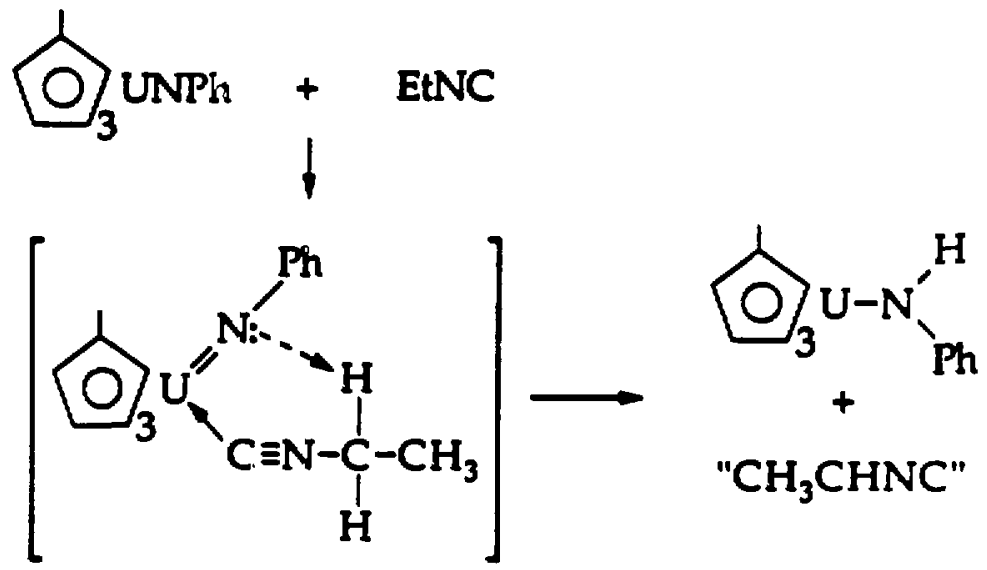

Scheme 1-23: Possibie mechanism for reduction of $\left(\mathrm{MeC}_{5} \mathrm{H}_{4}\right)_{3} \mathrm{UNTh}$ withEtNC.

A labelling study of this reaction using $\mathrm{PhCH}_{2} \mathrm{NC}$ and $\mathrm{PhCD}_{2} \mathrm{NC}$ would help elucidate the mechanism. In addition, we did not search for the organic 
byproducts of this reaction; identifying these could also help with an understanding of the process. This reaction formally involves the transfer of an $\mathrm{H}$. from the isocyanide to the uranium, thus attempting to protonate the imide using an acid should not result in the same product. Indeed, we found that $\left(\mathrm{MeC}_{5} \mathrm{H}_{4}\right)_{3} \mathrm{UNR}$ does not undergo any reaction with p-toluenesulfonic acid.

Of course, if this postulate of the mechanisin is correct, reaction of (MeC $\left.\mathrm{H}_{4}\right)_{3} \mathrm{UNPh}$ with an teocyanide containing no $\alpha$-hydrogens should not give this product. This was found to be the case. Reaction of the phenylimide with either 'BuNC or 2,6-xylylisocyanide yielded orange crystalline products. In both cases, the 'H NMR of the materials was extremely complex. The xylylisocyanide reaction was not pursued any further.

Attempts at characterization of the 'BuNC reaction product were unsuccessful. As stated above, the orange crystals gave an extremely complex ${ }^{1} H$ NMR spectrum in $C_{6} D_{6}$ and the spectrum was observed to change over several hours, along with a change in solution color from orange to pale yellow. This spectrum was complex. An attempt to obtain the spectrum in $\mathrm{d}_{8}$-thf also failed, as the color lightened and the spectrum changed even more quickly. The infrared spectrum of this material showed a sharp stretch at 2180 $\mathrm{cm}^{-1}$, in the $\mathrm{C}=\mathrm{N}$ region of the spectrum (free 'BuNC has a stretch at 2135$\left.2140 \mathrm{~cm}^{-1}\right)$. This increase in the stretching frequency is consistent with a coordinated 'BuNC. Similar results have been observed with other cyclopentadienyl uranium isocyanide complexes. 50 The remainder of the spectrum was quite different from the phenylimide starting material. A mass spectrum of this material gave little useful information, and elemental analysis showed a high percentage of nitrogen. 
A single crystal of this material was mounted in a quartz capillary and $X$-ray diffraction analysis performed. The crystal was found to be in a Pcentared, orthorhombic space group $\left(P 2,2,2_{1}\right)$ with unit cell parameters a = 15.24 $A, b=18.21 A$, and $c=12.10 A$. Unfortunately, the crystal structure could not be solved.

It seems likely that this material is an insertion product of some sort, although it is unfortunate that the material could not be characterized. It should be noted that a second product was obtained in this reaction, and this material was found to be $\left(\mathrm{MeC}_{5} \mathrm{H}_{4}\right)_{4} \mathrm{U}$ by compurison of the ${ }^{1} \mathrm{H}$ NMR spectrum of this compound with the spectrum of an authentic sample provided by $M$. Weydert." The presence of this product suggests a redistribution of ligands in the course of the reaction, perhaps explaining the appareni complexity of this reaction as well as the high nitrogen content found in the product.

The reactions of $\left(\mathrm{MeC}_{5} \mathrm{H}_{4}\right)_{3} \mathrm{UNPh}$ and $\left(\mathrm{MeC} \mathrm{C}_{5} \mathrm{H}_{4} \mathrm{USiMe}_{3}\right.$ with organoazides, $\mathrm{RN}_{3}$. proved particularly interesting. In cases where reaction occurred, the uranium(V) imide was reduced to the uranium(IV) azide, as shown below (Scheme 1-24):

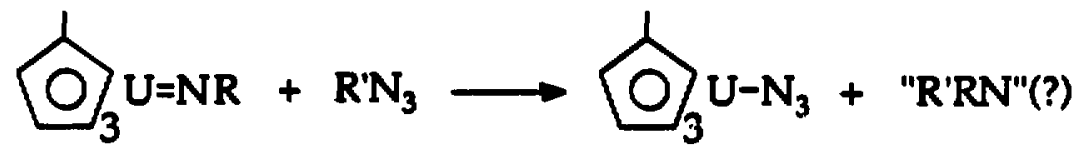
Scheme 1-24: Reaction of uranium(V) imix: 3 with azides.

Siveral different azides were used in these reactions (Figure 1-25): 


$$
\begin{aligned}
& \mathrm{R}-\mathrm{O}-\mathrm{N}_{3} \quad \mathrm{Me}_{3} \mathrm{Si}-\mathrm{N}_{3} \quad \mathrm{Ph}_{3} \mathrm{C}-\mathrm{N}_{3} \quad \mathrm{Me}_{3} \mathrm{Sn}-\mathrm{N}_{3} \\
& \mathbf{R}=\mathbf{H}, \mathbf{M e}
\end{aligned}
$$

Figure 1-25. Arides used in reactions with uranium(V) imides.

To compare the effects of the $R$ and $\mathbf{R}^{\prime}$ groups in the reaction shown in Scheme 1-24, a series of eight reactions wos carried out under similar conditions. The uranium(IV) imide was dissolved in toluene with ca. 1.6-1.7 molar equivalents of the appropriate azide, $\mathbf{R N}_{3}$. The mixture was then stirred for 24 hours at room temperature. At the end of this time, volatile materials were removed and the residues examined by ${ }^{1} \mathrm{H}$ NMR spectroscopy, to determine the relative amounts of $\left(\mathrm{MeC}_{5} \mathrm{H}_{4}\right)_{3} \mathrm{UNR}$ remairing and $\left(\mathrm{MeC}_{5} \mathrm{H}_{4}\right)_{3} \mathrm{UN}_{3}$ produced. Table 1-10 below summarizes the results of these

\begin{tabular}{|c|c|c|c|}
\hline $\mathbf{R}$ & $\mathbf{R}^{\prime}$ & $\begin{array}{c}\left(\mathrm{MeC}_{3} \mathrm{H}_{4}\right)_{3} \mathrm{UNR} \\
(\bar{x})\end{array}$ & $\begin{array}{l}\left(\mathrm{MeC}_{5} \mathrm{H}_{4}\right)_{3} \mathrm{UN}_{3} \\
(\mathrm{x})\end{array}$ \\
\hline $\mathbf{P h}$ & $\mathrm{P}-\mathrm{MeC}_{4} \mathrm{H}_{4}$ & 100 & 0 \\
\hline $\mathbf{P h}$ & $C P h_{3}$ & 100 & 0 \\
\hline $\mathbf{P h}$ & $\mathrm{SiMe}_{3}$ & 85 & 15 \\
\hline $\mathbf{P h}$ & $\mathrm{SnMe}_{3}$ & 5 & 95 \\
\hline SiMe, & $\mathbf{P h}$ & 100 & 0 \\
\hline $\mathrm{SiMe}_{3}$ & $\mathrm{CPh}_{3}$ & 98 & 2 \\
\hline $\mathrm{SiMe}_{3}$ & SiMeg & 92 & 8 \\
\hline $\mathrm{SiMe}_{3}$ & $\mathrm{SnMe}_{3}$ & 7 & 93 \\
\hline
\end{tabular}
reactions:

Table 2-10: Sirmmary oi resuls of reaction of $\left(\mathrm{MeC}_{5} \mathrm{H}_{4}\right)_{3} \mathrm{UNR}$ with $\mathrm{R} \mathrm{N}_{3}$. 
The results shown above can be rationalized easily by once again looking at the resonance structures of azides (Figure 1-26):
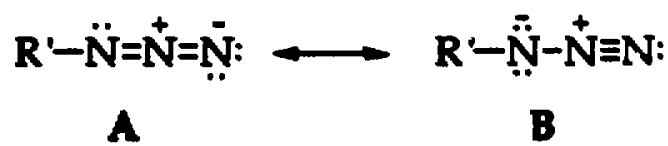

Fyun 126. Resonance structures of asides.

In this case, we would predict that reconance structure $A$ is more likely to produce the uranium(IV) azide product from the uranium(V) imide. This is because the electron density and negatively charged $\gamma$ nitrogen will be more likely to coordinate to the highly positiveij' charged metal center.

Presumably, a y-coordination of this type is necessary to avoid steric interactions at the transition state and enable the reaction to occur.

The reaction product distribution did inderd seem to follow the expected order based on the above prediction. Trimethyltinazide is certainly the most ionic azide of the group, therefore tending more towards structure A. It easily reacted the iritest, with the reaction going approximately $90 \%$ to the uranium(IV) azide after one day. Silyl azides are reported to tend more towards structure $A$ than alkyl azides; ${ }^{60}$ and we would thus expect $\mathrm{Me}_{3} \mathrm{SiN}_{j}$ to react somewhat faster than $\mathrm{Ph}_{3} \mathrm{CN}_{3}$ and this is the observed result. Neither azide reacts quickly; $\mathrm{Me}_{3} \mathrm{SiN}_{3}$, when reacted with the imide, yielded less than $10 \%$ of the azide after one day, while $\mathrm{Ph}_{3} \mathrm{CN}_{3}$ does not react appreciably at all with $\mathrm{A}_{4} \mathrm{C}_{5} \mathrm{H}_{4} \mathrm{UNN}_{3} \mathrm{Uh}$ and only very slightly with $\left(\mathrm{MeC}_{5} \mathrm{H}_{4}\right)_{3} \mathrm{UNSiMe}$ after one day. Finally, aryl azides tend quite strongly towards structure B, and are, as expected, the slowest to react. In fact, no uranium(IV) azide was observed 
when $\mathrm{ArN}_{3}\left(\mathrm{Ar}=\mathrm{Ph}\right.$ or $\left.\mathrm{p}-\mathrm{MeC}_{6} \mathrm{H}_{4}\right)$ was allowed to react with either of the uranium(V) imides.

In order to show that this reaction simply replaces the NR group with the $\mathrm{N}_{3}$ group from $\mathrm{RN}_{3}$ and that no odd rearrangement occurs, a labelling reaction was carried out. $\left(\mathrm{MeC}_{5} \mathrm{H}_{4}\right)_{3} \mathrm{U}^{15} \mathrm{NPh}\left[\mathrm{ca} .99 \%{ }^{15} \mathrm{~N}\right.$, prepared from $\left(\mathrm{MeC}_{5} \mathrm{H}_{4}\right)_{3} \mathrm{U}\left(\right.$ tht) and $\left.\mathrm{Ph}^{15} \mathrm{NNN}\right]$ was allowed to react with $\mathrm{Me}_{3} \mathrm{SnN}_{3}$ for four days in toluene. At the end of this time, the volatile materials were removed and collected in a liquid nitrogen trap. The ${ }^{1} \mathrm{H}$ NMR spectrum of the greenbrown residue indicated only uranium(IV) azide and no remaining imide. There were also several peaks in the diamagnetic region of the spectrum, presumably from the byproducts of the reaction. A mass spectrum of this material indicated that no ${ }^{15} \mathrm{~N}$ remained in the product $\left(\mathrm{MeC}_{5} \mathrm{H}_{4}\right)_{3} \mathrm{UN}_{3}$. The spectrum and a simulation of the molecuiar ion are shown in Figure 1-27.

Interestingly, a second product was also seen in the mass spectrum. The spectrum is consistent with the formulation $\left(\mathrm{MeC}_{5} \mathrm{H}_{4}\right) \mathrm{SnMe}_{3}$, and this spectrum is shown with the simulation of the molecular ion in Figure 1-28. Further confirmation that this material was produced was found when the ${ }^{1} \mathrm{H}$ NMR spectrum was studied more closely. The spectrum of $\left(\mathrm{MeC}_{5} \mathrm{H}_{4}\right) \mathrm{SnMe}_{3}$ has been reported, at $31^{\circ} \mathrm{C}$ in $\mathrm{CS}_{2}$ solvent. ${ }^{61}$ The report assigns the $\mathrm{MleC}_{5} \mathrm{H}_{4}$ ring resonances at $\delta=5.66$ and $5.53 \mathrm{ppm}$, the $\mathrm{MeC}_{5} \mathrm{H}_{4}$ methyl group resonance at $\delta=2.04 \mathrm{ppm}$, and the trimethyltin methyl groups at $\delta=-0.01 \mathrm{ppm}$. In order to look for these resonances and examine the by-products more closely, the reartion of $\left(\mathrm{MeC}_{5} \mathrm{H}_{4}{ }_{3} \mathrm{UNPh}\right.$ and $\mathrm{Me}_{3} \mathrm{SnN}_{3}$ was run once again. This time, the maturials were allowed to react for nine days in toluene. The volatile materials were removed, and the mixture was extracted with hexane. When the hexane was removed, a pale brown oily solid was obtained, which was dissolved in $\mathrm{C}_{6} \mathrm{D}_{6}$ and transferred to a $10 \mathrm{~mm}$ NMR tube. The ${ }^{1} \mathrm{H}$ NMR 

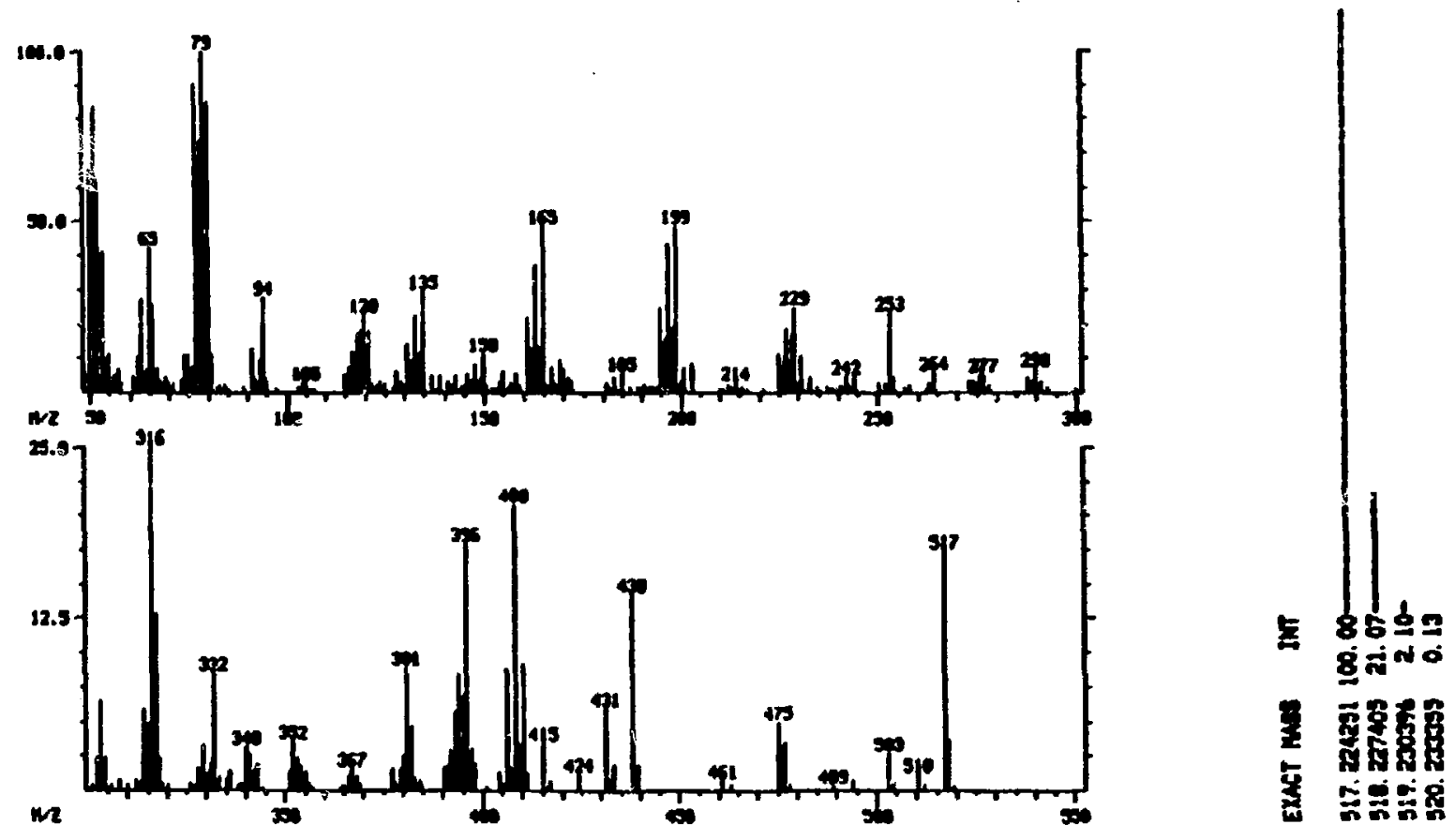

Figure 1-27: The mass spectrum of the product mixture from the reaction of $\left(\mathrm{MeC}_{5} \mathrm{H}_{4}\right)_{3} \mathrm{U}^{15} \mathrm{NPh}$ with $\mathrm{Me}_{3} \mathrm{SnN}_{3}$. The highest observed mass is for $\left(\mathrm{MeC}_{5} \mathrm{H}_{4}\right)_{3} \mathrm{UN}_{3}$, and the simulation of the isotopic cluster for this unit is shown on the right. There is no ${ }^{15} \mathrm{~N}$ in the product. 


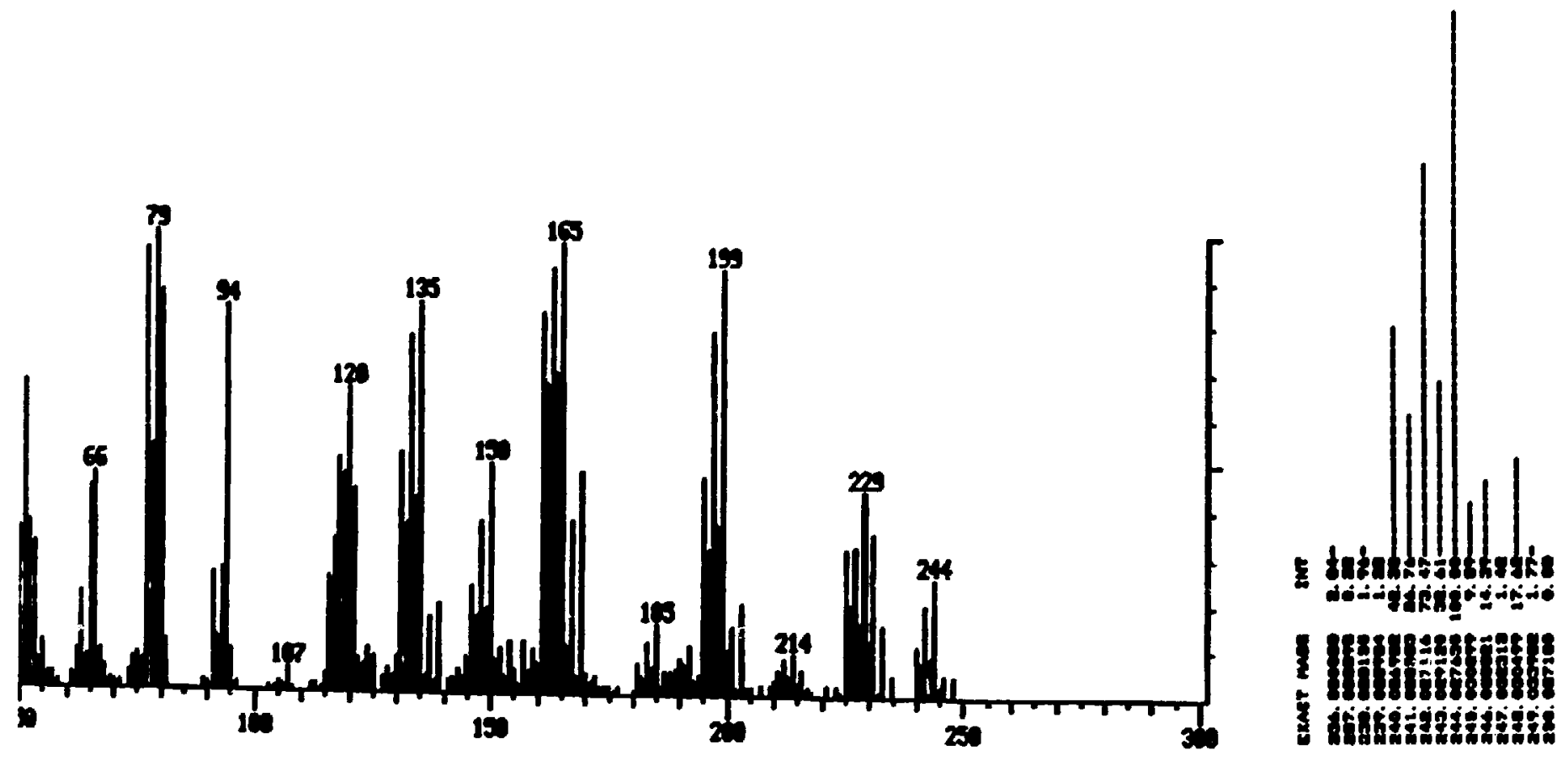

Figure 1-28: The mass spectrum of the product mixture from the reaction of $\left(\mathrm{MeC}_{5} \mathrm{H}_{4}\right)_{3} \mathrm{U}^{1 \mathrm{NPh}_{2}}$ with $\mathrm{Me}_{3} \mathrm{SnN}_{3}$. The highest observed mass is for $\left(\mathrm{MeC}_{5} \mathrm{H}_{4}\right) \mathrm{SnMe}_{3}$, and the simulation of the isolopic cluster for this unit is shown
on the right. 
spectrum of this material indicated that $\left(\mathrm{MeC}_{5} \mathrm{H}_{4}\right) \mathrm{SnMe}_{3}$ is formed in the reaction. Two small peaks are seen in the spectrum at $\delta=5.6-5.8 \mathrm{ppm}$, and a larger peak is observed at $\delta=c a .2 .1 \mathrm{ppm}$. These are consistent with the values described above for $\left(\mathrm{MeC}_{5} \mathrm{H}_{4}\right) \mathrm{SnMe}_{3}$. Between cr. 0 and $0.5 \mathrm{ppm}$ the spectrum contains several peaks, and it is difficult to definitively identify any other byproduct.

However, additional information is obtained by taking the ${ }^{119} \mathrm{Sn}$ NMR of the material at $33.3 \mathrm{MrEz}$. This was done using the conditions described in the experimental section (Chapter 4). After 3500 accumulations, a very dean spectrum was obtained, which contained the following peaks (referenc ad to $\mathrm{Me}_{4} \mathrm{Sn}$ at $\left.\delta=0.0 \mathrm{ppm}\right): \delta=+64.6 \mathrm{ppm}, \delta=+48.9 \mathrm{ppm}$, and $\delta=+26.3 \mathrm{ppm}$. The spectrum is shown in Figure 1-29.

What do we leam from this spectrum? First of all, the ${ }^{119} \mathrm{Sn}$ spectrum of $\mathrm{CpSnMe}_{3}$ is known. The tin resonance is reported to occur at either $\delta=-26$ $\mathrm{ppm}^{62}$ or $\delta=+32 \mathrm{ppm}^{13}$ We would expect the spectrum of $\left(\mathrm{MeC}_{5} \mathrm{H}_{4}\right) \mathrm{SnMe}$ : to be almost identical, thus we conclude that the peak we observed at $\delta=+263$ Ppm is from (MeCs $\left.\mathrm{H}_{4}\right) \mathrm{SnMe}_{3}$.

What about the other two peaks in our tin spectrum? If the $\mathrm{Me}_{3} \mathrm{Sn}$ group from the starting azide couples with the NPh group that dissociates from the uranium(V) imide in this reaction, we could easily envision two other products being formed: $\mathrm{Me}_{3} \mathrm{SnNHPh}$, from the coupled byproduct picking up a proton, or $\left[\mathrm{Me}_{3} \mathrm{SnNPh}\right]_{2}$, from dimerization to form the substituted hydrazine (see Scheme 1-25). The ${ }^{119} \mathrm{Sn}$ NMR spectrum of $\mathrm{Me}_{3} \mathrm{SnNHPh}$ has been reported, with a tin resonance at $\delta=+46.4 \mathrm{ppm} .44$ This is very close to the peak we observed at $\delta=+48.9 \mathrm{ppm}$. In addition, the ${ }^{1} \mathrm{H}$ NMR of our material showed a fairly distinct, broad resonance at $\delta=2.65$ Ppm. This is quite consistent with the reported value for the $\mathrm{N}-\mathrm{H}$ resonance 


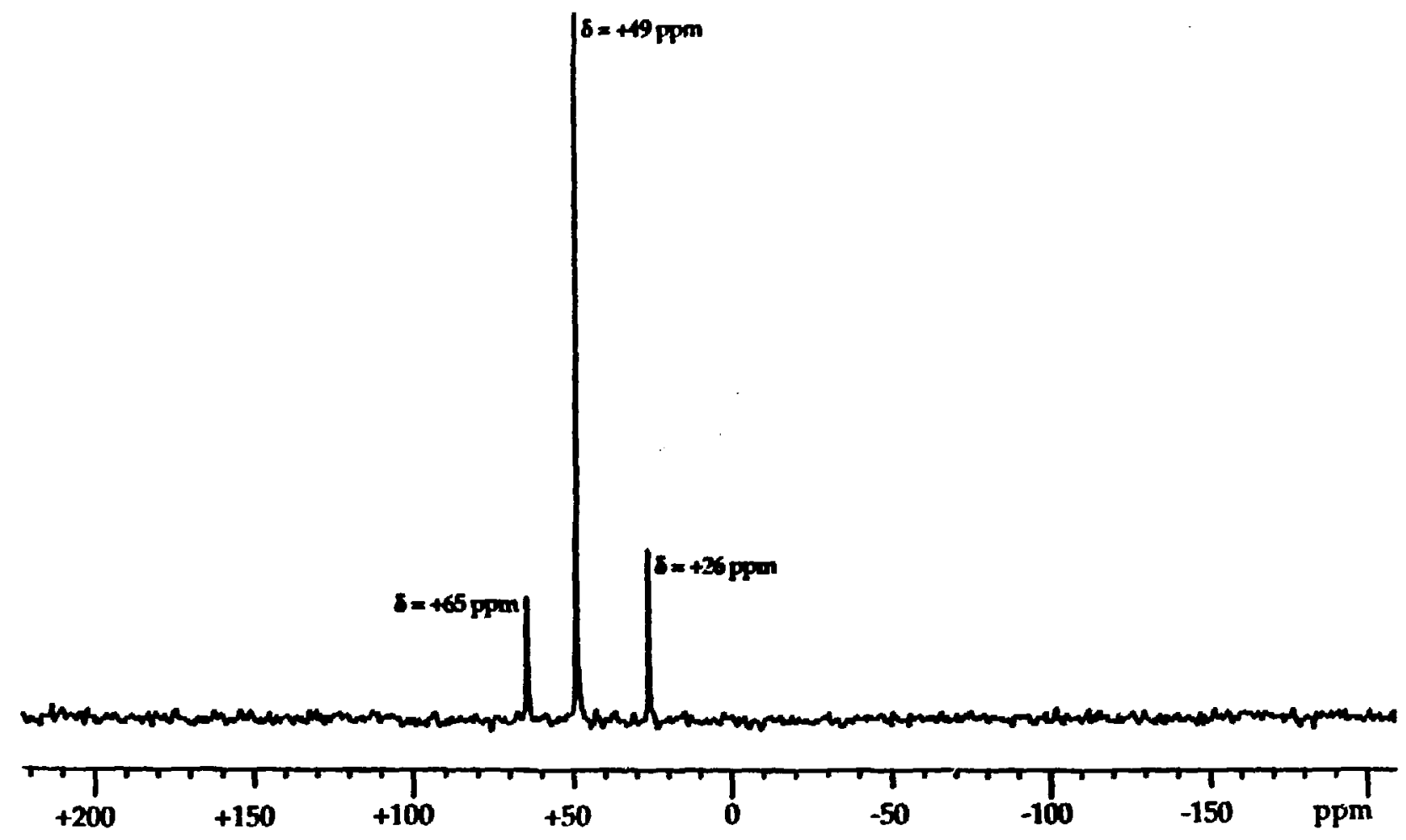

Figure 1-29: The "19Sn NMR specii um of the residue from the hexane extract of the reaction of $\left(\mathrm{MeC}_{5} \mathrm{H}_{4}\right)_{3} \mathrm{UNPh}$ with $\mathrm{Me}_{3} \mathrm{SnN}_{3}$. 
$\mathrm{O}_{3} \mathrm{U}=\mathrm{NPh}$

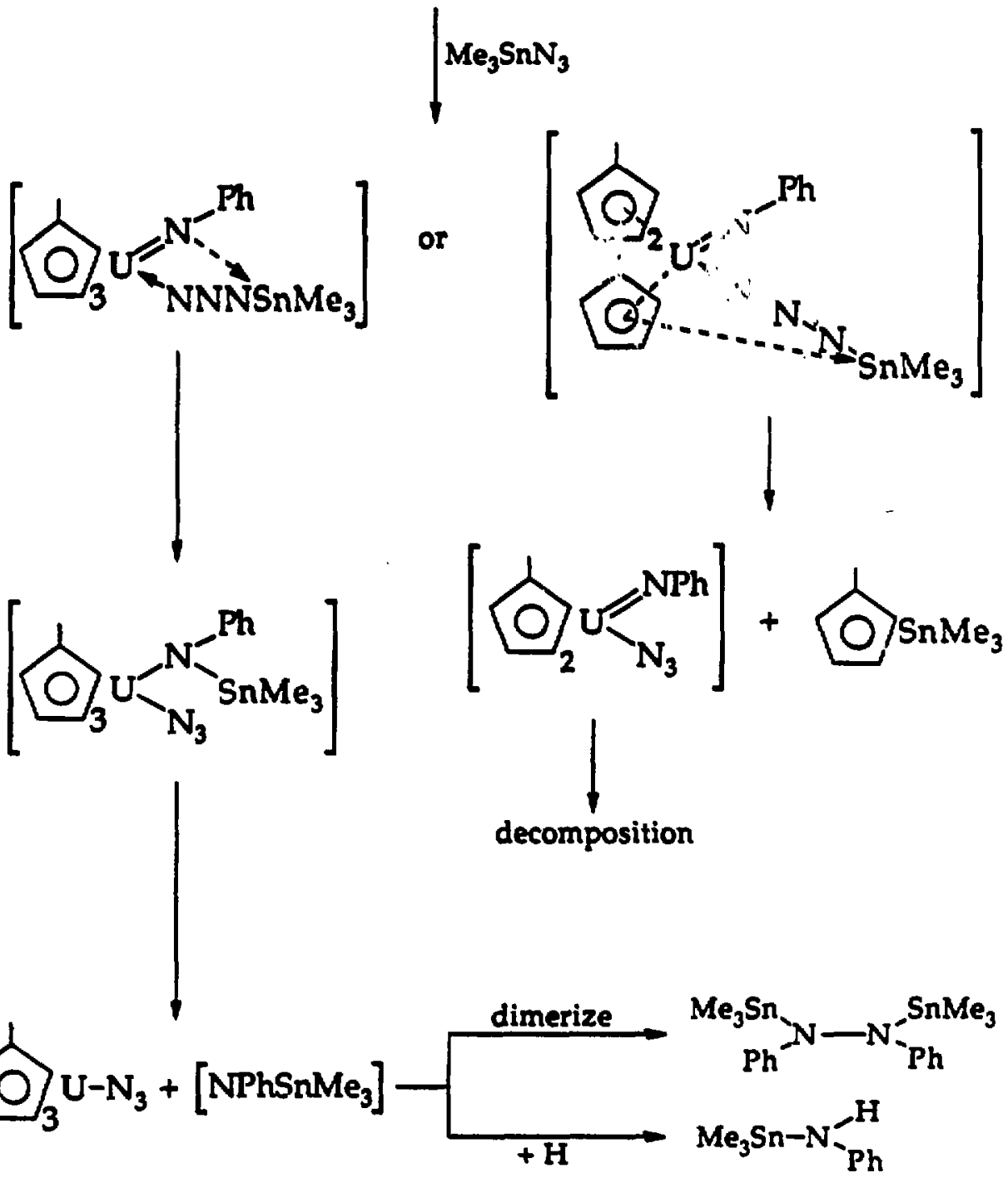

Scherne 1-25: Possible mechanism for the reaction of $\left(\mathrm{MeC}_{5} \mathrm{H}_{4}\right)_{3} \mathrm{UNPh}$ with $\mathrm{Me}_{3} \mathrm{SnN}_{3}$, atlempting to show the formation of the observed and postulated by-products. 
of $\mathrm{Me}_{3} \mathrm{SnNHPh}$, which is $\delta=2.8 \mathrm{ppm}$. The $\mathrm{Me}_{3} \mathrm{Sn}$ resonance in the ${ }^{1} \mathrm{H}$ NMR of this compound is reported to be found at $\delta=0.21 \mathrm{ppm}$; we see a large resonance at $\delta=0.28 \mathrm{ppm}$ (although impurities such as grease make this resonance impossible to identify unambiguously).

Presumably, the remaining resonance in the ${ }^{119}$ Sn NMR $(\delta=+64.6$ $\mathrm{ppm})$ is due to the hydrazine, $\left(\mathrm{Me}_{3} \mathrm{Sn}\right)(\mathrm{Ph}) \mathrm{NN}(\mathrm{Ph})\left(\mathrm{Me}_{3} \mathrm{Sn}\right)$. Unfortunately, the ${ }^{119} \mathrm{Sn} \mathrm{NMR}$ of this compound has not been reported. However, the $\mathrm{Me}_{3} \mathrm{Sn}$ group in the ${ }^{1} \mathrm{H}$ NMR is reported at $\delta=0.40 \mathrm{ppm},{ }^{65}$ and we observe a fairly small resonance at this value. Also, since this $\mathrm{Me}_{3} \mathrm{Sn}$ resonance shifts downfield in the ${ }^{1} \mathrm{H}$ NMR relative to that in the compound $\mathrm{Me}_{3} \mathrm{SnNHPh}$, we would expect the "119s resonance to also move downfield, and this is consistent with what we observed in the 11'Sn NMR.

The finding that $\left(\mathrm{MeC}_{5} \mathrm{H}_{4}\right) \mathrm{SnMe}_{3}$ is one of the by-products in the reaction suggests that once the azide has coordinated to the metal center, it may choose to react with either a cyclopentadienyl ring lleaving $\left(\mathrm{MeC}_{5} \mathrm{H}_{4}\right) 2 \mathrm{U}(\mathrm{NR})\left(\mathrm{N}_{3}\right)$, which presumably decomposes] or the imido ligand. This may mean that in some cases the azide coordinates opposite from the imido ligand in a trigonal bipyramidal type of arrangement (as discussed earlier in this chapter), while it sometimes coordinates adjacent to the imide.

A very similar reaction to the one described above has recently been reported using germanium compound. ${ }^{\text {G6 }}$ When a germanium(II) silylamide is reacted with $\mathrm{Me}_{3} \mathrm{SiN}_{3}$ a mixed amido/azido compex is obtained, as shown below (Scheme 1-26): 


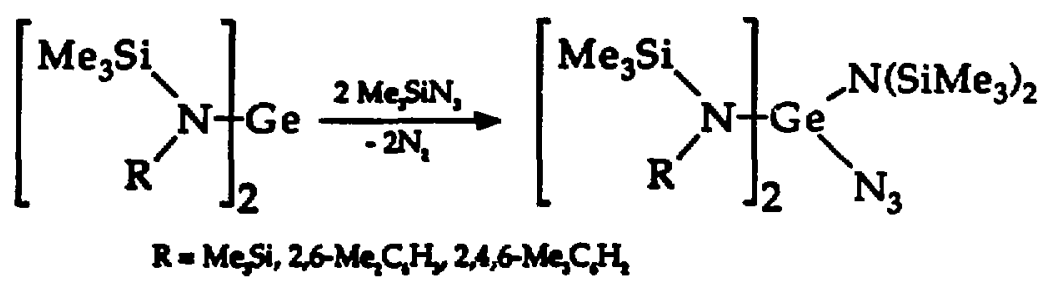

Scheme 1-26: Reaction of a germanium silyiamide with $\mathrm{Me}_{3} \mathrm{SiN}_{3}$.

Presumably, this reaction proceeds in a similar manner to the one we obeerved with uranium. A germanium stlylimide is probably initially formed, followed by coordination of a second azide $\left(\mathrm{Me}_{3} \mathrm{SiN}_{3}\right)$ and transfer of the MegSi group to the imido ligand. This then yields the stable germanium(IV) product. This mechanism is outlined below (Scheme 1-27):

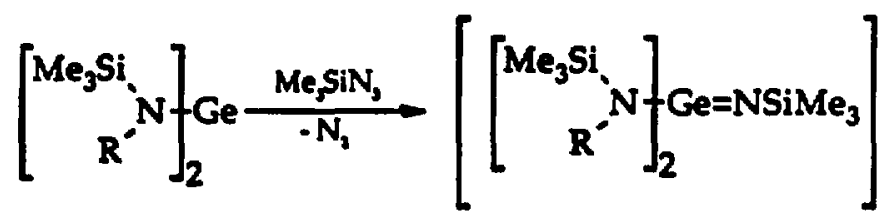
$\mid \mathrm{Me}, \mathrm{SiN}_{2}$

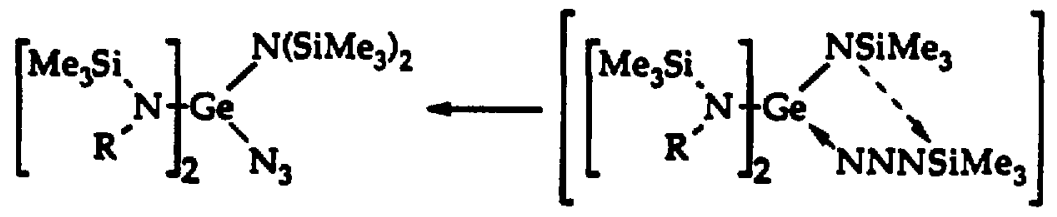

Scheme 1-27: Possible mechanism for germanium amide/azide complex formation.

The first step of this, the formation of the germanium imide, is expected since $\mathrm{R}_{3}^{\prime} \mathrm{SiN}_{3}\left(\mathrm{R}^{\prime}=\mathrm{Et}, \mathrm{O}^{\prime} \mathrm{Bu}\right)$ react with the germanium(II) compound to give stable imides (Scheme 1-28): 


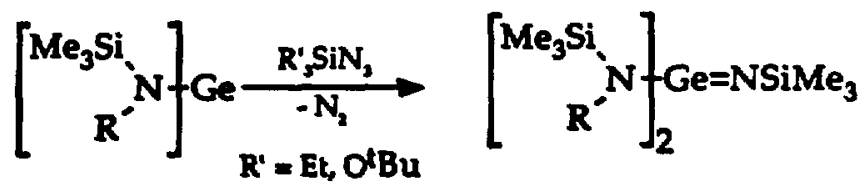

Scheane 1-21: Preparation of a germanium(IV; imide.

These two imides appear to stop at this stage due to the steric requirements of the $\mathbf{R}^{\prime}$ group.

It seems sensible that the germanium amide/aride complex is favored because it is a stable germanium(IV) compound. However, in the case of uranium, the compound $\left(\mathrm{MeC}_{5} \mathrm{H}_{4}\right)_{3} \mathrm{U}\left(\mathrm{N}_{3}\right)(\mathrm{NRR})$ would presumably be extremely bulky and, since energy is gained by reduction to uranium(IV), the amido ligand is lost. Our observation that the imido $\mathbf{R}$ group couples with the R' group from the incoming azide appears to be supported by these germanium complexes in which an identical coupling is seen.

Two other reactions of the imides were done. The first is the reaction of $\left(\mathrm{MeC}_{5} \mathrm{H}_{4}\right)_{3} \mathrm{UNSiMe}_{3}$ with alcohols. When the silylimide was heated in toluene with one molar equivalent of methanol for several days, a mixture of the unreacted starting material and the uranium(IV) methoxide, $\left(\mathrm{MeC}_{5} \mathrm{H}_{4}\right)_{3}$ UOMe, was produced. The methoxide was identified by its ${ }^{1} \mathrm{H}$ NMR spectrum, which was identical to material produced by the two reactions below (Scheme 1-29): 


$$
\begin{aligned}
& \mathrm{O}_{3} \mathrm{UCl}+\mathrm{NaOMe} \longrightarrow \mathrm{O}_{3} \mathrm{UOMe}+\mathrm{NaCl} \\
& \mathrm{O}_{3} \mathrm{U}(\mathrm{thf})+\mathrm{MeOH} \stackrel{\mathrm{Et} \mathrm{O}}{\longrightarrow} \mathrm{O}_{3} \mathrm{UOMe}+1 / 2 \mathrm{H}_{2}
\end{aligned}
$$

Scheme 1-25: Preparations of a uranium(IV) methoxide. The top reaction is from this work; the boltom reaction is from reference 67.

Similarly, a mixture of starting material and the uranium phenoxide $\left(\mathrm{MeC} \mathrm{H}_{4}\right)_{3}$ UOPh was obtained from the silylimide and phenol in diethylether. Again, the phenoxide was identified by its ' ${ }^{1} \mathrm{H}$ NMR, which was found to be identical to the NMR of the product obtained by Stults from the reaction of $\left(\mathrm{MeC}_{5} \mathrm{H}_{4}\right)_{3} \mathrm{U}($ thf $)$ with phenol. ${ }^{67}$ The apparently slow rate of these reactions may reflect the need for two molar equivalents of the alcohol to protonate off the imide as the amine.

These reactions are not particularly unusual; in 1961 Thomas found that a tantalum imido/amido complex could be easily converted to the alkoxide (Scheme 1-30): $:^{60}$

$$
\begin{aligned}
& \left(\mathrm{Pr}_{2} \mathrm{~N}\right)_{3} \mathrm{Ta}=\mathrm{NPr} \stackrel{\text { excess } \mathrm{ROH}}{\longrightarrow} \mathrm{Ta}(\mathrm{OR})_{5} \\
& \text { 92-98\% }
\end{aligned}
$$

Scheme 1-30: Reaction of a tantulum imide with alcohol.

In fact, the germanium imide compound discussed earlier also forms an alkoxide upon reaction with methanol (Scheme 1-31): 66 


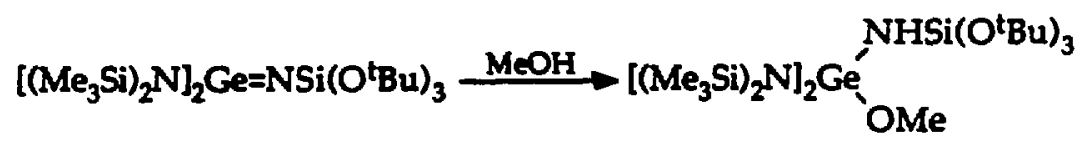

Scheme 1-31: Reaction of a germanium imide with methanol.

In Section 1.3, the reaction of $\mathrm{CO}_{2}(\mathrm{CO})_{8}$ with $\left(\mathrm{MeC}_{5} \mathrm{H}_{4}\right)_{3} \mathrm{UN}_{3}$ was discursed. This reaction was found to produce the bridged isocarbonyl complex, $\left(\mathrm{MeC}_{5} \mathrm{H}_{4}\right)_{3} \mathrm{U}_{-} \mu-\mathrm{OC}\left[\mathrm{Co}_{3}(\mathrm{CO})_{9}\right]$. Surprisingly, when $\left(\mathrm{MeC}_{5} \mathrm{H}_{4}\right)_{3} \mathrm{UNR}$

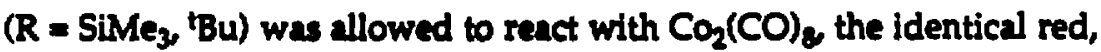
crystalline product was obtained (Scheme 1-32).

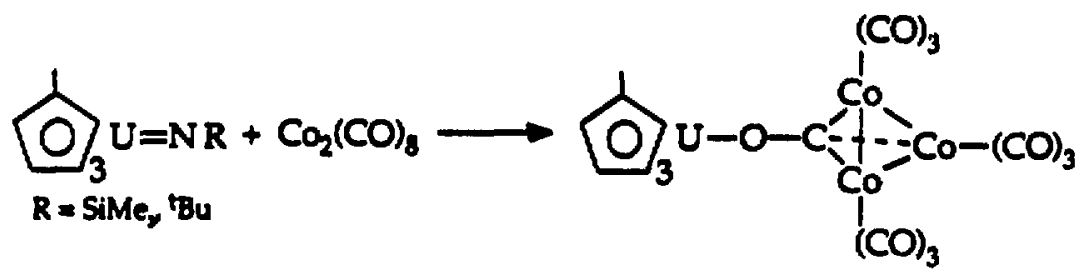

Scheme 1-32: Reaction of uranium(V) imides with cobalt carbonyl.

As mentioned earlier, the analogous $\mathrm{C}_{5} \mathrm{H}_{5}$ compound has been synthesized by Stutte and Schmid, $\boldsymbol{M}$ and is also bright red.

This uranium(IV) complex shows a typical ' $\mathrm{H}$ NMR, with a 3:2:2 pattern for the $\mathrm{MeC}_{5} \mathrm{H}_{4}$ at $\delta=-10.19 \mathrm{ppm}(3 \mathrm{H}), \delta=-1.49 \mathrm{ppm}(2 \mathrm{H})$, and $\delta=$ $+5.16 \mathrm{ppm}(2 \mathrm{H})$. The infrared spectrum of the compound shows several overlapped stretches in a somewhat broad carbonyl region: 2080, 2015, and $1965 \mathrm{~cm}^{-1}$ are the most obvious peaks. The infrared spectrum was also recorded in $\mathrm{Et}_{2} \mathrm{O}$ solution, and the carbonyl region appeared sharper; stretches were observed at 2080, 2050, 2020, 1960, 1930, 1900, and $1860 \mathrm{~cm}^{-1}$. The spectra both as a Nujol mull and in solution are shown in Figure 1-30. 
95

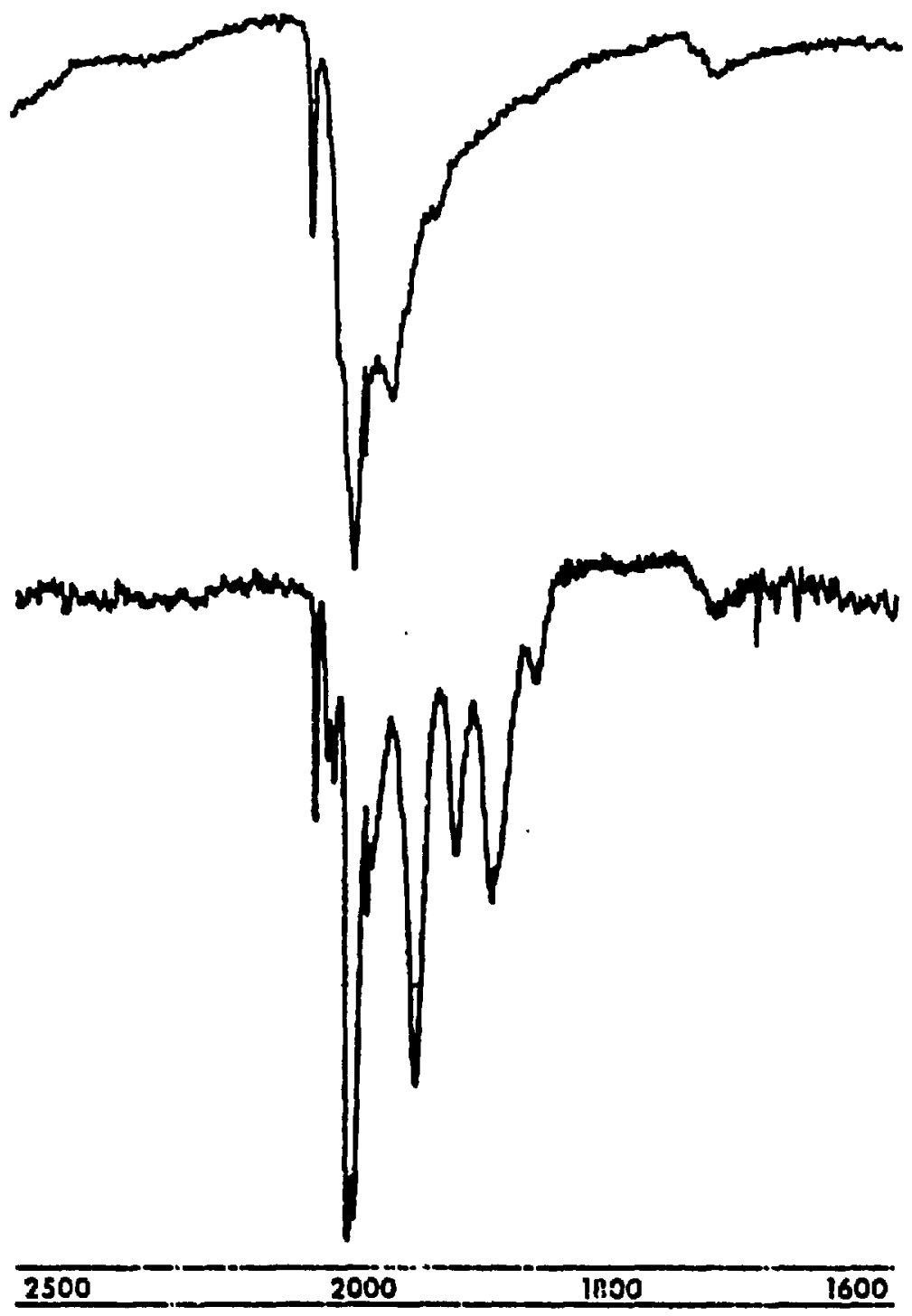

Figure 1-30: Infrared spectra of $\left(\mathrm{MeC}_{5} \mathrm{H}_{4}\right)_{3} \mathrm{U}-\mu-\mathrm{OC}\left[\mathrm{CO}_{3}(\mathrm{CO})_{9}\right]$, showing the $\mathrm{CO}$ stretching region. The top spectrum was taken as a Nujol mull, the bottom as a diethylether solution. 
The analogous reaction was also performed using $\mathrm{Cp}_{3} \mathrm{UNSiMe}_{3}$ and cobalt carbonyl. Red cystals were obtained from toluene, and the ${ }^{1} \mathrm{H}$ NMR showed a single sharp resonance at $\delta=-3.3 \mathrm{ppm}$. This is identical to the value reported by Stutte and Schmid. The carbonyl region of the infrared spectrum (Nujol mull) was found to be almost identical to the methycyclopentadienyl derivative, with three easily identifiable stetches at 2080,2020 , and $1970 \mathrm{~cm}^{-1}$. Stutte and Schmid report similar data; they find a sharp $V_{C O}$ at $2070 \mathrm{~cm}^{-1}$, and four other bands at 2000, 1985, 1970, and $1940 \mathrm{~cm}^{-1}$.

The reaction between $\mathrm{CP}_{3} \mathrm{UNSIM}_{3}$ and $\mathrm{CO}_{2}\left(\mathrm{CO}_{8}\right.$ was also performed in an NMR tube in dy-toluene at room temperature, to see both how quickly the reaction proceeded and how cleanly. It was found that the reaction is essentially complete after one hour. The ${ }^{1} \mathrm{H}$ NMR is extremely clean, showing only two resonances (other then solvent): the dimishing peak at $\delta=$ -6.4 ppm from $\mathrm{CP}_{3} \mathrm{UNSiMe}_{3}$ and the growing resonace at $\delta=-3.3 \mathrm{ppm}$ from $\mathrm{C}_{p_{3}} \mathrm{U}-\mu-\mathrm{OC}\left[\mathrm{CO}_{3}(\mathrm{CO})_{9}\right]$. The reaction has a $t_{1 / 2}$ of $15-20$ minutes under these conditions. 


\section{References}

1 Cotton, F. A.; Wilkinson, G. Adoanced Inorganic Chemistry, Fifth Edition, John Wiley and Sons, New York, 1988, pp. 98G-993.

2 Brennan, J. G.; Andersen, R. A. J. Am. Chem. Soc. 1985, 107, 514.

3 Brennan, J. G.; Andersen, R. A.; Zalkin, A. Inorg. Chem. 1986, 25, 1756.

4 Berg, D., personal communication.

s (a) Gomberg, M. J. Am. Chem. Soc. 1900, 22, 757. (b) Gomberg, M. Ber. Dtsch. Chem. Ges. 1900, 33, 3150. (c) Jacobson, P. Ber. Disch. Chem. Ges. 1905, 38, 196. (d) Lankamp, H.; Nauta, W. T.; MacLean, C. Tetrahedron Letters 1968, 249. In addition, an excellent review entitled "The Hexaphenylethane Riddle" has appeared: (e) McBride, J. M. Tetrahedron 1974, 30, 2009.

- See, for example, the following review articles: (a) Scriven, E. F. V.; Tumbull, K. Chem. Rev. 1988, 88, 297. (b) Thayer, J. S. Orgenomet. Chem. Rev. 1966, 1, 157. (c) Peterson, W. R, Ir. Reviews on Silicon, Cermanium, Tin, and Lead Compounds 1974, 1, 193. An example utilizing a transition metal that is particularly relevent to this work is: (d) Osborne, J. H.; Rheingold, A. L.; Trogler, W. C. J. Am. Chem. Soc. $1985,107,7945$.

7 Dormond, A.; Duval, C. J. Organomet. Chem. 1979, 178, C5.

- Stults, S. D. personal communication.

- (a) Brennan, J. G.; Andersen, R. A.; Zalkin, A. Inorg. Chem. 1986, 25, 1761. (b) Brennan, J. G. Ph.D. Thesis, Unioersity of California, Berkeley 1985. 
10 Kanellakopulos, B. in Marks, T. J.; Fischer, R. D., eds. Organometallics of the f-Elements D. Reidel Publishing Company, Dordrecht, Holland, 1978, pp. 1-35.

11 Reynolds, L. T.; Wilkinson, G. J. Inorg. Nucl. Chem. 1956, 2, 246.

12 (a) Fisher, R. D.; Sienel, G. R. Z. Anorg. Allg. Chem. 1976, 119, 126. (b) Sienel, G. R. Ph.D. Thesis, Unioersittit Erlangen-Nürnberg 1976.

13 Two excellent introductory texts discusaing azides are: (a) Patai, S., ed. The Chemistry of the Azido Group Intereclence Publishers, London, 1971. (b) Fair, H. D.; Walker, R. F. Energetic Materials, Volume I: Physics and Chemistry of the Inorgenic Azides, Volume 2: Technology of the Inorganic Azides Plenum Press, New York, 1977.

14 (a) Pritzkow, V. W.; Timm, D. J. Prakt. Chem. 1966, 32, 178. (b) Thayer, J. S.; West, R. Inorg. Chem. 1964, 3, 889. (c) Arcus, C. L.; Mesley, R. J. J. Chem. Soc. 1953, 178, 181. (d) Thayer, J. S.; West, R. Inorg. Chem. 1964, $3,406$.

13 (a) Nölting, Chem. Ber. 1893, 26, 86. (b) Smith, P. A. S. Org. Syn. 1951, 31,14 .

16 Note: The ${ }^{119} \mathrm{Sn}$ chemical shift we report for the byproduct in the reaction of $\left(\mathrm{Me}_{3} \mathrm{SiC}_{5} \mathrm{H}_{4} \mathrm{U}_{3} \mathrm{U}\right.$ with $\mathrm{Ph}_{3} \mathrm{SnN}_{3}, 8=-138 \mathrm{ppm}$, is referenced to the ${ }^{119} \mathrm{Sn}$ chemical shift of $\mathrm{Ph}_{3} \mathrm{SnCl}$ in $\mathrm{C}_{6} \mathrm{D}_{6}$, which we set as $\delta=-44.7$ ppm. This shift is reported at $\delta=-44.7 \mathrm{ppm}$ in $\mathrm{CDCl}_{3}$ (from the review article in reference 15). Thus, the difference between the value we observe and the reported values for $\mathrm{Ph}_{3} \mathrm{SnSnPh}_{3}$ may be due to poor referencing as the preferred reference for ${ }^{119} \mathrm{Sn} \mathrm{NMR}$ is $\mathrm{Me}_{4} \mathrm{Sn}(\delta=0.0$ ppm). 
A useful review of ${ }^{119} \mathrm{Sn}$ NMR data is available: Wrackmeyer, B. Annual Reports on NMR Spectroscopy 1985, 16, 73.

\section{Heathcock, C. H. Introduction to Organic Chemistry, Second Edition} Macmillan Publishing Co., Inc., New York, 1981. (b) Lowry, T. H.;

Richardson, K. S. Mechanism and Theory in Organic Chemistry, Second Edition Harper and Row, Publishers, New York, 1981. Specific examples that deal with substituent effects on reactivities of phenylazides are: (c) Ugi, I.; Perlinger, H., Behringer, L. Chem. Ber. 1958, 91, 2330. (d) Scheiner, P.; Schomaker, S. D.; Libbey, W. J.; Nowack, G. P. J. Am. Chem. Soc. 1965, 87, 306. (e) Leffler, J. E.; Temple, R. D. J. Am. Chem. Soc. 1967, $89,5235$.

Kaftory, M. In The Chemistry of Halides, Pseudohalides, and Azides Patai, S.; Rappoport, Z. Eds., Wiley, New York, 1983, pp. 1254-1258. Audrieth, L. F.; Gibbs, C. F. Inorg. Synth. 1, 78.

See reference 1, p. 121.

Bagnall, K. W.; Plews, M. J.; Brown, D.; Fischer, R. D.; Klahne, E.;

Landgraf, G. W.; Sienel, G. R. J. Chem. Soc. Dalton Trans. 1982, 1999.

Fischer, R. D.; Sienel, G. R. Z. enorg. allg. Chem. 1976, 419, 126. 
29 Fischer, R. D.; Sienel, G. R. J. Organomet. Chem. 1978, 156, 383.

30 Fischer, R. D.; Klähne, E.; Kopf, J. Z. Naturforsch. 1978, 336, 1393.

31 Matsunaga, P., personal communication.

32 Thayer, J. S. Organometal. Chem. Reo. 1966, 1, 157.

33 Three reviews in which deal pyrolysis of azides is discussed are: (a) Bock, H.; Dammel, R. Angew. Chem. Int. Ed. Engl. 1987, 26, 504. (b) Griffith, W. P. Coond. Chem. Reo. 1972, 8, 369. (c) Dari, Z; Ziolo, R. F. Chem. Reo. $1973,73,247$. See also reference $4 b$.

34 Thayer, J. S.; West, R. Inorg. Chem. 1965, 4, 114.

33 Thayer, J. S.; West, R. Inorg. Chem. 1964, 3, 406.

36 Goubeau, J.; Allenstein, E.; Schmid, A. Chem. Ber. 1964, 97, 884.

37 Leffler, J. E.; Honsberg, U.; Tsuno, Y.; Forsblad, I. J. Org. Chem. 1961, 26, 4810.

31 Horner, L; Gross, A. Ann. Chem. 1955, 591, 117.

39 Staudinger, H.; Hauser, E. Helo. Chim. Acte 1921, 4, 861.

40 (a) Reichle, W. T. Inorg. Chem. 1964, 3, 402. (b) Wiberg, N.; Raschig, F.; Sustmann, R. Angew. Chem. 1962, 74, 388. (c) Wiberg, N.; Raschig, F.; Sustmann, R. Angew. Chem. 1962, 74, 716. (d) Birkofer, L.; Ritter, A.; Richter, P. Chem. Ber. 1963, 96, 2750. (e) Birkofer, L.; Kim, S. M. Chem. Ber. 1964, 97, 2100.

41 (a) Smith, P. A. S.; Clegg, J. M.; Lakrita, J. J. Org. Chem. 1958, 23, 1595. (b) Bleiholder, R. F.; Schechter, H. J. Am. Chem. Soc. 1968, 90, 2131.

42 (a) Birkofer, L.; Ritter, A. Angew. Chem. Intern. Ed. Engl. 1965, 4, 417.

(b) Birkofer, L.; Ritter, A.; Uhlenbranck, H. Chem. Ber. 1963, 96, 3280. (c) Luijten, J. G. A. Abstracts of the First International Symposium on Orgenometallic Chemistry, Summer, 1963, p. 44. 
4

P. G.; Sheldrick, G. M.; Stalke, D. J. Chem. Soc., Dalton Trans. 1984, 1765.

(b) Cenini, S.; Pizzotti, M.; Crotti, C.; Porta, F.; La Monica, G. L. J. Chem. Soc., Chem. Commun. 1984, 1286. (c) Alper, H.; Hashem, K. E. J. Am. Chem. Soc. 1981, 103, 6514. (d) La Monica, G.; Cenini, S. J. Organomet. Chem. 1981, 216, C35. (e) Alper, H.; Paik, H. N. Nouv. J. Chem. 1978, 2, 245. (A) Des Abbayes, H.; Alper, H. I. Am. Chem. Soc. 1977, 99, 98. (g) Iqbal, A. F. M. J. Org. Chem. 1972, 37, 2791. (h) L'Eplattenier, F.; Matthys, P.; Calderazzo, F. Inorg. Chem. 1970, 9, 342.

Han, S. H.; Geoffroy, G. L.; Rheingold, A. L. Inorg. Chem. 1987, 26, 3426.

Ge, Y. W.; Sharp, P. R. Organometallics 1988, 7, 2234. 
36 Glueck, D. S.; Hollander, F. J.; Bergman, R. G. J. Am. Chem. Sac. 1989, $111,2719$.

57 See, for example: (a) Williams, G. D.; Whittle, R. R.; Geoffroy, G. L.; Rheingold, A. L. J. Am. Chem. Soc. 1987, 109, 3936. (b) Han, S. H.; Geoffroy, G. L.; Rheingold, A. L. Organometallics 1987, 6, 2380. (c) Basu, A.; Bhaduri, S.; Khwaja, H. J. Organomet. Chem. 1987, 319, C28. (d) Basu, A.; Bhaduri, S.; Khwaja, H.; Jones, P.G.; Meyer-Base, K.; Sheldrick, G. M. J. Chem. Soc., Dalton Trans. 1986, 2501. (e) Smieja, J. A.; Gozum, J. E.; Gladfelter, W. L. Organometallics 1984, 3, 1311. (f) Alper, H.; Petrignani, J. F.; Einstein, F. W. B.; Willis, A. C. J. Am. Chem. Soc. 1983, 105, 1701. (g) Nugent, W. A.; Haymore, B. L. Coord. Chem. Rev. 1980, 31, 123.

(a) Kanellakopulos, B.; Fischer, E. O.; Dornberger, E.; Baumgartner, F. J. Organomet. Chem. 1970, 18, 1507. (b) Beshouri, S., personal communication.

Weydert, M., personal communication.

Zigler, S. S.; Hallel, K. J.; West, R. Organometallics 1989, 8, 1656.

Davison, A.; Rakita, P. E. Inorg. Chem. 1970, 9, 289.

Torocheshnikov, V. N.; Tupciauskas, A. P.; Ustynyuk, Y. A. J.

Organomet. Chem. 1974, 81, 351.

Wrackmeyer, B., unpublished results, as oted in reference 15.

Kennedy, J. D.; McFarlane, W.; Pyne, G. S.; Wrackmeyer, B. J. Chem.

Sac., Dalton Trans. 1975, 386.

Wiberg, N.; Veith, M. Chem. Ber. 1971, 104, 3191.

Pfeiffer, J.; Maringgele, W.; Noltemeyer, M.; Meller, A. Chem. Ber. 1989, $122,245$. 
67 Stults, S. D. Ph.D. Thesis, University of California, Berkeley 1988. GE Thomas, J. M. Cen. J. Chem. 1961, 39, 1386. 


\section{Chapter 2 \\ Reactions of $\left(\mathrm{MeC}_{5} \mathrm{H}_{4}\right)_{3} \mathrm{U}($ thf $)$ \\ with Diazides}

The subject of this chapter is the study of reactions of trivalent uranium with diazidobenzene derivatives. These reactions were designed to produce bridged, dinuclear uranium-dilmides of the type shown in Figure 2-1 below, where $\mathbf{R}$ is an organic residue:

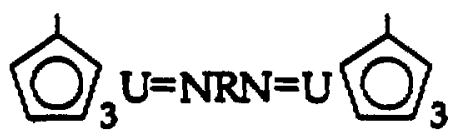

Figure 2-1: General structure of a bridged uranium diimide.

Several of these molecules have been synthesized by techniques analogous to those used for preparation of the mononuclear uranium imides, as discussed in Chapter 1. All the diazides used in these syntheses are some type of aryl diazide, with the exception of one silyl diazide, $\mathrm{Me}_{2} \mathrm{Si}\left(\mathrm{N}_{3}\right)_{2}$. This latter material is the only one of the diazides used which produces the uranium(IV) azide as the product.

Our purpose in preparing and studying these bridged diimide complexes was to investigate whether the proper combinations of the electronic natures of the ligand and the metal could be used to observe electronic interaction across the bridge. A great deal of interest over the last twenty years or so has focused upon metal complexes linked by various 
bridging groups. In particular, groups with delocalized $\pi$-systems have been used extensively to study electron transfer processes in dinuclear systems. ${ }^{1}$ This is demonstrated by studies involving pyrazine, a ligand used by Creutz and Taube in early electron transfer studies on what is now called the CreutzTaube ion (Figure 2-2). ${ }^{2}$

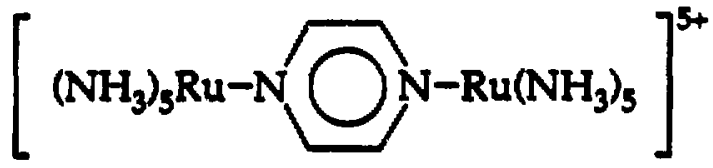

Figure 2-2: Structure of the Creutz-Taube ion.

Similar dinuclear cyclopentadienyl pyrazine complexes of uranium have been synthesized, by Raymond and Eigenbrot in $1982,{ }^{3}$ with the general structure shown below (Figure 2-3):

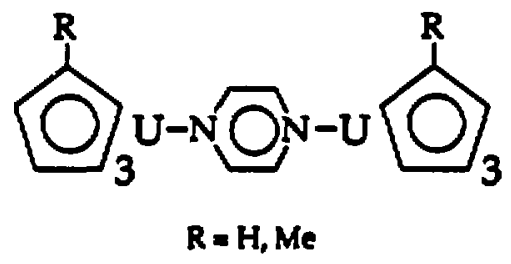

Figure 2-3: Structure of a $\left(\mathrm{C}_{\mathrm{P}_{3}} \mathrm{U}\right)_{2}$-pyrazine complex.

Their goal was to look for some type of electronic exchange between the actinide metal centers. However, the early magnetic susceptibility results on these compounds were somewhat inconclusive. According to the authors, "The magnetic behavior of the methylated compound has been investigated four times. Three times the data indicate the compound is only weakly paramagnetic, and that the paramagnetism varies slowly with temperature. 
The fourth investigation produced results that suggest an abrupt spin-state change at very low temperature. Any further interpretation of the magnetic behavior of this compound will require further investigation. ${ }^{n 4}$

We have synthesized the uranium-pyrazine complex [(MeC $\left.\mathrm{H}_{4}\right)_{3} \mathrm{U}_{2}$ (pyrazine) by Raymond and Eigenbrot's procedure, and done a further investigation of its magnetic behavior. The data, shown in Figures $2-4$ and 2-5, does not indicate the presence of any interaction between the uranium nucle. Fitting this data to the Curie-Weiss law yields a magnetic moment $\mu_{\text {eff }}=5.22 \mathrm{~B} . \mathrm{M} .\left(\theta=-277 \mathrm{~K} ; \mu_{\text {off }}=3.69 \mathrm{~B} . \mathrm{M}\right.$. per uranium atom) in the low temperature region $(5-40 \mathrm{~K})$ and a value of $\mu_{\text {eff }}=4.28 \mathrm{~B} . \mathrm{M} .\left(\theta=-154 \mathrm{~K} ; \mu_{\text {eff }}\right.$ $=3.03$ B. M. per uranium atom) in the high temperature region (160-300 K). One of the problems with the pyrazine ligand in a uranium system involves the redox potentials of both the ligand and metal. The Raymond complexes, if viewed as simple Lewis base coordination adducts, are uranium(II) materials. However, the pyrazine ligand is capable of accepting an electron from one of the metal centers, reducing the ligand and oxidizing one of the uraniums to U(IV). The reduction potential for the ligand is shown below (Scheme 2-1):

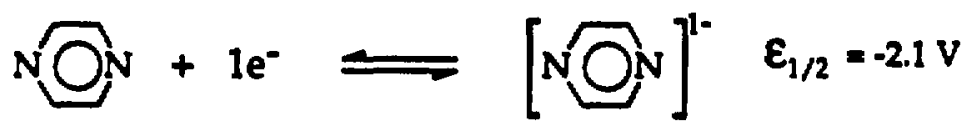

Scheme 2-1: One-ectron reduction of pyrazine to the radical/anion.

This can be compared with the potential for oxidizing the uranium(III). In aqueous solution, the $U($ III)/U(TV) oxidation potential is reported to be +0.63 
Fig. 2-4: Chi vs Temp. plot for the pyrazine complex.

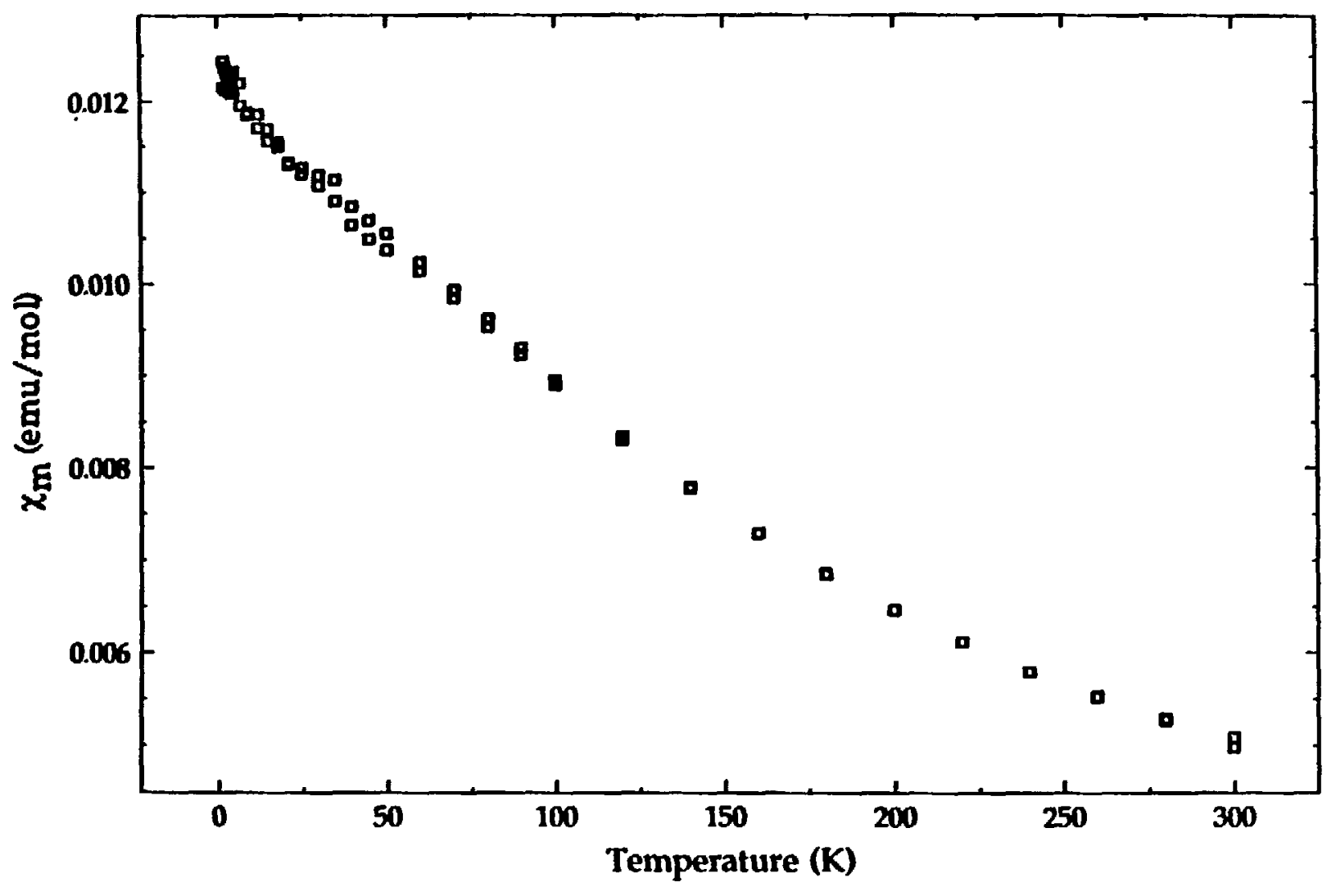


Fig. 2-5: 1/Chi vs Temp. plot for the pyrazine complex.

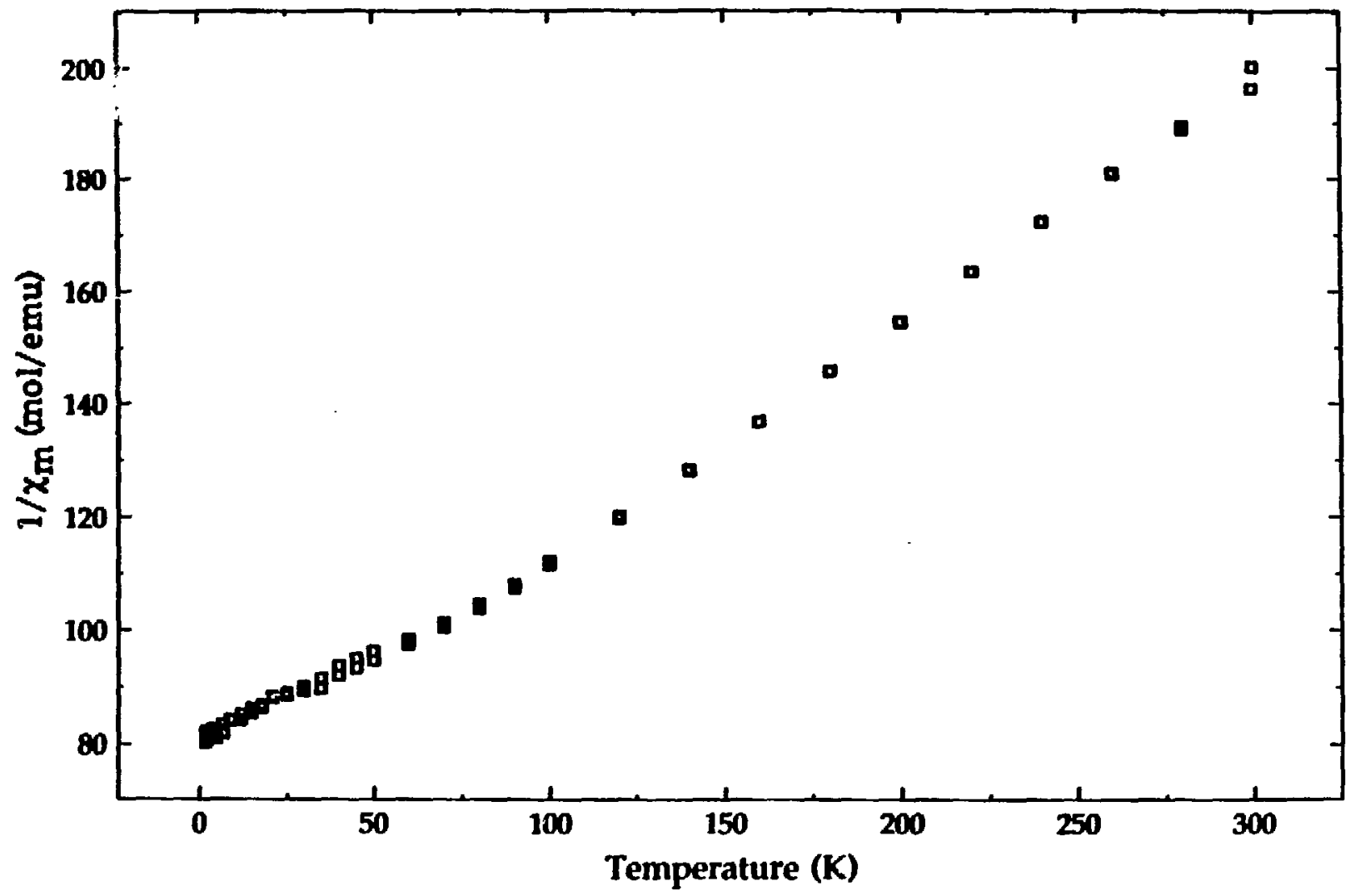


V.6 However, in organometallic systems, higher values have been obtained for the reductions of $\left(\mathrm{RC}_{5} \mathrm{H}_{4}\right)_{3} \mathrm{UCl}$, as shown below (Scheme 2-2):7

$$
\begin{aligned}
& \hat{\mathrm{O}} \mathrm{UCl}+1 \mathrm{e}^{-}=\left[\hat{\mathrm{O}} \mathrm{UCl}_{3}\right]^{1-} \varepsilon_{1 / 2}=-1.53 \mathrm{~V} \\
& \hat{\mathrm{O}} \mathrm{UCl}+1 \mathrm{e}^{-}=\left[\mathrm{O}_{3} \mathrm{UCl}\right]^{1-} \varepsilon_{1 / 2}=-1.86 \mathrm{~V}
\end{aligned}
$$

Scheme 2-2: Reduction potentials of $\left(\mathrm{RC}_{5} \mathrm{H}_{4}\right)_{3} \mathrm{UCl}$.

If, as often occurs, the reduction potential of the base (pyrazine) is lowered upon coortination to the metal center, the uranium may indised be capable of reducing the pyrazine ligand. It should be noted that in other work from our group, D. Berg found that $\mathrm{Yb}(\mathrm{II})$ [as $\left.\left.\mathrm{Cp}_{2} \mathrm{Yb}_{(\mathrm{O}} \mathrm{OE}_{2}\right)_{2}\right]$ was oxidized to $\mathrm{Yb}(\mathrm{II})$ by pyrazine, even though the $Y b(I I) / Y b(I I)$ oxidation potential has been measured at only ca. $+1.3 \mathrm{~V}$ in $\mathrm{CP}_{2}^{*} \mathrm{Yb}(\mathrm{MeCN})_{2}$.

If a redox process like this occurs in the uranium compound, the reduction of the ligand could possibly destroy any electronic interactions between the uranium metal centers. Although the formal oxidation state of the uranium-pyrazine complex is difficult to determine unambiguously, we can easily imagine that at least one of the metal centers may have been oxidized to uranium(IV), and that this may be the reason no electronic exchange is observed in the system. Indeed, the rather narrow 'H NMR linewidths for the cyclopentadienyl ring protons in $\left[\left(\mathrm{MeC}_{5} \mathrm{H}_{4}\right)_{3} \mathrm{U}\right]_{2}$ (pyrazine) (Eigenbrot reports $v_{1 / 2}=15 \mathrm{~Hz}$; we obtained a value of $v_{1 / 2}=12 \mathrm{~Hz}$ ) help to support this idea; these linewidths seem somewhat intermediate between those expected for uranium(III) and uranium(IV). In addition, the shape of 
the $1 / \chi_{\mu}$ versus $T$ curve does not resemble the curves obtained for other trivalent uranium compounds, and may again indicate that an oxidation took place.

This leaves us in a rather interesting position with our uranium(V) dinuclear diimides. Pyrazine, as stated above, is considered to be an excellent ligand for preparing linked dinuclear metal systems. But, in these uranium compounds, it may cause oxidation of the metal, therefore making it ineffective as a ligand which allows electron exchange between the metal centers. Our imide ligands, on the other hand, are already constrained in a system where they are stabilizing the uranium in a particular oxidation state. Moreover, these uranjum( $V$ ) atoms have an $f^{1}$ configuration, and electron interaction which causes pairing of the spins may be quite favorable in the jight system. This puts us in a unique position, as these imides are the only reported uranium(V) organometallic compounds.

It should be noted here that yery fow exariples of magnetic interaction between actinide nuclei have been reported, and these examples occur in extended lattice systems rather than simple molecular materials. For example, the magnetism of the trivalent actinide halides $\left(A \cap X_{3}\right)$ has been investigated. ${ }^{10}$ In the case of uranium, $\mathrm{UCl}_{3}, \mathrm{UBr}_{3}$, and $\mathrm{UI}_{3}$ all become antiferromagnetic at low temperatures, with Neal temperatures of $22 \mathrm{~K}, 15 \mathrm{~K}$, and $3.4 \mathrm{~K}$, respectively. The decrease in the $\mathbf{T}_{\mathbf{N}}$ predictably follows the increase in the minimum metal-ion to metal-ion distance in the lattice; in $\mathrm{UCl}_{3}$, the minimum $\mathrm{U}-\mathrm{U}$ distance is $\mathrm{Ca} 4.3 \mathrm{~A}$, in $\mathrm{UBr}_{3}, 4.4 \AA$, and in $\mathrm{UI}_{3}, 5.4 \AA$. $\mathrm{PuCl}_{3}$ also becomes antiferromagnetic, with a $\mathrm{T}_{\mathrm{N}}$ of $4.5 \mathrm{~K}$. Note thit the ground state configurations of $\mathrm{U}^{3+}$ and $\mathrm{Pu}^{3+}$ are $\mathrm{f}^{3}$ and $\mathrm{f}^{5}$, and that no magretic interaction was observed for the neptunium(III) halides, whose ground state is $f^{4}$. 
Why do we feel that an $\mathrm{f}^{1}$ electron configuration may favor electronic exchange? A quote from the papur above in which the magnetic behavior of $\mathrm{AnX}_{3}$ was evaluated may hedp explain this:

"In a qualitative assessment of the factors that lead to cooperative magnetic phenomena - ferromagnetism or antiferromagnetism - electronic factors appear to be of major importance, crystal field splittings and metal-ion to metal-ion distance are of seconiary importance, and the detailed structure of the crystal appears to be a minor factor. With a single exception, cooperative magnetic phenomena were found for the two ions with half-integer values of $J, U^{3+}(J=9 / 2)$ and $\mathrm{Pu}^{3+}(\mathrm{J}=5 / 2\}$. 5m ions with half-integer I values necessarily have a magnetically degenerate lowest crystal field level (Kramers doublet), and thus will have a finite magnetic moment at low temperatures. Magnetic ordering can occur at temperatures sufficiently low that the exchange energy is greater than the thermal energy of the lattice. For $\mathrm{Np}^{3+} \mathrm{O}=4$ ), the crystal field splitting leads to a singlet ground level which is magnetically inactive. ${ }^{11}$ Cooperative magnetic phenomena may also occur for ions of integer J values with a multiplet lowest state split by the crystal field, such as in uranium dioxide $\left(T_{N}=29\right.$ $\mathrm{K}^{12}$ ). ${ }^{\text {"13 }}$

Thus, since we are dealing with a ground state $J=5 / 2$, we should have afi opportunity to observe magnetic interaction in our system. This, of course, also suggests that uranium(III) should be a good ion for seeing these effects ias it proves to be in $\mathrm{UCl}_{3}$ etc.); the problem seems to be in producing a discrete, dinuclear uranium(III) mo'?cule where the metal is stabilized in this oxidation state. Uranium(IV), on the other hand, would be a poorer choice for these systems, despite the apparently unique behavior of $\mathrm{UO}_{\mathbf{4}}$. 
What is the right bridging ligand to maximize the possibility of electron exchange in a dinuclear uranium(V) compound? It seems logical that the proper ligand to choose would have a $\pi$-conjugated system, aid therefore the para-phenylenediimido ligand, $\mathrm{NC}_{6} \mathrm{H}_{4} \mathrm{~N}^{4}$, seems a logical choice.

Several recent papers from Matta et. al. 14 have appeared utilizing this ligand. The first compounds were prepared by reaction of Mo(IV) with p-diezidobenzene, as shown below (Scheme 2-3):

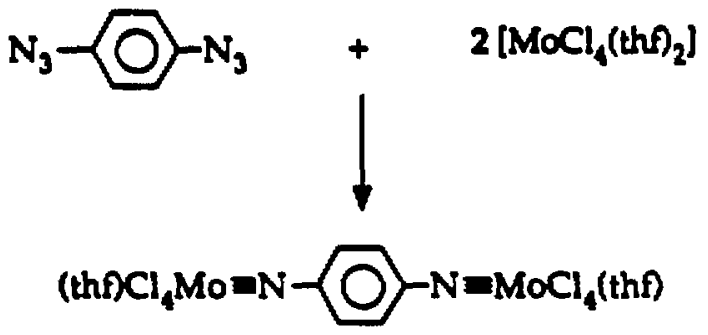

Scheme 2-3: Preparation of a molybdenum(vi) dilmide from p-diazidobenzene.

These dimolybdenum complexes may easily be reduced to form, in addition to the $M o(V I)-M o(V I)$ system, the $M o(V)-M o(V), M o(I V)-M o(I V)$, and Mo(III)-Mo(III) complexes. Unfortunately, no magnetic data has appeared concerning these materials. Maatta et. al. also synthesized several dirhenium complexes using the puphenylenediimido ligand, but once again, no magnetic information is available.

The two-electron oxidation of the metal in the scheme shown above is precisely the reaction we would like to perform with a uranium system, and therefore this ligand seemed to be a good starting point for our study of diimide complexes. 
In the remainder of this chapter, I will discuss the preparation and properties of our uranium diimide complexes. They will be presented one by one, with a particular focus on the comparison between the properties of the compounds using the para-phenylesediimido ligand and the metaphenylenediimido ligand, shown below (Figure 2-6):<smiles>[N]c1ccc([N+]#N)cc1</smiles><smiles></smiles>

Flgure 24: Structures of the para-and meta-phenylenediimido ligands. 


\section{Section 2.1: Preparation and Properties of $\left[\left(\mathrm{MeC}_{5} \mathrm{H}_{4}\right)_{3} \mathrm{U}_{2}\left(1,4-\mathrm{N}_{2} \mathrm{C}_{6} \mathrm{H}_{4}\right)\right.$}

Our first attempt at preparation of a uranium diimide involved chemistry analogous to that utilized by Matta in synthesizing the molybdenum diimides and our own work with the mononuclear uranium imides. Para-diaxidobenzene is easily prepared by diszotization of the corresponding diamine as shown below (Scheme 2-4):1s

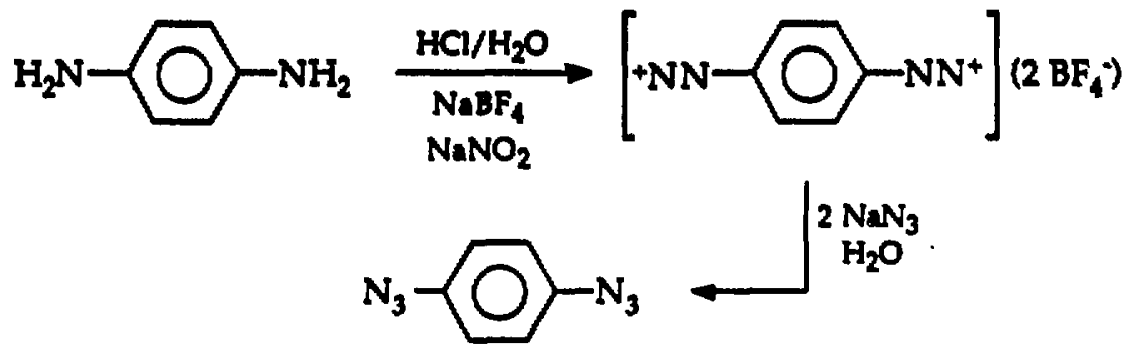

Scheme 2-4: Preparation of p-diazidobenzene.

When a solution of this diazide in ether was added to two molar equivalents of $\left(\mathrm{MeC}_{5} \mathrm{H}_{4}\right)_{3} \mathrm{U}($ thr), immediate evolution of nitrogen was observed, and a deep purple solution with a purple precipitate was obtained. Purple flakes could then be crystallized from warm toluene in fairly good yield.

The color of this material seemed to indicate that this compound was unusual when compared with the other uranium( $V$ imides we had prepared. As mentioned in Chapter 1, every one of those mononuclear materials was a very deep red or red/brown in color; this material was dark purple. The color led us to wonder if this material was indeed an analogous 
imide, but characterization of the complex (which will be described subsequently) confirmed that it is the diimide shown below (Figure 2-7):

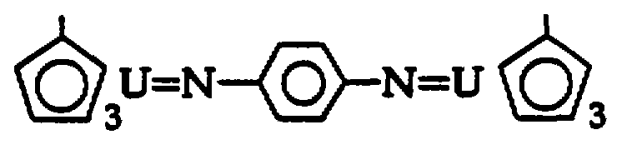

Figure 2-7: Structure of the uranium diimide $\left[\left(M \mathrm{C}_{3} \mathrm{H}_{4}\right)_{3} \mathrm{U}_{2}\left(1,4-\mathrm{N}_{2} \mathrm{C}_{6} \mathrm{H}_{4}\right)\right.$.

The ' $H$ NMR spectrum of this compound, which will be referred to as the "para-diimide," indicated a highly symmetric material. Four peaks are seen in the spectrum, which is shown later in this chapter in Figure 2-13. The 3:2:2 pattem of the $\mathrm{MeC}_{5} \mathrm{H}_{4}$ appears at $\delta=4.69 \mathrm{ppm}(\mathrm{Me}$ ), $\delta=-2.46 \mathrm{ppm}$ (ring $\mathrm{H}$ ) and $\delta=-9.01 \mathrm{ppm}$ (ring $\mathrm{H}$ ). These values are very similar to those obtained in the ${ }^{1} \mathrm{H}$ NMR spectra of the mononuclear phenylimides discussed in Chapter 1 (see Table 1-6). The fourth resonance is observed at $\delta=+15.11 \mathrm{ppm}$, and is due to the four chemically equivalent protons of the p-phenylenediimido ligand [which are magnetically inequivalent ( $\left.\left.A A^{\prime} A^{\prime \prime} A^{\prime \prime \prime}\right)\right]$ Since these protons may be viewed as being both ortho to one uranium(V) and meta to another uranium(V), we would expect this resonance to be intermediate between the usual ortho and meta resonances seen in the mononuclear phenylimide complexes, and this is indeed the case.

One particular feature of the NMR spectrum should be discussed. The linewidths of the protons in this spectrum are somewhat unusual when compared to other uranium(V) phenylimide complexes. The cyclopentadienyl methyl group has $v_{1 / 2}=6 \mathrm{~Hz}$, while in $\left(\mathrm{MeC}_{5} \mathrm{H}_{4} \mathrm{UNPh}\right.$, the analogous peak has $v_{1 / 2}=20 \mathrm{~Hz}$. Similarly, the cyclopentadienyl ring protori resonances in $\left(\mathrm{MeC}_{5} \mathrm{H}_{4} \mathrm{UNPh}\right.$ have $v_{1 / 2}=60$ and $49 \mathrm{~Hz}$, while in the para- 
diimide, these resonances have $v_{1 / 2}=23$ and $17 \mathrm{~Hz}$. We will not try to read too much into these numbers, since the bridged complex of this sort represents a different system from the simpler $\left(\mathrm{RC}_{5} \mathrm{H}_{4}\right)_{3} \mathrm{UX}$.

Other methods of characterization gave results consistent with the formulation of this material as $\left[\left(\mathrm{MeC}_{5} \mathrm{H}_{4}\right)_{3} \mathrm{U}\right]_{2}\left(\mathrm{p}-\mathrm{NC}_{6} \mathrm{H}_{4} \mathrm{~N}\right)$. The melting point, $261-263^{\circ} \mathrm{C}$, was high relative to the mononuclear compounds, and suggested a dinuclear material. The compound exhibited a molecular ion in the electron impact mass spectrum, at 1054 amu. The elemental analysis was also consistent, and the infrared spectrum appeared to be similar to the other uranium phenylimides.

The interesting measurement made on this compound was the magnetic susceptibility. The data is shown in Figures 2-8 and 2-9 as plots of $\chi_{M}$ vs. temperature and $1 / \chi_{M}$ vs. temperature, at magnetic fields of $5 \mathrm{kG}$ and 40 kG. From linear regression performed on the high temperature region (140 280K) of the $1 / \chi_{M}$ plot, a $\mu_{\text {eff }}=2.94$ B.M. $(\theta=-147 \mathrm{~K})$ was obtained. This yields a value of $\mu_{\text {eff }}=2.08$ B.M. per uranium atom, consistent with the high temperature results obtained in the mononuclear uranium( $V$ ) imides [See Table 1-7; the value obtained for $\left(\mathrm{MeC}_{5} \mathrm{H}_{4}\right)_{3} \mathrm{UNPh}$ from 140 - $280 \mathrm{~K}$ was 1.96 B.M.].

The fascinating feature of the magnetic data is the antiferromagnetic coupling obeserved with a Néel temperature $\left(T_{N}\right)$ of $18 \mathrm{~K}$. This is the first example of antiferromagnetic exchange observed in a discrete compound of the actinides (as opposed to in the extended lattices of $\mathrm{UCl}_{3}$ or $\mathrm{PuCl}_{3}$ ). The low temperature behavior of this material has been modeled by calculations performed by Dr. Norman Edelstein at the Lawrence Berkeley Laboratory. His calculations indicate an exchange interaction of approximately $\mathrm{J}=-19 \mathrm{~cm}^{-1}$. 
Fig. 2-8: Chi vs Temperature plot for the para-diimide.

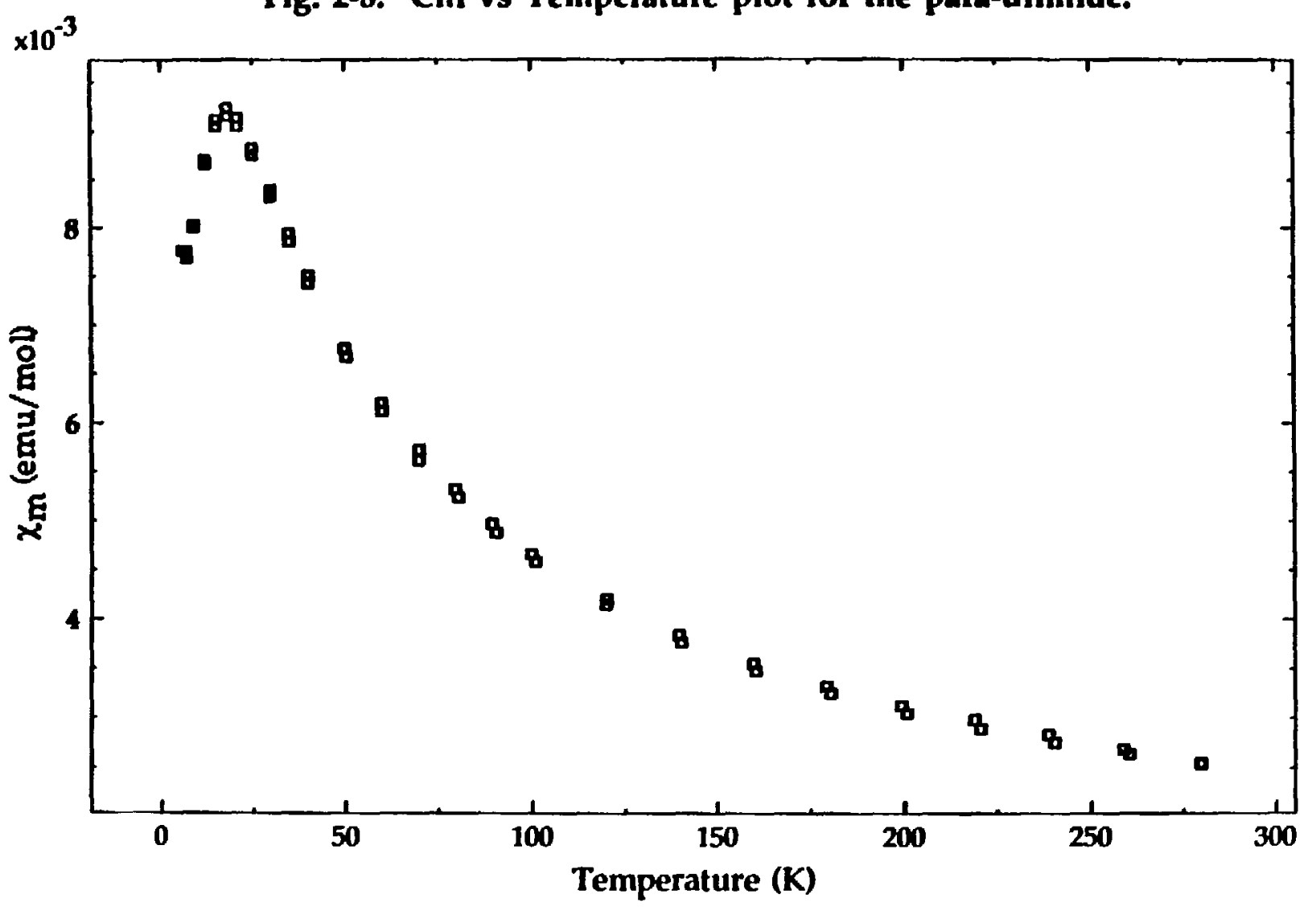


Fig. 2-9; 1/Chi vs Temperature plot for the para-diimide.

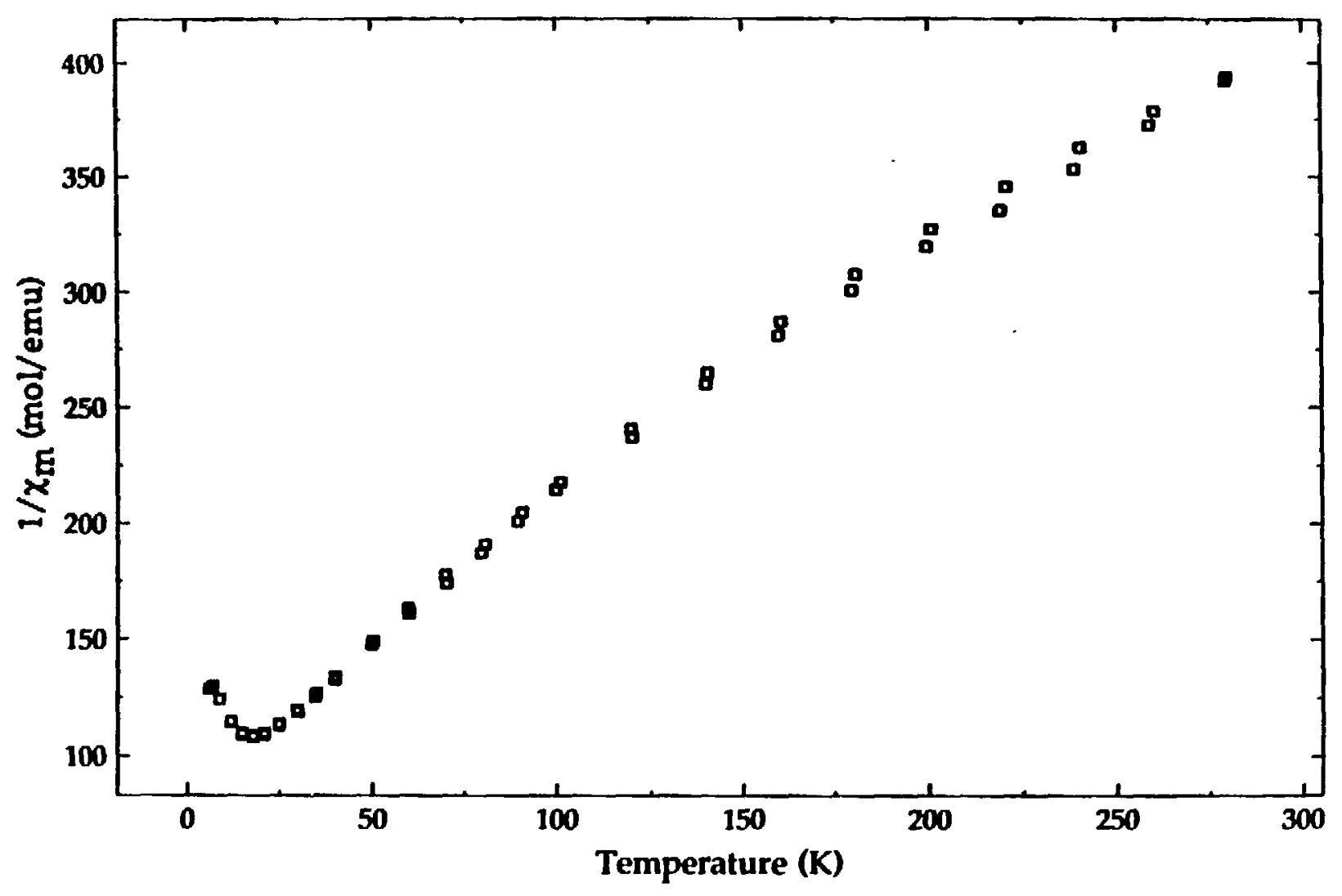


These calculations are discussed in more detail at the end of this chapter (Section 2.5).

The exchange interaction observed is fairly considerable when one takes into account the large distance between the metal centers. We can estimate this distance, based on the crystal structure of $\left(\mathrm{MeC}_{5} \mathrm{H}_{4} \mathrm{UNNh}_{3}\right.$ reported by Brennan and Andersen, 16 and using a very simple modeling program for the Apple Macintosh' called the "Molecular Editor." ${ }^{17}$ The model of the core of the compound is shown in Figure 2-10, and the U-U distance is ca. 9.6 A. This distance should be kept in mind for comparisons later in this chapter.

It should be noted that the magnetic behavior of this material is strongly dependent on the purity. Six independant magnetic susceptibility measurements were made on different samples, and although the $T_{N}$ remained consistent at $c a .16-18 \mathrm{~K}$, the data for the various runs differed considerably at extremely low temperatures (below 5-7 K). Because the susceptibility of the antiferromagnetic material $\left[\left(\mathrm{MeC}_{5} \mathrm{H}_{4}\right)_{3} \mathrm{U}_{2}\left(\mathrm{p}-\mathrm{NC}_{6} \mathrm{H}_{4} \mathrm{~N}\right)\right.$ becomes extremely small at these low temperatures, very small amounts of paramagnetic impurities will greatly affect the data, and in fact should dominate. This is an occurance that is not uncommon in attempting to measure the susceptibility of antiferromagnetic materials; 10 Ginsberg, in a review on magnetism, states that, "The largest effect [of a paramagnetic impurity] is found for clusters with antiferromagnetic exchange...In this case the impurity causes a minimum to appear in the susceptibility versus temperature curve at a temperature below the susceptibility maximum."19 Repeated attempts at recrystallizing the compound did not alleviate the problem. The consistancy of the $T_{N}$, and the reproducibility of the higher temperature data, however, give us great confidence in these results. Plots of 


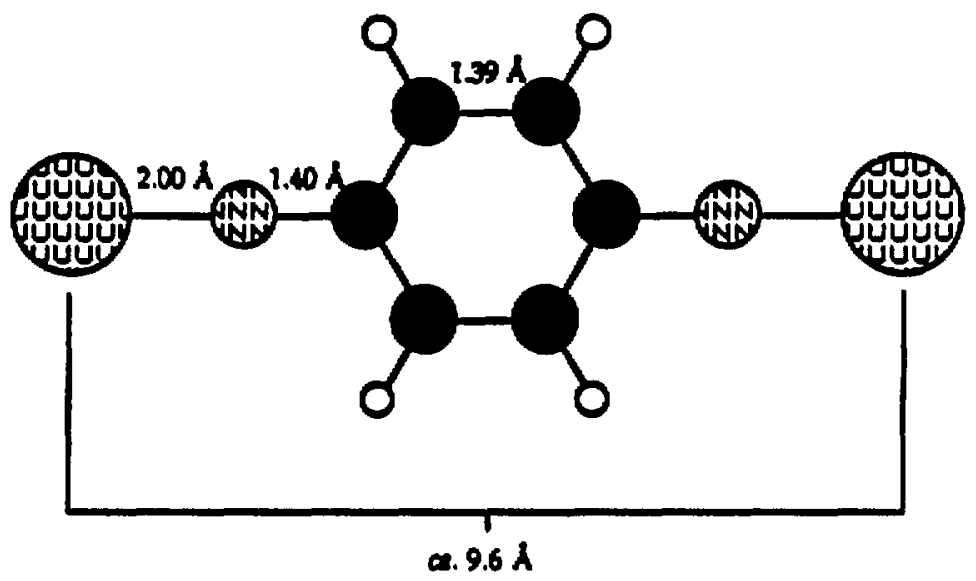

Figure 2-10: Para-Diimide Molecular Editor ${ }^{\circ}$ Model 
the runs made using several samples to show the variation are shown in Figure 2-11.

The observation that the spins on each uranium of the para-diimide antiferromagnetically couple may be rationalized by a super-exchange pathway. This can be demonstrated by examining several possible resonance structures that may be drawn for this compound. Two of these structures are shown in Figure 2-12. These resonance forms are not meant to suggest any type of ground state structure for the material, but instead are used to show the way a completely conjugated $\pi$-system may be drawn which extends from one uranium center across the bridging ligand to the other metal. It is possible that the presence of this $\pi$-conjugation is what allows the two uranium $\mathrm{f}^{1}$ centers to "communicate" electronically. (Please note that a large number of other resonance structures may be drawn to represent this compound; these three are simply meant to illustrate a point and are by no means exclusive.)

Additionally, Hendrickson et. al. have done considerable magnetic investigations on compounds containing related ligands. ${ }^{20}$ They found that dinuclear copper complexes containing a p-phenylenediamine bridging ligand ( $\mathrm{p}-\mathrm{H}_{2} \mathrm{NC}_{6} \mathrm{H}_{4} \mathrm{NH}_{2}$ ) exhibit antiferromagnetic coupling. For example, the complex $\left[\mathrm{Cu}_{2}(\text { tren) })_{2}(\mathrm{PPD})\right]\left[\mathrm{NO}_{3}\right]_{4}$ (tren = 2,2',2"-triaminotriethylamine; PPD = p-phenylenediamine) becomes antiferromagnetic with $T_{N}=67 \mathrm{~K}$ and an exchange interaction $\mathrm{J}=-35.1 \mathrm{~cm}^{-1}$. The authors discuss possible exchange mechanisms in some detail using molecular orbital calculations, and conclude that the pathway for the exchange is primarily a $\sigma$-type pathway. However, it must be noted that this bridging ligand is a $\sigma$-donating ligand with $\mathrm{sp}^{3}$ hybridized nitrogens and therefore should have $\mathrm{Cu}-\mathrm{N}-\mathrm{C}$ angles which are far from linear, with no p-orbital on the nitrogen parallel to the 
Fig. 2-11: Chi vs $T$ plot for six para-diimide samples.

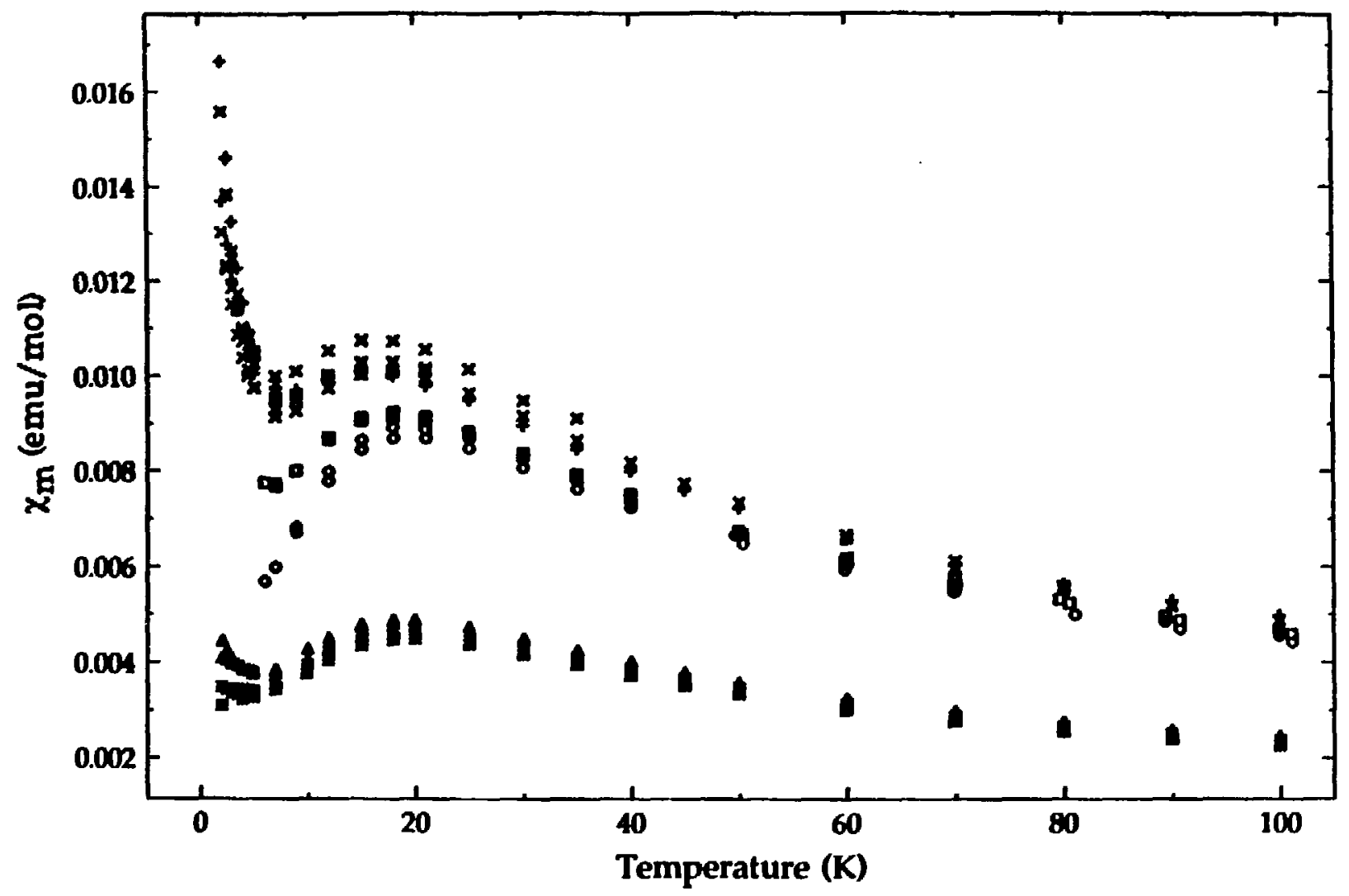



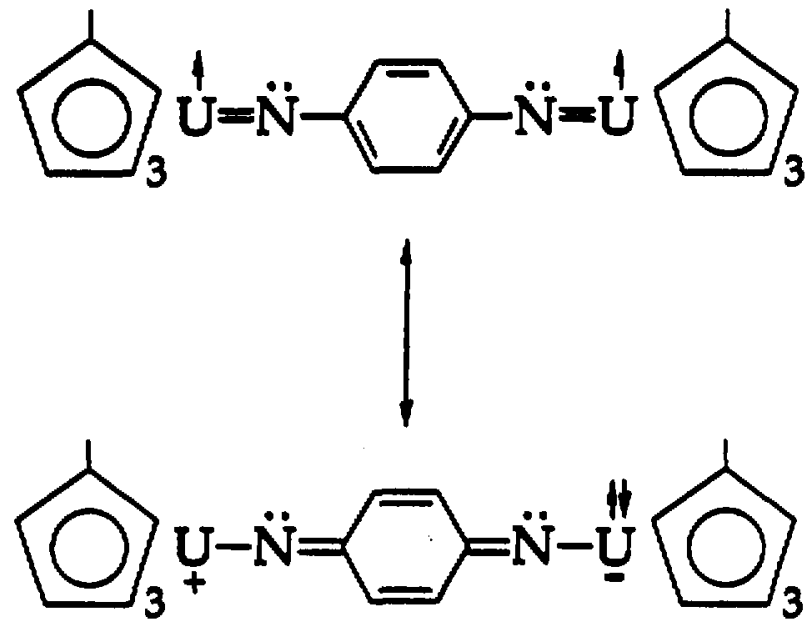

Figure 2-12: Resonance structures of the para-diimide attempting to demonstrate the existance of a completely conjugated $x$-system across the ligand. 
aromatic system to conduct the exchange. This should not be the case in a system like ours in which each amine has been doubiy deprotonated.

It is possible that both the unusual color and the NMR linewidths observed for the para-diimide complex of uranium reflect the unusual electronic nature of this compound. We decided that it would, of course, be interesting to synthesize a second uranium dilmide that does not have the same type of conjugated x-system. We hoped to answer the following questions by performing this experiment. Does the non-conjugated material exhibit electronic exchange between the uranium centers? Will the nonconjugated diimide show the sarne surprising color and NMR linewidths? What other differences in properties will we observe in a dimide made with a non-cinjugated bridge? These questions are answered in the next section. 


\section{Section 2.2: Preparation and Properties of $\left[\left(\mathrm{MeC}_{5} \mathrm{H}_{4}\right)_{3} \mathrm{U}\right]_{2}\left(1,3-\mathrm{N}_{2} \mathrm{C}_{6} \mathrm{H}_{4}\right)$}

In deciding which diimide to synthesize in order to atter pt to answer the questions posed above, se turned to an orgaric chemist's viev: of these materials. While a conjugated $x$-system may be drawn to bridge the metal centers using the p-phenylenediimido ligand, it is a basic organic chemistr $j$ fact that similar resonance structures may not be drawn for metadisubstituted phenyl rings.

For this reason, we synthesized the compound mata-diazidobenzene by a similar diazotization method as that used to make other phenylazides. ${ }^{21}$ An ether solution of ihis diazide was then allowed to react with two molar equivalents of $\left(\mathrm{MeC}_{5} \mathrm{H}_{4}\right)_{3} \mathrm{U}($ th? $)$, yielding immediate gas evolution and a color change to a very deep red. Crystallization of the materiai from warm toluene solution gave red/browit needles, presumably of the "Ireta-diir:ide," $\left[\left(\mathrm{MeC}_{5} \mathrm{H}_{4}\right)_{3} \mathrm{U}\right]_{2}\left(\mathrm{~m}-\mathrm{NC}_{6} \mathrm{H}_{4} \mathrm{~N}\right)$.

The first indication that the meta- and para-diimides differed substantially in their properties was the color. However, a second indication was quickly seen in the ${ }^{2} \mathrm{H}$ NMR of the meta-diimide. The ${ }^{1} \mathrm{H}$ NMR spectra of both the meta-diimide and the para-diimide are shown in Figure 2-13. The most glaring differences be!ween the two spectra are the linewidths of the resonances arising from the $\mathrm{MeC}_{5} \mathrm{H}_{4}$ groups. At room temperature, the resonances from these rings in this meta-diimide appear at $\delta=4.46 \mathrm{ppm}(\mathrm{Me})$, $\delta=-2.57$ ppm (ring $\mathrm{H}$ ), and $\delta=-10.53 \mathrm{ppm}$ (ring H), fairly similar positions to the matching resonances in the para-diimide spectrum. However, while the resonance from the methyl group has $v_{1 / 2}=6 \mathrm{~Hz}$ in the para-diimide, this resonance has $v_{1 / 2}=18 \mathrm{~Hz}$ in the meta-diimide. Similarly, the 


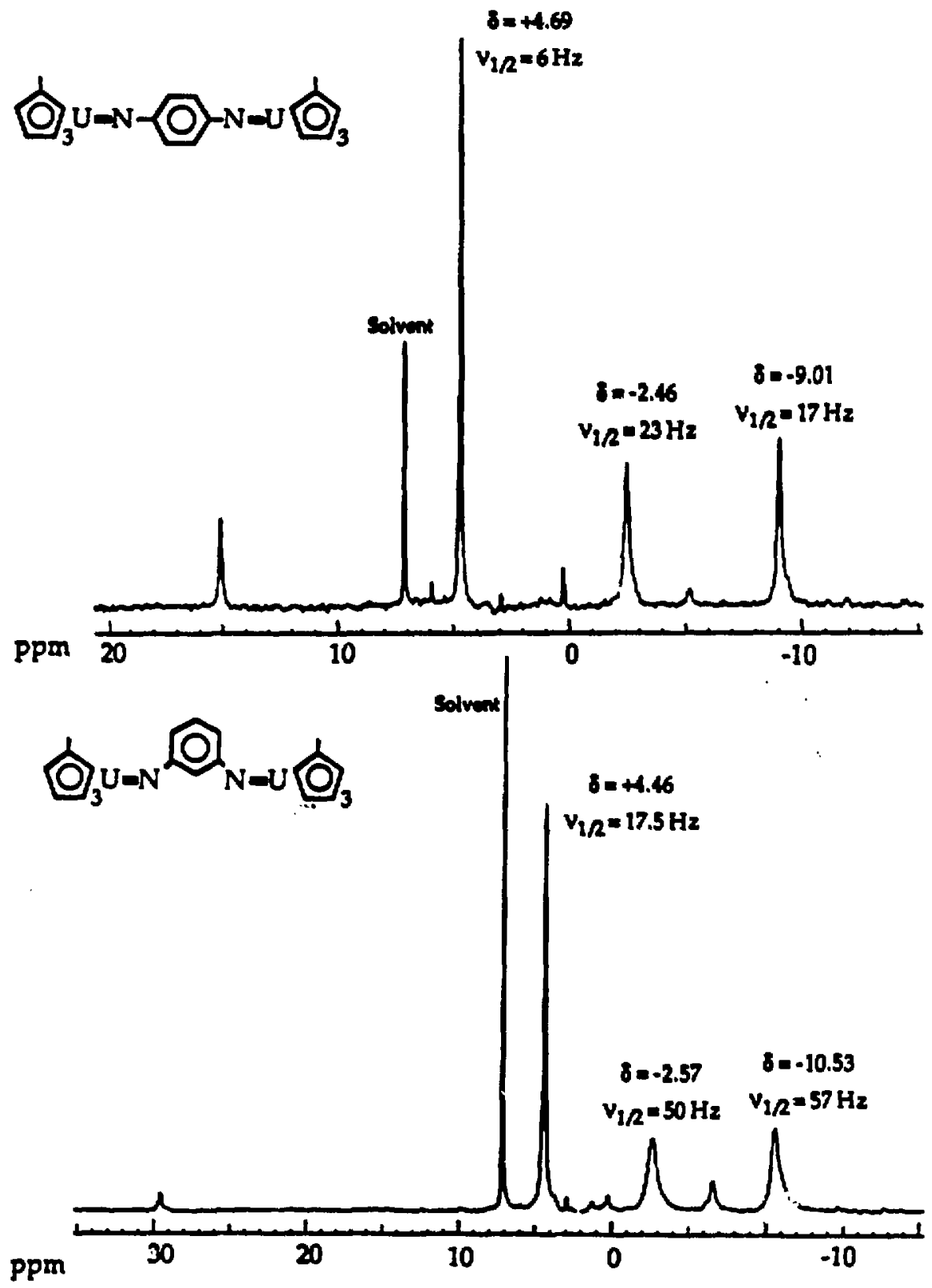

Figure 2-13: ' ${ }^{\mathrm{H}}$ NMR spectra of the para- and meta-dijmides in $\mathrm{C}_{6} \mathrm{D}_{6}$. 
methylcyclopentadienyl ring protons, with widths of $v_{1 / 2}=23$ and $17 \mathrm{~Hz}$ in the para-diimide, have $v_{1 / 2}=57$ and $50 \mathrm{~Hz}$ in the meta compound. These linewidths are much more typical of those seen in the mononuclear uranium( $V$ imides, suggesting that there was indeed something particularly unusual about the para-diimide.

In order to assist us in looking at the ${ }^{1} \mathrm{H}$ NMR resonances of the phenylimide protons, they have been assigned as shown in Figure 2-14 below:

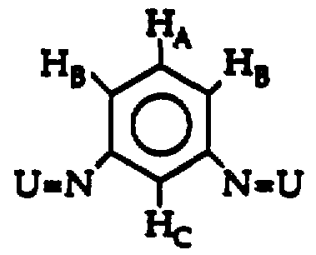

Figure 2-14: Proton designations in the meta-phenylenediimido ligand.

Proton $H_{A}$ is meta to both of the imide functionalities: As we have seen in previous examples of uranium phenylimides, the meta proton is shifted downfield, to $\delta=c a$. 18-21 ppm in the mononuclear compounds. In this case, having two meta imido groups shifts the resonance even further; it is observed at $\delta=+29.58 \mathrm{ppm}$ at room temperature. The two equivalent protons on the phenyl ring, $H_{B}$ are para to one imide and ortho to the other. Their resonance is observed at $\delta=-6.54 \mathrm{ppm}$.

The remaining phenyl ring proton, $\mathrm{H}_{C}$, is ortho to both imide groups. Perhaps because of its close proximity to the rwo uranium(V) centers, the resonance for $\mathrm{H}_{\mathrm{C}}$ is relatively broad at room temperature and is not observed in the spectrum. A variable temperature ${ }^{1} \mathrm{H}$ NMR spectrum helped to locate this resonance. At $59^{\circ} \mathrm{C}$ in perdeuterated toluene, it appears at $\delta=-0.46 \mathrm{ppm}$ with $v_{1 / 2}=32 \mathrm{~Hz}$. The resonance gets somewhat sharper at higher 
temperatures, shifting to $\delta=-0.77 \mathrm{ppm}$ at $80^{\circ} \mathrm{C}, \delta=-0.98 \mathrm{ppm}$ at $96^{\circ} \mathrm{C}$, and $\delta=$ $-1.22 \mathrm{ppm}$ at $110^{\circ} \mathrm{C}$. A plot of $\delta(\mathrm{ppm})$ vs. $1 / \mathrm{T}\left(\mathrm{K}^{-1}\right)$ is linear, showing that the material follows Curie-Weiss behavior in the VT-NMR experiment. Extrapolating the data to $30^{\circ} \mathrm{C}$, we find a value of $\mathrm{ca} . \delta=+0.09 \mathrm{ppm}$ for the $\mathrm{H}_{\mathrm{C}}$ resonance. Assuming that this resonance is fairly broad, and since it arises in a region of the spectrum where we may find small diamagnetic impurities, it is not surprising, that it is difficult to observe at room temperature.

Other characterization techniques were both interesting as a contrast with the para-diimide as well as consistent with our formulation of the meta compound. The melting point was again high, $213-215^{\circ} \mathrm{C}$, as expected for a dimetallic uranium compound. Interestingly, a gas phase EI mass spectrum could not be obtained for this material; no molecular jon was observed. This suggests that the para-diimide may have some type of extra stability imparted by the $\pi$-conjugation of the bridging ligand which is unavailable to the meta-diimide, allowing the para compound to remain intact in the gas phase while the meta disproportionates. Air-sensitive techniques for Fast Atom Bombardment Mass Spectroscopy were utilized, using 18-crown-6 and tetraglyme as solvents. This yielded at strong $\mathrm{M}^{+}$at 1054 amu.

The measurement of the magnetic susceptibility of the meta-diimide seems to strongly support our theory that the x-conjugation of the bridging ligand is vital to electron exchange in these compounds. The data is shown in Figures 2-15 and 2-16 ( $\chi_{M}$ vs. $T$ and $1 / \chi_{M}$ vs. $T$; magnetic fields of 5 and 40 $k G)$. The linear regression on the high temperature region (140-280 K) of the $1 / \chi_{\mathrm{M}}$ plot yields a $\mu_{\mathrm{eff}}=3.00$ B.M. $(\theta=-134 \mathrm{~K})$, or $\mu_{\text {eff }}=2.12$ B.M. per uranium. This is once again consistent with the high temperature data on $\left(\mathrm{MeC}_{5} \mathrm{H}_{4}\right)_{3} \mathrm{UNPh}\left(\mu_{\text {eff }}=1.96\right.$ B.M.) and the para-diimide $\left(\mu_{\text {eff }}=2.08\right.$ B.M.). 
Fig. 2-15: Chi vs Temperature plot for the meta-diimide.

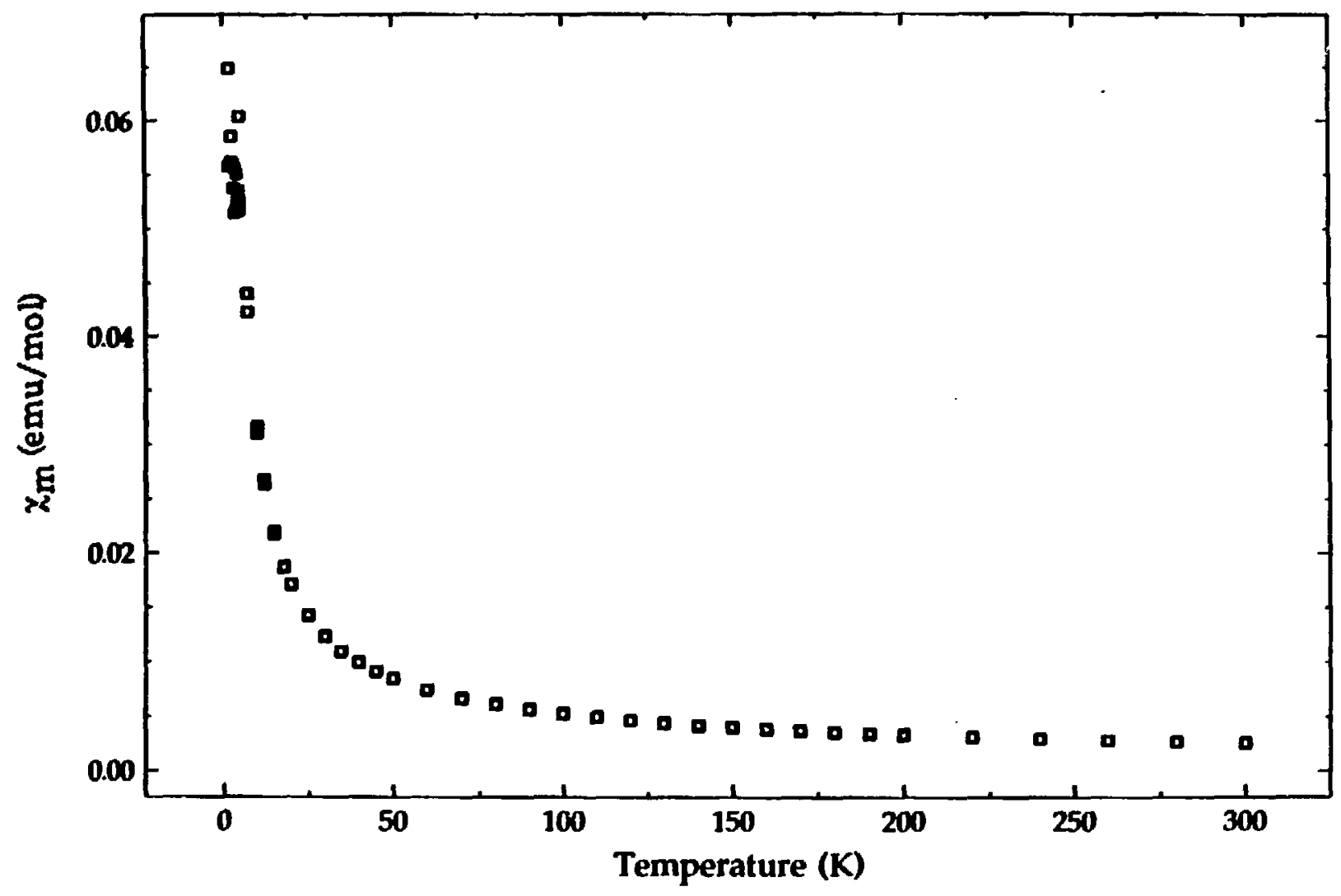


Fig. 2-16: 1/Chi vs Temperature plot for the meta-diimide.

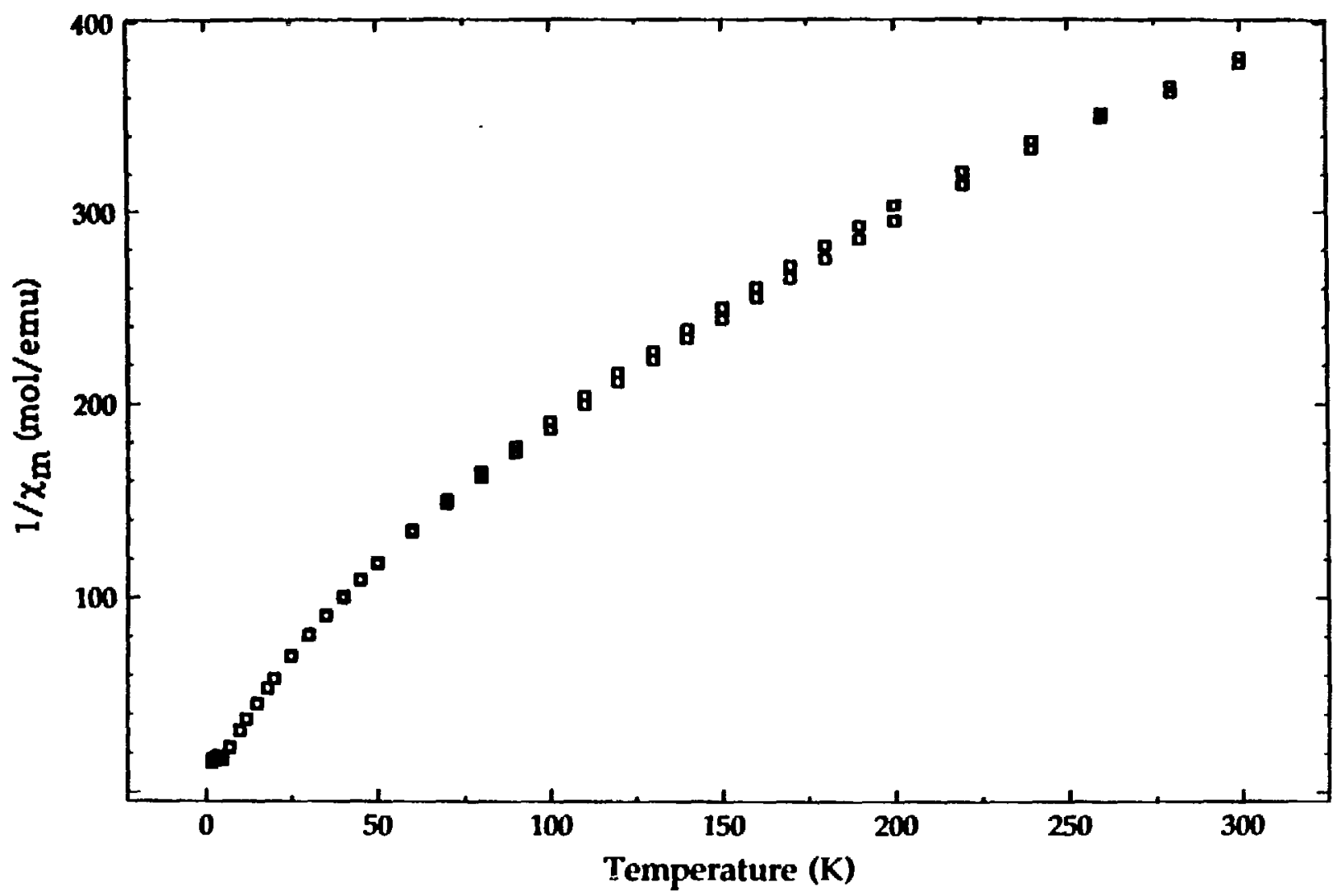


Obviously, the most striking feature of the magnetic measurements on the meta-diimide is the lack of antiferromagnetic coupling, even down to temperatures of $2 \mathrm{~K}$. In the low temperature region $(5-40 \mathrm{~K})$, the linear regression yields a value of $\mu_{\text {eff }}=1.84$ B.M. $\left(\theta=-4.0 \mathrm{~K} ; \mu_{\text {eff }}=1.30\right.$ B.M. per uranium). Again, this may be favorably compared with the mononuclear $\left(\mathrm{MeC}_{5} \mathrm{H}_{4}\right)_{3} \mathrm{UNPh}$, which showed a low temperature $\mu_{\text {eff }}=1.25 \mathrm{~B} . \mathrm{M}$.

By modelling the distance between the metal centers using the same software used for the para-diimide, a uranium-uranium distance of $c a .8 .3 \AA$ was obtained (Figure 2-17). This is a shorter distance than in the para-diimide, strongly suggesting that the electronic nature of the bridge, rather than simply the distance between the metals, is the dominant cause for whether antiferromagnetic exchange will or will not occur.

The differences between the susceptibilities of these compounds is graphically demonstrated in Figures 2-18 and 2-19, showing the overlaid $1 / \chi_{M}$ vs. $T$ and $\chi_{M}$ vs. $T$ plots for the para- and meta-diimides. Note the extremely strong similarity in both the shapes and magnitudes of the curves for temperatures greater than $\mathrm{ca} .80 \mathrm{~K}$. It is at this point where the curves begin to separate, with paramagnetism continuing to dominate the behavior of the meta-diimide, while the antiferromagnetism begins to become dominant in the para-dimide.

Two other plots (Figures 2-20 and 2-21) show how strongly the magnetic behavior of the meta-diimide mirrors that of the typical mononuclear complex. The scale on the left of these plots is for $\left(\mathrm{MeC}_{5} \mathrm{H}_{4}\right)_{3} \mathrm{UNPh}$, while that on the right is for $\left[\left(M e \mathrm{C}_{5} \mathrm{H}_{4}\right)_{3} \mathrm{U}\right]_{2}\left(\mathrm{~m}-\mathrm{NC}_{6} \mathrm{H}_{4} \mathrm{~N}\right)$.

Note the extreme similarity between the two data sets. 


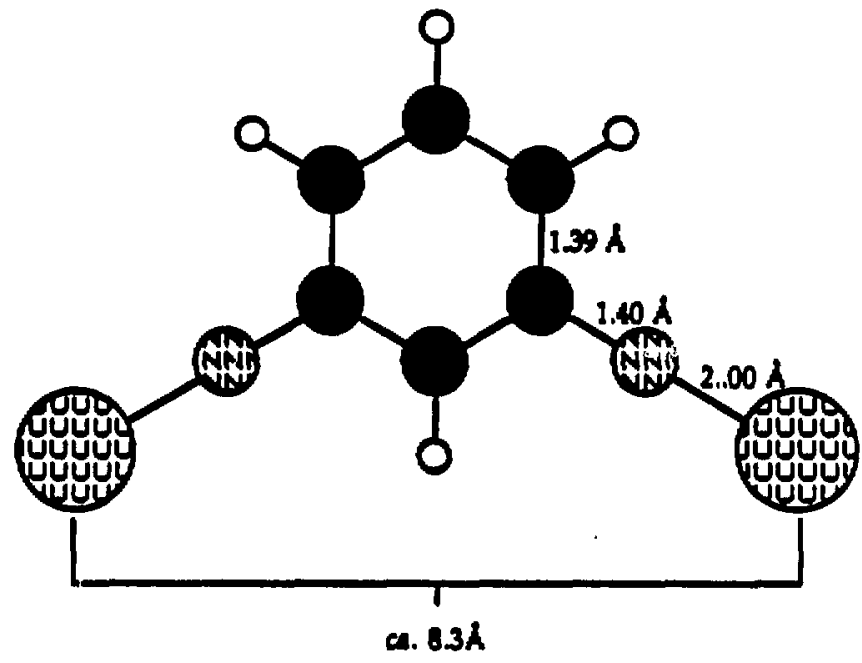

Figure 2-17: Meta-Diumide Molecular Editor ${ }^{\circ}$ Model 
Fig. 2-18: 1/Chi vs $T$ plot for the para- and meia-diimides.

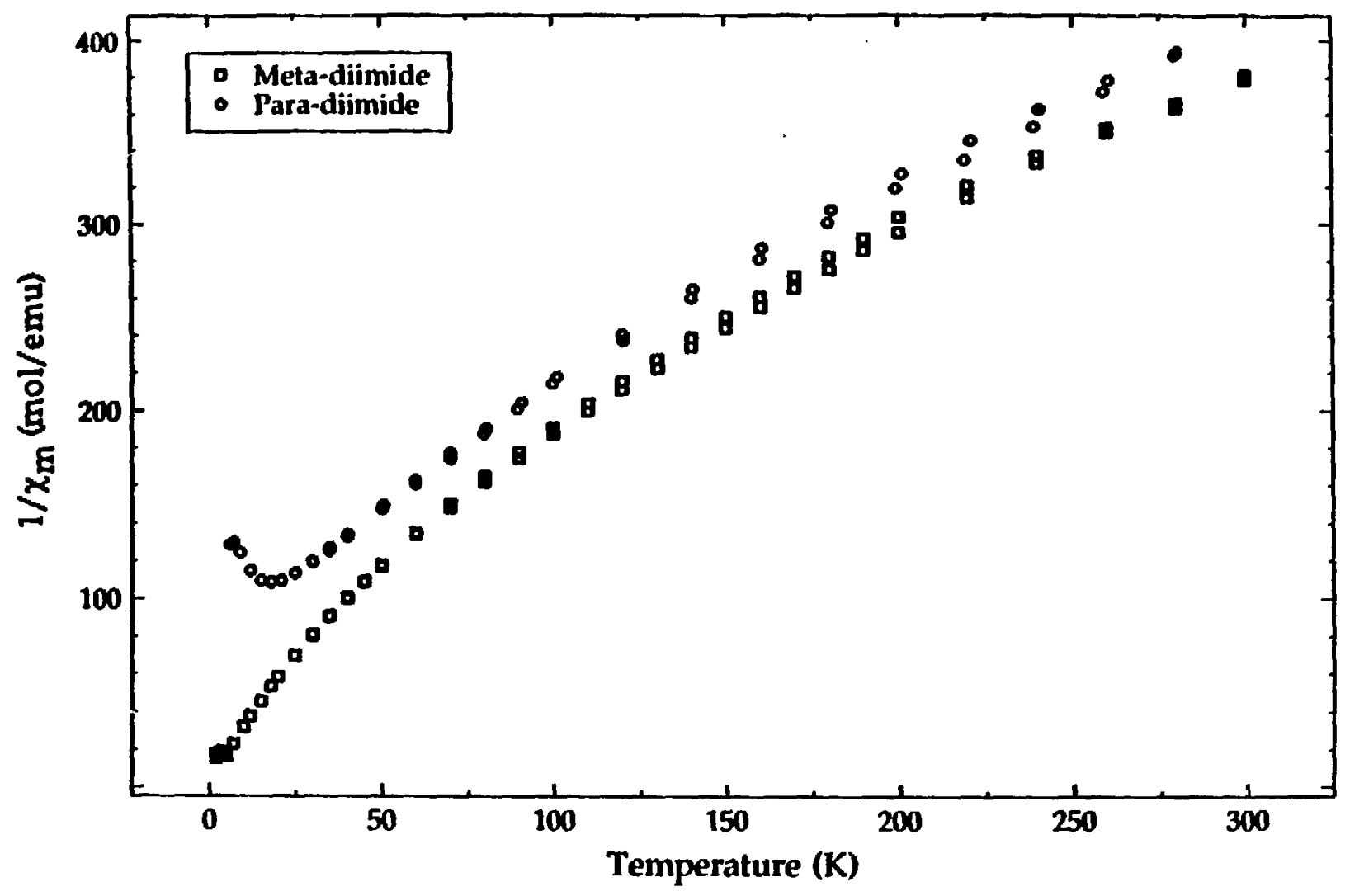


Fig. 2-19: Chi vs $T$ plot for the para- and meta-diimides.

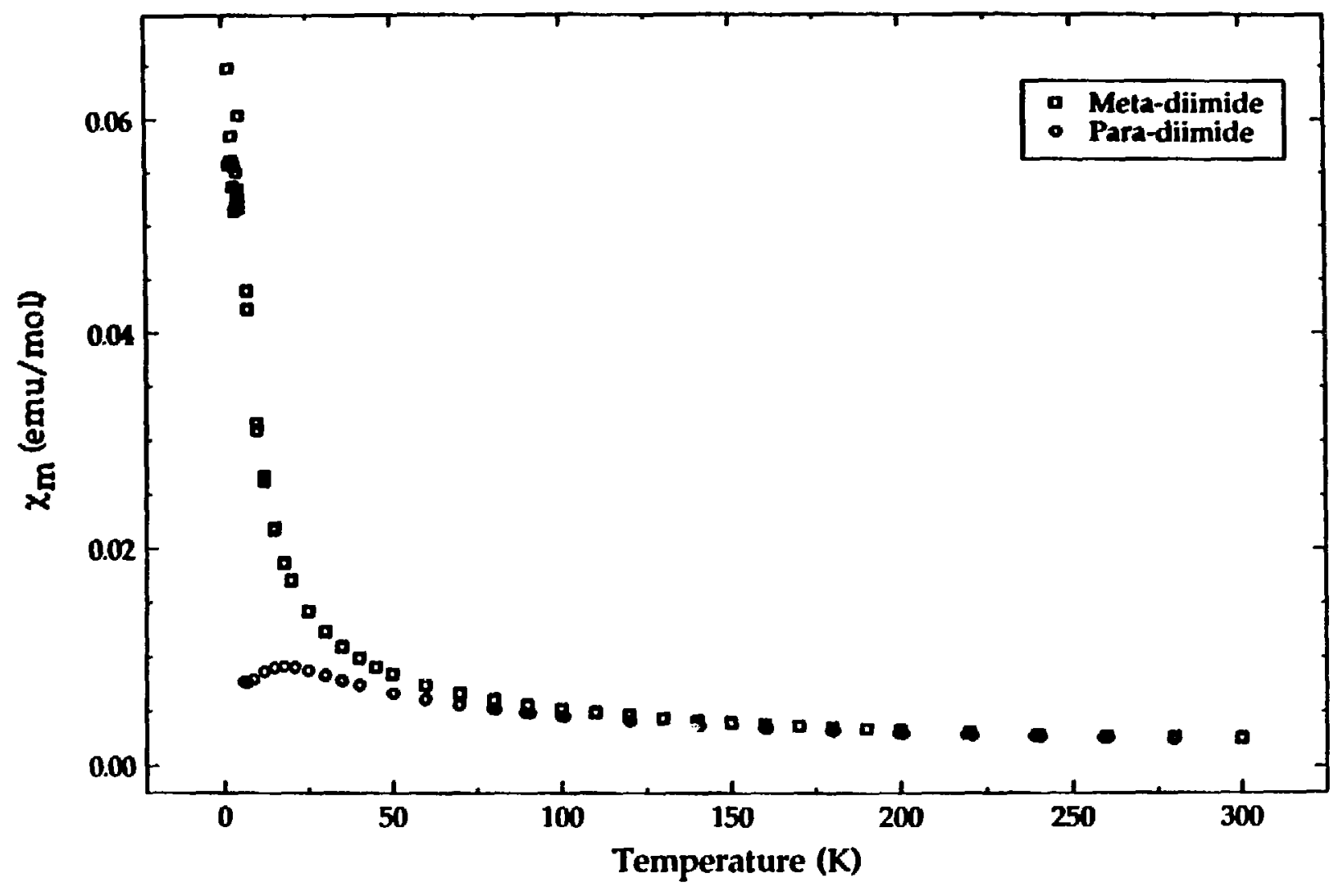




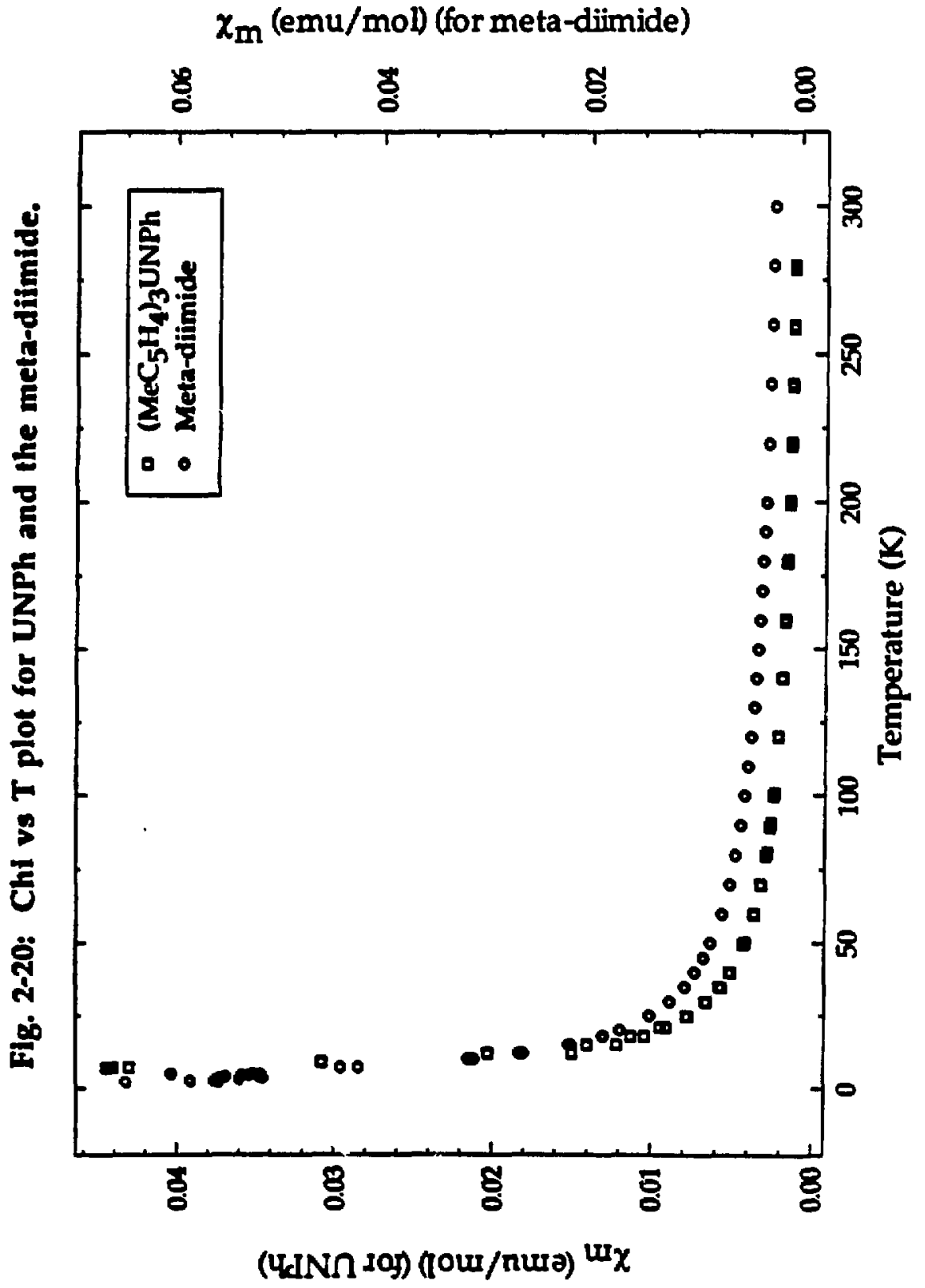


Fig. 2-21: 1/Chi vs $T$ plot for UNPh and the meta-diimide.

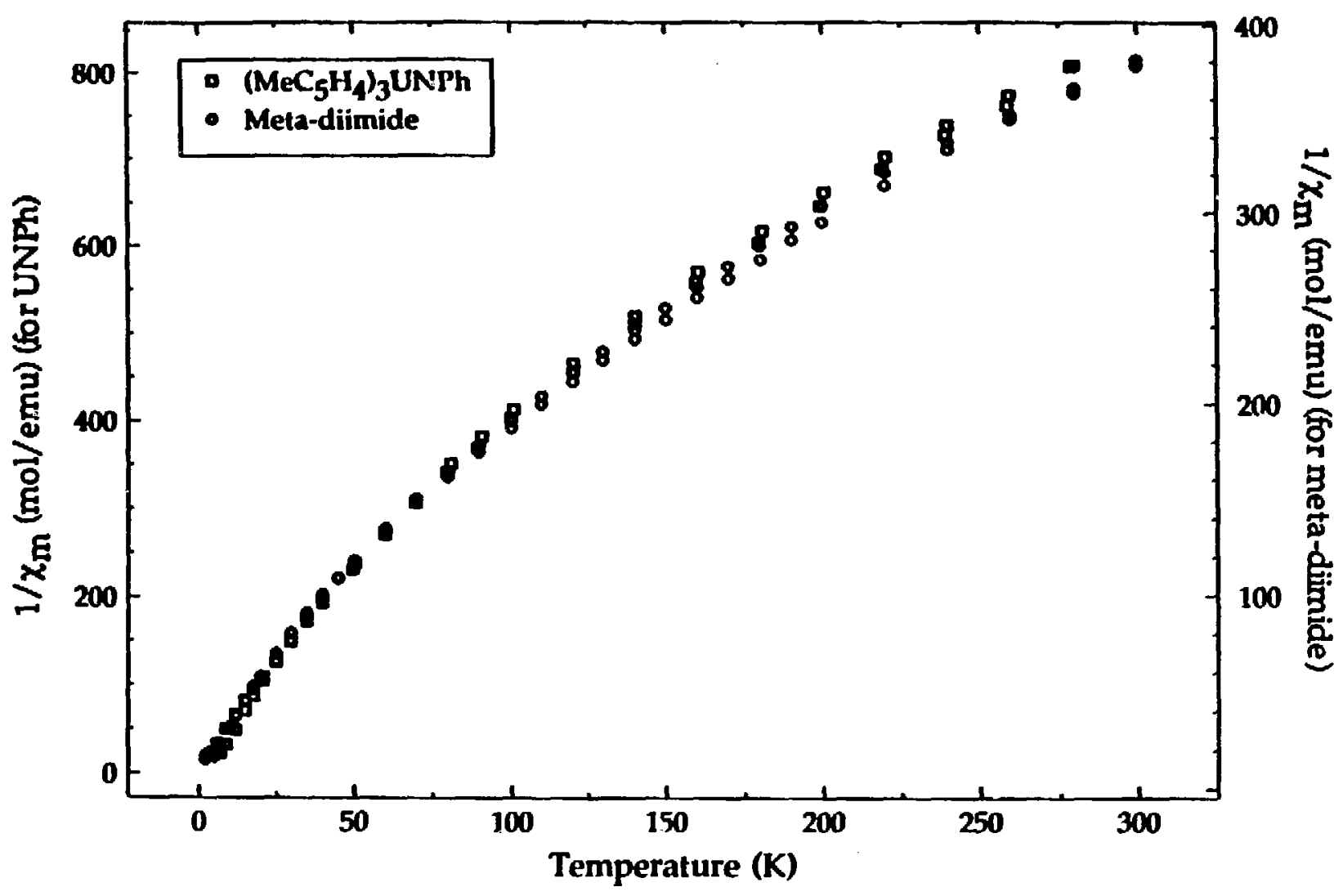


To sum up these results, it certainly appears that using the $\pi$-conjugation of the bridging para-phenylenediimido ligand gives us a very plausible explanation of the magnetic exchange observed in the para-diimide uranium(V) system. The lack of a similar conjugation in the metaphenylenediimido ligand and the subsequent finding that the meta-diimide uranium(V) complex shows no electron exchange strongly supports this argument.

In the next section, we take a brief look at two other dinuclear uranium(V) diimides. Both of these dilmides were synthesized to see whether other conjugated materials could produce any electronic exchange. 


\section{Section 2.3: Two Other Diimides of Uranium(V)}

Before going into details about the synthesis and properties of these two other diimides, it should be mentioned that these compounds were synthesized with only the magnetic susceptibility measurements in mind. The compounds were recrystallized prior to measuring the susceptibility, however additional characterization was not done for either of the materials. We are quite confident that the compounds are what we claim them to be, especially for three main reacons: the organic and organometallic starting materials were quite pure, the reactions are directly analogous to those used to product the para- and meta-diimides, and the ${ }^{2} H$ NMR spectra of the materials are, by comparison, quite similar to the other imides and diimides.

\subsection{1: Preparation and Properties of a Diuranium Stilbene Diimide}

The first of our other diimides was based upon the stilbene (1,2diphenylethylene) unit. It is well known in organic chemistry that an extended $\pi$-conjugation exists in the trans form of stilbene, although steric effects from the interaction of the two phenyl rings greatly decreases this conjugation in the cis-stilbene. 22
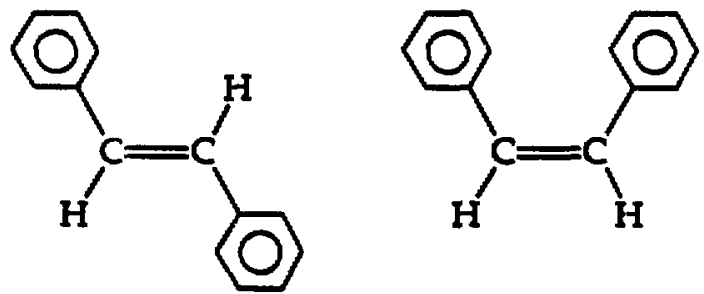

Figure 2-22: The trans and cis forms of stilbene. 
4,4' diazidostilbene (Figure 2-23) is easily prepared from the corresponding diamine by diazotization (cis and trans isomers).

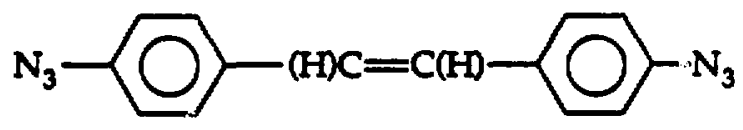

Figure 2-23: 4,4'-diaridostilbene.

When the stilbene dizzide was allowed to react with two molar equivalents of $\left(\mathrm{MeC}_{5} \mathrm{H}_{4} \mathrm{U}\right.$ (th), gas evolution was observed instantly and the color darkened to a deep red. Cystallization from toluene afforded brown needles. The high melting point of these needles $\left(241-245^{\circ} \mathrm{C}\right)$ suggested that wa had successfully synthesized the desired "stilbene-diimide". Similarly with the meta-diimide, the stilbene-diimide gave no nolecular ion in the E.I.-M.S. Air-sensitive F.A.B.-M.S. was performed on the sample using crown ether, and a molecular ion was observed at 1156 anu, in agreement with the calculated molecular weight. The 'H NMR spectrum of the material was again consistent with the formulation of a stilbene-diimide. The 3:2:2 pattern typical of the $\mathrm{MeC}_{5} \mathrm{H}_{4}$ was observed at $\delta=3.99 \mathrm{ppmi}, \delta=-3.33 \mathrm{ppm}$, and $\delta=$ $-10.68 \mathrm{ppm}$. The ring methyl had $v_{1 / 2}=22 \mathrm{~Hz}$, and the methylcyclopentadienyl ring protons had $v_{1 / 2}=60$ and $62 \mathrm{~Hz}$. These values are quite similar to those observed in the meta-diimide.

There should be three other resonances in the spectrum, labelled as $\mathrm{H}_{A}$, $H_{B}$, and $H_{C}$ below (Figure 2-24): 


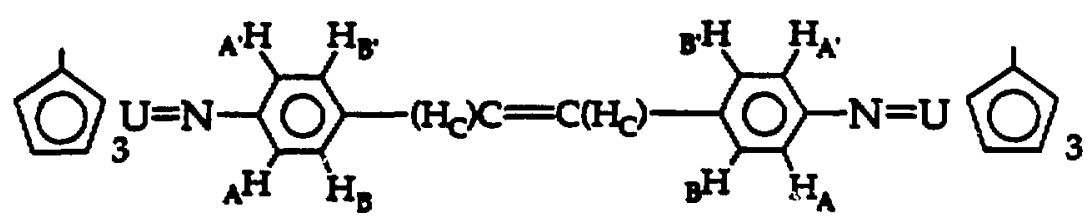

Jigure 2-24: Labelling of protons in the stibbene-diimide.

The meta protons of the phenyl rings (H) apparar to be at $\delta=+19.40 \mathrm{ppm}$. This is consistent with the mononuclear, para-substituted uranium phenylimides discusead in Chapter 1, not a surprising result since the paramagnetic metal centers are so fur apart and we may expect this material to behave like a simple para-substituted phenylimide. Using this assumption, the ortho protons $\left(\mathrm{H}_{A}\right)$ should be found in the vicinity of +2 to $+5 \mathrm{ppm}$. A shoulder on the large peak at $\delta=+3.99$ is observed, and is assigned to the ortho protons. Recall that (at room temperature) the ortho protons in $\left(\mathrm{MeC}_{5} \mathrm{H}_{4}\right)_{3} \mathrm{UNPh}$ overlap with the cyclopentadienyl methyl resonance (see Chapter 1). The ethylene protons $\left(\mathrm{H}_{\mathrm{C}}\right)$ are observed at $\delta=+9.48 \mathrm{ppm}$.

The magnetic susceptibility of the stilbene-diimide is shown in Figure 2-25 as $\chi_{M}$ vs. $T$ and Figure $2-26$ as $1 / \chi_{M}$ vs. $T$ (5 and $40 \mathrm{kG}$ fields). The data, like that for the meta-diimide, shows no indication of magnetic interaction between the metal centers. Linear regression was performed on the $1 / \chi_{M}$ plot. This yields a high temperature $\mu_{\text {eff }}=2.73$ B.M. $\left(\theta=-48 \mathrm{~K} ; \mu_{\text {eff }}=1.93\right.$ B.M. per uranium), which compares favorably with the values obtained for the other uranium( $V$ imides, both mononuclear and dinuclear. The low temperature $(5-40 \mathrm{~K})$ value is $\mu_{\text {eff }}=1.94$ B.M. $\left(\theta=-6.3 \mathrm{~K} ; \mu_{\text {eff }}=1.37\right.$ B.M. $)$ per uranium. This is, once again, in the expected region for the uranium imides which show no unusual coupling. 
Fig. 2-25: Chi vs Temperature plot for the stilbene-dilimide.

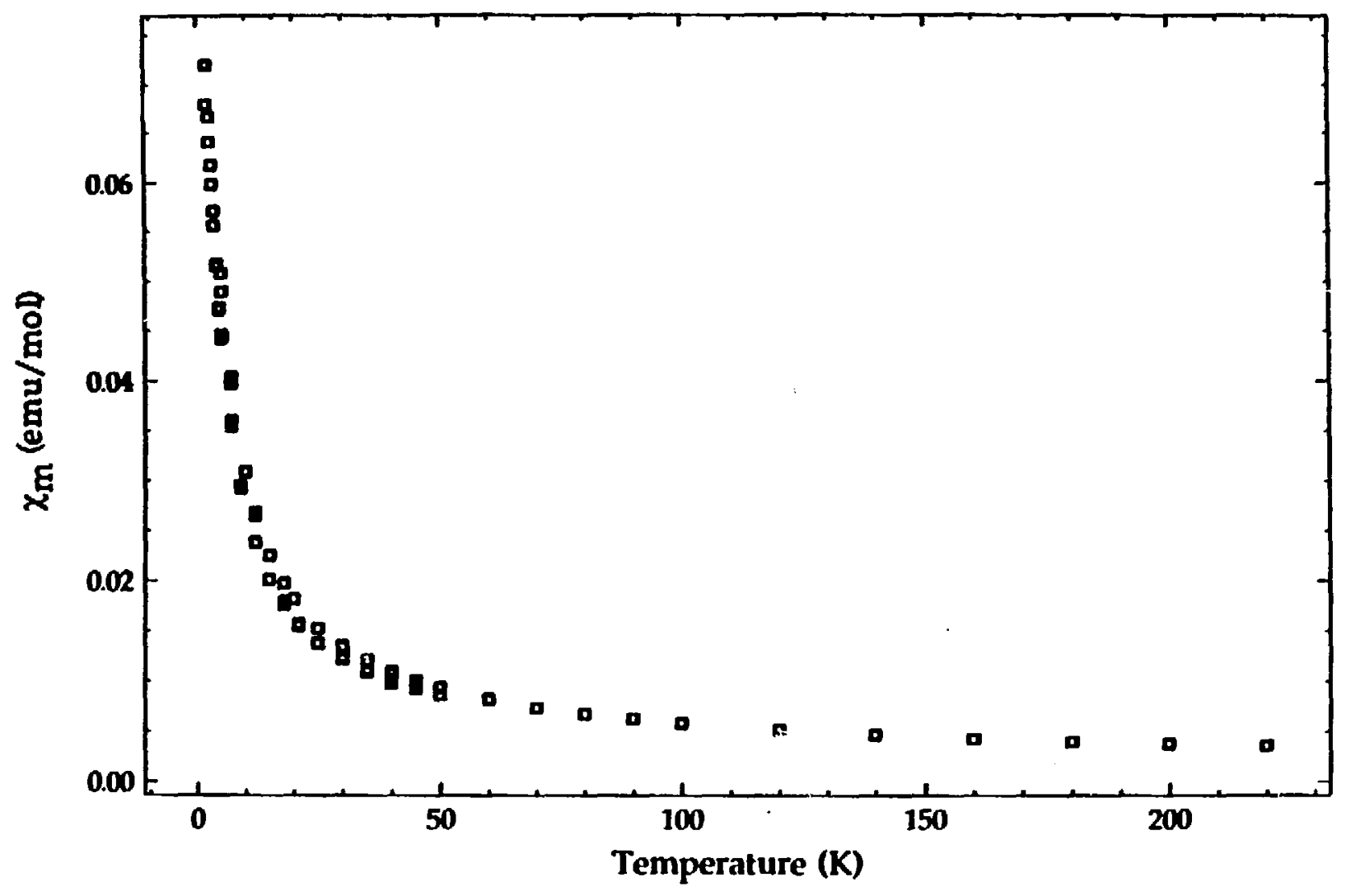


Fig. 2-26: 1/Chi vs Temperature plot for the stilbene-diimide.

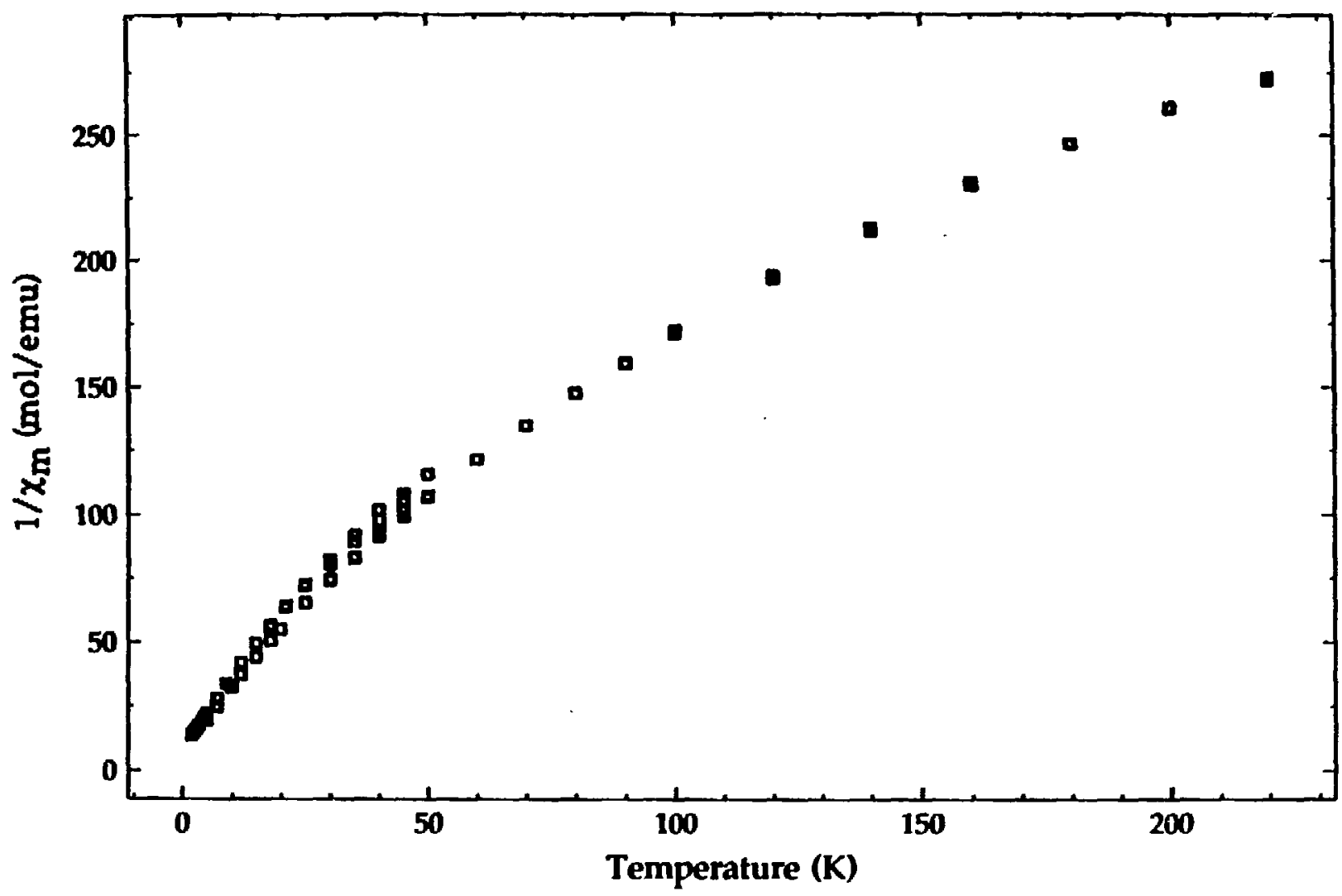


As mentioned earlier, the stilbene unit may be drawn showing a conjugated $\pi$-system. This is indicated by the following two resonance structures for the stilbene-diimide (using the trans form; Figure 2-27):
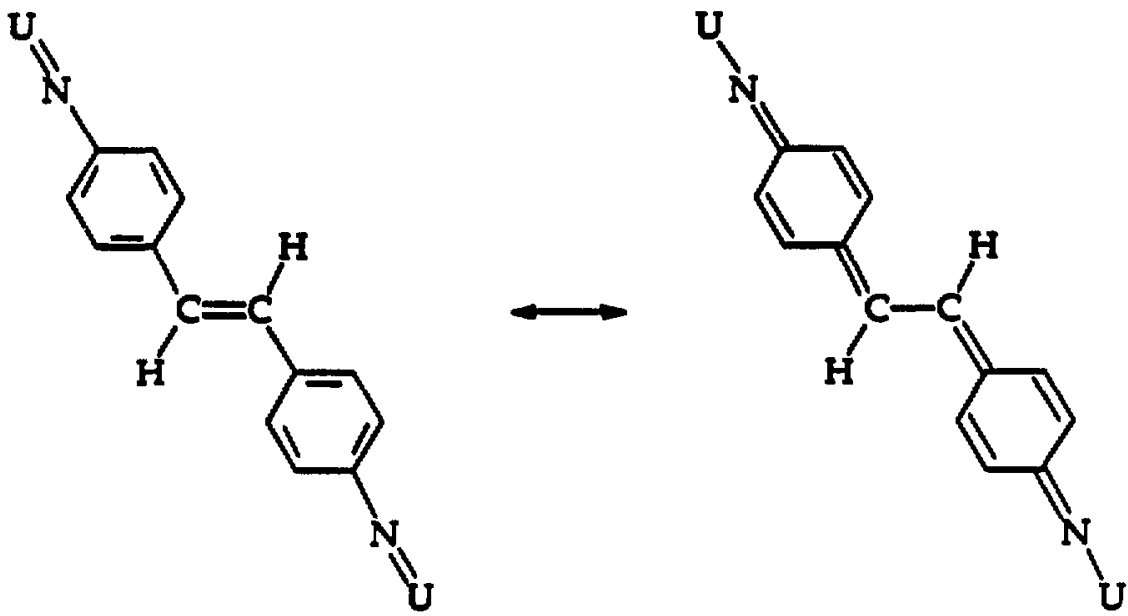

Figure 2-27: Resonance structures of the stilbene-diimide.

Why, if we can draw such a conjugated resonance structure, is no electronic interaction between the uranium centers observed? One reason may be the long metal-metal distarce; modelling this as described earlier with the $\left(\mathrm{MeC}_{5} \mathrm{H}_{4}\right)_{3} \mathrm{UNPh}$ distances and standard $\mathrm{C}-\mathrm{C}$ bond distances ${ }^{23}$ (Figure 2-28) yields a U-U separation of ca. 16.0 A. This is considerably longer that found in the para-diimide and may contribute to the lack of observed electronic exchange.

\subsection{2: Preparation and Properties of a Diuranium Naphthalene Diimide}

The second of our other diimides uses a naphthalene based system. This material was based upon the 1,5-diazidonaphthalene shown below (Figure 2-29): 


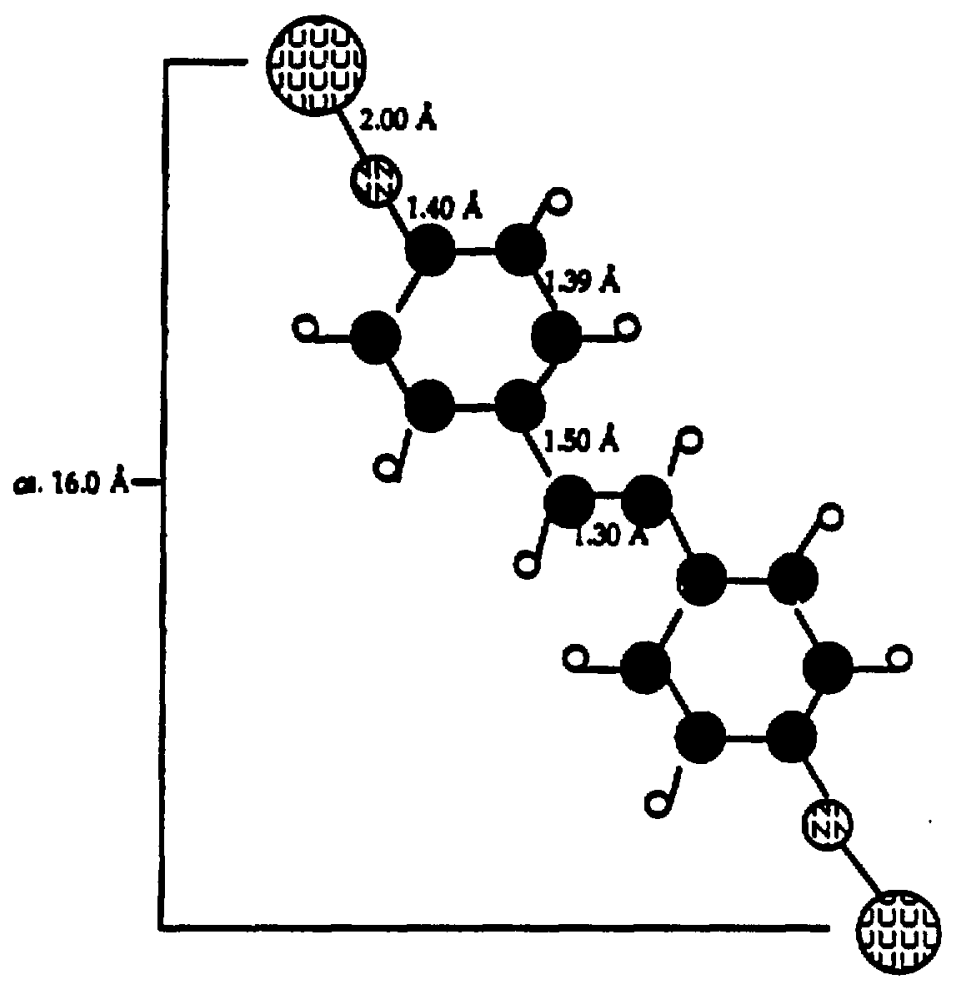

Figure 2-28: Stilbene-Diimide Molecular Editor ${ }^{\circ}$ Model 
<smiles>N#Cc1cccc2c(N)cccc12</smiles>

Iigure 2-29: 1,5-dinzidonaphthalene.

Like the other diazides, this one was prepared by a straightforward dizotization of the diamine. The diazide was then allowed to react with two molar equivalents of $\left(\mathrm{MeC}_{5} \mathrm{H}_{4}\right)_{3} \mathrm{U}(\mathrm{th})$ to give immediate gas evolution and a red/purple color. Crystallization from hot toluene gave black/purple needles of the naphthalene-diimide shown below (Figure 2-30).

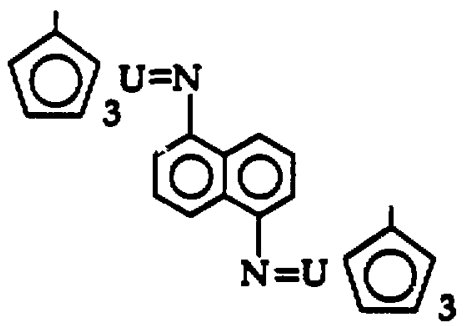

Figure 2-30: Structure of the uranium(V) maphthalene-diimide complex

This material was not thoroughly characterized. The ${ }^{1} H$ NMR spectrum could not be obtained in $\mathrm{C}_{6} \mathrm{D}_{6}$ due to its insolubility; instead it was taken in $d_{8}$-thf. The pattern for the $\mathrm{Me}_{5} \mathrm{H}_{4}$ was clearly seen at $\delta=+5.35 \mathrm{ppm}$ (ring Me), $\delta=-5.18 \mathrm{ppm}$ (ring $\mathrm{H}$ ), and $\delta=-8.19 \mathrm{ppm}$ (ring $\mathrm{H}$ ). The linewidths of the cyclopentadienyl ring protons were $v_{1 / 2}=65$ and $49 \mathrm{~Hz}$, consistent again with many of the uranium(V) imides, and much broader than the unusual 
linewidths in the para-diimide. Only one of the three expected naphthalene ring proton resonances (Figure 2-31) was unambiguously identified; this is presumabiy from the meta protons $\mathrm{H}_{\mathrm{B}}$ at $\delta=+16.95 \mathrm{ppm}$.<smiles>Cc1ccccc1N=O</smiles>

Flgure 2-31: Desigration of protons in the raphthulene-dlimide.

The other resonances presumably overlap with other peaks and this matter was not pursued further.

Magnetic susceptibility for this naphthalene-diimide was obtained at low temperatures only, in order to look for antiferromagnetic coupling. No such behavior was observed from $2.120 \mathrm{~K}$, and the plots of $\chi_{M}$ vs. $T$ and $1 / \chi_{M}$ vs. $T$ are shown in Figures 2-32 and 2-33. $A \mu_{\text {off }}=2.00$ B.M. $(\theta=-5.5 \mathrm{~K})$ was obtained over the low temperature region $(5-40 \mathrm{~K})$, or $\mu_{\text {eff }}=1.41$ B.M. per uranium. This is similar to the mononuclear uranium(V) imides, as well as the non-coupled dinuclear materials. No antiferromagnetic coupling is seen in this system, despite the fact that a conjugated x-system may again be drawn, as illustrated by the following example (Figure 2-34): 
Fig. 2-32: Chi ve Temp. plot for the napthalene-diimide.

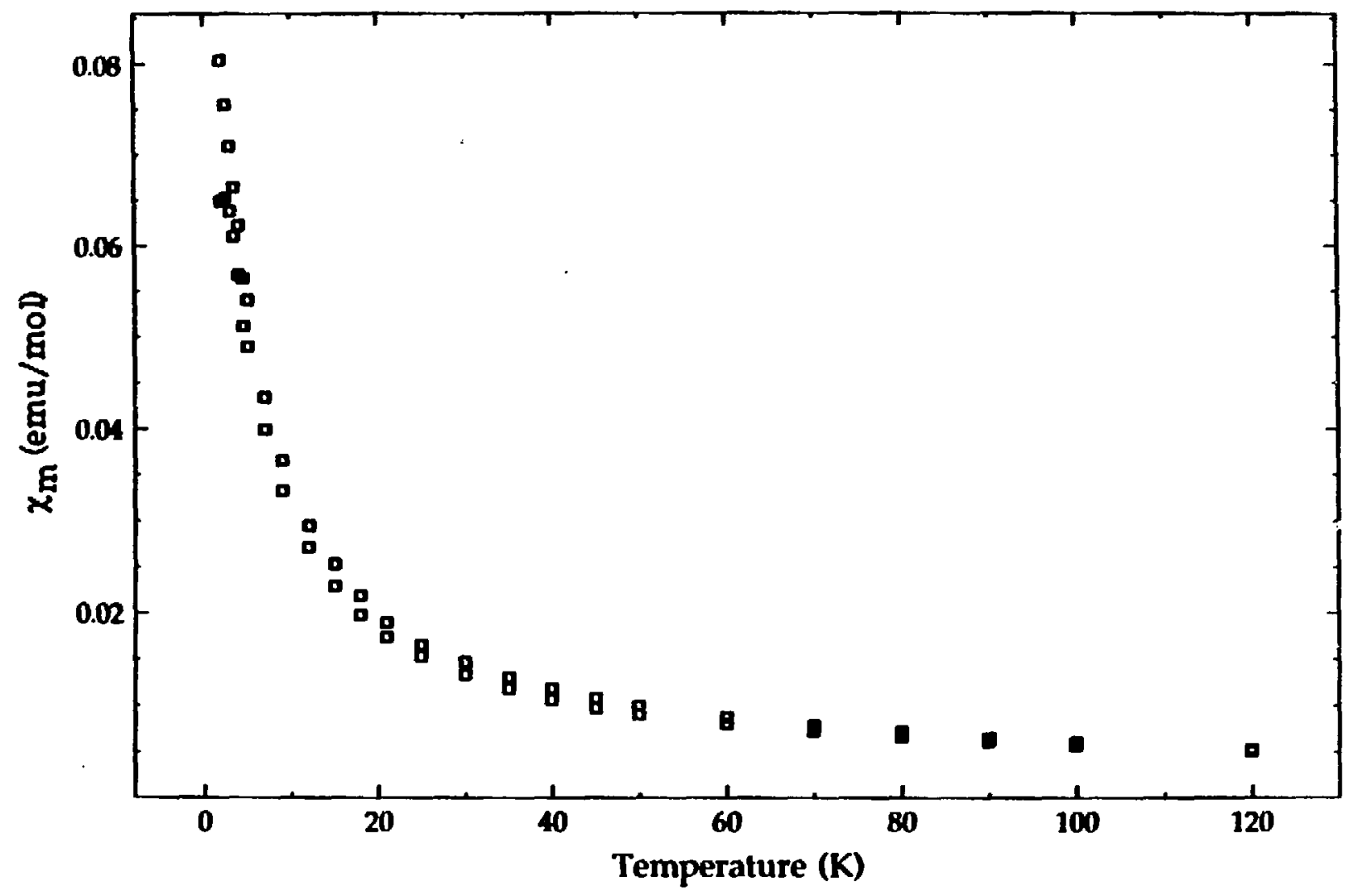


Fig. 2-33: 1/Chi vs Temp. plot for the napthalene-diimide.

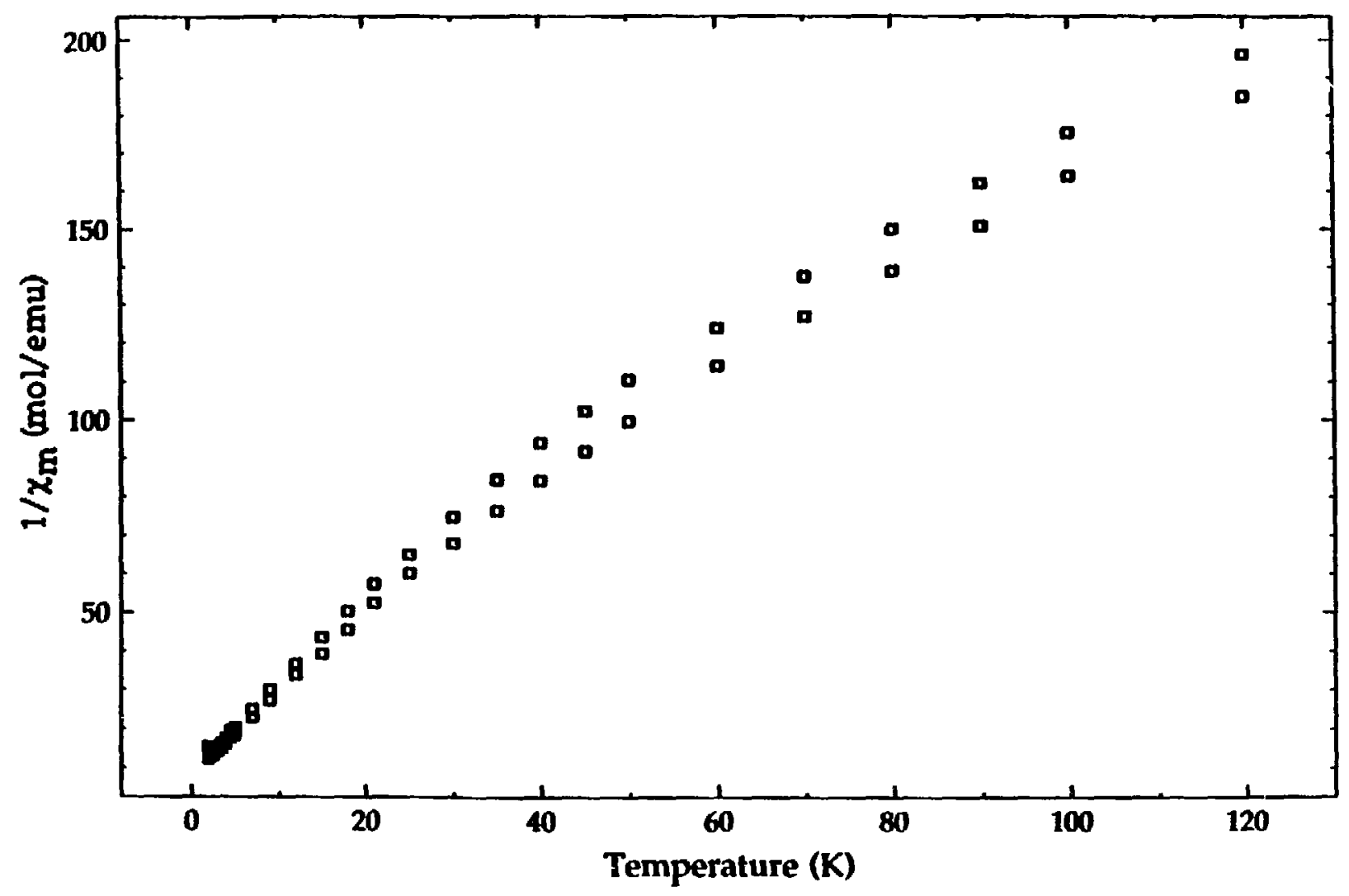


<smiles>O=Nc1cccc2c(N=O)cccc12</smiles><smiles></smiles>

Bipure 2-34: Resonance structures of the naphthalene-diimide.

Modelling the structure of this compound (Figure 2-35) as described earlier gives a $U-U$ distance of ca. 9.9 \&. This is close to that found in the para-diimide. Since the distance is similar and conjugation across the naphthalene ring should exist, what other reasons can we give for the lack of exchange? We assume that the p-phenylenediimido ligand and this naphthalene-diimido ligand are sufficiently different in their electronic natures to prevent electron i.xcharige from occurring. The fact that two aromatic systems must be perturbed in bott: ine naphthalene-diimide and the stilbene-diimidn to arrive at completely conjugated resonance forms may play a role electronically. It is impossible to say anything more definitive on this subject, since the mechanism of exchange of this type is not well understood and varies widely from compound to compound.

A summary of all magnetic susceptibilty measurements of the uranium(V) compounds studied in this work is presented in Table 2.1: 


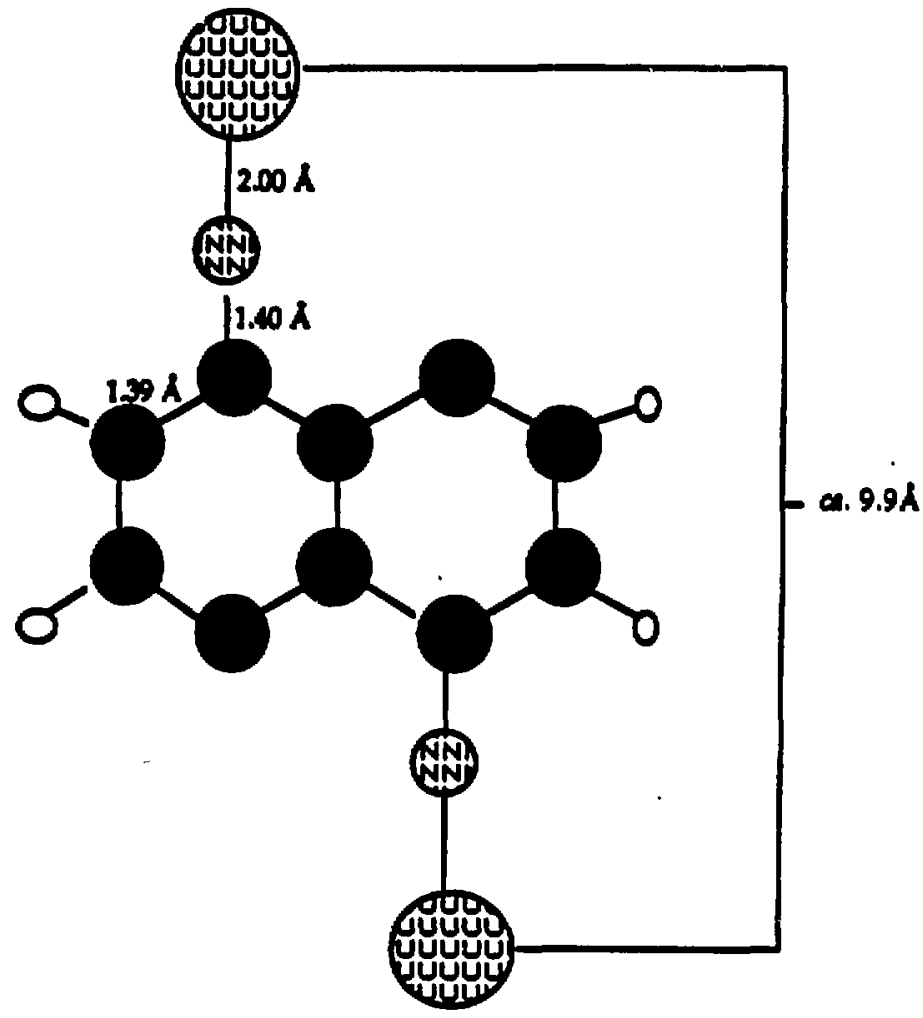

Figure 2-35: Napthalene-Diimide Molecular Editor ${ }^{\circ}$ Model 


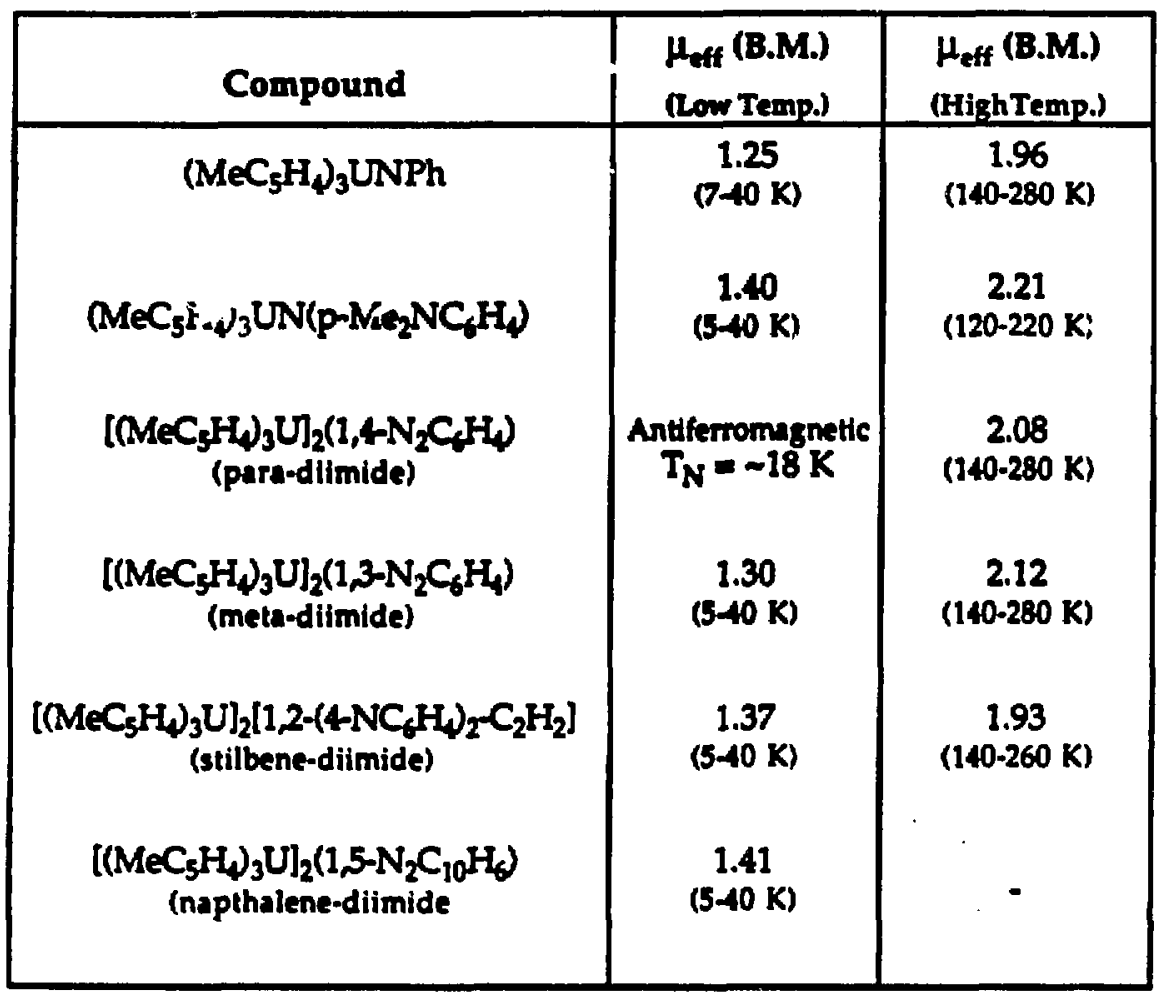

Table 2.: Summary of uranium(V) magnetic measurements (all $\mu_{\text {au }}$ are given per uranium).

The plots of $\chi_{M}$ versus temperature all have similar appearances, with the exception of the unusual low temperature behavior of the para-diimide. By preparing several of these diimides, we have demonstrated that conjugation across the $x$-5ystem of the bridging ligand seems important if electronic exchange is to occur in systems of this type. In addition, the results from the napthalene-diimide suggest that this conjugation is most effective in conducting the super-exchange for systems containing only one aromatic ring. 


\section{Section 2.4: Reaction of $\left(\mathrm{MeC}_{5} \mathrm{H}_{4}\right)_{3} \mathrm{U}($ thf $)$ with $\mathrm{Me}_{2} \mathrm{Si}\left(\mathrm{N}_{3}\right)_{2}$}

The purpose of synthesizing dimethyldiazidosilane was to attempt to produce a uranium diimide that has no aryl system, once again showing that the electronic coupling must proceed through some sort of $\pi$-system rather than simply "through space."

Dimethyldiazidosilane was prepared by the method of Washburne and Peterscn 24 as follows (Scheme 2-5): .

$$
\mathrm{Me}_{2} \mathrm{SiCl}_{2} \frac{\left(\mathrm{Me}_{2} \mathrm{~N}_{3} \mathrm{PO}\right.}{2 \mathrm{NaN}_{3}} \rightarrow \mathrm{Me}_{2} \mathrm{Si}\left(\mathrm{N}_{3}\right)_{2}+2 \mathrm{NaCl}
$$

Scheme 2-5: Preparation of a silicon diazide.

The compound has been found to be unpredictably explosive, ${ }^{25}$ and thus caution was used in the handling of the reaction mixture. We found that the solvent hexamethylphosphoric triamide (HMPT) had to be dried over sodium slices prior to use in this reaction in order to minimize the production of silyl alcohols. By this technique, we were able to obtain fairly pure $\mathrm{Me}_{2} \mathrm{Si}\left(\mathrm{N}_{3}\right)_{2}$ by fractional distillation. The material used in the reaction with uranium distilled at $50-53^{\circ} \mathrm{C}$ at $17 \mathrm{~mm} \mathrm{Hg}$. The infrared spectrum of this colorless liquid showed a strong $\mathrm{N}_{3}$ stretch at $\mathrm{Ca} .2140 \mathrm{~cm}^{-1}$, and in the ${ }^{1} \mathrm{H}$ NMR spectrum a single resonance at $\delta=-0.1 \mathrm{ppm}$ was observed. A small $\mathrm{OH}$ stretch from apparent silanol impurities was seen in the $\mathbf{R}$.

When this material was reacted with $c a .2 .1$ molar equivalents of $\left(\mathrm{MeC}_{5} \mathrm{H}_{4}\right)_{3} \mathrm{U}\left(\right.$ thr), a light green precipitate was immediately obtained. The ${ }^{1} \mathrm{H}$ NMR spectrum of the crude material from the reaction showed only $\left(\mathrm{MeC}_{5} \mathrm{H}_{4}\right)_{3} \mathrm{UN}_{3}$ along with some small peaks in the diamagnetic region of the 
spectrum. Green microcrystals of the compound were obtained in fair yield [29\% based on total azide present, 53\% based on $\mathrm{Me}_{2} \mathrm{Si}_{(\mathrm{N}} \mathrm{N}_{2}$ ] from toluene recrystallization, and this material was found by ${ }^{1} \mathrm{H}$ NMR to be pure $\left(\mathrm{MeC}_{5} \mathrm{H}_{4} \mathrm{UN}_{3}\right.$. 


\section{Section 2.5: Model for the Interpretation of the Antiferromagnetism of the Para-diimide}

The interpretation of the antiferromagnetic coupling observed in $\left.\left[\left(\mathrm{MeC}_{5} \mathrm{H}_{4}\right)_{3} \mathrm{U}\right]_{2}{ }^{\prime}-\mathrm{NC}_{6} \mathrm{H}_{4} \mathrm{~N}\right)$ was evaluated by $\mathrm{Dr}$. Norman Edelstein of the Lawrence Berkeley Laboratory.

For a $\mathrm{U}^{\text {st }}$ compound with approximate $\mathrm{C}_{3 v}$ symmetry the ground J a $5 / 2$ term splitu in a crystal field into six crystal field levels $(\mu)$, two $\mu_{1 / 2}$ states and one $\mu_{3 / 2}$ state plus their Kramers' conjugates. These states may be written as the following linear combinations of $\mathrm{J}, \mathrm{J}_{2}$ states:

$$
\begin{array}{ll}
\mu=1 / 2 & \Psi_{1 / 2}=a|5 / 2, \pm 1 / 2\rangle+b|5 / 2, \pm 5 / 2\rangle \\
\mu=3 / 2 & \Psi_{32}=a^{\prime}|5 / 2,3 / 2\rangle+b^{\prime}|5 / 2,-3 / 2\rangle
\end{array}
$$

It is likely in this system that the crystal field will be strong enough so that the higher-lying $\mathrm{J}=7 / 2$ state will not be mixed into the ground state. The important point to note is that for $\mu=1 / 2$ both $g_{11}$ (along the three fold axis) and $g_{1}$ may be non-zero but for the $\mu=3 / 2$ state $g_{1}=0$. Thus, no normal epr spectrum will be observed for the $\mu_{3 / 2}$ state because the intensity of the epr signal is proportional to $\mathbf{g}_{1}^{2}$.

For the $\left(\mathrm{RC}_{5} \mathrm{H}_{\downarrow_{3}} \mathrm{UNR}\right.$ mononuclear compounds, no epr signals were observed at low temperatures (i.e., at $-4 K$ ). Therefore, we assume the ground state is $\mu_{3 / 2}$ and $8 .=0$.

With thi: assumption and also assuming that only the ground state is populated, we can derive:

$$
g_{11}=2.0 \mu_{\text {eff }}
$$


This expression should be valid at low temperatures. Thus we can evaluate $8_{11}$ from the magnetic susceptibility data of a dinuclear $\left[\left(\mathrm{RC}_{5} \mathrm{H}_{4}\right)_{3} \mathrm{U}\right]_{2}(\mathrm{NRN})$ which does not exhibit antiferromagnetic coupling. This was done using the meta-diimide, $\left[\left(\mathrm{MeC}_{5} \mathrm{H}_{4}\right)_{3} \mathrm{U}_{2}\left(m-\mathrm{NC}_{6} \mathrm{H}_{4} \mathrm{~N}\right)\right.$, and a value of $\mu_{\text {eff }}=1.30 \mathrm{~B} . \mathrm{M}$. per uranium in the low temperature region (5-40 $\mathrm{K}$ ) was obtained. From this, we calculate $8_{11}=2.60$.

For a dinuclear uranium(V) diimide compound we assume the ground state does not change from the mononuclear species. This model assumes a one-dimensional exchange interaction along the three-fold or $z$ axis, and this is called the Ising model for an isolated dimer. ${ }^{26}$

The Hamiltonian for an interacting pair of spins is written as:

$$
H=-2] S_{21} S_{22}+g_{11} H_{B} H_{2}\left(S_{21}+S_{22}\right)
$$

The susceptibility along the three-fold axis for this system is

$$
x_{11}=\frac{N g_{11}^{2}+k^{2}}{k T}(1-e-1 / k T)-1
$$

for a dinuclear compound, or

$$
x_{11}=\frac{N g_{11}^{2} \mu g^{2}}{2 k T}(1-e-f / k T)-1
$$

per metal ion.

For a powder of this system (remember $\boldsymbol{g}_{\perp}=0$ ):

$$
x_{A v g}=\frac{1}{3} \frac{N_{g_{11}^{2}}^{2} \mu_{B}^{2}}{2 k T}\left(1+e^{-1 / k T}\right)-1
$$


Since all values in the above equation other than $\chi_{\mathrm{Avg}}, T$, and $I$ are known, we can calculate $\chi_{\text {Avg }}$ versus $T$ for various values of $J$. This is shown, along with the experimental data from two magnetic susceptibility runs on the para-diimide, in Figure 2-36. From this model we conclude $J=c r .-19 \mathrm{~cm}^{-1}$, the antiferromagnetic state is lowest, and that there is a small impurity [probably uranium(III)] which is the primary contribution to the paramagnetism at low temperatures. The deviations at higher temperatures could be due to the thermal population of higher-lying crystal field states. 


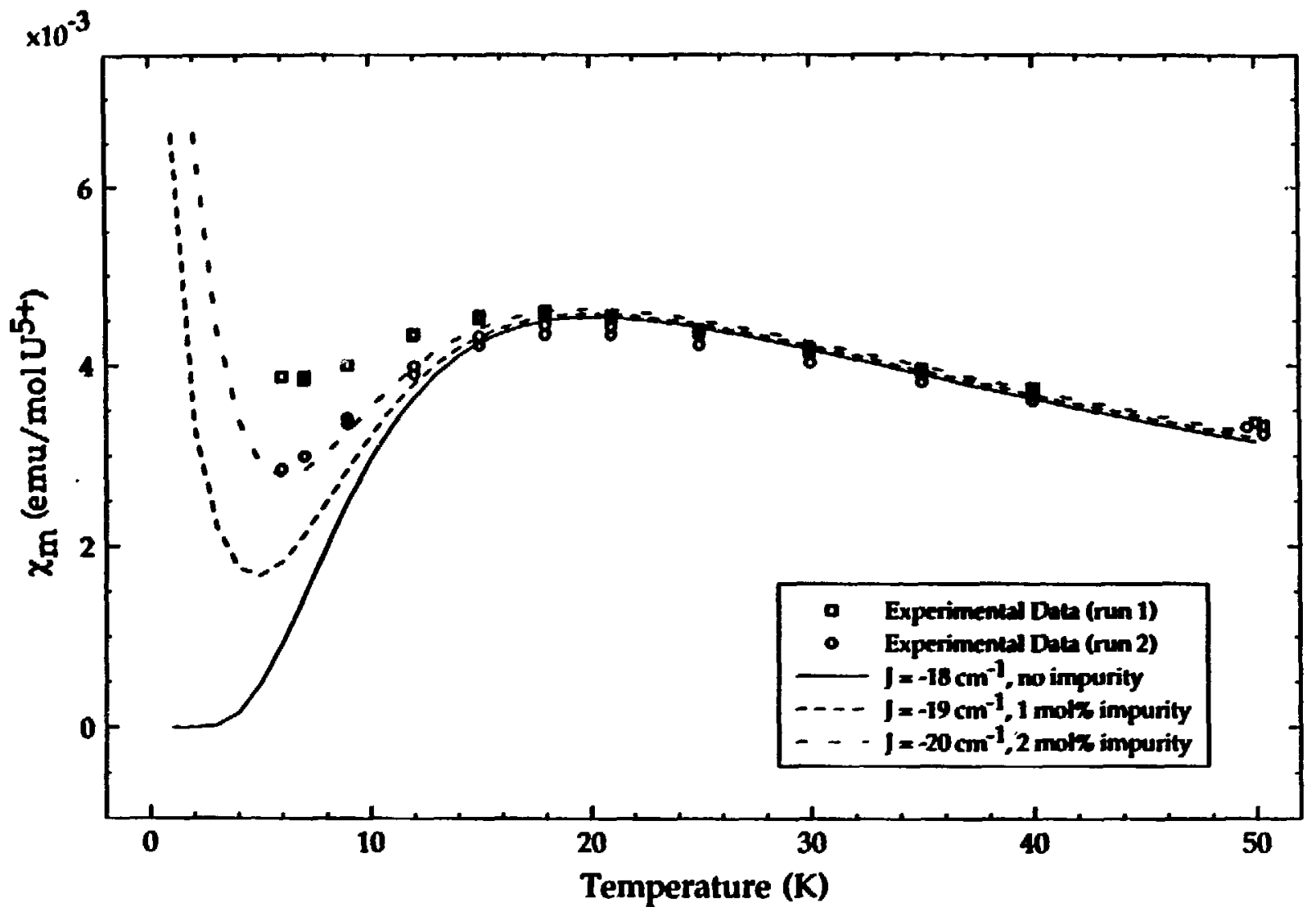

Figure 2-36: Experimental magnetic susceptibility of the para-diimide along with Ising model susceptibilities calculated for ] $=-18 \mathrm{~cm}^{-1}, \mathrm{~J}=-19 \mathrm{~cm}^{-1}$, and $]=-20 \mathrm{~cm}^{-1}$ [with a uranium(III) impurity). Note that $\mathrm{g}_{1}$ । $=2.60$. 


\section{References}

1 See, for example: (a) Creutz, C. Prog. Inorg. Chem. 1983, 30, 1. (b) Haim, A. Prog. Inorg. Chem. 1983, 30, 273. (c) Meyer, T. J. Prog. Inorg. Chem. 1983, 30, 389. (d) Meyer, T. J. in Brown, D. D., Ed. Mixed-Valence Compounds, Reidel, Dordrecht, 1980, p. 75. (e) Miller, J. S. Ado. Chem. Ser. 1976, 150, 18.

2 (a) Creutz, C.; Taube, H. J. J. Amer. Chem. Soc. 1969, 91, 3988. (b) Creutz, C.; Taube, H. J. J. Amer. Chem. Soc. 1973, 95, 1086.

3 (a) Eigenbrot, C. W.; Raymond, K. N. Polyhedron 1982, 1, 417. (b) Eigenbrot, C. W. Ph.D. Thesis, Univ. of California, Berkeley, 1981. - see reference 32 , page 419.

5 (a) O'Reilly, J. E.; Elving, P. J. J. Amer. Chem. Soc. 1972, 94, 7941. (b) Maruyama, M.; Murakami, K. J. Electroanal. Chem. 1979, 102, 221. (c) Millefiori, S. J. Heteracycl. Chem. 1970, 7, 145. (d) Tabner, B. J.; Yandle, J. R. J. Chem. Soc. (A) 1968, 381.

- Cotton, F. A.; Wilkinson, G. Advanced Inorganic Chemistry, Fourth Edition, John Wiley and Sons, New York, 1980, p. 1018.

7 (a) Sonnenberger D. C.; Gaudiello, J. G. Inorg. Chem. 1988, 27, 2747. (b) Gaughan, G. Ph.D. Thesis, Univ. of Oregon, 1983.

- Berg, D. B. Ph.D. Thesis, Unio. of California, Berkeley, 1987.

- Finke, R G.; Keenan, S.; Schiraldi, D. A.; Watson, P.L. Sixteenth Rare Earth Research Conference, Florida State Unioersity, April 18-21, 1983.

10 Jones, Jr., E. R.; Hendricks, M. E.; Stone, J. A.; Karraker, D. G. J. Chem. Phys. 1974, 60, 2088. 
11 Lea, K. R.; Leask, M. J. M.; Wolf, W. P. J. Phys. Chem. Solids 1962, 23, 1381.

12 Leask, M. J. M.; Roberts, L. E. J.; Walter, A. J.; Wolf, W. P. J. Chem. Soc. $1963,4788$.

13 See reference 10, page 2092.

14 (a) Maatta, E. A.; Devore, D. D. Angew. Chem. Int. Ed. Engl. 1988, 27, 569. (b) Matta, E. A.; Kim,C. Inorganic Chemistry 1989, 28, 623.

15 Herring, D. L. 1. Org. Chem. 1961, 26, 3998.

16 Brennan, J. G.; Andersen, R. A. J. Amer. Chem. Sac. 1985, 107, 514.

17 Molecular Editor, version 1.1, @1986, Drexel University, available through Kinko's Academic Courseware Exchange (1-800-235-6919).

18 See, for example: (a) Ginsberg, A. P.; Koubek, E.; Williams, H. J. Inorg. Chem. 1966, 5, 1656. (b) Ginsberg, A. P.; Sherwood, R. C.; Koubek, E. J. Inorg. Nucl. Chem. 1967, 29, 353. (c) Hyde, K. E.; Gordon, G.; Kokoszka, G. F. J. Inorg. Nucl. Chem. 1968, 30, 2155. (d) Sinn, E. Inorg. Chem. $1970,9,2376$.

19 Ginsberg, A. P. Inorg. Chim. Acta. Rev. 1971, 5, 45.

20 Felthouse, T. R.; Hendrickson, D. N. Inorg. Chem. 1978, 17, 2636.

21 Forster, M. O.; Fierz, H. E. J. Chem. Soc. 1907, 91, 1942.

22 Streitwieser, A.; Heathcock, C. H. Introduction to Organic Chemistry. Second Edition, MacMillan Publishing Co., Inc., New York, 1981, p. 658. Huheey, J. E. Inorganic Chemistry, Second Edition, Harper and Row, New York, 1978, pp. 839-851.

Washburne, S. S.; Peterson, Jr., W. R. J. Organomet. Chem. 1971, 33, 153.

Wolfsberger, W.; Schmidbauer, H. J. Organomet. Chem. 1971, 28, 301. 
26 For a discussion of the Ising model, see: (a) Carlin, R. L. Magnetochemistry Springer-Verlag, Berlin, 1986, pp. 105-108. (b) McCoy, B. M.; Wu, T. T. The Two Dimensional Ising Model Harvard University Press, Cambridge, Mass., 1973. (c) Nakatsuka, S.; Osaki, K.; Urya, N. Inorg. Chem. 1982, 21, 4332. 


\section{Chapter 3}

\section{Tris(cyclopentadienyl)uranium Amine, Amide, and Hydrazide Compounds}

Most of the chemistry involving the tris(cyclopentadienyl) systems of trivalent uranium has revolved around compounds of the type $C_{p_{3}} U(L)$, where $L$ is a Lewis base. The earliest report deccribed the preparation of the compounds with $\mathrm{L}=$ thf, nicotinamide, and cyclohexylisocyanide. ${ }^{2}$ Because of the relative insolubility of these compounds, work has more frequently focused on the methyl substituted cyclopentadienyl derivatives. ${ }^{2}$ However, very little information has appeared concerning non-heterocyclic amine complexes of trivalent uranium. Brennan has prepared the compound $\left(\mathrm{MeC}_{5} \mathrm{H}_{4}\right)_{3} \mathrm{U}$ (quin) [quin = quinudidine, $\mathrm{N}\left(\mathrm{CH}_{2} \mathrm{CH}_{2}\right)_{3} \mathrm{CH}$ ), 20,26 utilizing this "tied back" tertiary amine, but he was unable to prepare stable uranium(III) coordination complexes using either $\mathrm{Me}_{3} \mathrm{~N}$ or $\mathrm{Et}_{3} \mathrm{~N}$.

We had an interest in examining compounds similar to the uranium(V) imides discussed in Chapter 1, but utilizing different oxidation states of the metal. This should allow us to make a "family" of related molecules like those shown below (Figure 3-1):<smiles></smiles>

U(II)<smiles></smiles>

U(IV)<smiles>[R]N[As]1CCCC1</smiles>

$U(V)$

Figure 3-1: A family of uranium(III), uranium(IV), and uranium (V) compounds with U-N bonds. 
By synthesizing such a group, we could compare the properties of these compounds, which can be referred to as uranium(III) amines, uranium(IV) amides, and uranium( $V$ imides. Additionally, we were interested in seeing whether the compounds could be interconverted formally by either addition or removal of an H. as shown below (Scheme 3-1):

$$
\widehat{Q}_{3} \mathrm{U}-\mathrm{NH}_{2 \cdot x} \mathrm{R}=\frac{+\mathrm{H} \cdot}{-\mathrm{H} \cdot} \widehat{\Theta}_{3} \mathrm{U}-\mathrm{NH}_{1 \cdot x^{R}}
$$

Scheme 3-2: Interconversion of uranium anines, ambles, and imides.

This chapter describes the preparation and properties of the uranium amine and amide complexes which have been synthesized, as well as some reactions involving the related hydrazine species. 


\section{Section 3.1: Preparation and Properties of $\left(\mathrm{MeC}_{5} \mathrm{H}_{4}\right)_{3} \mathrm{U}\left(\mathrm{NH}_{2} \mathrm{R}\right)$ Compounds}

Several amine complexes of trivalent uranium have been prepared of the general formula $\left(\mathrm{MeC}_{5} \mathrm{H}_{4}\right)_{3} \mathrm{U}\left(\mathrm{NH}_{2} \mathrm{R}\right)$. These compounds and some of their properties are listed below in Table 3-1.

\begin{tabular}{|c|c|c|c|c|}
\hline $\mathbf{R}$ & color & m.p. $\left(\mathrm{CO}^{\mathrm{C}}\right.$ & $\mathrm{V}_{\mathrm{N} \cdot \mathrm{H}}\left(\mathrm{cm}^{-1}\right)$ & $\delta_{\mathrm{N} \cdot \mathrm{H}}(\mathrm{ppm})$ \\
\hline $\mathrm{H}$ & red-brown & $206-210(\mathrm{dec})$ & 3312,3239 & -137 \\
$\mathrm{Me}$ & red-brown & dec $>170$ & 3290,3245 & -128 \\
$\mathrm{Ph}$ & red-brown & $155-157$ (dec) & 3310,3225 & -121 \\
${\mathrm{p}-\mathrm{MeC}_{6} \mathrm{H}_{4}}_{4}$ & red-brown & $166-169$ (dec) & 3324,3221 & -121 \\
\hline
\end{tabular}

Table 3.1: Properties of $\left.\left(\mathrm{MCC}_{5} \mathrm{H}_{4}\right)_{3} \mathrm{UNH}_{2} \mathrm{R}\right)$ compounds.

Preparation of these compounds is straightforward, proceeding by displacement of the thf ligand in $\left(\mathrm{MeC}_{5} \mathrm{H}_{4}\right)_{3} \mathrm{U}($ thr) by the amine (Scheme 3-2):<smiles>[R9]Nc1ccccc1</smiles>

Scheme 3-2: Preparation of uranium anine complexes.

In the cases where $R=$ Ph or $p-M e C_{6} H_{4}$ one molar equivalent of the amine was added to a solution of the thf complex in toluene. Dark brown needles of

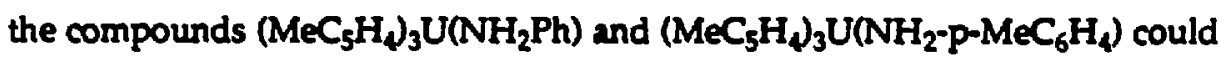
then be crystallized from the toluene solution. For $\mathrm{R}=\mathrm{H}$ or $\mathrm{Me}$, two methods of preparation were employed: either a saturated toluene solution of the 
amine was added to $\left(\mathrm{MeC}_{5} \mathrm{H}_{4}\right)_{3} \mathrm{U}$ (thr) or $\mathrm{CR} .1 .5$ - 2 molar equivalents of the gaseous amine was condensed onto a frozen toluene solution of $\left(\mathrm{MeC}_{5} \mathrm{H}_{4}\right)_{3} \mathrm{U}(\mathrm{thf})$. Once again, the amine coordination compounds could then easily be obtained by cystallization from toluene as brown needles. All four of these materials are rather insoluble in common organic solvents. None of the compounds are soluble in hexane, though slightly soluble in ether, and more soluble in toluene.

The compounds all exhibit two N-H stretches in their infrared spectra. The spectrum of the compound with $\mathrm{R}=\mathrm{p}-\mathrm{MeC}_{6} \mathrm{H}_{4}$ is shown in Figure 3-2. The 'H NMR spectra of these compounds are typical of uranium(III) coordination compounds. The spectra show the expected 3:2:2 pattern of the $\mathrm{MeC}_{5} \mathrm{H}_{4}$ rings with ring proton linewidths of $\mathrm{v}_{1 / 2}=16-20 \mathrm{~Hz}$. The positions and linewidths of these resonances are shown in Table 3-2. All of the compounds show a upfield shifted resonance for the amine protons, at $\delta=$ -121 to -137 ppm (see Table 3-2). This is a typical result for uranium compounds in which protons are attached to an atom that is directly o-bonded to a uranium center. For example, in $\mathrm{CP}_{3} \mathrm{U}^{n} \mathrm{Bu}$, the ${ }^{1} \mathrm{H}$ NMR resonance of the protons on the $\alpha$-carbon is found at ca. $-200 \mathrm{ppm}^{3}$ This resonance is relatively sharp in uranium(IV) compounds, and we find it to be broad but observable in our uranium(III) complexes. The positions of these resonances reflect the donating ability of the substituent on the amine. For the electron-withdrawing arylamines $\left(\mathrm{PhNH}_{2}\right.$ and $\left.\mathrm{p}-\mathrm{MeC}_{6} \mathrm{H}_{4} \mathrm{NH}_{2}\right)$, the resonances are further downfield (deshielded), consistent with less electron density on the nitrogen of these amines. In addition, the arylamine complexes have broader $\mathrm{N}-\mathrm{H}$ resonances than the ammonia or methylamine compounds. The resonances due to the amine substituents are also shown in Table 3-2. A typical spectrum, that of $\left(\mathrm{MeC}_{5} \mathrm{H}_{4}\right)_{3} \mathrm{UNH}_{3}$, is shown in Figure 3-3. 


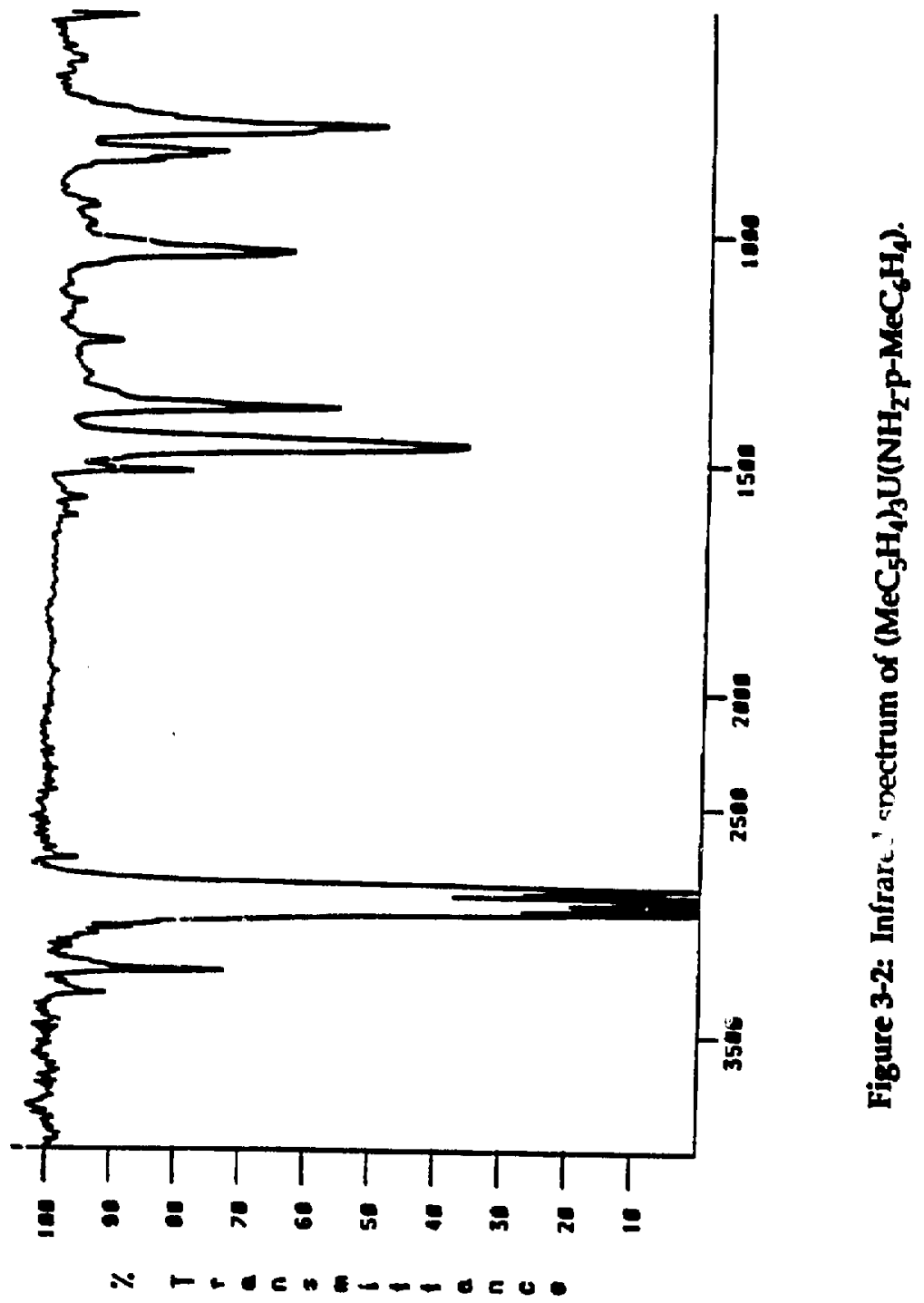




\begin{tabular}{|c|c|c|c|c|c|}
\hline $\mathbf{R}$ & Ring Me & Ring $H$ & Ring $H$ & $\mathbf{N H}_{2}$ & Substituent \\
\hline $\mathbf{H}$ & $\begin{array}{c}-15.5 \\
\left(v_{1 / 2}=6 \mathrm{~Hz}\right)\end{array}$ & $\begin{array}{c}-9.3 \\
\left(v_{1 / 2}=16 \mathrm{~Hz}\right)\end{array}$ & $\begin{array}{c}-18.7 \\
\left(v_{1 / 2}=16 \mathrm{~Hz}\right)\end{array}$ & $\begin{array}{c}-137 \\
\left(v_{1 / 2}=39 H z\right)\end{array}$ & \\
\hline Me & $\begin{array}{c}-17.1 \\
\left(V_{1 / 2}=8 \mathrm{~Hz}\right)\end{array}$ & $\begin{array}{c}-11.5 \\
\left(v_{1 / 2}=19 \mathrm{~Hz}\right)\end{array}$ & $\begin{array}{c}-15.1 \\
\left(v_{1 / 2}=17 \mathrm{~Hz}\right)\end{array}$ & $\begin{array}{c}-129 \\
\left(v_{1 / 2}=70 \mathrm{~Hz}\right)\end{array}$ & $\begin{array}{c}-30.3 \\
\left(v_{1 / 2}=34 \mathrm{~Hz}\right)\end{array}$ \\
\hline $\mathbf{P h}$ & -19.8 & $\begin{array}{c}-10.7 \\
\left(v_{1 / 2}=16 \mathrm{~Hz}\right)\end{array}$ & $\begin{array}{c}-13.9 \\
\left(v_{1 / 2}=16 \mathrm{~Hz}\right)\end{array}$ & $\begin{array}{c}-121 \\
\left(v_{1 / 2}=115 \mathrm{~Hz}\right)\end{array}$ & $\begin{array}{r}-15.20(2 \mathrm{H}) \\
+0.75(2 \mathrm{H}) \\
+2.16(1 \mathrm{H})\end{array}$ \\
\hline $\mathrm{p}-\mathrm{MeC}_{6} \mathrm{H}_{4}$ & -19.6 & $\begin{array}{c}-10.6 \\
\left(v_{1 / 2}=17 \mathrm{~Hz}\right)\end{array}$ & $\begin{array}{c}-13.7 \\
\left(v_{1 / 2}=17 \mathrm{~Hz}\right)\end{array}$ & $\begin{array}{c}-121 \\
\left(v_{1 / 2}=200 \mathrm{~Hz}\right)\end{array}$ & $\begin{array}{c}-15.09(2 \mathrm{H}) \\
+0.59(2 \mathrm{H}) \\
-0.78(3 \mathrm{H})\end{array}$ \\
\hline
\end{tabular}

Table 3-2: Chemical shifts (ppm) of the resonances in the ${ }^{1} \mathrm{H}$ NMR spectra of the uranium(III) amine complexes $\left(\mathrm{MeC}_{5} \mathrm{H}_{4}\right)_{3} \mathbf{U}\left(\mathrm{NH}_{2} \mathrm{R}\right)$. 

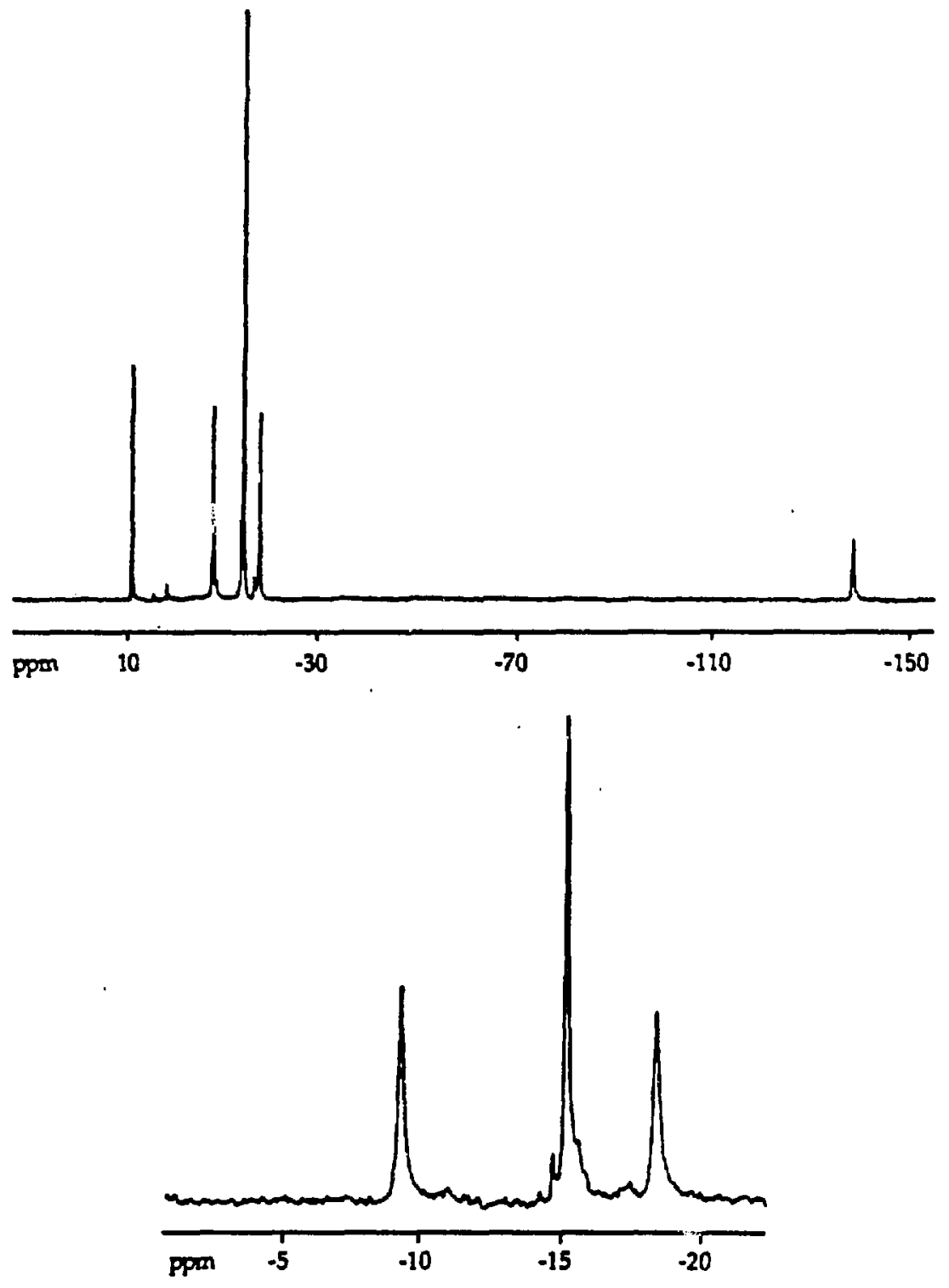

Figure 3-3: ${ }^{1} \mathrm{H}$ NMR spectra of $\left(\mathrm{MeC}_{5} \mathrm{H}_{4}\right)_{3} \mathrm{U}\left(\mathrm{NH}_{3}\right)$. 
The compound $\left(\mathrm{MeC}_{5} \mathrm{H}_{4}\right)_{3} \mathrm{U}^{15} \mathrm{NH}_{3}$ was also synthesized, by condensing 1.5 molar equivalents of ${ }^{15} \mathrm{NH}_{3}$ onto a frozen solution of $\left(\mathrm{MeC}_{5} \mathrm{H}_{4}\right)_{3} \mathrm{U}$ (thf) and (Tystallizing the cumpound from toluene. This material showed $V_{N-H}$ in the infrared spectrum at 3320 and $3241 \mathrm{~cm}^{-1}$, as opposed to 3312 and $3239 \mathrm{~cm}^{-1}$ in the unlabelled material. The N-H resonance in the ${ }^{1} H$ NMR spectrum was observed as a broad doublet at $\delta=-136 \mathrm{ppm}$ with $J_{1 \mathrm{~W} \cdot \mathrm{H}}=60 \mathrm{~Hz}$. It should be noted that $\mathrm{It}_{\mathrm{N} \cdot \mathrm{H}}$ is actually megative due to the negative gyromagnetic ratio of ${ }^{15} \mathrm{~N}$; the coupling constants are reportad as abolute values in this chapter. This value may be compa: ad with the coupling constant in free ${ }^{15} \mathrm{NH}_{3}$, which has been mensured to be $\mathrm{J}_{1 \mathrm{~s}_{\mathrm{N}} \cdot \mathrm{H}}=61 \mathrm{~Hz} .{ }^{4}$. The ${ }^{1} \mathrm{H}$ NMR spectra in the $\mathrm{N}-\mathrm{H}$ region of both the labelled and unlabelled species is shown in Figure 3-4.

Andersen et. al. ${ }^{2 a}$ and Fabiano ${ }^{2 c}$ have done extensive studies on ligand base-competition studies involving trivalent uranium. cyclopent:ienyl compounds. They have found that compounds of the type $\left(\mathrm{MeC}_{5} \mathrm{H}_{4}\right)_{3} \mathrm{U}(\mathrm{L})$ will rapidly exchange with additiosial free ligand $(L)$. When this process is observed by ${ }^{1} \mathrm{H} N M R$ spectroscopy, the resonances from $\left(\mathrm{MeC}_{5} \mathrm{H}_{4} \mathrm{U}(\mathrm{L})\right.$ due to the ligand $L$ shift towards the position of the resonances of free $L$. This phenomenon is also observed in the case of $\left(\mathrm{MeC}_{5} \mathrm{H}_{4}\right)_{3} \mathrm{U}\left(\mathrm{NH}_{2}-\mathrm{p}-\mathrm{MeC}_{6} \mathrm{H}_{4}\right)$. When a small amount of p-toluidine was added to a d6-benzene solution of $\left(\mathrm{MeC}_{5} \mathrm{H}_{4}\right)_{3} \mathrm{U}\left(\mathrm{NH}_{2}-\mathrm{p}-\mathrm{MeC}_{6} \mathrm{H}_{4}\right)$, the resonances from the p-toluidine ligand shifted towards the diamagnetic region of the NMR spectrum. While the $\mathrm{MeC}_{5} \mathrm{H}_{1}$ resonances at $\delta=-19.6 \mathrm{ppm},-10.6 \mathrm{ppm}$, and $\cdot 13.7 \mathrm{ppm}$ remained constant, the ligand resconance at $\delta=+0.60 \mathrm{ppm}$ shifted to $\delta=+2.44 \mathrm{ppm}$, the one at $\delta=-15.1 \mathrm{ppm}$ shifted to $\delta=-8.7 \mathrm{ppm}$, and the one at $\delta=-0.80 \mathrm{ppm}$ shified to $\delta=+0.10 \mathrm{ppm}$. The N-H protons not observed, presumably because they are broadened by the chemical exchange. 

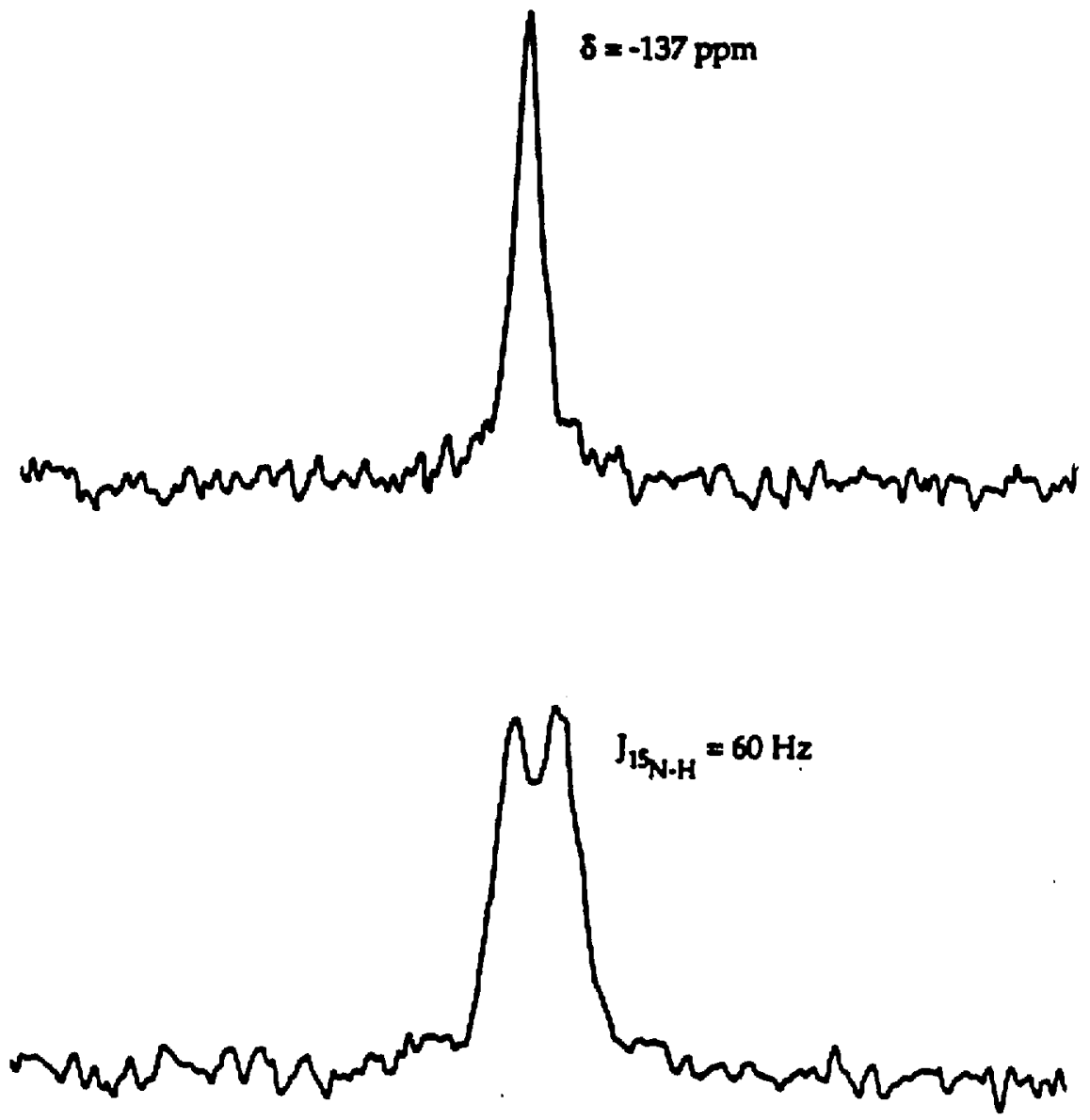

Figure 3-4: 'H NMR spectra showing the N-H resonances of $\left(\mathrm{MeC}_{5} \mathrm{H}_{4}\right)_{3} \mathrm{U}\left(\mathrm{NH}_{3}\right)$ (top) and $\left(\mathrm{MeC}_{5} \mathrm{H}_{4}\right)_{3} \mathrm{U}\left({ }^{15} \mathrm{NH}_{3}\right)$ (bottom). 
A similar process can be used with a second ligand, L', to gauge the relative affinity of the ligands towards uranium(III). A large number of these experiments have been performed, ${ }^{2}$ and the following order for the strengths of Lewis bases toward trivalent uranium has been established (Figure 3-5):

$$
\mathrm{OPME}_{3} \gg \mathrm{PME}_{3} \gg>\text { pyridine }>\text { quinuclidine } * \text { thf } \approx \text { tht }
$$

Mgure s-sk Onder of Lewis base strengths toward trivalent uranium (the - Wotrahydrofuran, the = retrahydrothiophene)

It is of interest to place $\mathrm{NH}_{3}$ in this ligand displacement series. To a solution of $\left(\mathrm{MeC}_{5} \mathrm{H}_{4}\right)_{3} \mathrm{U}\left(\mathrm{NH}_{3}\right)$ in $\mathrm{C}_{6} \mathrm{D}_{6}$ was added approximately two molar equivalents of $\mathrm{PMe}_{3}$. From the observed spectrum at $30^{\circ} \mathrm{C}$, it can be calculated that $55-62 \%$ of the material is in the form $\left(\mathrm{MeC}_{5} \mathrm{H}_{4}\right)_{3} \mathrm{U}\left(\mathrm{NH}_{3}\right)$, while the remaining $38-45 \%$ is $\left(\mathrm{MeC}_{5} \mathrm{H}_{4}\right)_{3} \mathrm{U}\left(\mathrm{PMe}_{3}\right)$ (Scheme 3-3):

$$
\widehat{\mathrm{O}}_{3} \mathrm{U}\left(\mathrm{PMe}_{3}\right)+\mathrm{NH}_{3}=\mathrm{C}_{6} \mathrm{D}_{6}=\hat{\mathrm{O}}_{3} \mathrm{U}\left(\mathrm{NH}_{3}\right)+\mathrm{PMe}_{3}
$$

Scheme 33: Equilibrium between the uranium amine and trimethylphosphine complexes.

An equilibrium constant for the reaction was calculated, and found to be in the range $K_{\mathrm{oq}}=4-7$. Thus ammonia is a better base towards trivalent uranium than $\mathrm{PMe}_{3}$.

A small needle-shaped crystal of $\left(\mathrm{MeC}_{5} \mathrm{H}_{4}\right)_{3} \mathrm{U}\left(\mathrm{NH}_{3}\right)$ suitable for $\mathrm{X}$-ray diffraction was obtained by slowly cooling a saturated ether solution to $-20^{\circ} \mathrm{C}$. The cystal was sealed in a quartz capillary under argon, and the $X$-ray diffraction analysis was performed by Dr. A. Zalkin of Lawrence Berkeley Laboratory. ${ }^{5}$ The crystal was found to be in the monoclinic space group Im, with $a=12.129(3) A, b=24.197(3) \AA, c=8.725(3) A$, and $\beta=92.85^{\circ}$. There are 
six molecules in the unit cell, of two different types. Four of the molecules lie on a general position (Figure 3-6), and the other two sit astride a mirror plane (Figure 3-7). Although the orientation of components in the two types of molecules is different, the bond distances and angles are comparable within the estimated statistics (Tables 3-3 and 3-4).

\begin{tabular}{|cc|cc|}
\hline Bond & Dintance $(\mathcal{A})$ & Bond & Distance $(A)$ \\
\hline U1-Cpl & 2.51 & U2-Cpt & 2.53 \\
U1-Cp2 & 2.57 & U2-Cp5 & 2.51 \\
U1-Cp3 & 2.58 & U2-N2 & $2.633(19)$ \\
U1-N1 & $2.595(12)$ & & \\
\hline
\end{tabular}

Table 3-3: Distances in $\left(\mathrm{MeC}_{5} \mathrm{H}_{4}\right)_{3} \mathrm{U}\left(\mathrm{NH}_{3}\right)$.

\begin{tabular}{|cc|cc|}
\hline Bond & Angle ( & Bond & Angle $\left({ }^{\circ}\right)$ \\
\hline Cp1-U1-Cp3 & 118.1 & Cp4-U2-Cp4 & 114.4 \\
Cp2-U1-Cp3 & 118.1 & Cp4-U2-Cp5 & 120.5 \\
N1-U1-Cp1 & 98.1 & N2-U2-Cp4 & 98.5 \\
N1-U1-Cp2 & 97.4 & N2-U2-Cp5 & 94.5 \\
N1-U1-Cp3 & 97.6 & & \\
\hline
\end{tabular}

Table 3-1: Angles in $\left.\left(\mathrm{MeC}_{5} \mathrm{H}_{4}\right)_{3} \mathrm{UNH}_{3}\right)$.

The average U-N distance of 2.61(3) $A$ in the ammonia complex may be compared with other trivalent uranium coordination complexes with nitrogen-containing donor ligands: $2.64(2) \AA$ in $\left(\mathrm{MeC}_{5} \mathrm{H}_{4}\right)_{3} \mathrm{U}\left(4-\mathrm{NC}_{5} \mathrm{H}_{4} \mathrm{NMe}_{2}\right)^{6}$ and 2.764(4) $\mathrm{A}$ in $\left(\mathrm{MeC}_{5} \mathrm{H}_{4}\right)_{3} \mathrm{U}\left[\mathrm{N}\left(\mathrm{CH}_{2} \mathrm{CH}_{2}\right)_{3} \mathrm{CH}\right] .{ }^{22}$ The large variation in these distances reflects the relative steric demands of the ligands, 


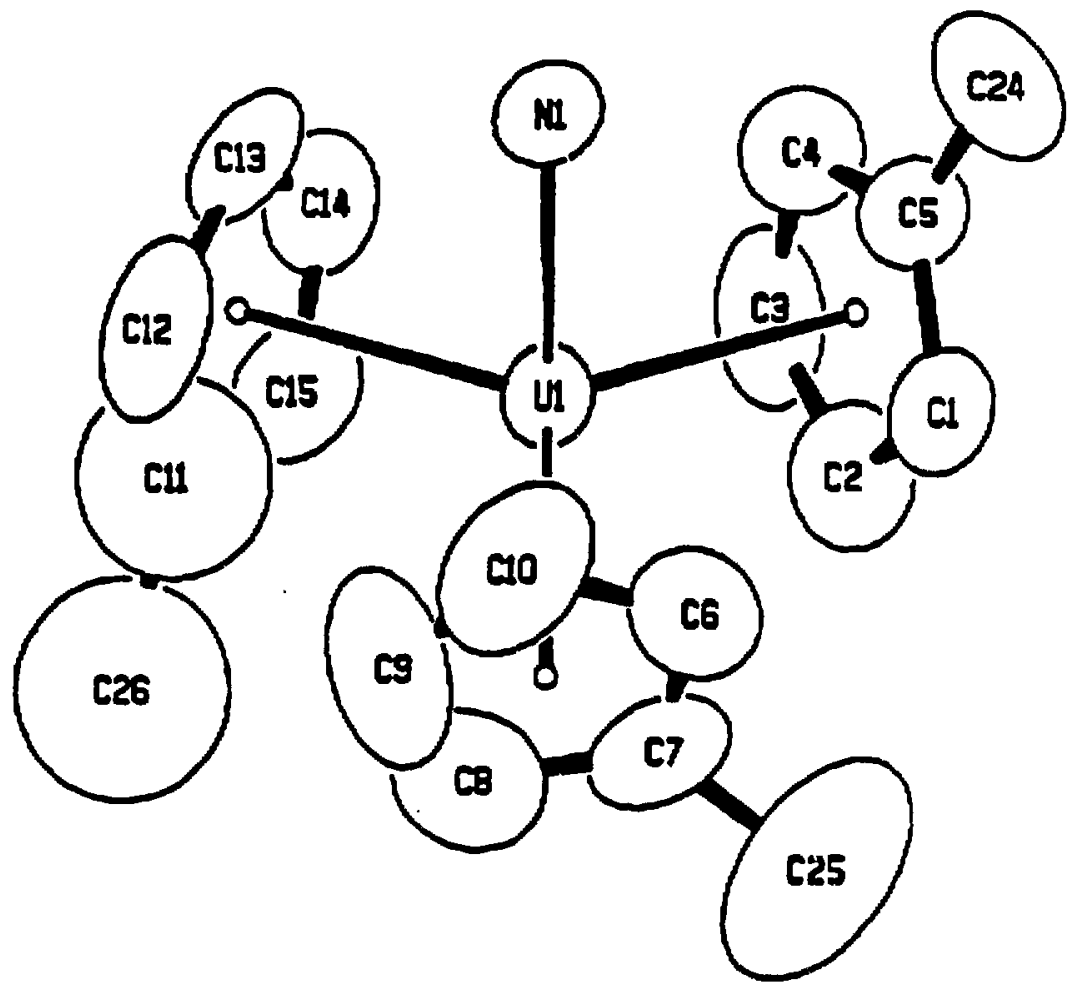

Figure 3-6: ORTEP view of the molecule on the general position from the X-ray crystal structure of $\left.\left(\mathrm{MeC}_{5} \mathrm{H}_{4}\right)_{3} \mathrm{U}_{\left(\mathrm{NH}_{3}\right.}\right)$. 


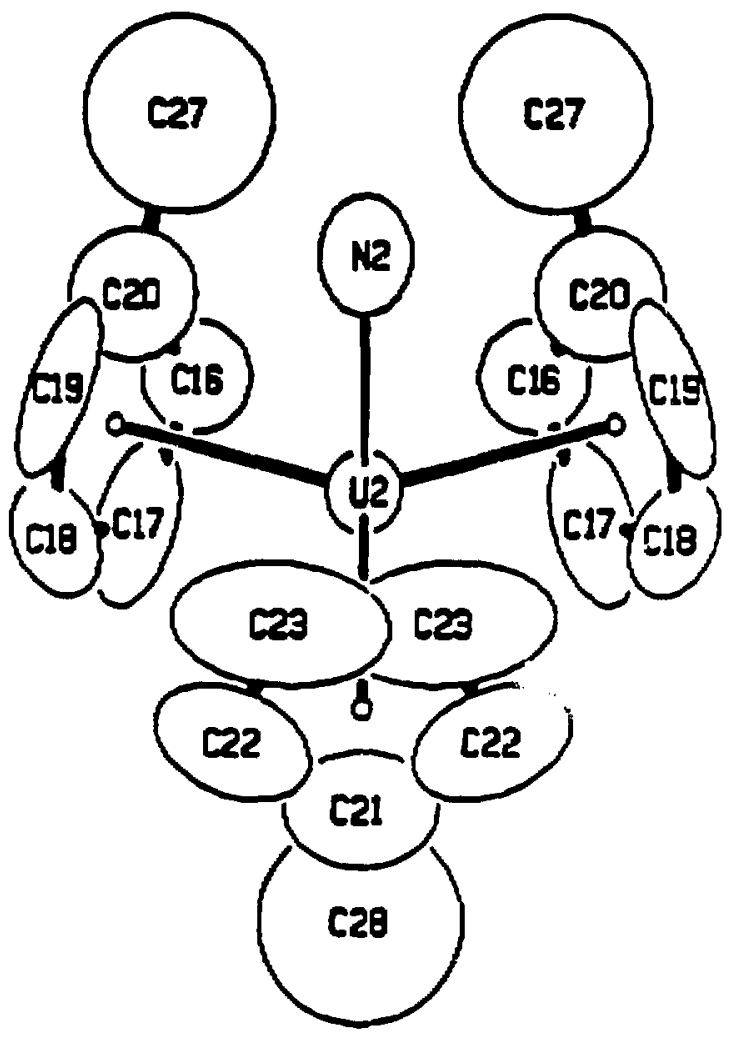

Figure 3-7: ORTEP view of the molecule on the mirror plane from the X-ray crystal structure of $\left(\mathrm{MeC}_{5} \mathrm{H}_{4}\right)_{3} \mathrm{U}\left(\mathrm{NH}_{3}\right)$. 
since $\mathrm{NH}_{3}$ is smaller than either pyridine or quinuclidine. The average $\mathrm{Cp}-\mathrm{U}$ $\mathrm{Cp}$ and $\mathrm{Cp}-\mathrm{U}-\mathrm{N}$ angles also reflect the steric differences between these ligands, although the differences are small. In $\left(\mathrm{MeC}_{5} \mathrm{H}_{4} \mathrm{U}_{3}\left(\mathrm{NH}_{3}\right)\right.$, these angles are $118^{\circ}$ and $97^{\circ}$ respectively, while in $\left(\mathrm{MeC}_{5} \mathrm{H}_{4}\right)_{3} \mathrm{U}\left(4-\mathrm{NC}_{5} \mathrm{H}_{4} \mathrm{NMe}_{2}\right)$ and $\left(\mathrm{MeC}_{5} \mathrm{H}_{4}\right)_{3} \mathrm{U}\left[\mathrm{N}\left(\mathrm{CH}_{2} \mathrm{CH}_{2}\right)_{3} \mathrm{CH}\right]$ the $\mathrm{Cp}-\mathrm{U}-\mathrm{Cp}$ angles are $117^{\circ}$ and $116^{\circ}$ and the Cp-U-N angles are $100^{\circ}$ and $101^{\circ}$.

The electron impact mass spectra of these amine coordination compounds fail to yield molecular ions in all but one case. This is for the ammonia complex, which exhibited a weak $\mathrm{M}^{+}$at 492 amu. However, this compound showed an unusually large M-I peak (491 amu), with an intensity $54 \%$ that of the $\mathrm{M}^{+}$. For the other compounds, only the M-1 peak was observed. Presumably, this is due to a thermal reaction of the molecule that occurs when it is heated in the mass spectrometer source (Scheme 3-4).

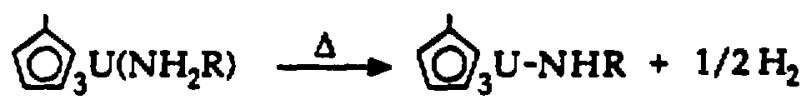

Scheme 3-4: Thermal decompostion of the uranium amine.

We indeed find that the observed spectra obtained from these amines are consistent for the corresponding uranium(IV) amides. The spectrum obtained for $\left(\mathrm{MeC}_{5} \mathrm{H}_{4} \mathrm{~J}_{3} \mathrm{U}\left(\mathrm{NH}_{2} \mathrm{Ph}\right)\right.$ is shown in Figure 3-8, along with the simulation for the molecular ion of the corresponding amide, $\left(\mathrm{MeC}_{5} \mathrm{H}_{4}\right)_{3} \mathrm{LNHPh}$. Note that the simulation predicts an $\mathrm{M}+1$ with intensity $27 \%$ that of the $\mathrm{M}^{+}$; we observe the $\mathrm{M}+1$ with an intensity of $29 \%$. Thus the observed spectrum is in excellent agreement with that expected for the uranium(IV) amide. 

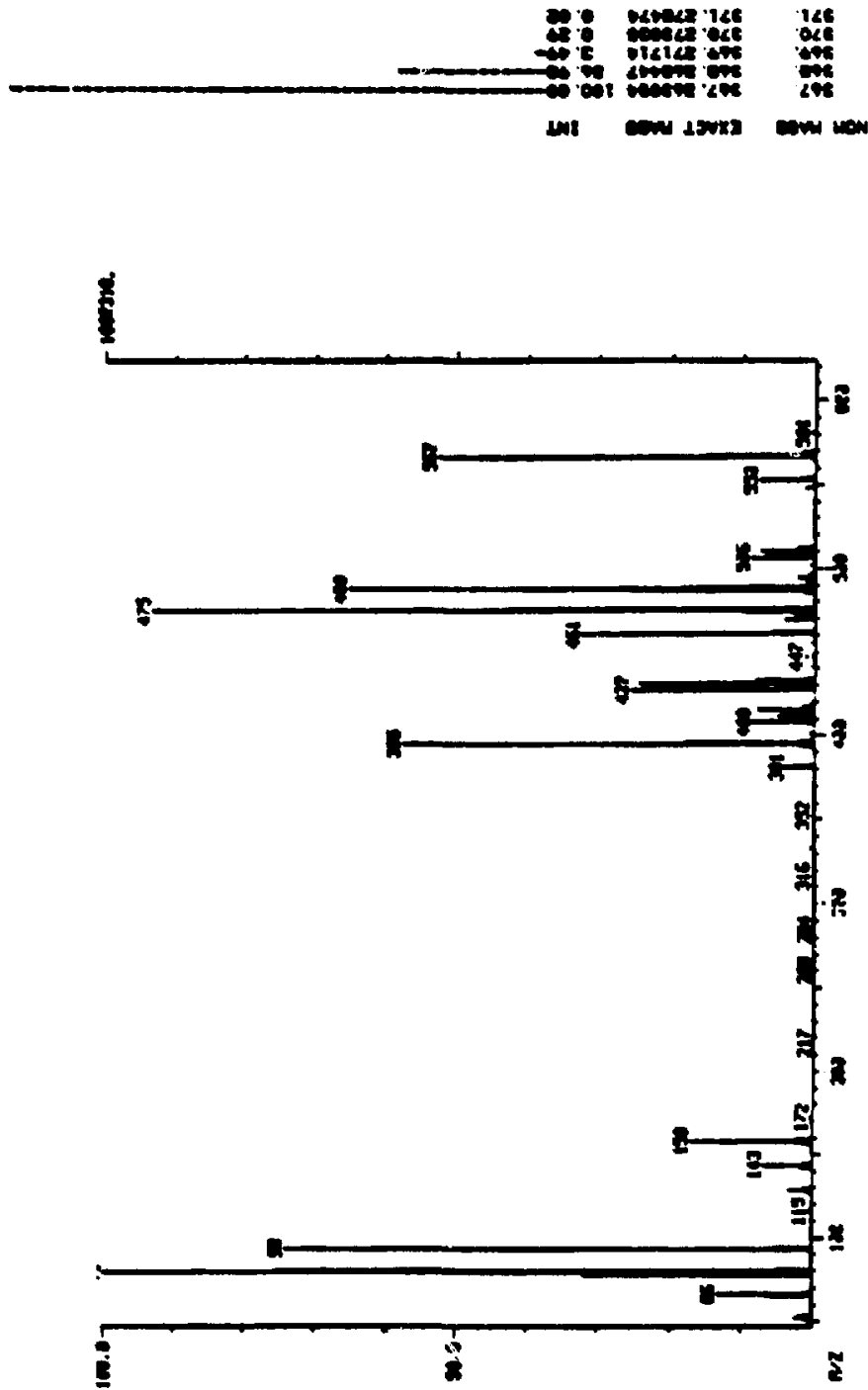
These results are less surprising when we observe the melting behavior of these amine complexes. As noted in Table 3-1, all of the amine compounds melt with decomposition. This is easily observed when the materials are melted in sealed capillaries. At the point where melting begins, the compounds all evolve a gas and the color changes. For the arylamines, the color change is from the dark red-brown of the uranium(III) amine to a very bright cherry red. For the methylamine and ammonia compounds, the color changes from red-brown to a greenish-brown. The methylamine compound behaves slightly more oddly than the others since it "softens" from $170-200^{\circ} \mathrm{C}$, then slowly changes color and melts at $237-238^{\circ} \mathrm{C}$.

Because gas evolution was seen in the melting behavior and the $M-1$ peaks of the amides were observed in the mass spectra, we decided to repeat this procedure on a preparative scale in an attempt to isolate the uranium(IV) amide. The compound $\left(\mathrm{MeC}_{5} \mathrm{H}_{4}\right)_{3} \mathrm{U}\left(\mathrm{NH}_{2} \mathrm{Ph}\right)$ was heated in a Schlenk tube to $160^{\circ} \mathrm{C}$ under a nitrogen atmosphere. The dark solid melted, bubbled, and turned bright red. After cooling, the residwe was extracted with hexane and bright red bricks were crystallized from the solution. These were found to be the amide, $\left(\mathrm{MeC}_{3} \mathrm{H}_{4}\right)_{3} \mathrm{UNHPh}$. The properties of these amides as weil as further details on their methods of preparation will be discussed in Section 3.2.

We should note that the melting behavior of the urarium(III) amines follow the order expected based on how difficult it should be to oxidize the compounds to uranium(IV). In this process, the amine ligand niust be reduced to the negatively charged amide, (NHR): When $R$ is an electron withdrawing group such as an aryl, the negative charge will be stabilized, thus the arylamine ligands should be easier to reduce (with concurrent oxidation of the metal center) than methylamine or ammonia. This is seen in the 
melting behavior; the $\mathrm{PhNH}_{2}$ and $\mathrm{p}-\mathrm{MeC}_{6} \mathrm{H}_{4} \mathrm{NH}_{2}$ compounds decompose below $170^{\circ} \mathrm{C}$, while the $\mathrm{MeNH}_{2}$ and $\mathrm{NH}_{3}$ compounds require somewhat higher temperatures.

It should be noted that the ammonia complex is the most difficult of the group to oxidize. As stated earlier, this is the only compound of the group which gave an $\mathbf{M}^{+}$in the mass spectrum. Additionally, when the compound was heated under vacuum (ca. $10^{-4}$ torr) to approximately $100^{\circ} \mathrm{C}$, the material sublimed without decomposton, although the yield was poor.

The thermolysis reaction of the uranium(ID) amines were studied in more detail by 'H NMR spectroscopy. The goal of this study was to, at least crudely, measure the rate of conversion of the amine to the amide. We chose the p-toluid complex, $\left(\mathrm{MeC} \mathrm{C}_{5} \mathrm{H}_{3} \mathrm{U}\left(\mathrm{p}-\mathrm{MeC} \mathrm{C}_{6} \mathrm{H}_{4} \mathrm{~N}_{2}\right)\right.$, for this study because of its desireable solubility properties as well as the favorable positions of the ${ }^{1} \mathrm{H}$ NMR resonances of the compound and the amide derived from it.

A d $\mathrm{d}_{\mathrm{g}}$-toluene solution of the amine of known concentration was prepared in the drybox, and the compound was thermolyzed in a constant temperature bath. After designated time intervals, the compound was removed from the heating bath, cooled briefly in an ice water bath, and the ${ }^{1} H$ NMR spectrum obtainsd. The integration of the methyl resonance of the cyclopentadienyl ring was used to compare the relative amounts of the uranium(III) and (IV) species present. The experiments were continued to ca. $21 / 2$ half-lives, rather than the customary three. This was due to the fact that the resonances from the uranium(II) species are somewhat broad, and when the concertration is relatively low, the integration is difficult to measure accurately. An example of the ${ }^{1} H$ NMR spectrum obtained partway along one of these experiments is shown in Figure 3-9, and a plot of the logarithm of the uranium(III) concentration ratio versus time is shown in Figure 3-10. Note 
from this plot that the reaction follows first-order kinetics. The rate constants were obtained from measuring the slopes of these first-order plots, and the values are:

$$
\begin{aligned}
& k\left(120^{\circ} \mathrm{C}\right)=6.2 \pm 0.6 \times 10^{-4} \mathrm{sec}^{-1} \\
& k\left(110^{\circ} \mathrm{C}\right)=2.7 \pm 0.3 \times 10^{-4} \mathrm{sec}^{-1} \\
& k\left(102^{\circ} \mathrm{C}\right)=1.4 \pm 0.3 \times 10^{-4} \mathrm{sec}^{-1}
\end{aligned}
$$

The error values were obtained simply by using a best estimate for the intergration accuracy, applying these errors, and then finding the meximum and minium slopes that could be obtained in the plot. An Arrhenius plot of ln $k$ vs. $1 / T$ was then used to obtain the activation energy of this reaction, and a value of $E_{a}=24 \pm 6 \mathrm{kcal} \mathrm{mol}^{-1}$ was obtained. 


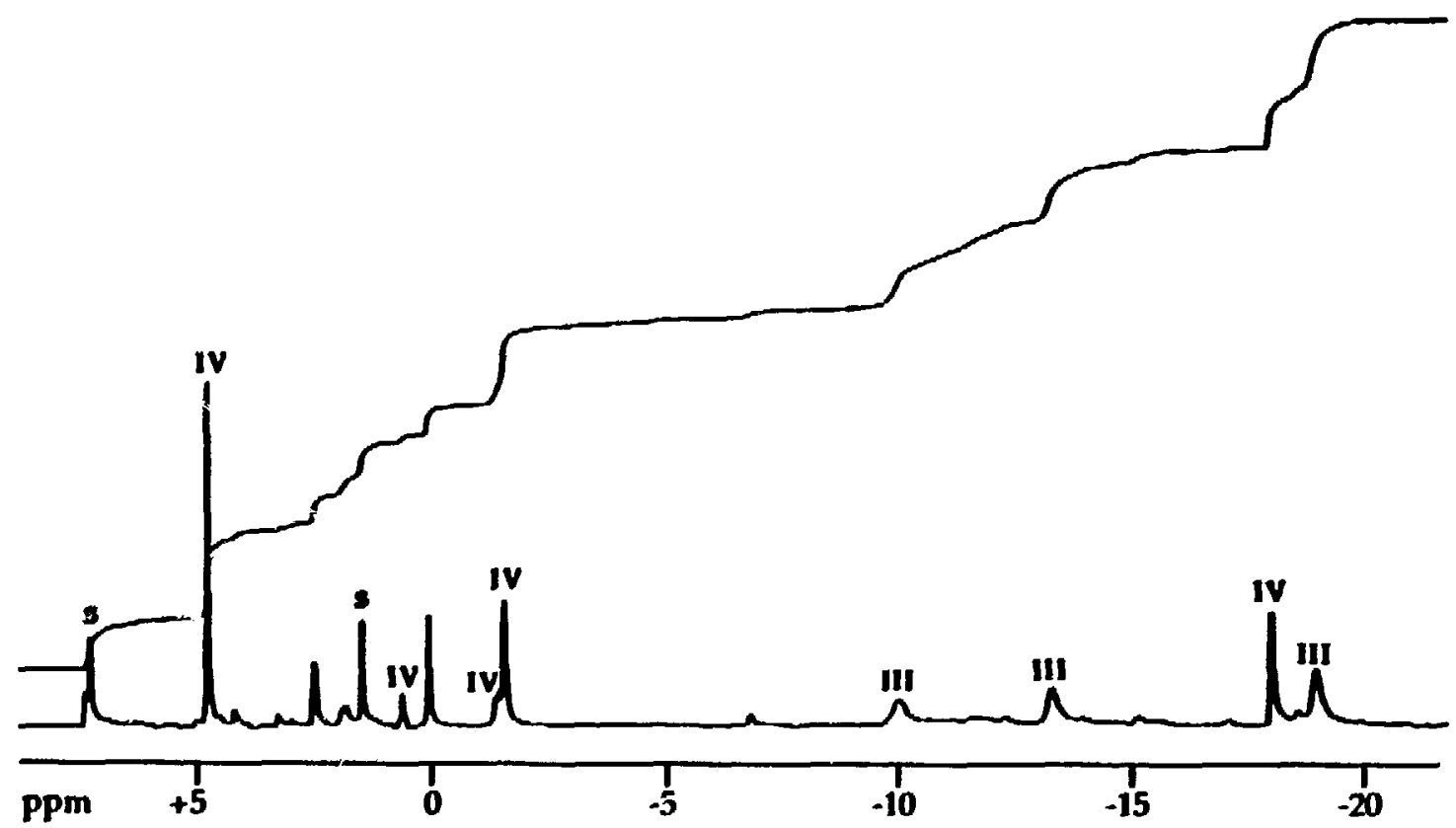

Figure 3-9: The ' $\mathrm{H}$ NMR spectrism of the thermolysis of (Me $\left.C_{-5} \mathrm{ri}_{4}\right)_{3} \mathrm{U}\left(\mathrm{NH}_{2}-\mathrm{p}-\mathrm{MeC}_{6} \mathrm{H}_{4}\right)$ after 1200 seconds at $120^{\circ} \mathrm{C}$. The peaks marked "IV" are from the uranium(IV) amide, those marked "III" are from the uranium(III) amine, and those marked " $\mathrm{s}$ " are from solvent. 
Figure 3-10: Kinetles plot of the thermal decomposition of $\left(\mathrm{MeC}_{5} \mathrm{H}_{4}\right)_{3} \mathrm{U}\left(\mathrm{NH}_{2}-\mathrm{p}-\mathrm{MeC}_{6} \mathrm{H}_{4}\right)$.

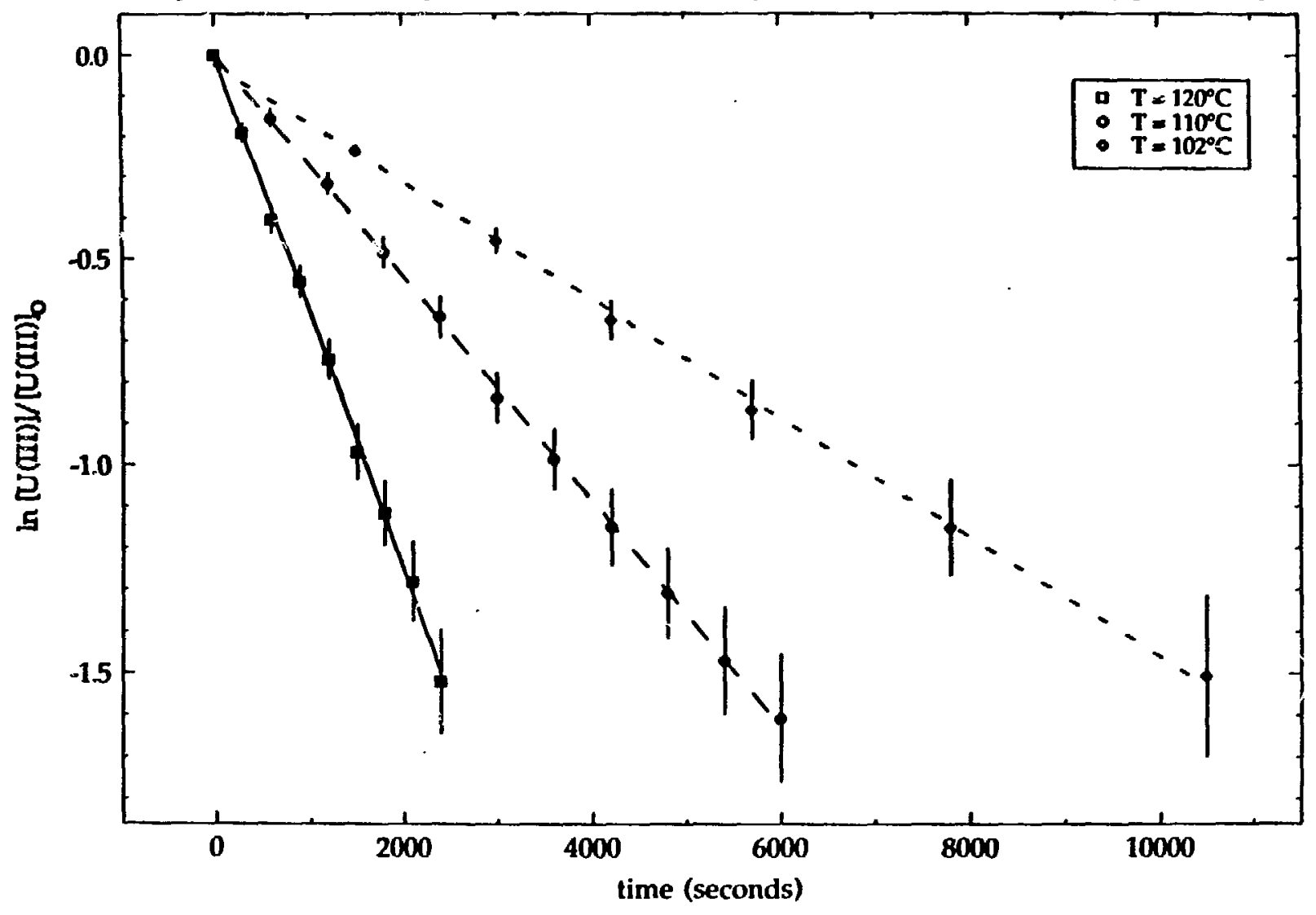




\section{Section 3.2: Preparation and Properties of $\left(\mathrm{MeC}_{5} \mathrm{H}_{4}\right)_{3}$ UNHR Compounds}

A number of cyclopentadienyl uranium(IV) amides have been previously reported. The first of these was $\mathrm{CP}_{2} \mathrm{U}\left(\mathrm{NEt}_{2}\right)_{2}$, which was synthesized in 1974 by Jamerson and Takats. ${ }^{7}$ More recently, several reports of triscyclopentadienyl uratium amides of the form $\mathrm{CP}_{3} \mathrm{UNR}_{2}$ have appeared, with $\mathrm{R}=\mathrm{Et}$ or $\mathrm{Ph}$. Thit insertion chemistry of the various bis- and triscyclopentadienyl uranium amides has also been investigated to some exient." However, it should be noted that all of these materials are amides derived from secondary amines.

Sevaral methods were used to prepare the uranium(IV) amides described in this work. One of the compounds had been prepared previously by Brennan, ${ }^{2 b}\left(\mathrm{MeC}_{5} \mathrm{H}_{4}\right)_{3} \mathrm{UNHPh}$. He made this material by a reduction of the uranium( $V$ ) imide using ethylisocyanide, as described in Chapter 1. Table 3.5 below summarizes the properties of the $\left(\mathrm{MeC}_{5} \mathrm{H}_{4}\right)_{3} \mathrm{UNHR}$ compounds that have been synthesized:

\begin{tabular}{|c|c|c|c|}
\hline $\mathbf{R}$ & color & m.p. $\left(^{\circ} \mathrm{C}\right)$ & $\delta_{\mathrm{N} \cdot \mathrm{H}}$ (ppm) \\
\hline $\mathrm{H}$ & green & $\operatorname{dec}>260$ & -135.4 \\
$\mathrm{Mc}$ & green-red & $215-220$ & -103.8 \\
$\mathrm{Ph}$ & red & $128-129$ & -164.6 \\
${\mathrm{p}-\mathrm{MeC}_{6} \mathrm{H}_{\mathrm{*}}}$ & red & $92-94$ & -1588 \\
\hline
\end{tabular}

Table 3.5: Properties of $\left(\mathrm{MeC}_{5} \mathrm{H}_{4}\right)_{3} \mathrm{UNHR}$ compounds. 
The most common technique used to prepare these amides was the thermal decomposition of the corresponding amines, as described in the previous section. For the arylamides, this technique works extremely well at relatively low temperatures $\left(\mathrm{ca} .160^{\circ} \mathrm{C}\right.$ ). The bright red residue formed on heating can be extracted with hexane and red blocks of $\left(\mathrm{MeC}_{5} \mathrm{H}_{4}\right)_{3} \mathrm{UNHAr}(\mathrm{Ar}=\mathrm{Ph}$ or $\mathrm{p}-$ $\mathrm{MeC}_{\mathbf{6}} \mathrm{H}_{4}$ were cystallized from the solution. Isolated yields from this procedure were typically on the order of 50\%.

This solid phase thermolysis reaction also works for formation of the methylamide, $\left(\mathrm{MeC}_{3} \mathrm{H}_{4} \mathrm{~V}_{3} \mathrm{UNH}\right.$ Me. However, this compound is much less soluble than the arylamides, and the material must be extracted with hot toluene. In addition, this reaction required a somewhat higher temperature (ca. $200^{\circ} \mathrm{C}$ ). In contrast, $\left(\mathrm{MeC}_{5} \mathrm{H}_{4}\right)_{3} \mathrm{UNH}_{2}$ could not be prepared from the ammonia complex by a solid phase reaction.

These pyrolysis reactions may also be accomplished in solution. This was described in Section 3.1 for the kinetics measurements of the decompostion of the uranium(III) arylamines. For the compound $\left(\mathrm{MeC}_{5} \mathrm{H}_{4}\right)_{3} \mathrm{U}\left(\mathrm{NH}_{2}-\mathrm{p}-\mathrm{MeC}_{6} \mathrm{H}_{4}\right)$, this reaction is ressonably rapid at $100-120^{\circ} \mathrm{C}$. However, when an analogous reaction was performed on a preparative scale with $\left(\mathrm{MeC}_{3} \mathrm{H}_{4}\right)_{3} \mathrm{U}\left(\mathrm{NH}_{3}\right)$, it was found to be somewhat slower. The ammonia complex was dissolved in toluene and heated to reflux $\left(-110^{\circ} \mathrm{C}\right)$ for several hours, but at the end of this period the material still seemed to be the dark color of the trivalent uranium species. The reaction may be done using xylenes as solvent (b.p. $-140^{\circ} \mathrm{C}$ ) and in less than two hours of reflux $\left(\mathrm{MeC}_{5} \mathrm{H}_{4}\right)_{3} \mathrm{UNH}_{2}$ can be isolated.

Several other reactions have been used to produce the uranium(IV) amide compounds. In general, these reactions were used to prepare one or two of the compounds rather than the whole group of amides. The first of 
these reactions was displacement of the methyl group of a uranium(IV) alkyl using aniline (Scheme 3-5):

$$
\widehat{\mathrm{O}}_{3} \mathrm{UMe}+\mathrm{PhNH}_{2} \underset{\text { hexane }}{\rightarrow} \widehat{\mathrm{O}}_{3} \mathrm{U}-\mathrm{NHPh}+\mathrm{MeH}
$$

Scheme 3-5: Preparation of a uranium anide by raction of an alkyl with aniline.

This reaction is accomplished simply by refluxing $\left(\mathrm{MeC}_{5} \mathrm{H}_{4} \mathrm{U}_{3} \mathrm{UN}\right.$ \% with excess aniline in hexane solvent. The reaction appeared to be quite slow, as the color change from the green of the uranium methyl compound to the bright cherry red of the amide occurred over ca. 2 1/2 days. The amide $\left(\mathrm{MeC}_{3} \mathrm{H}_{4}\right)_{3} \mathrm{UNH}$ Ph was isolated in 38\% yield. One apparent problem with this process that may account for the low yield is the instability of $\left(\mathrm{MeC}_{5} \mathrm{~F}-\mathrm{D}_{3} \mathrm{UMe}\right.$ at elevated temperatures. Although $\mathrm{Cp}_{3} \mathrm{UMe}$ is reported to be quite suble at high temperatures, ${ }^{3}$ we have found that $\left(\mathrm{MeC}_{5} \mathrm{H}_{4}\right)_{3} \mathrm{UMe}$ decomposes fairly rapidly below $100^{\circ} \mathrm{C}$ when heated in a sealed capillary. Indeed, in the reaction of the methyl compound with aniline in refluxing hexane, considerable amount of insoluble material was produced. Attempts to speed up this reaction using a higher boiling solvent such as toluene were futile; in this case, even more decomposition was noted and the yield of the uranium(IV) amide was far poorer. The driving force for this reaction should be the pKa of aniline vs. methane; aniline has a pKa of ca. 28, while MeH has a pKa of -58.10 Thus aniline should be deprotonated.

A second reaction used to prepare the uranium(IV) amides was oxidation of the corresponding amine using the trityl radical. In particular, this reaction was used for the conversion of the ammonia complex to the amide (Scheme 3-6): 


$$
\widehat{\mathrm{Q}}_{3} \mathrm{U}\left(\mathrm{NH}_{3}\right)+\mathrm{Ph}_{3} \mathrm{C} \cdot \stackrel{\text { bluene }}{\longrightarrow} \widehat{\mathrm{O}}_{3} \mathrm{U}-\mathrm{NH}_{2}+\mathrm{Ph}_{3} \mathrm{CH}
$$

Schene 3-6 Reaction of the uranium(III) ammonis complex with trityl radical.

Preparation of the trityl dimer was accomplished by a previously described procedure (Scheme 3-7):11

$$
\mathrm{Ph}_{3} \mathrm{Cl} \underset{\text { toluere }}{\stackrel{\text { "molecular" }}{\longrightarrow}} \mathrm{Ph}_{3} \mathrm{C} \cdot+\mathrm{AgCl}_{8}
$$

Scheme 3-7: Preparation of the trityl radical.

It was found that "molecular" silver was necessary to get complete reduction of the chloride; the electrochemical preparation of this material has been described by Brauer. 12 We found that when the toluene solvent was removed, the trityl dimer contained one molecule of solvent. Thus, the material was used as though ic had the composition $\left(\mathrm{Ph}_{3} \mathrm{C}\right)_{2}(\mathrm{PhMe})$. When one-half molar equivalent of this material was added to a toluene solution of $\left(\mathrm{MeC}_{5} \mathrm{H}_{4}\right)_{3} \mathrm{U}\left(\mathrm{NH}_{3}\right)$, the color immediately changed from deep red-brown to pale green. After filtration and removal of the solvent, the ${ }^{1} \mathrm{H}$ NMR spectrum of the residue showed a mixture of the compounds $\left(\mathrm{MeC}_{5} \mathrm{H}_{4}\right)_{3} \mathrm{UNH}_{2}$ and $\mathrm{Ph}_{3} \mathrm{CH}$. Attempts at fractional recrystallization of this mixture were futile. Thus, oxidation of the uranium(III) amine using the trityl radical is favored, but purification of the uranium(IV) product is difficult. This reaction is not surprising; the oxidation from uranium(III) to uranium(IV) and the formation of a C-H bond (even a weak $\mathrm{C}-\mathrm{H}$ bond as should exist in $\mathrm{Ph}_{3} \mathrm{CH}$ ) should be enough of a driving force to make the 
reaction occur. In addition, the $\mathrm{U}-\mathrm{N}$ bond in the tetravalent uranium product should be stronger than in the trivalent uranium coordination complex.

It should briefly be noted here that attempts to oxidize an amide to the uranium( $V$ ) imide using this procedure were unsuccessful. In one attempt, $\left(\mathrm{MeC}_{5} \mathrm{H}_{4} \mathrm{UU}_{2} \mathrm{NH}_{2}-\mathrm{p}-\mathrm{MeC} \mathrm{C}_{4}\right)$ and two molar equivalents of $\mathrm{Ph}_{3} \mathrm{C}$. were mixed

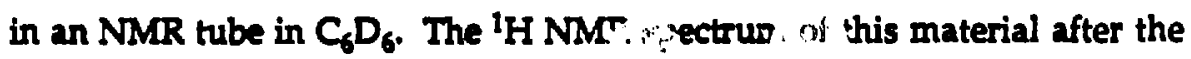
initial mixing indicated the presence af three rens $p$ inds: $\left(\mathrm{MeC}_{5} \mathrm{H}_{4}\right)_{3} \mathrm{UNH}-\mathrm{p}-\mathrm{MeC}_{6} \mathrm{H}_{4}$ (from oxddation of the amine by the trityl radical), $\mathrm{Ph}_{3} \mathrm{CH}$, and $\mathrm{Ph}_{3} \mathrm{C}$. After the $\mathrm{NMR}$ tube had been heated to $120^{\circ} \mathrm{C}$ for twenty minutes, another spectrum was taken. No $\left(\mathrm{MeC}_{5} \mathrm{H}_{4}\right)_{3} \mathrm{UN}-\mathrm{p}-\mathrm{MeC}_{6} \mathrm{H}_{4}$ had been formed, and the amount of $\mathrm{Ph}_{3} \mathrm{C}$. remaining seemed to have slightly decreased. After $91 / 2$ hours of heating at $120^{\circ} \mathrm{C}$, there was still no uranium(V) imide in the solution, and the trityl radical had completely decomposed. Again this is not a surprising result, since the oxidation of uranium(IV) to uranium(V) is an endothermic process.

One final method used to prepare uranium(IV) amides was the reaction of a uranium(II) amine with a uranium(V) imide. This reaction was described in Section 1.4.B, and was performed with the p-tolyl compounds $\left(\mathrm{MeC}_{5} \mathrm{H}_{4}\right)_{3} \mathrm{U}\left(\mathrm{NH}_{2}-\mathrm{p}-\mathrm{MeC}_{6} \mathrm{H}_{4}\right)$ and $\left(\mathrm{MeC}_{5} \mathrm{H}_{4} \mathrm{UN}-\mathrm{p}-\mathrm{MeC}_{6} \mathrm{H}_{4}\right.$ to form (MeC5 $\left.\mathrm{H}_{4}\right)_{3} \mathrm{UNH}-\mathrm{p}-\mathrm{MeC}_{6} \mathrm{H}_{4}$. The driving force for this process is apparently the energy gain from conversion of uranium(II) and uranium(V) to uranium(IV).

The 'H NMR spectra of these uranium amides are typical of tetravalent uranium cyclopentadienyl compounds. The chemical shifts and linewidths of the compounds are shown in Table 3-6. The resonance due to the amide $\mathrm{N}-\mathrm{H}$ proton is shifted far upfield, as was seen for the amine protons in the uranium(III) compounds. A typical spectrum is shown in Figure 3-11. J. 


\begin{tabular}{|c|c|c|c|c|c|}
\hline $\mathbf{R}$ & Ring Me & Ring $H$ & Ring $\mathbf{H}$ & $\mathbf{N H}$ & Substituent \\
\hline $\mathbf{H}$ & +0.39 & -5.73 & -17.07 & $\begin{array}{c}-135.4 \\
(t, J=44 \mathrm{~Hz})\end{array}$ & \\
\hline Me & +1.44 & $\begin{array}{c}-10.71 \\
\left(v_{1 / 2}=7 \mathrm{~Hz}\right)\end{array}$ & $\begin{array}{c}-14.98 \\
\left(v_{1 / 2}=7 \mathrm{~Hz}\right)\end{array}$ & $\begin{array}{c}-103.8 \\
\left(v_{1 / 2}=50 \mathrm{~Hz}\right)\end{array}$ & $\begin{array}{c}+7.29 \\
(\mathrm{~d}, J=6 \mathrm{~Hz})\end{array}$ \\
\hline Ph & +4.20 & $\begin{array}{c}-1.03 \\
\left(v_{1 / 2}=8 \mathrm{~Hz}\right)\end{array}$ & $\begin{array}{c}-18.56 \\
\left(v_{1 / 2}=9 \mathrm{~Hz}\right)\end{array}$ & $\begin{array}{c}-164.6 \\
\left(v_{1 / 2}=24 \mathrm{~Hz}\right)\end{array}$ & $\begin{array}{l}-33.58(\mathrm{~d}, 2 \mathrm{H}) \\
-2.10(\mathrm{t}, 2 \mathrm{H}) \\
-5.18(\mathrm{t}, 1 \mathrm{H})\end{array}$ \\
\hline $\mathrm{p}-\mathrm{MeC}_{6} \mathrm{H}_{4}$ & $\begin{array}{c}+4.38 \\
\left(v_{1 / 2}=2 \mathrm{~Hz}\right)\end{array}$ & $\begin{array}{c}-1.91 \\
\left(v_{1 / 2}=7 \mathrm{~Hz}\right)\end{array}$ & $\begin{array}{c}-18.46 \\
\left(v_{1 / 2}=7 \mathrm{~Hz}\right)\end{array}$ & $\begin{array}{c}-158.8 \\
\left(v_{1 / 2}=19 \mathrm{~Hz}\right)\end{array}$ & $\begin{array}{c}-32.78(\mathrm{~d}, 2 \mathrm{H}, \mathrm{J}=8 \mathrm{~Hz}) \\
-1.80(2 \mathrm{H}) \\
+1.04(3 \mathrm{H})\end{array}$ \\
\hline
\end{tabular}

Table 3-6: Chemical shifts (ppm) of the resonances in the 'H NMR spectra of the uranium(IV) amide complexes $\left(\mathrm{MeC}_{5} \mathrm{H}_{4}\right)_{3} \mathrm{UNHR}$. 

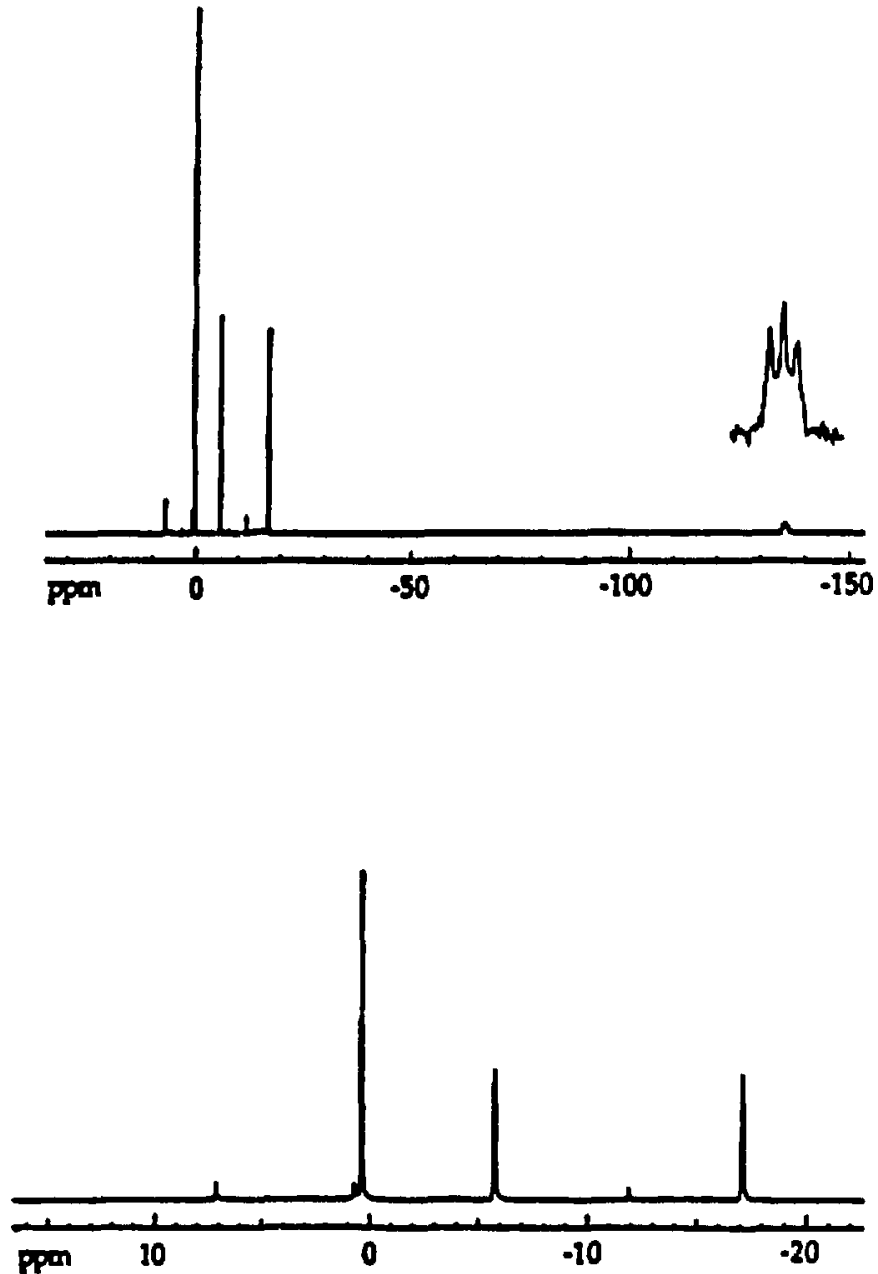

Figure 3-11: ${ }^{1} \mathrm{H}$ NMR spectra of $\left(\mathrm{MeC}_{5} \mathrm{H}_{4}\right)_{3} \mathrm{UNH}_{2}$. 
Stewart observed a similar shift in the compound $\left[\left(\mathrm{Me}_{3} \mathrm{Si}\right)_{2} \mathrm{~N}\right]_{3} \mathrm{UNH}-\mathrm{p}-\mathrm{MeC}_{6} \mathrm{H}_{4}$ with $\delta_{\mathrm{N} \cdot \mathrm{H}}=-213 \mathrm{ppm} .{ }^{13} \mathrm{It}$ is interesting to note that the arylamine $\mathrm{N}-\mathrm{H}$ resonances are shifted the furthest upfield in these tetravalent species, which is opposite to that seen in the trivalent compounds. It is difficult to explain what causes these shifts, but one possible explanation is that the more the lone pair on the ritrogen in these amides is involved in donation to the metal center, the less negative the nitrogen will be and the further downfleld the N-H risonance should shift. When the substituent on the amide is electron-donating such as a methyl, the nitrogen lone pair will be destabilized and the lone pair will be more likely to interact with the uranium. Conversely, in the arylamides, the lone pair will be stabilized by the electron-withdrawing nature of the substituent, leaving the nitrogen with more partial negative charge and shifting the $\mathrm{N}-\mathrm{H}$ resonance upfield.

The most interesting feature of the ${ }^{1} \mathrm{H}$ NMR spectra of the amides was seen in the spectrum of $\left(\mathrm{MeC}_{5} \mathrm{H}_{4}\right)_{3} \mathrm{UNH}_{2}$. The peak due to the $\mathrm{NH}_{2}$ protons was observed as a 1:1:1 triplet, due to coupling between the protons and the ${ }^{14} \mathrm{~N}$, which has a nuclear spin of 1 . The coupling constant was measured to be $J_{11} \cdot \mathrm{H}=44 \mathrm{~Hz}$. The compound $\left(\mathrm{MeC}_{5} \mathrm{H}_{4}\right)_{3} \mathrm{U}\left({ }^{15} \mathrm{NH}_{3}\right)$, discussed earlier in this chapter, was oxidized using the trityl radical technique to prepare the labelled tetravalent amide, $\left(\mathrm{MeC}_{5} \mathrm{H}_{4}\right)_{3} \mathrm{U}^{15} \mathrm{NH}_{2}$. The ${ }^{1} \mathrm{H}$ NMR spectrum of the labelled material showed a doublet for the $\mathrm{NH}_{2}$ resonance, with $\mathrm{J}_{13 \mathrm{~N} \cdot \mathrm{H}}=65 \mathrm{~Hz}$. These resonances are shown in Figure 3-12. It is very unusual to observe ${ }^{14} \mathrm{~N}$ coupling in molecules of this nature, and it is interesting that it is not seen in the substituted amides. The observation of this coupling is directly related to the relaxation time of the ${ }^{14} \mathrm{~N}$ nucleus. ${ }^{14}$ These data prove that the 1:1:1 
189
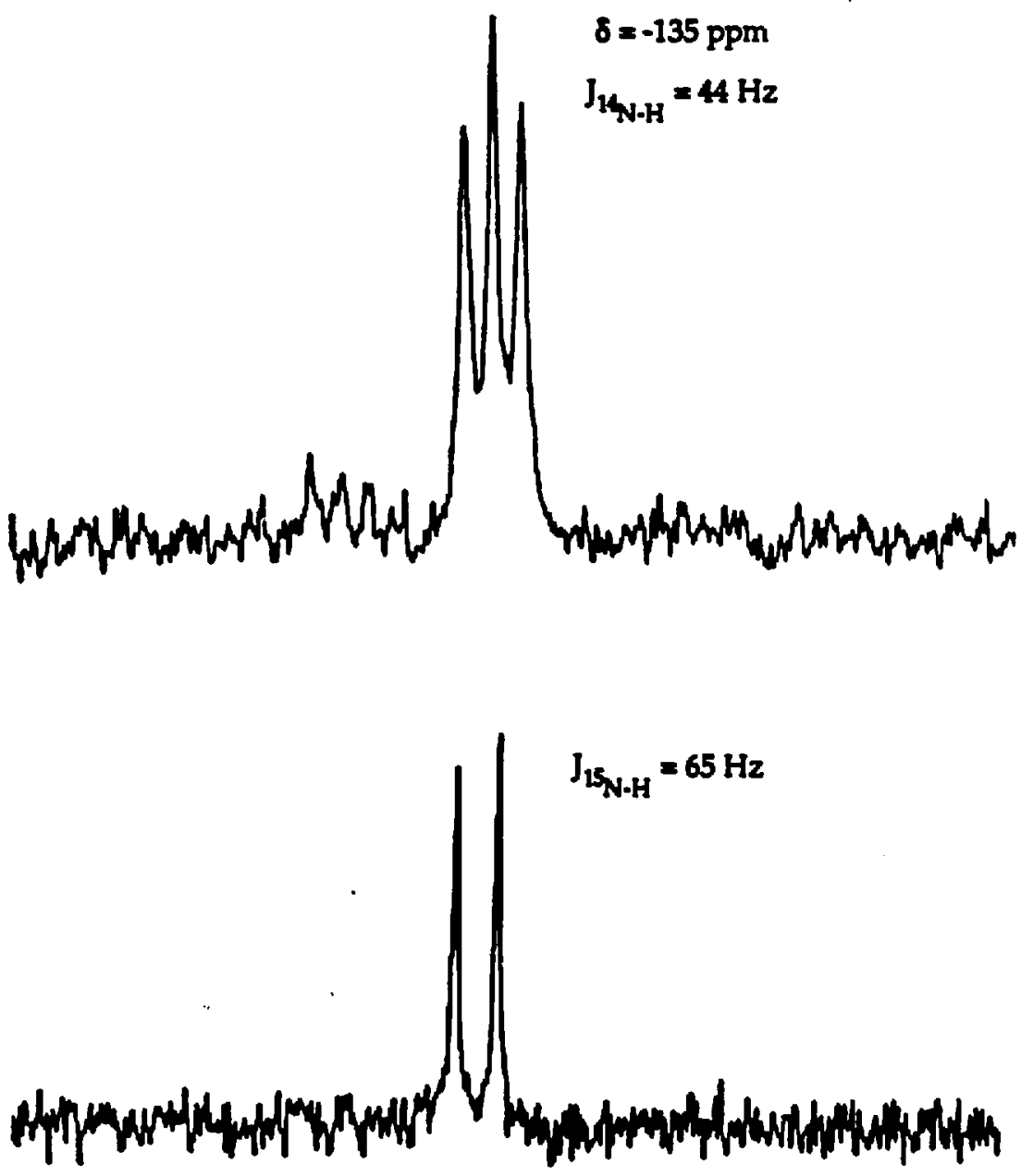

Figure 3-12: 'H NMR spectra showing the N-H resonances of $\left(\mathrm{Me} \mathrm{C}_{3} \mathrm{H}_{4}\right)_{3} \mathrm{UNH}_{2}$ (top) and $\left(\mathrm{Me} \mathrm{C}_{3} \mathrm{H}_{4}\right)_{3} \mathrm{U}^{13} \mathrm{NH}_{2}$ (bottom). 
triplet is due to ${ }^{14} \mathrm{~N}-\mathrm{H}$ coupling since $\left|\mathrm{J}_{14} \mathrm{~N}-\mathrm{H}\right|=0.713 \cdot\left|\mathrm{J}_{15} \mathrm{~N}-\mathrm{H}\right|^{13}$ and the values obtained for these uranium amides fit this formula.

The value of $\mathrm{J}_{25} \mathrm{~N} \cdot \mathrm{H}$ in $\left(\mathrm{MeC}_{5} \mathrm{H}_{4}\right)_{3} \mathrm{U}\left(\mathrm{NH}_{3}\right)$ is $60 \mathrm{~Hz}$ and in $\left(\mathrm{MeC}_{5} \mathrm{H}_{4}\right)_{3} \mathrm{UNH}_{2}$ it is $65 \mathrm{~Hz}$, indicating that the amount of s-character (hybridization) at nitrogen in both compounds is similar. This can be stated because the coupling constant is directly related to the amount of s-character in the N-H bonds; an empirical reault is given by $\left.\% s=0.34[]_{15} \mathrm{~N} \cdot \mathrm{H}\right]^{13}$ This suggests that $\mathrm{NH}_{2}$ is pyramidal in $\left(\mathrm{MeC} \mathrm{CH}_{4}\right)_{3} \mathrm{UNH}_{2}$, though we have no supporting evidence for this deduction.

No N-H stretches are observed in the infrared spectra of the amides, with the exception of the compound $\left(\mathrm{MeC}_{5} \mathrm{H}_{4}\right)_{3} \mathrm{UNH}_{2}$. This material exhibits a single very weak stretch at $3315 \mathrm{~cm}^{-1}$. Note that Stewart also did not observe an $\mathrm{N}-\mathrm{H}$ stretch in the uranium amide complex $\left[\left(\mathrm{Me} \mathrm{Si}_{2} \mathrm{~N}\right]_{3} \mathrm{UNH}-\mathrm{p}-\mathrm{MeC}_{6} \mathrm{HI}_{4}{ }^{\mathrm{L3}}\right.$ All of the amides exhibit parent molecular ions in the electron impact mass spectra.

Very few reactions involving these uranium amides were carried out, although several reactions were attempted using $\left(\mathrm{MeC}_{5} \mathrm{H}_{4}\right)_{3} \mathrm{UNH}_{2}$. When this material was dissolved in toluene and placed under ca. 15 atmospheres of $C O$ or $D_{2}$, tan insoluble precipitates were obtained, and the reactions were not pursured further. Interestingly, (MeC $\mathrm{CH}_{4} \mathrm{UNNH}_{2}$ reacted with trimethylaluminum to give the known tetravalent uranium alkyl, $\left(\mathrm{MeC}_{5} \mathrm{H}_{4}\right)_{3} \mathrm{CMe}$. When the reaction was performed with dichloromethane as solvent, a mixture of the methylated material and $\left(\mathrm{MeC}_{5} \mathrm{H}_{4}\right)_{3} \mathrm{UCl}$ was obtained (as observed by ' $\mathrm{H}$ NMR spectroscopy). We believed that the uranium(IV) chloride was being formed by reaction of the methyl compound with the $\mathrm{CH}_{2} \mathrm{Cl}_{2}$ solvent, since the uranium amide is stable in this solvent. To test this, $\left(\mathrm{MeC}_{5} \mathrm{H}_{4}\right)_{3} \mathrm{UNH}_{2}$ and $\mathrm{AlMe}_{3}$ were allowed to react for three days 
in toluene. The ${ }^{1} H$ NMR spectrum of the green residue indicated that relatively pure $\left(\mathrm{MeC}_{5} \mathrm{H}_{4}\right)_{3} \mathrm{UMe}$ was formed. Presumably, the mechanism of this reaction involves coordination of the $\mathrm{AlMe}_{3}$ aluminum to the nitrogen lone pair and attack of a methyl group on the uranium through a $\mu$-methyl bridge, resulting in the uranium(IV) methyl product and $\mathrm{Me}_{2} \mathrm{AlNH}_{2}$ (Scheme 3-8):

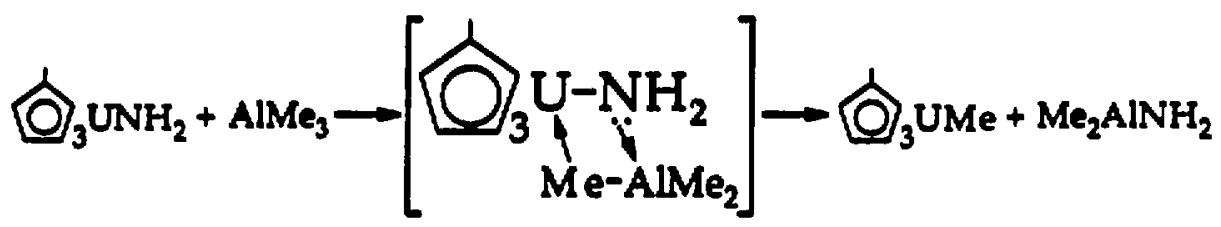

Scheme 3-1: Possible mechanism for the methylation of the $\mathrm{UNH}_{2}$ compound with AlMe3. 


\section{Section 3.3 Preparation and Properties of $\left(\mathrm{MeC}_{3} \mathrm{H}_{4}\right)_{3} \mathrm{U}-\mathrm{N}(\mathrm{R}) \mathrm{NH}_{2}$ Compounds}

A number of reactions between both trivalent and tetravalent uranium and hydrazines have been studied in this work, and these reactions are described in this section. Most of the work has focused on phenylhydrazine; this system has been the most well-behaved and thus easiest to study. The goal of this research was to see whether uradum(II) hydrazine coordination compounds could be prepared in an analogous manner to the uranium amines, and whether these could then be oxidized to the uranium(IV) hydrazide species.

One reason why we were particularly interested in hydrazines as ligands is the variety of different forms this species can take; compounds utilizing neutral hydrazines, hydrazido(1-), and hydrazido(2-) have all been reported. ${ }^{26}$ In addition, these compounds exhibit both $\eta^{1}$ and $\eta^{2}$ types of bonding, leading to interesting molecules.

Our earliest attempts at preparation of these compounds involved the reaction of $\left(\mathrm{MeC} \mathrm{C}_{4}\right)_{3} \mathrm{U}$ (th) with $\mathrm{PhNHNH}_{2}$ in toluene solution. When one molar equivalent of phenylhydrazine was added to the thf-complex, an immediate lightening of the color to bright red was observed. After one hour, tire volatile materials were removed, and the residue extracted with ether. Attempts to crystallize a product from this extract yielded only red oily material. The ${ }^{1} \mathrm{H}$ NMR spectrum of this material indicated that two products formed; one was a new material with linewidths in the NMR spectrum that indicated tetravalent uranium (this was, by integration, $c a .2 / 3$ of the product) and the second was the uranium(IV) amide, $\left(\mathrm{MeC}_{5} \mathrm{H}_{4}\right)_{3} \mathrm{UNNHPh}$. Recrystallization of the oily solid from an ether/hexane mixture gave 
orange/red crystals whose ${ }^{1} \mathrm{H}$ NMR spectrum showed it to be the unknown product, formulated as a uranium(IV) hydrazide, as shown below (Figure 313):

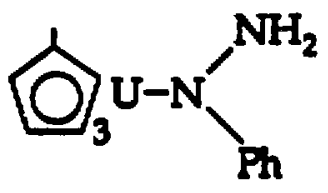

Foure 312. Propond etructure of the urenium(V) phenythydraxde.

Formation of this product, with loss of a proton from the ritrogen containing the aryl group, is not surprtsing. The proton on the phenyl nitrogen shculd be more acidic than those on the the $\mathrm{NH}_{2}$ end of phenylhydrazine, due to the presence of the electron withdrawing aryl group which can help stabilize the negative charge.

The properties of this molecule and detail on its characterization will be discussed later in this section.

The observation that this reaction also produced $\left(\mathrm{MeC}_{5} \mathrm{H}_{4}\right)_{3} \mathrm{UNH} P h$ led us to wonder whether the hydrazide compound could be forced to rearrange to this molcule. Heating some of the plire $\left(\mathrm{MeC} \mathrm{CH}_{4} \mathrm{~J}_{3} \mathrm{LN}(\mathrm{Ph}) \mathrm{NH}_{2}\right.$ to $100^{\circ} \mathrm{C}$ in a Schlenk tube for several hours and subsequent examination of the ${ }^{1} \mathrm{H}$ NMR spectrum showed that the hydrazide was completely converted to the amide. This thermolysis reaction will be discuseed in more detail later in this section.

The fact that the phenylhydrazide was converted to the amide at $100^{\circ} \mathrm{C}$ led us to attempt the preparation at lower temperatures. Thus, $\left(\mathrm{MeC}_{5} \mathrm{H}_{4}\right)_{3} \mathrm{U}$ (thi) and phenylhydrazine were allowed to react in ether at $0^{\circ} \mathrm{C}$ for less than five minutes. The ethar was then removed, and the reaction mixture extracted with ether while keeping tile temperature below $0^{\circ} \mathrm{C}$. 
Crystallization at $80^{\circ} \mathrm{C}$ gave brown crystals in very low yield, which the ${ }^{1} \mathrm{H}$ NMR spectrum showed to be the uranium(III) ammonia complex, $\left(\mathrm{MeC}_{5} \mathrm{H}_{4}\right)_{3} \mathrm{U}\left(\mathrm{NH}_{3}\right)$. Further concentration of the remaning ether solution and addition of hexane to this solution eventually gave orange crystals of the pure uranium(IV) phenylhydrazide in $<20 \%$ yield.

Although it is difficult to speculate on how the uranium(III) ammonia complex was formed in this resction, it was evident that the isolation of the phenylhydruxide by this method was tadious, complicated by the formation of other products, and accompliahed in very poor yield. We thereiore decided to take advantage of the acidity of the phenylhydratine to prepare the compound by reaction with a uranium alkyl as shown in Scheme 3-9:

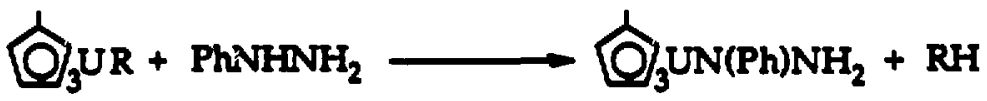

Schene 3-: Formation of the urasium(IV) phenylhydraside from alkyls.

Note that this reaction is directly analogous to the reaction of the uranium(IV) methyl compound with aniline discussed in Section 3.2 .

Two different alkyls were used in this reaction. The compound with $R$ - Bu has been prepared by Brennan 25 . This material was found to react with phenylhydruzine in either toluene or ether for about one hour to give the phenylhydrazide. However, it was again difficult to obtain the product in high purity and in crystalline form; an oily product was repeatedly obtained. One ceason for this may be that the tert-butyl alkyl slowly decomposes in solution, ${ }^{17}$ thus excess phenylhydrazine in the reaction mixture will lead to impure products. An attempt was made to substitute the uranium(IV) methyl compound for the t-butyl; this reaction was also found to produce the 
uranium(IV) hydrazide, however the reaction required elevated temperatures (ca. $80-100^{\circ} \mathrm{C}$ ) and again nicely crystalline product was difficult to obtain. Thus we conclude that replacement of the alkyl group with the phenylhydrazide by a protonation reaction is, as we'd expect, favored, however it is a poor synthetic route to give us $\left(\mathrm{MeC}_{5} \mathrm{H}_{4}\right)_{3} \mathrm{UN}(\mathrm{Ph}) \mathrm{NH}_{2}$ in high yield and purity.

An additional attempt to prepare this compound was then made using the tatrakis(cyclopentadienyl) uranium specles, $\left.\mathrm{MeC}_{5} \mathrm{H}_{4}\right)_{4} \mathrm{U}$. A good preparation for this material has recently been developed by Weydert ${ }^{17}$, and we felt that relief of the steric congention in this molecule might be a driving force for the removal of one cyclopentadienyl ring by protonation (Scheme 3 10).

$$
\hat{\mathrm{Q}}_{4} \mathrm{U}+\mathrm{PhNHNH}_{2} \longrightarrow \hat{\mathrm{Q}}_{3} \mathrm{UN}(\mathrm{Ph}) \mathrm{NH}_{2}+\mathrm{MeC}_{5} \mathrm{H}_{5}
$$

Scheme 3-10. Preparation of the urasium(IV) phenylhydrazide from $\left(\mathrm{MeC}_{5} \mathrm{H}_{4}\right)_{4} \mathrm{U}$.

The acidities of the phenylhydrazine versus methylcyclopentadiene (pKa ca. 18), however, made this reaction seem unlikely to proceed lthe pKa of phenylhydrazine should be greater than that of aniline $(-28)$, since the protonated form of phenylhydrazine ( $\left.\mathrm{PhNH}_{\mathrm{NH}} \mathrm{H}, \mathrm{pKa}=7.95\right)$ is less acidic than the protonated form of aniline $\left(\mathrm{PhNF}_{3}^{+}, \mathrm{pKa}=4.60\right)^{10}$. When $\left(\mathrm{MeC}_{5} \mathrm{H}_{4}\right)_{4} \mathrm{U}$ and phenylhydrazine were allowed to react in toluene, a gradual lightening of the solution color from red to orange was observed over a period of two days. Removal of volatile materials and crystallization from an ether/hexane mixture gave $\left(\mathrm{MeC}_{5} \mathrm{H}_{4}\right)_{3} \mathrm{UN}(\mathrm{Ph}) \mathrm{NH}_{2}$ in $>50 \%$ yield as red- 
orange bricks. The material was found to be pure and this is the best preparation of the phenylhydrazide we have found thus far.

The characterization of this material was accomplished mainly through infrared and ${ }^{1} H$ NMR spectroscopy, with the aid of a labelling experiment using an ${ }^{15} \mathrm{~N}$-oubstituted phenythydrazine that will be described shortly. The infrared spectrum of $\left(\mathrm{MrC} \mathrm{CH}_{4} \mathrm{H}_{3} \mathrm{UN}(\mathrm{Ph}) \mathrm{NH}_{2}\right.$ is shown in Figure 3-14. Two N-H stretches are observed, at 3285 and $3223 \mathrm{~cm}^{-1}$. The ${ }^{1} \mathrm{H}$ NMR spectrum of the compound is shown in Figure 3-15. The typical 3:2:2 pattern from the $\mathrm{MeC}_{5} \mathrm{H}_{4}$ rings is seen at $8=-0.03 \mathrm{ppm},-5.7 \mathrm{ppm}$, and $-18.3 \mathrm{ppm}$. Only two of the resonances from the phenyl ring were obeerved at room temperature; these appear as a doublet at $\delta=10.9 \mathrm{ppm}$ and a doublet of doublets at $\delta=8.2 \mathrm{ppm}$. These resonances both integrate to two protons, and are assigned as the ortho and meta protons, respectively. The para proton is probably under the solvent signal at $\delta=7.15 \mathrm{ppm}$ at room temperature; the variable temperature NMR spectrum of this compound will be discussed later. The $\mathrm{NH}_{2}$ resonance is seen as a sharp singlet at $\delta=-9.3 \mathrm{ppm}$. The position of this resonance seems to suggest that this nitrogen is not interacting strongly with the metal center, since we have observed large upfield shifts for protons on atoms directly bonded to the uranium (as mentioned earlier for the uranium amines and amides).

To confirm our formulation of the compound, a ${ }^{15} \mathrm{~N}$ labelling study was performed. $\mathrm{PhNH}^{15} \mathrm{NH}_{2}$ was allowed to react with $\left(\mathrm{MeC} \mathrm{CH}_{4} \mathrm{H}_{4} \mathrm{U}\right.$ in toluene, and the product was again cystallized from an ether/hexane mixture. This material was not as nicely crystalline as the material obtained from the unlabelled phenylhydrazine; this may be due to problems with water in the labelled phenythydrazine provided by Cambridge Isotope Laboratories, and some insoluble material was produced in this reaction. The 


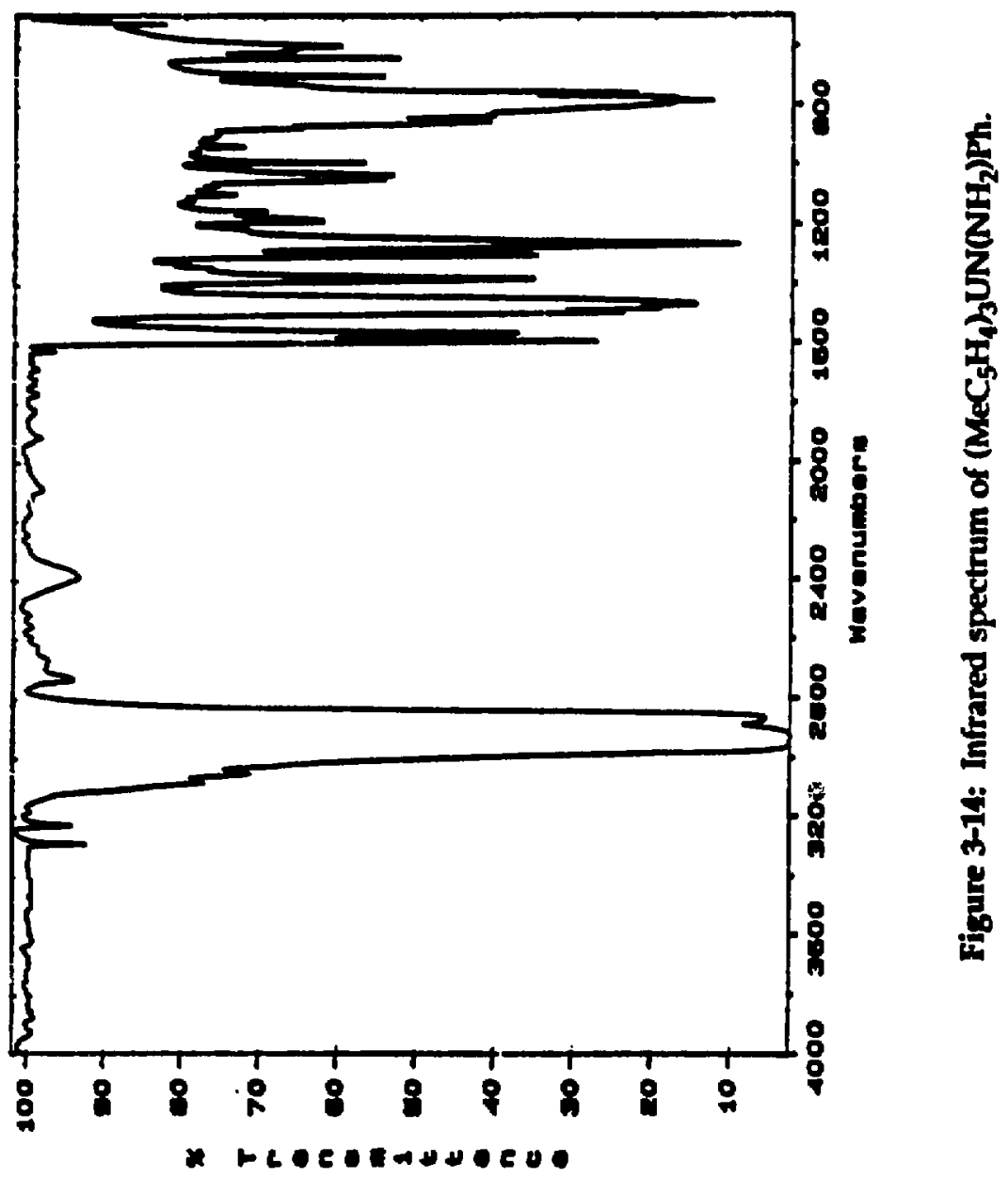




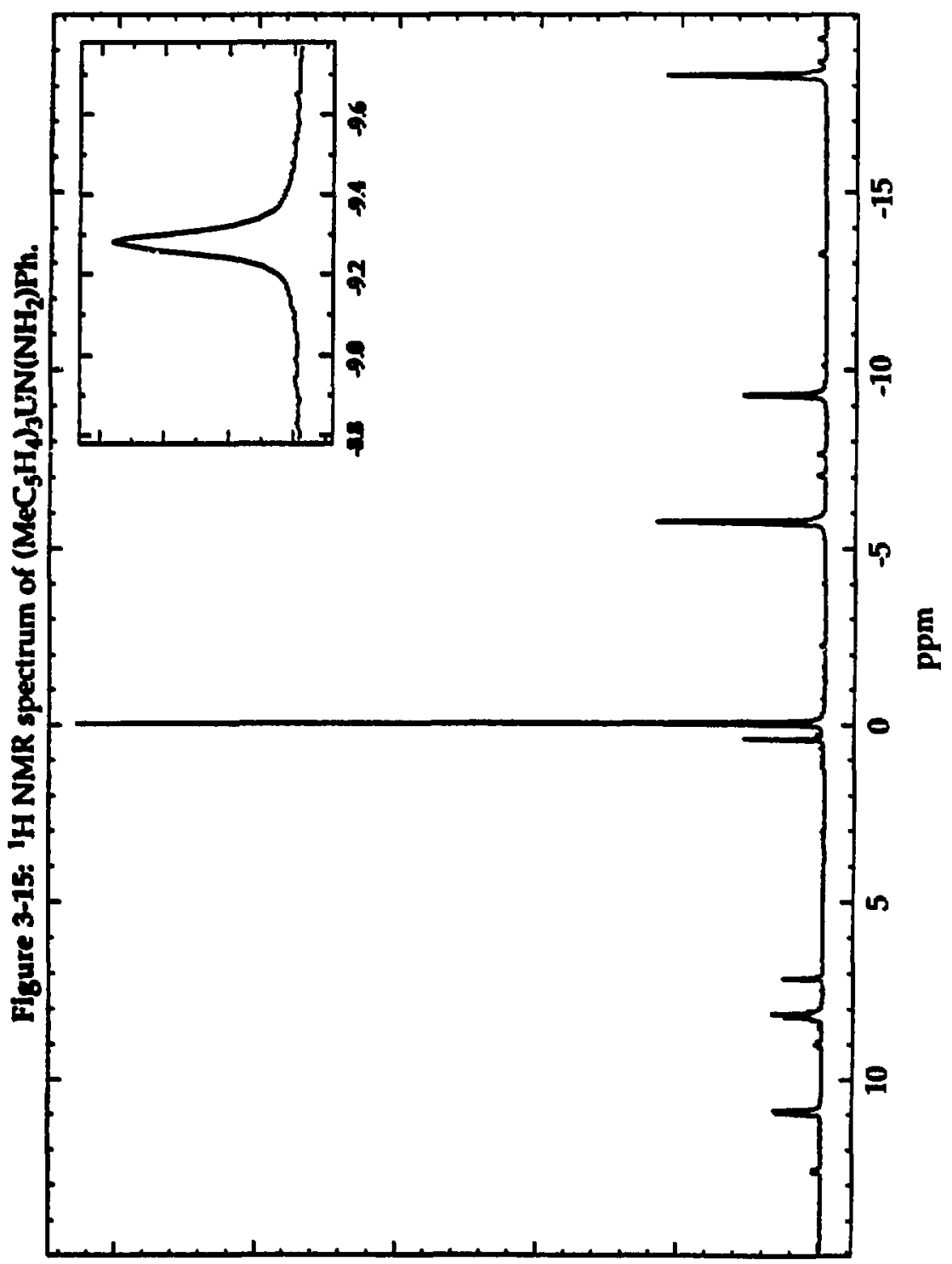


${ }^{1} H$ NMR spectrum of this product showed a change in only one resonance, and is shown in Figure 3-16. This is the resonance assigned to the $\mathrm{NH}_{2}$ protons at $-9.3 \mathrm{ppm}$, which splits into a doublet due to ${ }^{15} \mathrm{~N}-\mathrm{H}$ coupling. The coupling constant $J_{L_{\mathrm{N}}-\mathrm{H}}$ was measured to be $76 \mathrm{HL}_{2}$; this may be compared to the value of $65 \mathrm{~Hz}$ found in $\left(\mathrm{MeC}_{5} \mathrm{H}_{4}\right)_{3} \mathrm{U}^{15} \mathrm{NH}_{2}$. Note in the spectrum that a smaller peak between the two peaks of the doublet was also observed; we believe that this pank is due to unlabelled material contaminating the labelled product. A comparieon of the ${ }^{13} \mathrm{~N}-\mathrm{H}$ coupling constant may be made with a - tungsten hydrazido(1-) compound prepared by Sulton et. al.; in the molecule

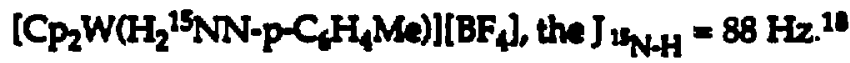

A low temperature ${ }^{1} \mathrm{H}$ NMR experiment was performed on $\left(\mathrm{MeC} \mathrm{H}_{4} \mathrm{H}_{3} \mathrm{UN}(\mathrm{Ph}) \mathrm{NH}_{2}\right.$, with spectra obtained from $30^{\circ} \mathrm{C}$ to $-72^{\circ} \mathrm{C}$. As the temperature is lowered, the peak from the para proton of the phenyl ring appears to shift downfield from under the solvent resonance. However, the interesting feature of this experiment is seen when plots of chemical shift versus $T^{-1}$ are made for the various resonances. One such representative plot is shown in Figure 3-17, for the cyclopentadienyl ring methyl group. Note that the compound does not obey the Curie Law; this plot is not linear. In fact, plots of chemical shift vs. 1/T for the cyclopentadienyl ring protons also exhibit curvature, as do the phenyl ring resonances. This is consistent with some type of exchange process occurring in solution; ${ }^{19}$ two such processes are monomer-dimer equilibrium or $\eta^{1}-\eta^{2}$ interconversion as shown in Scheme 3-11: 


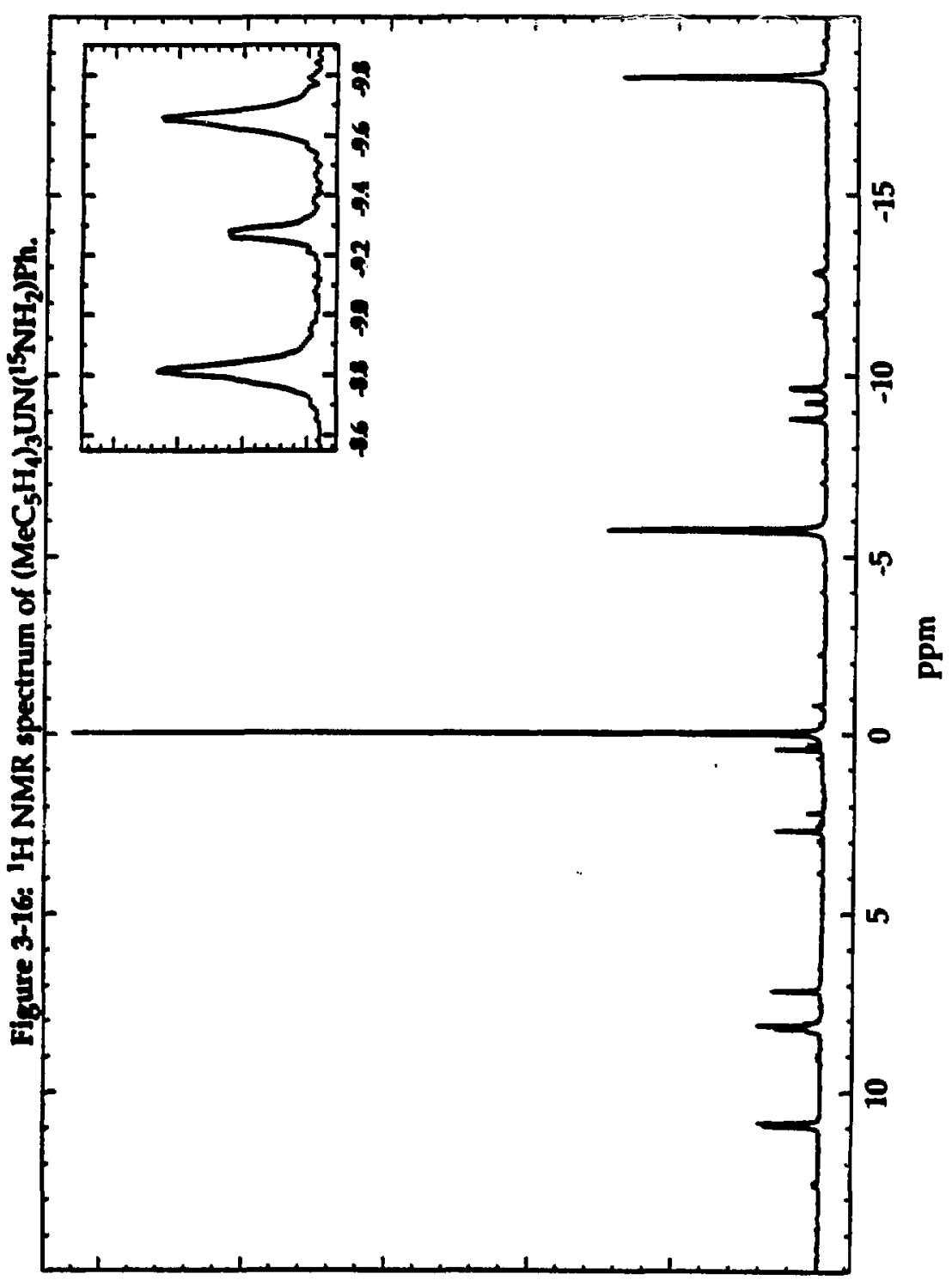




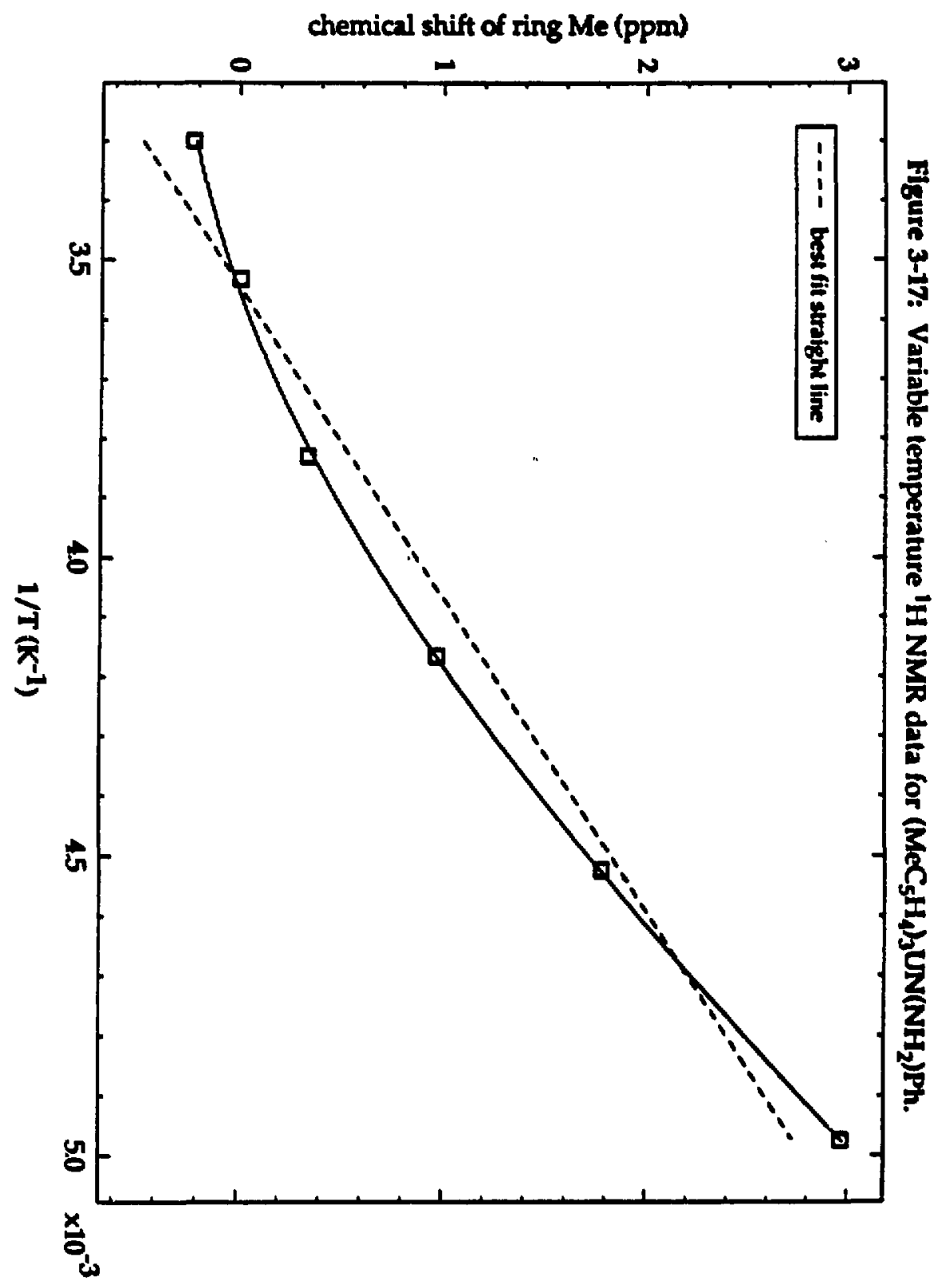


2

$\widehat{Q}_{3} \mathrm{UN}(\mathrm{Ph}) \mathrm{NH}_{2}=$<smiles>c1ccc(-n2n(-c3ccccc3)n(-c3ccccc3)n(-c3ccccc3)n2-c2ccccc2)cc1</smiles><smiles>NN(c1ccccc1)c1ccccc1</smiles>

Schene 3-14 (Top) Powibls colution monomes/dimer equilibotum in the uranium(IV) phenylhydrasde. (Bottom) Poulbie $\eta^{1}-\eta^{2}$ incerconversion in the uranium(IV) phenylhydrazide.

The mass spectrum of the phenylhydrazide compounc exhibits a small molecular ion at 582 amu. However, a much larger peak is found for M-15, presumably due to $\left(\mathrm{MeC}_{5} \mathrm{H}_{4}\right)_{3} \mathrm{UNHPh}$.

Thermolysis of the labelled and unlabelled phenylhydrazide compounds in an NMR tube with dr-toluene as solvent was done at $120^{\circ} \mathrm{C}$. In both cases, the uranium(IV) amide was formed (Scheme 3-12):

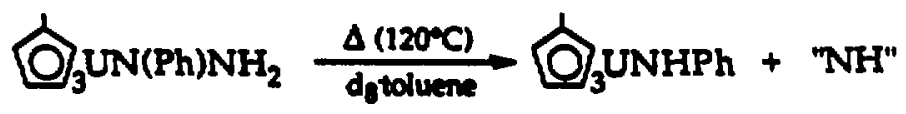

Scheme 3-12: Thermolysis of the uranium phenylhydrazide.

The 'H NMR spectra showed relatively clean conversions to the amide, although the times required for complete conversion are irreproducible and further investigation is warranted. The $\mathrm{N}-\mathrm{H}$ resonance of the amide from the thermolysis using the ${ }^{15} \mathrm{~N}$ labelled phenylhydrazide appeared as a singlet in the NMR spectrum, showing that no ${ }^{15} \mathrm{~N}$ remains. Thus, the nitrogen that is lost is the one from the $\mathrm{NH}_{2}$ group of the phenylhydrazide, and no 
rearrangement is taking place. The thermolysis was also performed with some trans-stilbene present in the NMR tube. However, no trapping of the "NH" species could be observed by this technique.

Although cleavage of the N-N bond in coordinated hydrazido(2-) species by protonation with acid has been reported, ${ }^{16}$ no such reaction has yet been obeerved for hydrazido(1-) compounds. For example, McCleverty et. al. reported that the acidolysis of [Mo(HB(M(2) 2$\left.)_{3}\right)$ (NO)(D)(NFNH $\left.)\right]\left(\mathrm{Me}_{2} \mathrm{pz}=\right.$ 3,5-dimethylpyrazolyl) with HCl ylelded hydraxine and the molybdenum dihalide, while the reaction of [Mo(HB(Me2pz) $3(\mathrm{NO})(\mathrm{I})(\mathrm{NHNH}) \mathrm{Ph})]$ with $\mathrm{HI}$ gave the dihalide and $\left(\mathrm{PhNFNH}_{3}\right)(\mathrm{I}) .{ }^{\mathrm{IC}}$

Several other reactions of trivalent uranium with hydrazines were attempted, with poor results. As in the case of the reaction of $\mathrm{PhNHNH}_{2}$ with $\left(\mathrm{MeC}_{5} \mathrm{H}_{4}\right)_{3} \mathrm{U}($ thf), the reactions gave several products, and these were not vigorously pursued. A brief summary of these reactions and what products were observed is given below.

When $\mathrm{MeNH} \mathrm{NHH}_{2}$ was allowed to react with $\left(\mathrm{MeC}_{5} \mathrm{H}_{4}\right)_{3} \mathrm{U}\left(\right.$ thf) at $0^{\circ} \mathrm{C}$ in ether, the material obtained was predominantly the uranium(II) amine, $\left(\mathrm{MeC}_{5} \mathrm{H}_{4} \mathrm{U}\left(\mathrm{NH}_{2} \mathrm{Me}\right)\right.$. This is similar to the result noted in the phenylhydrazide reaction at low temperature, where a small amount of the ammonia complex was isolated. It is conceivable that coordination of the hydrazine to the trivalent metal center occurs, followed by a 1,2-hydrogen shift and concurrent breaking of the $\mathrm{N}-\mathrm{N}$ bond giving this product. The formation of this product may reflect the relative difficulty in deprotonating this species; methylhydrazine should be someswhat less acidic than phenylhydrazine.

When 1,1-diphenylhydrazine $\left(\mathrm{Ph}_{2} \mathrm{NNH}_{2}\right)$ was allowed to react with the uranium thf-complex (at room temperature in toluene), the dominant 
product in the ${ }^{1} \mathrm{H}$ NMR spectrum appeared to be the diplienylamide, $\left(\mathrm{MeC}_{5} \mathrm{H}_{4} \mathrm{UNPh}_{2}\right.$. This compound has been previously prepared ${ }^{20, d}$ and was identified by comparison of the NMR spectrum with the reported values.

The reaction of $\left(\mathrm{MeC} \mathrm{CH}_{4} \mathrm{U}\right.$ (thf) with hydrazine, $\mathrm{H}_{2} \mathrm{NNH}_{2}$, was complex and not reproducible. It appears that a hydrazide complex was formed, but two different species are obeerved in separate reactions run under similar conditions. One of these spectes converts slowly to the other upon heating in an NMR tube, and, eventually, all the material converts to the .uranium amide, $\left(\mathrm{MeC}_{3} \mathrm{H}_{4} \mathrm{UNH}_{2}\right.$. The purity of the hydrazine, which can easily become hydrated, may play a large role in these reactions, and the matter was not pursued further. It should be noted, however, that when hydrazine was allowed to react with $\left(\mathrm{MeC}_{5} \mathrm{H}_{4} \mathrm{U}(\mathrm{th})\right.$ in the for several days, $\left(\mathrm{MeC} \mathrm{H}_{4}\right)_{3} \mathrm{UNH}_{2}$ was isolated.

The development of the reaction using $\left(\mathrm{MeC}_{5} \mathrm{H}_{4}\right)_{4} \mathrm{U}$ to prepare the uranium(IV) phenylhydrazide will help to extend the chemistry of these hydrazide compounds, as they can now be prepared in good yield and in high purity. 


\section{Section 3.4: Preparation of a Dinuclear Uranium Amine}

In order to look for magnetic interactions between uranium(III) nuciei, a dinuclear uranium diamine complex was synthesized, using F. Fhenylenediamine as the bridging ligand. This compound is similar to the para-dimide discused in Chapter 2. One of the reasons for investigating this system was that antiferromagnetic coupling had been obearved in copper complexs using the same bridging ligand; a mentioned in Chapter 2, the compound $\left[\mathrm{Cu}_{2}\right.$ (tren) $\left.{ }_{2}(\mathrm{PPD})\right]\left[\mathrm{NO}_{3}\right]_{4}$ (tren = 2,2',2"-triaminotriethylamine, PPD

= p-phenylenediamine) exhibits an antiferromagnetic coupling with $T_{N}=67$ $\mathbf{K}^{20}$

The diamine complex is straightforwardly syrithesized by reaction of two molar equivalents of $\left(\mathrm{MeC}_{5} \mathrm{H}_{4}\right)_{3} \mathrm{U}$ (thf) with p-phenylenediamine in toluene (Scheme 3-13):

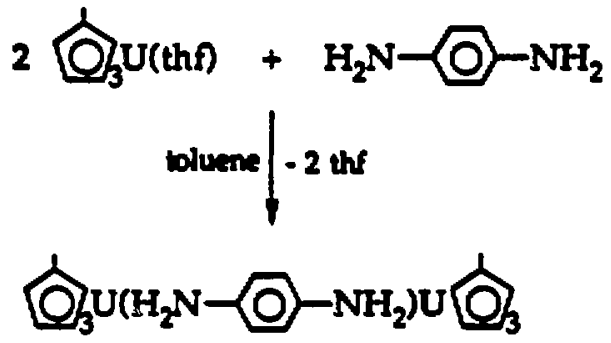

Scheme 3-13: Preparation of a brid jed dinuclear urenium diamine.

The compound is insoluble in toluene, and precipitates out of the reaction mixture as brown microcrystals.

A ${ }^{1}$ H NMR spectrum of this compound could not be obtained, due to its insolubility in either $C_{6} D_{6}$ or $C_{7} D_{8}$. An attempt to obtain the spectrum in 
dothf was unsuccessful; although the material dissolved, the spectrum showed only the $\mathrm{MeC}_{5} \mathrm{H}_{4}$ resonances due to $\left(\mathrm{MeC}_{5} \mathrm{H}_{4}\right)_{3} \mathrm{U}($ thf). Thus, the bridging interaction is not strong, and the amine is displaced by the large excess of thr.

The infrared spectrum of the compound showed two N-H stretches at 3281 and $3228 \mathrm{~cm}^{-1}$. This is similar to the results obtained for the mononudear amine coordination compounds discusead in Section 3.1. An electron impact mass apectrum of the compound could not be obtained; the material apparently fragmented in the gas phase. The elemental analysis was also consistent with the proposed structure of the compound.

Magmetic susceptibility measurements were obtained on a sample of the diamine. Freshly prepared and recrystallized $\left(\mathrm{MeC} \mathrm{C}_{3} \mathrm{H}_{4} \mathrm{U}_{3} \mathrm{U}(\mathrm{thh})\right.$ was reasted with a sublimed, zone-refined sample of p-phenylenediamine; ${ }^{21}$ slightly more than two molar equivalents of the uranium species were usec to ensure that no excess base was present and prevent the formation of monotiuciear species. The product was washed several times with toluene and ethe: before measurement of the susceptibility.

The results of these measurements are shown in Figures 3-18 and 3-19 as plots of $\chi_{M}$ vs. $T$ and $1 / \chi_{M}$ vs. T. Note that no antiferromagnetic coupling is observed for the compound. Linear regression performed on the $1 / \chi_{M}$ data yielded $\mu_{\text {mf }}=4.17$ B.M. $1 \theta=-69 \mathrm{~K}$ for the high temperature region $(140-300 \mathrm{~K})$ and $\mu_{\text {eff }}=2.95$ B.M. $(\theta=-3.1 \mathrm{~K})$ for the low temperature region $(5-40 \mathrm{~K})$. 'This works out to values of $\mu_{\text {eff }}=2.95$ and $\mu_{\text {att }}=2.09$ per uranium for the high and low temperature regions, respectively. These values may be compared to those obtained for other $\left(\mathrm{RC}_{5} \mathrm{H}_{4}\right)_{3} \mathrm{U}(\mathrm{L})$ compounds. For the pyridine complex, $C p_{3} U(p y)$, values of $\mu_{\text {eff }}=3.20(110-300 \mathrm{~K})$ and $\mu_{\text {eff }}=2.33(6-90 \mathrm{~K})$ were measured, while in $\mathrm{Cp}_{3} \mathrm{U}\left(\mathrm{PMe}_{3}\right)$, the values were $\mu_{\text {eff }}=2.82(120-300 \mathrm{~K})$ and 
$H_{\text {eff }}=221$ (5-40 10.22 Thus the inagretic susceptibility of the bridged uranium(III) complex was found to be quite similar to mononuclear materials. 
F.8. 3-18: Chi vo Temperature plot for the para-diamine.

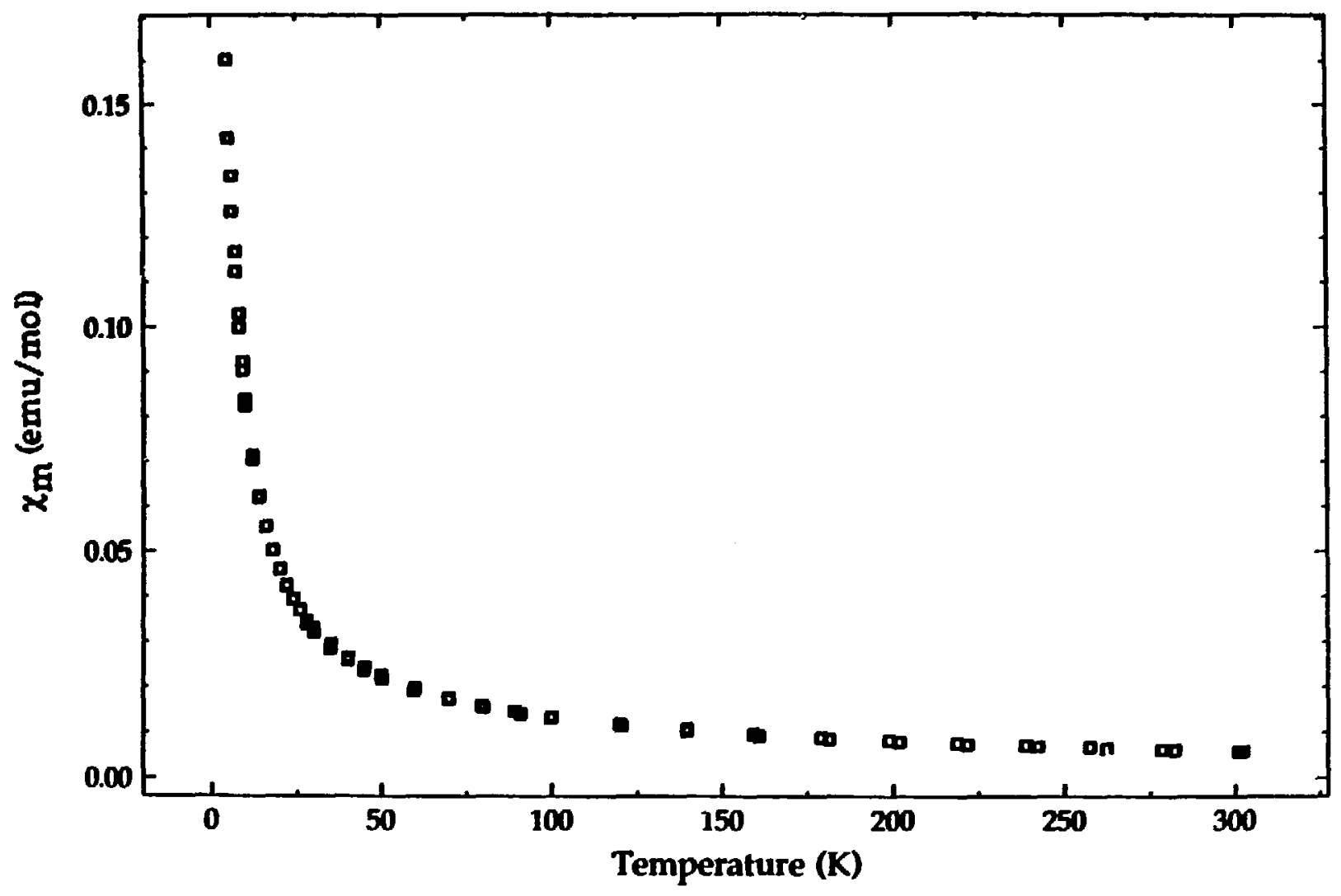


Fig. 3-19: 1/Chi vs Temperature plot for the para-diamine.

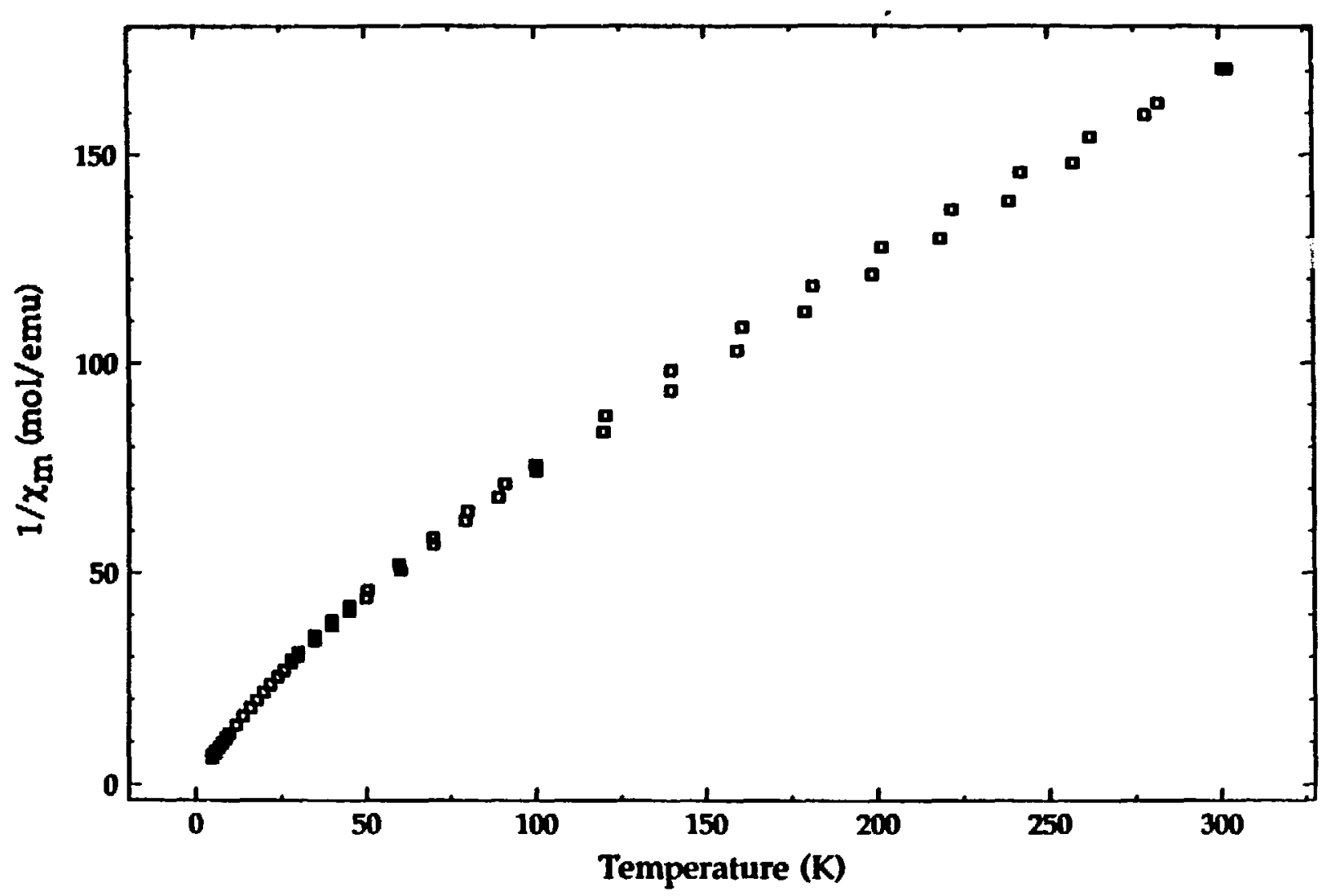




\section{References}

1 Kanellakopulos, B.; Fisher, E. O.; Dornberger, E.; Baumgärtner, F. J. Orgunomet. Chem. 1970, 24, 507.

(a) Brennan, J. G.; Stults, S. D.; Andersen, R A.; Zalkin, A.

Organometallics 1998, 7, 1329. (b) Brennan, J. G. Ph.D. Thesis, University of Californin, Berkeley 1985. (c) Fabiano, M. D. M.S. Thesis, Unioersity of California, Berkeley 1988.

3 Marks, T.J.; Seyam, A. M.; Kolb, J. R. J. Am. Chem. Soc. 1973, 95, 5529.

4 Bernheim, R. A.; Batz-Hernandez, H. J. Chem. Phys. 1964, 40, 3446.

3 Rosen, R. K; Zalkin, A. Acta Cryst. 1989, C45, 1139.

- Zalkin, A.; Brennan, J. G. Acta Cryst. 1987, C43, 1919.

7 (a) Jamerson, J. D., Takats, J. J. Organomet. Chem. 1974, 78, C23. (b) Arduini, A. L.; Edelstein, N. M.; Jamerson, J. D.; Reynolds, J. G.; Schmid, Ki Takats, J. Inorg. Chem. 1981, 20, 2470.

(a) Paolucd, G.; Rossetto, G.; Zanella, P.; Fischer, R. D. J. Organomet. Chem. 1985, 284, 213. (b) Arduini, A. L.; Jamerson, J. D.; Takats, J. Inorg. Chem. 1981, 20, 2474. (c) Arduini, A. L.; Takats, J. Inorg. Chem. 1981, 20, 2480. (d) Cramer, R. E; Engelhardt, U.; Higa, K. T.; Gilje, J. W. Organometallics 1987, 6, 41.

(a) Peolucei, G.; Rossetto, G.; Zanell, P.; Yünlü, K.; Fischer, R. D. J. Organomet. Chem. 1984, 272, 363. (b) Dormond, A.; Aaliti, A.; Moïse, C. J. Chem. Soc. Chem. Commun. 1985, 1231.

10 Stewart, R. The Proton: Applications to Organic Chemistry Academic Press, Orlando, Florida, 1985, and references therein. 
11 (a) Copenhaver, J. W.; Roy, M. F.; Marvel, C. S. J. Am. Chem. Soc. 1935, 57, 1311. (b) Hayes, J. Ph.D. Thesis, Harourd University 1984. Brauer, G. in Handbook of Preparative Inorganic Chemistry, 2nd Edition, Volume 2, Riley, R. F. ed., Academic Pres, New York, 1965, p. 1623.

13 Stewart, J. L. Ph.D. Thesis, Unioersity of Californin, Berkeley 1988.

14 Hiuris, R. K. Nuclear Magnetic Resonance Spectroscopy Pitman Books Ltd., London, 1923, pp. $138-139$.

15 Harris, R. K; Mann, B. E. NMR and the Periodic Table Academic Press, New York, 1978, p. 97.

16 See, for example, the following reviews: (a) Henderson, R. A.; Leigh, G. J.; Pickett, C. J. Ado. Inorg. Chem. Rediochem. 1983, 27, 198. (b) Chatt, J.; Dilworth, J. R.; Richards, R. L. Chem. Reo. 1978, 78, 589. (c) Dilworth, J. $R$ Coord. Chem. Reo. 1976, 21, 29. Other recent examples include: (d) Murray, R. C.; Schrock, R. R J. Am. Chem. Soc. 1985, 107, 4557. (e) Blum, L.; Williams, I. D.; Schrock, R. R. J. Am. Chem. Soc. 1984, 106, 8316. (f) MCCleverty, J. A.; Rae, A. E.; Wolochowica, I.; Bailey, N. A.; Smith, J. M. A. J. Chem. Soc. Dalton Trans. 1983, 71, and references therein. (8) Cowie, M.; Gauthier, M. D. Inorg. Chem. 1980, 19, 3142. (h) Sutton, D.; Carroll, J. A. Inorg. Chem. 1980, 19, 3137.

17 Weydart, M., personal communication.

18 (a) Carroll, J. A.; Sutton, D. Inorg. Chem. 1980, 19, 3137. (b) Cowie, M.; Gauthier, M. D. Inorg. Chem. 1980, 19, 3142.

19 Jahn, W.; Yünlü, K; Oroechin, W.; Amberger, H. D.; Fischer, R. D. Inorg. Chim. Acte 1984, 95, 85.

20 Felthouse, T. T.; Hendrickson, D. N. Inorg. Chem. 1978, 17, 2636. 
21 Obtained from Aldrich Chemical Company, Milwaukee, Wisconsin and used as received.

22 Berg, D. J., personal communication. 


\section{Chapter 4 \\ Experimental Details}

\section{General}

All manipulations involving air-aensitive materials were carried out under nitrogen using standing Schlenk techniques or in a Vacuum Atmospheres inert atmosphere dry box under argon. Diethylether, tetrahydrofuran, and hexane were dried and deoxygenated over sodium benzophenone ketyl, toluene was dried over sodium, and dichloromethane was dried over $\mathrm{CaH}$. All solvents were distilled from these drying agents under nitrogen prior to use.

Infrared spectra were recorded on either a Perkin-Elmer 283 grating spectrometer or a Matson Polaris F.T.L.R. spectrometer as Nujol mulls between CsI windows. Melting points were measured in sealed capillaries and are uncorrected. NMR spectra were recorded on a JEOL FX-900 spectrometer in perdeuterated benzene or toluene which had been dried over sodium and distilled under nitrogen. ${ }^{1} \mathrm{H}$ NMR spectra (89.6 MHz) were referenced to residual protons in the solvent; in $\mathrm{C}_{6} \mathrm{D}_{5} \mathrm{H}, \delta=7.15 \mathrm{ppri}$, in $\mathrm{C}_{6} \mathrm{D}_{5} \mathrm{CD}_{2} \mathrm{H}, \delta=2.09 \mathrm{ppm}$. ' $\mathrm{H} \mathrm{NMR}$ resonances are reported as $\delta$-values, with positive values at higher frequencies than $\mathrm{Me}_{4} \mathrm{Si}(=0 \mathrm{~Hz})$. ${ }^{119} \mathrm{Sn}$ NMR spectra (33.3 $\mathrm{MHz}$ ) were referenced to $\mathrm{Me}, \mathrm{Sn}, \delta=0.00 \mathrm{ppm}$. Mass spectroscopy and elemental analyses were performed by the University of California, Berkeley, Department of Chemistry mass spectral and microanalytical laboratories. The isotopic cluster of the parent molecular ion was simulated for many of the 
compounds and the experimental and simulated results are reported as follows: (experimental intensity; simulated intensity).

Magnetic susceptibility messurements were made using either a S.H.E. Model 905 or a Quantum Design Model MPMS superconducting magnetometer. A typical sample preparation is as follows: $50-100 \mathrm{mg}$ of the compound was ground with mortar and pestle in an argon dry box and weighed into the bottom half of a Kel-F ample container. The two halves of the container were saled uring a mall amount of sllicone grease and removed from the dry box. The container was then tied together using nylon thread and suspended in the ample container with cotton thread. Measurements were taken at magnetic fields of $5 \mathrm{kG}$ and $40 \mathrm{kG}$ at the following temperatures: 5 - $9 \mathrm{~K}$ (every $2 \mathrm{~K}$, 12 - $21 \mathrm{~K}$ (every $3 \mathrm{~K}$ ), 25 - $50 \mathrm{~K}$ (every $5 \mathrm{~K}$ ), 60 - $100 \mathrm{~K}$ (every $10 \mathrm{~K}$ ), and $120-300 \mathrm{~K}$ (every $20 \mathrm{~K}$ ). When lower temperatures were desired on the Quantum Design magnetometer, the measurements were also taken from 2 - $4.5 \mathrm{~K}$ (every $0.5 \mathrm{~K}$ ). All data were corrected for ample and container diamagnetism. Samples exhibiting CurieWeiss behavior were fit to the Curie-Weiss law $1 / \chi=(T-\theta) / C$ using a linear least-squares program written by Dr. E. Gamp and modified by Dr. N. Edelstein.

Commercially obtained uranium tetrachloride (Cerac) was treated with refluxing $\mathrm{SOCl}_{2}$ for ca. 7 days, followed by washing of the green powder with $\mathrm{CH}_{2} \mathrm{Cl}_{2}$ until the extracts were colorless and heating of the powder under reduced pressure ( $1 \mathrm{mTOrr}$ ) at $\mathrm{Cr} .150^{\circ} \mathrm{C}$ for 12 hours. (MeCsh $)_{3} \mathrm{U}($ thf), $\left(\mathrm{Me}_{3} \mathrm{SiC}_{5} \mathrm{H}_{4}\right)_{3} \mathrm{U},\left(\mathrm{MeC}_{5} \mathrm{H}_{4}\right)_{3} \mathrm{UCl},\left(\mathrm{Me}_{3} \mathrm{SiC}_{5} \mathrm{H}_{4}\right)_{3} \mathrm{UCl}, \mathrm{Cp}_{3} \mathrm{UNSiMe}_{3}$, and $\left(\mathrm{MeC}_{5} \mathrm{H}_{4} \mathrm{UNSiMe}_{3}\right.$ were prepared as described by Brennan'. $\left[\left(\mathrm{MeC}_{5} \mathrm{H}_{4}\right]_{3} \mathrm{U}_{2}\right.$ (pyrazine) was prepared as desribed by Eigenbrot and Raymond. ${ }^{2}$ 
The cyclopentadienide and methylcyclopentadienide anions were prepared from the freshly cracked $\mathrm{C}_{5} \mathrm{H}_{6}$ or $\mathrm{MeC}_{5} \mathrm{H}_{5}$ monomers as the sodium salts in tetrahydrofuran. Trimethylsilylcyclopentadiene was prepared as described by Brennan ${ }^{1}$ and used as the potassium salt in tetrahydrofuran. $\mathrm{BuN}_{3}{ }^{3} \mathrm{Me}_{3} \mathrm{GeN}_{3}{ }^{4} \mathrm{Me}_{3} \mathrm{SnN}_{3}{ }^{4} \mathrm{Ph}_{3} \mathrm{SnN}_{3}{ }^{3}$ and $\mathrm{Ph}_{2} \mathrm{CHN}_{3}{ }^{6}$ were synthesized from the appropriate halides. $\mathrm{Me}_{3} \mathrm{SWN}_{3}$ (Petrarch) was dried over $\mathrm{MgSO}_{4}$ and distllled before use. $\mathrm{PhN}_{3}{ }^{7}$ was synthecized by diezotization of aniline, and the subatituted phenylazides p-Mec, $\mathrm{H}_{4} \mathrm{~N}_{3}{ }^{\circ} \mathrm{p}-\mathrm{MeOC} \mathrm{C}_{6} \mathrm{H}_{4} \mathrm{~N}_{3}$

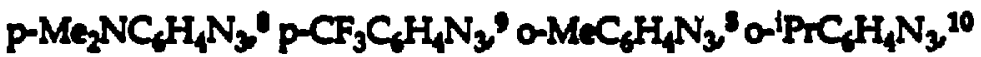
$0-\mathrm{CF}_{3} \mathrm{C}_{6} \mathrm{H}_{4} \mathrm{~N}_{3}{ }^{11} 2,6-\mathrm{Me}_{2} \mathrm{C}_{6} \mathrm{H}_{4} \mathrm{~N}_{3}{ }^{10}$ were synthesized by analogous procedures. ${ }^{12}$ The aryl azides that were solids at room temperature were recrystallized from ether or toluene, and liquids were distilled under vacuum $\left(10^{-3}\right.$ torr) through a $-20^{\circ} \mathrm{C}$ trap. A typical azide preparation by diazotizntion is given in Section 4.1. $\mathrm{Ph}^{15} \mathrm{NNN}$ was prepared by dizzotization of $\mathrm{Ph}^{15} \mathrm{NH} 2\left(99 \%{ }^{15} \mathrm{~N}\right.$, Cambridge Isotope Laboratories). $\mathrm{p}-\left(\mathrm{N}_{3}\right)_{2} \mathrm{C}_{6} \mathrm{H}_{4}{ }^{23} \mathrm{~m}-\left(\mathrm{N}_{3}\right)_{2} \mathrm{C}_{6} \mathrm{H}_{4}{ }^{14}$ 4,4-diazidostilbene, 15 and 1,5-diazidonapthalene ${ }^{16}$ were prepared by dizzotization routes and $\mathrm{Me}_{2} \mathrm{Si}\left(\mathrm{N}_{3}\right)_{2}{ }^{17}$ was prepared from the dichloride. 


\section{Section 4.1: Chapter 1 Experimental Details}

P-MeOC, $\mathrm{H}_{4} \mathrm{~N}_{3}$ (typical axide preparation by diacotization)

p-Anisidine (p-methoxyaniline, recrystallized from hot $\mathrm{H}_{2} \mathrm{O}, \mathrm{ca} .7 .5 \mathrm{~g}$ $61 \mathrm{mMol}$ ) was suspended in $50 \mathrm{~mL}$ of $\mathrm{H}_{2} \mathrm{O}$. Concentrated $\mathrm{HCl}(15 \mathrm{~mL})$ was added; all of the solid diseolved to give a pale crange solution. The solution was cooled to $\mathrm{O}^{\circ} \mathrm{C}$, then a solution of $\mathrm{NaNO}_{2}(4.4 \mathrm{~g}, 64 \mathrm{mMol})$ in $\mathrm{H}_{2} \mathrm{O}(3 \mathrm{OmL})$ was added dropwise over ca. 15 minutes, rosulting in a yollow-orange solution. While stlll maintaining a temperature of below $0^{\circ} \mathrm{C}, \mathrm{NaN}_{3}(4.2 \mathrm{~g}, 65$ $\mathrm{mMol})$ in $\mathrm{H}_{2} \mathrm{O}(30 \mathrm{~mL})$ was added dropwise over $\mathrm{ca} .30$ minutes. During the addition, gas evolution occurred and the solution became cloudy. After the addition was complete, the solution was warmed to room temperature and stirred for 30 minutes. Ether was added (100 mL), the mixture poured into a separatory funnel, and the layers were separated. The aqueous layer was extracted with an additional $50 \mathrm{~mL}$ of ether, the ether layers were combined, washed with $\mathrm{H}_{2} \mathrm{O}(50 \mathrm{~mL})$, and drizd over $\mathrm{MgSO}_{4}$ with a small amount of decolorizing carbon. The solution was filtered and rotovapped to give an orange oil, which was then distilled at $\mathrm{ca} .10^{-3}$ torr through a cold trap maintained at $-20^{\circ} \mathrm{C}$ to give a pale yellow liquid. ${ }^{1} \mathrm{H} \mathrm{NMR}\left(\mathrm{C}_{6} \mathrm{D}_{6}, 30^{\circ} \mathrm{C}\right): 3.2(\mathrm{~s}$, $3 \mathrm{H}), 6.6(\mathrm{~m}, 4 \mathrm{H})$.

\section{$\left(\mathrm{MeC}_{5} \mathrm{H}_{4}\right)_{3} \mathrm{UN}_{3}$}

Method A: $\left(\mathrm{MCC}_{5} \mathrm{H}_{4}\right)_{3} \mathrm{UCl}(2.0 \mathrm{~g}, 3.9 \mathrm{mmol})$ was suspended in $75 \mathrm{~mL}$ of deoxygenated $\mathrm{H}_{2} \mathrm{O}$ and stirred vigorously. A light green color developed in the solution. $\mathrm{NaN}_{3}(0.80 \mathrm{~g}, 12 \mathrm{mmol})$ in $15 \mathrm{~mL}$ of $\mathrm{H}_{2} \mathrm{O}$ was added by cannula, resulting in an immediate green precipitate. The mixture was stirred for 24 hours and then allowed to settle. The water was decanted and the green solid 
was dried under reduced pressure. Dichloromethane ( $30 \mathrm{~mL}$ ) was added and the green-brown solution was filtered. Concentration of the filtrate to $\mathrm{ca}$. 20$25 \mathrm{~mL}$ and cooling to $-80^{\circ} \mathrm{C}$ resulted in green microcrystals, which were isolated by filtration and dried in $90 \%(1.82 \mathrm{~g})$ yield, m.p. $152-160^{\circ} \mathrm{C}$. ${ }^{1} \mathrm{H}$ NMR $\left(\mathrm{C}_{6} \mathrm{D}_{6} 3^{\circ} \mathrm{C}\right):-3.11$ (3F), 11.08 (2F), -17.43 (2F). And. Calcd for $\mathrm{C}_{18} \mathrm{H}_{21} \mathrm{~N}_{3} \mathrm{U}: \mathrm{C}$, 41.8; $H, 4.09 ; N, 8.12$. Found: $C, 40.7 ; H, 4.61 ; N, 6.88$. Mass spectrum: 517 (100; 100), $518(17 ; 21)$. RR 2112 ve bx, 1299 w, 1093 w, 1065 w, 1050 w, 1034 m, 930 w, $846 \mathrm{~m}, 782 \mathrm{~s}, 727 \mathrm{~m}, 700 \mathrm{~m}, 638 \mathrm{w}, 606 \mathrm{w} \mathrm{cm}^{-1}$.

Method B: To $\left(\mathrm{MeC}_{5} \mathrm{H}_{4}\right)_{3} \mathrm{U}(\mathrm{th})(0.69 \mathrm{~g}, 1.3 \mathrm{mmol})$ dissolved in $20 \mathrm{~mL}$ of $\mathrm{Et}_{2} \mathrm{O}$ was added by syringe $6.0 \mathrm{~mL}$ of $\mathbf{a} 0.21 \mathrm{M}$ solution of $\mathrm{HN}_{3}{ }^{13}$ in $\mathrm{Et}_{2} \mathrm{O}$ (1.3 mmol). A bright green precipitate immediately formed, with very little color remaining in the solution. The mixture was stirred for one hour, then taken to dryness under reduced pressure. The solid that remained was sublimed $\left(10^{-4}\right.$ torr, $\left.120-130^{\circ} \mathrm{C}\right)$ to yield $0.17 \mathrm{~g}$ of a green solid. The ${ }^{1} \mathrm{H}$ NMR spectrum showed this solid to be $\left(\mathrm{MeC} \mathrm{C}_{4} \mathrm{U}_{3} \mathrm{UN}_{3}\right.$. The material that did not sublime was extracted with $\mathrm{CH}_{2} \mathrm{Cl}_{2}$ (50 mL), filtered, and taken to dryness to yield $0.08 \mathrm{~g}$ of additional (MeC $\left.5 \mathrm{H}_{4}\right)_{3} \mathrm{UN}_{3}$; the total yield was $38 \%(0.25 \mathrm{~g})$

$\left(\mathrm{Me}_{3} \mathrm{SiC}_{3} \mathrm{H}_{4}\right)_{3} \mathrm{UN}_{3}$

To a mixture of $\left(\mathrm{Me}_{3} \mathrm{SiC}_{5} \mathrm{H}_{\varphi_{3}} \mathrm{U}(1.01 \mathrm{~g}, 1.55 \mathrm{mMol})\right.$ and $\mathrm{Me}_{3} \mathrm{SnN}_{3}(0.40$ g. $1.9 \mathrm{mMol}$ ) was added $30 \mathrm{~mL}$ of $\mathrm{Et}_{2} \mathrm{O}$. The brown-green solution was stirred for 18 hours, then the volatile materials were removed under reduced pressure. The residue was extracted with hexamethyldisiloxane $(25 \mathrm{~mL})$, the solution was filtered, and the filtrate was concentrated to $\mathrm{ca} .20 \mathrm{~mL}$ and cooled to $-20^{\circ} \mathrm{C}$. Brown crystals were isolated by filtration and dried in $41 \%(0.44 \mathrm{~g})$ yield, m.p. $103-105^{\circ} \mathrm{C}$. ${ }^{1} \mathrm{H} N \mathrm{NR}\left(\mathrm{C}_{6} \mathrm{D}_{6}, 30^{\circ} \mathrm{C}\right) ;-7.07(9 \mathrm{H}),-15.10(2 \mathrm{H}),-13.69(2 \mathrm{H})$. Anal. Calcd for $\mathrm{C}_{24} \mathrm{H}_{39} \mathrm{~N}_{3} \mathrm{Si}_{3} \mathrm{U}: \mathrm{C}, 41.7 ; \mathrm{H}, 5.68 ; \mathrm{N}, 6.07$. Found: $\mathrm{C}, 37.6 ; \mathrm{H}, 5.83$; 
N, 5.44. Mass spectrum: 691 (100; 100), 692 (41; 13), 693 (15; 19), 694 (3; 5). IR: 2082 vs, 1249 s, $1174 \mathrm{~m}, 1046 \mathrm{~m}, 902 \mathrm{~m}, 836$ vs, 795 s, $753 \mathrm{~m}, 723,689$ w, $633 \mathrm{~m}$, $625 \mathrm{~m} \mathrm{~cm}^{-1}$.

This reaction was also performed in an NMR tube with $C_{7} D_{8}$ as solvent. The ${ }^{1} \mathrm{H}$ NMR spectrum obtained from this reaction showed that the reaction cleanly formed $\mathrm{M}_{3} \mathrm{SiC}_{3} \mathrm{H}_{3} \mathrm{UN}_{3}$. Several paks were also observed between 0.3 ppen and -0.1 ppon.

\section{MeCg $\left._{3}\right)_{3}$ UNCO}

$\left(\mathrm{MeC}_{5} \mathrm{H}_{4}\right)_{3} \mathrm{UCl}(2.9 \mathrm{~g}, 5.7 \mathrm{mmol})$ was suspended in $100 \mathrm{~mL}$ of deoxygenated $\mathrm{H}_{2} \mathrm{O}$ and stirred vigorously. A light green color developed in the solution. $\mathrm{KOCN}(1.42 \mathrm{~g}, 17.5 \mathrm{mmol})$ in $20 \mathrm{~mL}$ of $\mathrm{H}_{2} \mathrm{O}$ was added by connula, resulting in an immediate green precipitate. The mixture was stirred for 48 hours and then allowed to settle. The water was decanted and the green residue was dried under reduced pressure. Dichloromethane (50 $\mathrm{mL}$ ) was added and the green solution was filtered. The filtrate was concentrated to $\mathrm{Ca} .20-25 \mathrm{~mL}$ and then cooled to $-80^{\circ} \mathrm{C}$. Green crystals were isolated by filtration and dried in $23 \%\left(0.82\right.$ g) yield. ${ }^{1} \mathrm{H} N \mathrm{NM}\left(\mathrm{C}_{6} \mathrm{D}_{6},{ }^{2} 7^{\circ} \mathrm{C}\right)$; $267(3 \mathrm{H}), 13.23(2 \mathrm{H}),-19.16(2 \mathrm{H})$. And. Culcd for $\mathrm{C}_{1} \mathrm{H}_{21} \mathrm{NOU}$ : $\mathrm{C}, 44.1 ; \mathrm{H}, 4.06$; N, 271. Found: C, 4.3; H, 4.08; N, 264. IR: 2180 vs, 1070 w, 1050 w, $1030 \mathrm{~m}$, $930 w, 860 w, 840 \mathrm{~m}, 800 \mathrm{~m}, 785$ s, $620 \mathrm{~m}, 605 \mathrm{~m}, 345 \mathrm{w}, 310 \mathrm{w}, 265 \mathrm{~m}, 255 \mathrm{~m}$ $\mathrm{cm}^{-1}$.

\section{$\mathrm{MeC}_{5} \mathrm{H}_{4} \mathrm{UNCMe}_{3}$}

To $\left(\mathrm{MeC}_{5} \mathrm{H}_{4}\right)_{3} \mathrm{U}(\mathrm{thf})(0.47 \mathrm{~g}, 0.86 \mathrm{mMol})$ dissolved in $20 \mathrm{~mL}$ of diethyl ether was added $0.95 \mathrm{~mL}$ of $0.90 \mathrm{M}$ t-butylazide $(0.86 \mathrm{mMol})$ in cyclohexane. Gas was instantly evolved, and the color changed from brown-red to a deep 
red. The solution was stirred for 24 hours, then the volatile material was removed under reduced pressure. Hexane $(20 \mathrm{~mL})$ was added, the solution was filtered, and the filtrate was concentrated to $\mathrm{ca} .10 \mathrm{~mL}$, and then cooled to $-20^{\circ} \mathrm{C}$. Fine black-red neadles were isolated and dried in $49 \%(0.23 \mathrm{~g})$ yield,

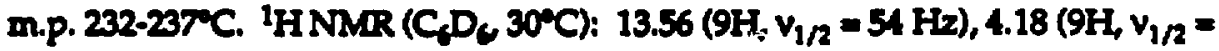
$30 \mathrm{H}(2),-4.21\left(6 \mathrm{H}, v_{1 / 2}=150 \mathrm{H} / 2\right),-9.87\left(6 \mathrm{H}, v_{1 / 2}=135 \mathrm{~Hz}\right)$. Mass spectrum: 546, $S 47(24.8 ; 21.9), 548(3.0 ; 21)$. Ans. Calcd for $\mathrm{C}_{22} \mathrm{H}_{30 \mathrm{NU}} \mathrm{C}, 48.4 ; \mathrm{H}, 5.53 ; \mathrm{N}$, 256. Found: C, 47.3; H, 5.50; N, 230. IR: $1348 \mathrm{~m}, 1260 \mathrm{~m}, 1210 \mathrm{~s}, 1090 \mathrm{w}, 1040$ $\mathrm{m}, 850 \mathrm{~m}, 800 \mathrm{~m}, 780 \mathrm{~m}, 760 \mathrm{~s}, 600 \mathrm{~m}, 525 \mathrm{w}, 320 \mathrm{w} \mathrm{cm}^{-1}$.

Reaction of $\left(\mathrm{MeC} \mathrm{CH}_{3}\right)_{3} \mathrm{U}\left(\right.$ thr) with $\mathrm{Me}_{3} \mathrm{GeN}_{3}$

To $0.50 \mathrm{~g}$ of $\left(\mathrm{MeC}_{\mathrm{g}} \mathrm{H}_{4}\right)_{3} \mathrm{U}(\mathrm{thh})(0.91 \mathrm{mMol})$ dissolved in $20 \mathrm{~mL}$ of $\mathrm{Et}_{2} \mathrm{O}$ was added $0.2 \mathrm{~mL}$ of $\mathrm{Me}_{3} \mathrm{GeN}_{3}$. The reaction mixture was stirred for 3 days with no obvious color change. At the end of this time, the volatile materials were renoved under reduced pressure. The red/brown residue was extracted with hexane, the red solution was filtered, and the filtrate was concentrated and cooled to $-200^{\circ} \mathrm{C}$. Brown flakes were isolated and dried $(0.15 \mathrm{~g})$. A second crop of $0.09 \mathrm{~g}$ was obtained by further concentration and cooling of the hexane solution. The total yield of $\left(\mathrm{MeC} 3 \mathrm{CH}_{4}\right)_{3} \mathrm{UNGeMe}$ was 44\% ( $\left.0.24 \mathrm{~g}\right)$, m.p. 187189 C. 'H NMR (C, $\left.\mathrm{D}_{6}, 3^{\circ} \mathrm{C}\right): 6.46\left(3 \mathrm{H}, v_{1 / 2}=11 \mathrm{~Hz}\right), 286\left(3 \mathrm{H}, v_{1 / 2}=15 \mathrm{~Hz}\right)$, $-1.53\left(2 \mathrm{H}, V_{1 / 2}=54 \mathrm{~Hz}\right),-11.10\left(2 \mathrm{H}, \mathrm{V}_{1 / 2}=51 \mathrm{~Hz}\right)$. AnN. Caled for $\mathrm{C}_{21} \mathrm{H}_{30} \mathrm{GeNU}$ : C, 41.5; H, 4.98; N, 2.31. Found: $C, 41.4 ; H, 5.13 ; N, 219$. Mass spectrum: 604 $(52 ; 52), 605(13 ; 3), 606(72 ; 83), 607(37 ; 35), 603(100 ; 100), 609(23 ; 22), 610(23 ;$ 26), $611(5 ; 5), 612(1 ; 1)$. IR: 1261 w, 1231 w, 70 w, 1098 w, $1029 \mathrm{~m}, 918 \mathrm{~m}, 808$ s, $771 \mathrm{~s}, 628 \mathrm{w}, 599 \mathrm{~m}, 564 \mathrm{w}, 535 \mathrm{w} \mathrm{cm}^{-1}$.

The material that was insoluble in hexane was extracted with $\mathrm{CH}_{2} \mathrm{Cl}_{2}$ $(20 \mathrm{~mL}$ ), the yellow-green solution was filtered, and the volatile materials 
were removed under reduced pressure, giving $0.08 \mathrm{~g}$ of material. ${ }^{1} \mathrm{H}$ NMR spectroecopy showed this to be primarily $\left(\mathrm{MeC}_{5} \mathrm{H}_{4}\right)_{3} \mathrm{UN}_{3}$.

Reaction of $\left(\mathrm{MeC} \mathrm{C}_{3} \mathrm{H}_{3} \mathrm{U}(\right.$ the $)$ with $\mathrm{Me}_{3} \mathrm{SnN}_{3}$

A solution of $\left(\mathrm{MeC} \mathrm{CH}_{4}\right)_{3} \mathrm{U}(\mathrm{thh})(1.90 \mathrm{~g}, 3.47 \mathrm{mMol})$ in $75 \mathrm{~mL}$ of $\mathrm{Et}_{2} \mathrm{O}$ was added to $\mathrm{Me}_{3} \mathrm{SnN}_{3}(0.90 \mathrm{~g}, 4.4 \mathrm{mMd})$. A light precipitate formed immediately. After stirring for one weak (one day is probably sufficient), the predpitate was allowed to sattle and the ether was removed by filtration. The green solld that remained was extracted with dichloromethane $(50 \mathrm{~mL})$, the solution was filtered, and the filtrate was concentrated to ca. $10 \mathrm{~mL}$. Hexane ( 3 $\mathrm{mL}$ ) was added to this solution, and it was cooled to $-80^{\circ} \mathrm{C}$. Green microcrystals were isolated by filtration and dried in $18 \%(0.32 \mathrm{~g})$ yield. ${ }^{1} \mathrm{H}$ NMR spectroecopy indicated that this material was $\left(\mathrm{MeC} \mathrm{C}_{5} \mathrm{H}_{3} \mathrm{UN}_{3}\right.$. The volatile materials were removed from the remaining dichloromethane solution under reduced pressure, and the ${ }^{1} \mathrm{H}$ NMR spectrum of the green reaidue $(0.16 \mathrm{~g})$ showed it to be fairly pure $\left(\mathrm{McC} \mathrm{C}_{5} \mathrm{H}_{3} \mathrm{UN}_{3}\right.$. The volatile materials from the ariginal ether solution were removed under reduced pressure. 'H NMR spectroscopy showed that the remaining solid consisted mainly of $\left(\mathrm{MeC}_{5} \mathrm{H}_{4}\right)_{3} \mathrm{UN}_{3}$, with several other peaks observed in the diamagnetic region (probably tin-containing materials).

This reaction was also performed in an NMR tube with $C_{6} D_{6}$ as solvent. The ${ }^{1} H$ NMR spectrum obtained from this reaction showed that the predominant species are: $\left(\mathrm{McC} \mathrm{C}_{5} \mathrm{H}_{4} \mathrm{UN}_{3}\right.$, thf, and several peaks between 0.5 ppm and -0.1 ppm. 
Reaction of $\left(\mathrm{MeC} \mathrm{C}_{3} \mathrm{H}_{4}\right)_{3} \mathrm{U}($ the $)$ with $\mathrm{Ph}_{3} \mathrm{CN}_{3}$

To $0.51 \mathrm{~g}\left(\mathrm{MeC}_{5} \mathrm{H}_{4}\right)_{3} \mathrm{U}$ thf $(0.93 \mathrm{mmol})$ dissolved in $10 \mathrm{~mL}$ of $\mathrm{Et}_{2} \mathrm{O}$ was added by cannula $0.32 \mathrm{~g} \mathrm{Ph}_{3} \mathrm{CN}_{3}$ (1.1 mmol) dissolvecis in $10 \mathrm{nii}$ of $\mathrm{Et}_{2} \mathrm{O}$. A bright green precipitate immediately formed. After stir.ing for 12 hours, the ether was removed by filtration, and the green powder driad under reduced pressure. ' $\mathrm{H} N \mathrm{MR}$ spectroscopy showed this powder to be $\left(\mathrm{MeC}_{5} \mathrm{H}_{1} \mathrm{LNN}_{3}\right.$; $0.24850 \%$.

Reartion of (MeC $\left.\mathrm{H}_{4}\right)_{3} \mathrm{U}(\mathrm{th})$ with $\mathrm{Ph}_{3} \mathrm{SnN}_{3}$

To a mixture of $\left(\mathrm{Mac}_{5} \mathrm{H}_{4}\right)_{3} \mathrm{U}$ (thr) $(0.25 \mathrm{~g}, 0.46 \mathrm{mMol})$ and $\mathrm{Ph}_{3} \mathrm{SnN}_{3}(0.18$ 8. $0.46 \mathrm{mMol}$ ) was added $20 \mathrm{~mL}$ of $\mathrm{Et}_{2} \mathrm{O}$, resulting in a light green solution with a green precipitate. The mixture was stirred overnight and the volatile materials were then removed under reduced pressure. The ${ }^{1} \mathrm{H}$ NMR spectrum of the green residue showed that it corsisted of $\left(\mathrm{MeC}_{5} \mathrm{H}_{4} \mathrm{UNN}_{3}\right.$ and other materials with resonances in the diamagnatic region of the spectrum. No attempt was made to separate the uranium compound from the tin containing by-products.

Reaction of $\left(\mathrm{Me} \mathrm{C}_{3} \mathrm{H}_{4}\right)_{3} \mathrm{U}(\mathrm{th})$ withPh $\mathrm{CHN}_{3}$

Preparative scale reaction: To $\left(\mathrm{MeC}_{5} \mathrm{H}_{4}\right)_{3} \mathrm{U}(\mathrm{th})(1.0 \mathrm{~g}, 1.8 \mathrm{mM} / \mathrm{ol})$ dissolved in $30 \mathrm{~mL}$ of $\mathrm{Et}_{2} \mathrm{O}$ was added $0.38 \mathrm{~g} \mathrm{Fh}_{2} \mathrm{CHN}_{3}$ (ca. $1.8 \mathrm{mMol}$ ). Gas evolution was immediately ubserved, and color turned dark red. After one hour, the volatile materials were removed under reduced pressure. The residue was extracted with hexane $(50 \mathrm{~mL})$, the solution swas filtered, and the filtrate was concentrated and cooled to $-20^{\circ} \mathrm{C}$. Brown crystals were isolated by filtration and dried in $58 \%(0.70 \mathrm{~g})$ yield, m.p. $89-91^{\circ} \mathrm{C}$. ${ }^{1} \mathrm{H} \mathrm{NMR}\left(\mathrm{C}_{6} \mathrm{D}_{6}, 30^{\circ} \mathrm{C}\right)$ : $4.27\left(9 \mathrm{H}, v_{1 / 2}=24 \mathrm{~Hz}\right),-4.6\left(6 \mathrm{H}, v_{1 / 2}=65 \mathrm{~Hz}\right),-10.3\left(v_{1 / 2}=80 \mathrm{~Hz}\right), 12.41(4 \mathrm{HD}), 8.62$ 
(4H, d, J = 7 Hz), 7.65 (2H). The benzhydryl C-H resonance was not located. Mass spectrum: 656 (100; 100), 657 (35; 35). IR: $1262 \mathrm{~m}, 1162 \mathrm{w}, 1010 \mathrm{~m}, 1073$ $\mathrm{m}, 1030 \mathrm{~s}, 845 \mathrm{~m}, 776 \mathrm{~s}, 741 \mathrm{~m}, 702 \mathrm{~s}, 610 \mathrm{~m} \mathrm{~cm}^{-1}$.

The hexane-insoluble material was extracted with dichloromethane, filtered, and the volatile materials removed under reduced pressure to give a green residue $(0.05-0.06 \mathrm{~g})$. The 'H NMR spectrum of this residue showed the

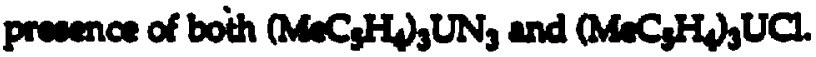

NMR tube ranction: To $20.5 \mathrm{mg}$ of (MaCgH) $\mathrm{U}$ (th) diseolved in ca. 1.5 $\mathrm{mL}$ of $\mathrm{C}_{6} \mathrm{D}_{6}$ was added by syringe $7.0 \mu \mathrm{L}$ of $\mathrm{Ph}_{2} \mathrm{CH}_{3}$. Gas evolution was noted, and the color changed from red to dark brown/red. An aliquot of the solution was transferred by pipette to an NMR tube, and the ${ }^{1} H$ NMR spectrum obtained. The ratio $\left(\mathrm{MeC}_{5} \mathrm{H}_{4}\right)_{3} \mathrm{UNC}(\mathrm{H}) \mathrm{Ph}_{2}$ : $\left(\mathrm{MeC} \mathrm{CH}_{4} \mathrm{UNN}_{3}\right.$ was measured by integration to be $c a .8: 1$.

\section{$\left(\mathrm{MeC}_{5} \mathrm{H}_{4}\right)_{3} \mathrm{UNCH}_{2} \mathrm{Ph}$}

To $1.45 \mathrm{~g}$ of $\left(\mathrm{MeC}_{\mathrm{gH}} \mathrm{H}_{3} \mathrm{U}(\mathrm{th})\right.$ (2.60 mMol) dissolved in $50 \mathrm{~mL}$ of diethyl ether was added $0.33 \mathrm{~mL}$ of benzylazide $(2.65 \mathrm{mMol})$. Gas was immediately evolved, and the color of the solution changed from red-brown to a dark brown-green. The solution was stirred for 5 hours then the volatile material was removed under reduced pressure. The brown solid was extracted with 60 $\mathrm{mL}$ of hexane, the brown solution was filtered, and the filtrate was concentrated to ca. $30 \mathrm{~mL}$ and cooled to $-20^{\circ} \mathrm{C}$. Brown flakes were isolated by filtration and dried in $60 \%(0.91 \mathrm{~g})$ yield, m.p. 57-59\% ${ }^{\circ}$ 'H NMR $\left(\mathrm{C}_{6} \mathrm{D}_{6}, 30^{\circ} \mathrm{C}\right)$ : $3.42\left(9 \mathrm{H}, v_{1 / 2}=23 \mathrm{~Hz}\right),-2.81\left(6 \mathrm{H}, v_{1 / 2}=94 \mathrm{~Hz}\right),-11.33\left(6 \mathrm{H}, v_{1 / 2}=78 \mathrm{~Hz}\right), 123.5$ $\left(2 \mathrm{H}, v_{1 / 2}=450-500 \mathrm{~Hz}\right), 12.73\left(2 \mathrm{H}, \mathrm{v}_{1 / 2}=27 \mathrm{~Hz}\right), 8.60\left(2 \mathrm{H}, \mathrm{V}_{1 / 2}=12 \mathrm{~Hz}\right), 7.63(1 \mathrm{H}$, $v_{1 / 2}=16 \mathrm{~Hz}$ ). Anal. Calcd for $\mathrm{C}_{25} \mathrm{H}_{25} \mathrm{NU}: \mathrm{C}, 51.7 ; \mathrm{H}, 4.86 ; \mathrm{N}, 2.41$. Found: $\mathrm{C}$, 
51.9; H, 5.01; N, 244. Mass spectrum: 580 (100; 100), 581 (28; 28). IR: 1298 w, $1264 \mathrm{w}, 1132 \mathrm{~m}, 1032 \mathrm{~m}, 972 \mathrm{w}, 932 \mathrm{w}, 850 \mathrm{~m}, 764 \mathrm{~s}, 729 \mathrm{~m}, 698 \mathrm{~m}, 615 \mathrm{w} \mathrm{cm}^{-1}$.

$\left(\mathrm{MeC}_{3} \mathrm{H}_{\varphi_{3}} \mathrm{UNPh}\right.$

$\left.a e_{5} \mathrm{H}_{4}\right)_{3} \mathrm{U}(\mathrm{th})(0.70 \mathrm{~g} 1.28 \mathrm{mM}$ (ol) was diseolved in diethyl ether (30 $\mathrm{mL}$ ) and the solution coolad to $0^{\circ} \mathrm{C}$. To this solution was added $0.81 \mathrm{~mL}$ of a $1.58 \mathrm{M}$ solution of phenylaxide $(1.28 \mathrm{mMol})$ in toluene. Gas was immediately evolved, and the color of the solution turned daep red. After 10 minutes, the solvent was removed under reduced pressure and the red-brown solid was extracted with hexane $(2 \times 25 \mathrm{~mL})$. The red solution was filtered, and the filtrate was concentrated to $\mathrm{ca}, 30 \mathrm{~mL}$ and cooled to $-20^{\circ} \mathrm{C}$. Red needles were isolated and dried in $45 \%(0.32 \mathrm{~g})$ yield, m.p. $109-112^{\circ} \mathrm{C}$. ${ }^{1} \mathrm{H} N \mathrm{NR}\left(\mathrm{C}_{6} \mathrm{D}_{6}, 60^{\circ} \mathrm{C}\right)$ : $3.68\left(9 \mathrm{H}, v_{1 / 2}=20 \mathrm{HL}\right),-2.96\left(6 \mathrm{H}, v_{1 / 2}=60 \mathrm{~Hz}\right),-9.64\left(6 \mathrm{H}, v_{1 / 2}=49 \mathrm{~Hz}\right), 17.93(2 \mathrm{H}$, $\left.v_{1 / 2}=18 \mathrm{H} / 2\right), 3.32(2 \mathrm{H}),-231\left(1 \mathrm{H}, v_{1 / 2}=20 \mathrm{~Hz}\right)$. The ${ }^{1} \mathrm{HNMR}$ was recorded at $60^{\circ} \mathrm{C}$ because at room temperature the peak at $3.32 \mathrm{ppm}$ is buried under the resonance at 3.68 ppm. Ans. Caled for $\mathrm{C}_{24} \mathrm{H}_{26 \mathrm{NU}} \mathrm{C}, 50.9 ; \mathrm{H}, 4.63 ; \mathrm{N}, 247$. Found: $C, 50.7 ; H, 4.60 ; \mathrm{N}, 2.34$. Mass spectrum: $566(100 ; 100), 567(27 ; 28), 568$ (4, 12). RR: $1589 \mathrm{~m}, 1574 \mathrm{~m}, 1555 \mathrm{w}, 1264 \mathrm{~s}, 1161 \mathrm{~m}, 1152 \mathrm{w}, 1067 \mathrm{w}, 1047 \mathrm{w}, 1034$ m, 1022 w, 992 w, 928 w, $907 \mathrm{~m}, 890$ w, 860 w, 849 s, 799 s, 760 s, 723 m, 693 s, $600 \mathrm{w}, 527 \mathrm{w} \mathrm{cm}^{-1}$. Magnetic susceptibility (5 and $40 \mathrm{kG}$ fields): $\mu_{\text {eff }}=1.96 \mathrm{~B} . \mathrm{M}$. $(140-280 \mathrm{~K} ; \theta=-110 \mathrm{~K}), \mu_{\text {atf }}=1.25$ B.M. $(5-40 \mathrm{~K} ; \theta=1.03 \mathrm{~K})$.

\section{$\left(\mathrm{MeC}_{5} \mathrm{H}_{4}\right)_{3} \mathrm{UN}-\mathrm{p}-\mathrm{MeC}_{6} \mathrm{H}_{4}$}

To $1.00 \mathrm{~g}$ of $\left(\mathrm{MeC}_{5} \mathrm{H}_{4}\right) \mathrm{U}(\mathrm{th})$ (1.83 mMol) dissolved in $30 \mathrm{~mL}$ of diethyl ether was added $0.76 \mathrm{~mL}$ of $2.39 \mathrm{M}$ p-tolylazide (1.82 mMol) in toluene. Gas was immediately evolved, and the color turned deep red. The mixture was stirred at room temperature for 45 minutes, then the solvent was removed 
under reduced pressure. The dark red residue was extracted with $50 \mathrm{~mL}$ of hexane, filtered, and the filtrate was concentrated to $\mathrm{ca} .25 \mathrm{~mL}$ and cooled to $-20^{\circ} \mathrm{C}$. Red-brown crystals were isolated in $66 \%(0.70 \mathrm{~g})$ yield, m.p. $89-92^{\circ} \mathrm{C}$. ${ }^{1} \mathrm{H}$ $\operatorname{NMR}\left(C_{8} D_{C} 30^{\circ} \mathrm{C}\right): 3.68\left(9 \mathrm{H}, V_{1 / 2}=20 \mathrm{~Hz}\right),-3.48\left(6 \mathrm{H}, V_{1 / 2}=50 \mathrm{~Hz}\right),-10.96(6 \mathrm{H}$, $\left.v_{1 / 2}=50 \mathrm{~Hz}\right), 19.01\left(3 \mathrm{H}, V_{1 / 2}=12 \mathrm{~Hz}\right), 18.65\left(2 \mathrm{H}, V_{1 / 2}=18 \mathrm{~Hz}\right), 3.37$ (2H. And. Calcd for $\mathrm{C}_{22} \mathrm{H}_{2,2 \mathrm{NU}} \mathrm{C}, 51.7 ; \mathrm{H}, 4.86 ; \mathrm{N}, 2.41$. Found: $\mathrm{C}, 51.7 ; \mathrm{H}, 4.80 ; \mathrm{N}, 2.41$. Mase spectrum: 380 (100; 100), 581 (28; 35), 582 (4; 9). IR: 1491 s, 1348 w, 1273 s, 1240 w, 1165 w, 1101 w, 1067 w, 1034 m, 974 w, 932 w, 912 m, 895 w, 843 m, 814 $s, 781 \mathrm{~s}, 768 \mathrm{~s}, 610 \mathrm{w}, 554 \mathrm{w}, 523 \mathrm{~m} \mathrm{~cm}^{-1}$.

$\left(\mathrm{MeC}_{3} \mathrm{H}_{4}\right)_{3} \mathrm{UN}-\mathrm{p}-\mathrm{Me}_{2} \mathrm{NC}_{6} \mathrm{H}_{4}$

To $\left(\mathrm{MeC} \mathrm{H}_{4} \mathrm{~J}_{3} \mathrm{U}\right.$ (th) $(0.71 \mathrm{~g}, 1.3 \mathrm{mMol})$ dissolved in $30 \mathrm{~mL}$ of diethyl ether was added $0.21 \mathrm{~g}$ (1.3 mMol) p-dimethylaminophenylazide in $10 \mathrm{~mL}$ of diethyl ether. Gas evolution was observed immediately, and the color of the solution changed from red-brown to a deep red. After 10 minutes, the volatile materials were removed under reduced pressure. The red-black solid was extracted with diethyl ether $(50 \mathrm{~mL})$, the extract was filtersd, and filtrate was concentrated to ca. $30 \mathrm{~mL}$ and cooled to $-20^{\circ} \mathrm{C}$. Red-black bricks were isolated and dried $(0.32 \mathrm{~g})$ m.p. $147-148^{\circ} \mathrm{C}$. An additional $0.12 \mathrm{~g}$ was isolated by concentrating the remaining ether solution to $\mathrm{ce} .10 \mathrm{~mL}$ and cooling to $-20^{\circ} \mathrm{C}$. Total yield was $0.44 \mathrm{~g}, 55 \%$. ${ }^{1} \mathrm{H}$ NMR $\left(\mathrm{C}_{6} \mathrm{D}_{G}, 30^{\circ} \mathrm{C}\right): 3.66\left(9 \mathrm{H}, \mathrm{V}_{1 / 2}=25 \mathrm{~Hz}\right),-4.01$ $\left(6 \mathrm{H}, v_{1 / 2}=70 \mathrm{H} 2\right),-10.92\left(6 \mathrm{H}, v_{1 / 2}=74 \mathrm{H} 2\right), 10.20\left(6 \mathrm{H}, v_{1 / 2}=5 \mathrm{H} 2\right), 17.85\left(2 \mathrm{H}, v_{1 / 2}\right.$ $=16 \mathrm{~Hz}), 2.60\left(2 \mathrm{H}, v_{1 / 2}=37 \mathrm{~Hz}\right)$. Anl, Calod for $\mathrm{C}_{26} \mathrm{H}_{31} \mathrm{~N}_{2} \mathrm{U}: \mathrm{C}, 51.2 ; \mathrm{H}, 5.13 ; \mathrm{N}$, 4.60. Found: $C, 51.3 ; H, 5.43 ; N, 1.90$. Mass spectrum: 609 (100; 100), 610 (30; 31). IR: 1588 s, 1494 s, 1339 s, $1266 \mathrm{~m}, 1216 \mathrm{~m}, 1178 \mathrm{~m}, 1162$ w, 1120 w, 1105 w, 1045 w, 1030 w, $941 \mathrm{~m}, 906$ w, 858 w, 834 m, 818 s, 800 m, 766 s, 605 w, 556 w, 
$539 \mathrm{w}, 517 \mathrm{w}, 333 \mathrm{w} \mathrm{cm}-1$. Magnetic susceptibility (5 and $40 \mathrm{kG}$ fields): $\mu_{\text {eff }}=$ 2.21 B. M. $(140-220 \mathrm{~K} ; \theta=-120 \mathrm{~K})$, $\mu_{\text {aff }}=1.40$ B.M. $(5-40 \mathrm{~K} ; \theta=-3.32 \mathrm{~K})$.

\section{$\left(\mathrm{MeC}_{3} \mathrm{H}_{4}\right)_{3} \mathrm{UN}-\mathrm{p}-\mathrm{MeOC} \mathrm{H}_{4}$}

To $\left(\mathrm{MeC} \mathrm{C}_{5} \mathrm{H}_{3} \mathrm{U}\right.$ (th) $(0.50 \mathrm{\&}, 0.91 \mathrm{mMol})$ dissolved in $20 \mathrm{~mL}$ of diethyl ether was added $0.148(0.94 \mathrm{mMol})$ of p-methoxyphenylavide in $10 \mathrm{~mL}$ of diethyl ether. Gas evolution was immediately observed, and the color of the solution changed from red-brown to a desp red. The solution was atirred for 10 minutes, then the volatile materials were removed under reduced pressure. The solid residue was extracted with $50 \mathrm{~mL}$ of hexane, the extract was filtered, and the filtrate was concentrated to ca. $40 \mathrm{~mL}$ and cooled to $-20^{\circ} \mathrm{C}$. Red-brown crystals were isolated by filtration and dried under reduced pressure to give $0.25 \mathrm{~g}$ m.p. $97-99^{\circ} \mathrm{C}$. An additional $0.08 \mathrm{~g}$ was obtained by concentrating the hexane mother liquor to $\mathrm{ca} .15 \mathrm{~mL}$ and cooling to $-20^{\circ} \mathrm{C}$. Total yield was $0.33 \mathrm{~g}, 60 \%$. ${ }^{1} \mathrm{H}$ NMR $\left(\mathrm{C}_{6} \mathrm{D}_{\mathrm{c}}, 30^{\circ} \mathrm{C}\right): 3.68\left(9 \mathrm{H}, \mathrm{v}_{1 / 2}=18 \mathrm{~Hz}\right),-3.66$ $\left(6 \mathrm{H}, v_{1 / 2}=75 \mathrm{~Hz}\right),-10.92\left(6 \mathrm{H}, V_{1 / 2}=60 \mathrm{~Hz}\right), 7.04\left(3 \mathrm{H}, v_{1 / 2}=5 \mathrm{~Hz}\right), 17.98\left(2 \mathrm{H}, V_{1 / 2}=\right.$

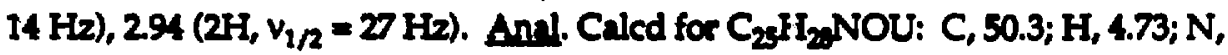
2.35. Found: $C, 50.0 ; H, 4.60 ; N, 2.35$. Mass spectrum: $596(100 ; 100)$. IR: 1586 $\mathrm{m}, 1482 \mathrm{~s}, 1435 \mathrm{~m}, 1290 \mathrm{w}, 1260 \mathrm{~m}, 1233 \mathrm{~s}, 1178 \mathrm{w}, 1155 \mathrm{w}, 1095 \mathrm{w}, 1030 \mathrm{~m}, 927$ $w, 908 w, 829 \mathrm{~m}, 763 \mathrm{~s}, 638 \mathrm{w}, 601 \mathrm{w}, 572 \mathrm{w}, 538 \mathrm{w}, 330 \mathrm{w} \mathrm{cm}-1$.

\section{$\left(\mathrm{MeC}_{5} \mathrm{H}_{4}\right)_{3} \mathrm{UN}-\mathrm{O}-\mathrm{MeC}_{6} \mathrm{H}_{4}$}

To $\left(\mathrm{MeC}_{5} \mathrm{H}_{4}\right)_{3} \mathrm{U}(\mathrm{th})(0.98 \mathrm{~g}, 1.79 \mathrm{mMol})$ dissolved in $40 \mathrm{~mL}$ of diethyl ether was added $0.25 \mathrm{~mL}$ of o-tolylazide (1.88 mMol). Gas evolution immediately occurred, and the color of the solution changed from red-brown to a darker red. The volatile materials were removed immediately under reluced pressure over a period of $c a$. 15 minutes. The brown solid residue 
was warmed to $50^{\circ} \mathrm{C}$ under vacuum for 15 minutes to remove excess azide. The residue was then extracted into $40 \mathrm{~mL}$ of diethyl ether, the extract was filtered, and the filtrated was concentrated to $c r .10 \mathrm{~mL}$ and cooled to $-20^{\circ} \mathrm{C}$. Brown-red needles were isolated and dried in $75 \%$ yjeld $(0.78$ g. m.p. 118

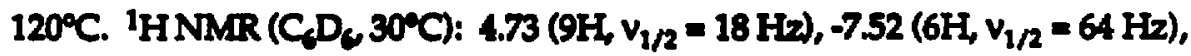
$8.67\left(6 \mathrm{H}, \mathrm{V}_{1 / 2}=67 \mathrm{H} 2\right), 15.27\left(3 \mathrm{H}, \mathrm{V}_{1 / 2}=27 \mathrm{~Hz}\right), 19.95\left(1 \mathrm{H}, \mathrm{V}_{1 / 2}=24 \mathrm{~Hz}\right), 19.29$ $\left(1 H, v_{1 / 2}=21 \mathrm{HZ}\right.$ ), 5.14 (1F, partly overlapped with the large peak at 4.73), -3.15 $\left(1 \mathrm{H}, v_{1 / 2}=17 \mathrm{~Hz}\right)$. Anv1. Caled for $\mathrm{C}_{25} \mathrm{H}_{2 \mathrm{NU}} \mathrm{N}$ :, $51.7 ; \mathrm{H}, 4.86 ; \mathrm{N}, 2.4$. Found: C, 51.5; H, 4.97; N, 236. Mass spectrum: 580 (100; 100), 581 (28; 25). IR: 1580 w, 1555 w, 1246 s, 1109 w, 1164 w, 1035 m, 911 w, $845 \mathrm{~m}, 771$ s, 758 s, 711 w, 601 w, $455 \mathrm{w}, 336 \mathrm{w}, 328 \mathrm{w} \mathrm{cm}^{-1}$.

\section{$\left(\mathrm{MeC}_{3} \mathrm{H}_{4}\right)_{3} \mathrm{UN}_{-0}-\mathrm{IPrC}_{6} \mathrm{H}_{4}$}

To $\left(\mathrm{MeC} \mathrm{C}_{5} \mathrm{H}_{3} \mathrm{U}(\mathrm{thr})(0.54 \mathrm{~g}, 0.99 \mathrm{mMol})\right.$ dissolved in $20 \mathrm{~mL}$ of diethyl ether was added $0.16 \mathrm{~mL}$ of o-isopropylphenylazide (ca. $1.0 \mathrm{mMol}$ ). Gas evolution immediately occurred, and the color of the solution changed from red-brown to a darker red. The volatile materials were removed immediately under reduced pressure. The residue was then extracted with $30 \mathrm{~mL}$ of hexane, the extract was filtered, and the filtrated was concentrated to cr. 5-10 $\mathrm{mL}$ and cooled to $-200^{\circ} \mathrm{C}$. Black-red needles were isolated and dried in $65 \%$ yield ( $0.39 \mathrm{~g})$, m.p. $77-83^{\circ} \mathrm{C}$. ${ }^{1} \mathrm{H}$ NMR $\left(\mathrm{C}_{6} \mathrm{D}_{6}, 30^{\circ} \mathrm{C}\right): 4.71\left(9 \mathrm{H}, \mathrm{v}_{1 / 2}=23 \mathrm{~Hz}\right),-8.18$ $\left(12 \mathrm{H}, v_{1 / 2}=78 \mathrm{~Hz}\right), 1.81\left(6 \mathrm{H}, v_{1 / 2}=12 \mathrm{~Hz}\right), 21.16\left(1 \mathrm{H}, v_{1 / 2}=18 \mathrm{~Hz}\right), 19.27\left(1 \mathrm{H}, v_{1 / 2}\right.$ $=18 \mathrm{~Hz}), 5.04(1 \mathrm{H}$, partly overlapped with the large peak at 4.71$),-2.75\left(1 \mathrm{H}, v_{1 / 2}\right.$ $=18 \mathrm{~Hz}), 9.24\left(1 \mathrm{H}, v_{1 / 2}=65 \mathrm{~Hz}\right)$. And. Calcd for $\mathrm{C}_{27} \mathrm{H}_{32} \mathrm{NU}: \mathrm{C}, 53.3 ; \mathrm{H}, 5.30 ; \mathrm{N}$, 2.30. Found: C, 52.1; H, 5.05; N, 1.91. Mass spectrum: 608 (100; 100), 609 (32; 30), 610 (15; 4). IR: 1580 w, $1280 \mathrm{~m}, 1245 \mathrm{~m}, 1085 \mathrm{w}, 1030 \mathrm{~m}, 910 \mathrm{w}, 859 \mathrm{w}, 839 \mathrm{w}$, $792 \mathrm{~m}, 768 \mathrm{~s}, 743 \mathrm{~m}, 606 \mathrm{w} \mathrm{cm}^{-1}$. 


\section{$\left(\mathrm{MeC}_{5} \mathrm{H}_{4}\right)_{3} \mathrm{UN}-2,6-\mathrm{Me}_{2} \mathrm{C}_{6} \mathrm{H}_{3}$}

To $\left(\mathrm{MeC}_{5} \mathrm{H}_{4}\right)_{3} \mathrm{U}(\mathrm{thh})(0.77 \mathrm{~g}, 1.41 \mathrm{mMol})$ dissolved in $30 \mathrm{~mL}$ of diethyl ether was added $0.21 \mathrm{~mL}$ of 2,6-dimethylphenylezide (1.43 mMol). Gas evolution immediately occurred, and the color changed from red-brown to deep red. The volatile materials were removed under reduced pressure, and the residue was extracted with $50 \mathrm{~mL}$ of diethyl ether. The ether extract was filtered, and the filtrate was concentrated to ce. $30 \mathrm{~mL}$ and cooled to $-20^{\circ} \mathrm{C}$. Red-black needles were isolated by filtration and dried in $51 \%(0.43 \mathrm{~g})$ yield, m.p. ${ }^{154-156^{\circ} \mathrm{C} .}{ }^{1} \mathrm{HNMR}\left(\mathrm{C}_{6} \mathrm{D}_{6}, 30^{\circ} \mathrm{C}\right): 5.67\left(9 \mathrm{H}, \mathrm{v}_{1 / 2}=25 \mathrm{~Hz}\right),-4.60\left(6 \mathrm{H}, \mathrm{v}_{1 / 2}=\right.$ $76 \mathrm{~Hz}),-14.23\left(6 \mathrm{H}, v_{1 / 2}=87 \mathrm{~Hz}\right), 19.79\left(6 \mathrm{H}, v_{1 / 2}=43 \mathrm{~Hz}\right), 20.58\left(2 \mathrm{H}, v_{1 / 2}=23 \mathrm{~Hz}\right)$, $-5.49\left(1 \mathrm{H}, v_{1 / 2}=19 \mathrm{~Hz}\right)$. Ansl. Calcd for $\mathrm{C}_{26} \mathrm{H}_{30} \mathrm{NU}: \mathrm{C}, 52.5 ; \mathrm{H}, 5.09 ; \mathrm{N}, 2.36$. Found: C, 50.9; H, 5.05; N, 2.17. Mass spectrum: 594 (100; 100), 595 (29; 28), 596 (4; 6). IR: $1490 \mathrm{~m}, 1260 \mathrm{w}, 1230 \mathrm{w}, 1090 \mathrm{~m}, 1068 \mathrm{w}, 1044 \mathrm{~m}, 1030 \mathrm{~m}, 975 \mathrm{w}, 929$ $w, 897 w, 889$ w, $866 w, 845 \mathrm{~m}, 795$ s, 788 s, 763 vs, 601 w, 385 w, $337 \mathrm{w} \mathrm{cm}^{-1}$.

Reaction of $\left(\mathrm{MeC} \mathrm{C}_{4}\right)_{3} \mathrm{U}\left(\right.$ thr) with $\mathrm{p}-\mathrm{CF}_{3} \mathrm{C}_{6} \mathrm{H}_{4} \mathrm{~N}_{3}$

To $\left(\mathrm{MeC}_{5} \mathrm{H}_{4}\right)_{3} \mathrm{U}(\mathrm{thh})(0.50 \mathrm{~g}, 0.91 \mathrm{mMol})$ dissolved in $15 \mathrm{~mL}$ of $\mathrm{Et}_{2} \mathrm{O}$ was added $0.17 \mathrm{~mL}$ of p-trifluoromethylphenylazide. Gas evolution immediately occurred, and the solution turned dark red. After 5 minutes, the volatile materials were removed under reduced pressure and the residue was extracted with hexane $(60 \mathrm{~mL})$. The red solution was filtered, and the filtrate was concentrated to $\mathrm{cr} .30 \mathrm{~mL}$ and cooled to $-20^{\circ} \mathrm{C}$. A small amount of brown powder was isolated $(0.04 \mathrm{~g})$. The volatile materials were then removed from the remaining hexane solution and the residue was extracted with diethyl ether $(20 \mathrm{~mL})$. The solution was filtered, and the filtrate was concentrated to ca. $10 \mathrm{~mL}$ and cooled to $-20^{\circ} \mathrm{C}$. Red-brown cystals $(0.21 \mathrm{~g})$ were isolated and 
dried. Both crops were examined by 'H NMR spectroscopy. Both spectra showed the presence of both $\left(\mathrm{MeC}_{5} \mathrm{H}_{4}\right)_{3} \mathrm{UN}-\mathrm{p}_{-}-\mathrm{CF}_{3} \mathrm{C}_{6} \mathrm{H}_{4}$ and $\left(\mathrm{Me} \mathrm{C}_{5} \mathrm{H}_{4}\right)_{3} \mathrm{UF}$ (by comparison with a spectrum obtained by Brennan'1), with the uranium(V) compound predominant. The ${ }^{2} \mathrm{H}$ NMR spectrum of $\left(\mathrm{MeC}_{5} \mathrm{H}_{4}\right)_{3} \mathrm{UN}_{-} \mathrm{PCF}_{3} \mathrm{C}_{6} \mathrm{H}_{4}$ is as follows: $3.59\left(9 \mathrm{H}_{1} \mathrm{~V}_{1 / 2}=16 \mathrm{~Hz}\right),-3.12\left(6 \mathrm{H}, \mathrm{V}_{1 / 2}=\right.$ $43 \mathrm{~Hz}),-11.29\left(6 \mathrm{H}, \mathrm{V}_{1 / 2}=37 \mathrm{~Hz}\right), 18.25\left(2 \mathrm{H}, \mathrm{V}_{1 / 2}=16 \mathrm{~Hz}\right), 3.16(2 \mathrm{H})$. Attempts to recrystallize the material always yidded a mbxture of compounds and the reaction was not puraued further.

Reaction of $\left(\mathrm{MeC}_{5} \mathrm{H}_{4}\right)_{3} \mathrm{U}($ the $)$ with o- $\mathrm{CF}_{3} \mathrm{C}_{6} \mathrm{H}_{4} \mathrm{~N}_{3}$

To $\left(\mathrm{Mt}=\mathrm{g}_{5} \mathrm{H}_{4} \mathrm{H}_{3} \mathrm{U}\right.$ (th) $(0.56 \mathrm{~g} 1.02 \mathrm{mMol})$ dissolved in $20 \mathrm{~mL}$ of $\mathrm{Et}_{2} \mathrm{O}$ was added $0.19 \mathrm{~g}$ of o-trifluoromethylphenylazide dissolved in $10 \mathrm{~mL}$ of $\mathrm{Et}_{2} \mathrm{O}$. The solution color immediately began to lighten, and a dark precipitate formed. After stirring for 14 hours, the volatile materials were removed under reduced pressure. The ${ }^{1} \mathrm{H}$ NMR spectrum of the green residue showed that it was primarily (MeC $\mathrm{H}_{4} \mathrm{H}_{3}$ UF. A trace amount of what is probably $\left(\mathrm{MeC} \mathrm{C}_{4}\right)_{3} \mathrm{UN}-0-\mathrm{CF}_{3} \mathrm{C}_{6} \mathrm{H}_{4}$ was also observed in the spectrum. The reaction was not pursued further.

\section{$\left(\mathrm{MeC}_{3} \mathrm{H}_{4}\right)_{3} \mathrm{UN}_{3}\left(\mathrm{AlMe}_{3}\right)$}

To $\left(\mathrm{MeC}_{5} \mathrm{H}_{4}\right)_{3} \mathrm{CN}_{3}(0.84 \mathrm{~g}, 1.6 \mathrm{mMol})$ dissolved in $20 \mathrm{~mL}$ of dichloromethane was added trimethylaluminum (13 mL of a $1.3 \mathrm{M}$ solution in hexane, $16.9 \mathrm{mMol}$ ). The solution immediately darkened. After 12 hours, the volatile materials were removed under reduced pressure, leaving a brown powder. This powder was extracted with toluene ( $25 \mathrm{~mL}$ ), the solution was filtered, and the filtrate was concentrated to ca. $20 \mathrm{~mL}$ and cooled to $-20^{\circ} \mathrm{C}$. Brown crystals were isolated by filtration and dried; a second crop was 
obtained an additional concentration and cooling of the solution. The total yield was $75 \%(0.72 \mathrm{~g})$, m.p. $152-154^{\circ} \mathrm{C}$. ${ }^{1} \mathrm{H}$ NMR $\left(\mathrm{C}_{6} \mathrm{D}_{6}, 30^{\circ} \mathrm{C}\right)$ : $-4.22(3 \mathrm{H}), 12.04$ $(2 \mathrm{H}),-16.54(2 \mathrm{H}),-7.62$ (ca. $2.5 \mathrm{H})$. The integration of the peak at -7.6 appears to increase as the temperature of the NMR is lowered (it is close to 3 at $-72^{\circ} \mathrm{C}$ ). Anal. Caled for $\mathrm{C}_{21} \mathrm{H}_{30} \mathrm{AlN}_{3} \mathrm{U}$ : $\mathrm{C}$ 2.8; $\mathrm{H}, 5.13 ; \mathrm{N}, 7.03$. Found: $\mathrm{C}, 38.9 ; \mathrm{H}, 5.10$; N, 7.03. The mase spectrum only showed a molecular ion for $\left(\mathrm{MeC}_{5} \mathrm{H}_{4} \mathrm{UN}_{3}\right.$ (517). R: 2110 s br, $1268 \mathrm{~m}, 1169 \mathrm{~m}, 1048 \mathrm{w}, 1030 \mathrm{~m}, 84 \mathrm{w}, 791 \mathrm{~s}, 710 \mathrm{~s}, 610 \mathrm{w}$, $525 \mathrm{w}, 425 \mathrm{w}, 347 \mathrm{w}, 248 \mathrm{~m} \mathrm{~cm}^{-1}$.

Reaction of $\left(\mathrm{Me}_{3} \mathrm{SiC}_{3} \mathrm{H}_{4}\right)_{3} \mathrm{UN}_{3}$ with $\left(\mathrm{Me}_{3} \mathrm{SiC}_{3} \mathrm{H}_{4}\right)_{3} \mathrm{U}$

To $\left(\mathrm{Me}_{3} \mathrm{SiC}_{5} \mathrm{H}_{4} \mathrm{U}(0.15 \mathrm{~g}, 0.23 \mathrm{mMol})\right.$ dissolved in $10 \mathrm{~mL}$ of hexane was added $\left(\mathrm{Me}_{3} \mathrm{SiC}_{5} \mathrm{H}_{4}\right)_{3} \mathrm{UN}_{3}(0.16 \mathrm{~g}, 0.23 \mathrm{mMol})$ dissolved in $10 \mathrm{~mL}$ of hexane. The color immediately changed to deep brown. After stirring overnight, the solution was filtered, and the filtrate was concentrated to ca. $5 \mathrm{~mL}$ and cooled to $-20^{\circ} \mathrm{C}$. Brown crystals were isolated and dried, m.p. $83-86^{\circ} \mathrm{C}$. ${ }^{1} \mathrm{H}$ NMR $\left(C_{6} D_{6}, 30^{\circ} \mathrm{C}\right):-8.79\left(9 \mathrm{H}, \mathrm{v}_{1 / 2}=7 \mathrm{~Hz}\right),-16.52\left(2 \mathrm{H}, \mathrm{v}_{1 / 2}=7 \mathrm{~Hz}\right), 0.9\left(2 \mathrm{H}, \mathrm{v}_{1 / 2}=\mathrm{ca}, 40\right.$ Hz). IR: 2122 s, 2081 s, 1246 s, $1177 \mathrm{~m}, 1042 \mathrm{~s}, 903$ s, 836 s, 785 s, 760 s, 750 s, 689 $w, 635 \mathrm{~m}, 625 \mathrm{~m} \mathrm{~cm}^{-1}$.

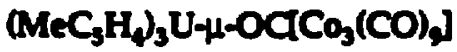

Method A: To $\left(\mathrm{MeC}_{5} \mathrm{H}_{4}\right)_{3} \mathrm{UN}_{3}(0.44 \mathrm{~g}, 0.85 \mathrm{mMol})$ dissolved in $30 \mathrm{~mL}$ of dichloromethane was added $\mathrm{CO}_{2}(\mathrm{CO})_{\mathrm{g}}(0.29 \mathrm{~g}, 0.85 \mathrm{mMol})$ dissolved in $15 \mathrm{~mL}$ of dichloromethane. The solution slowly turned from green to red. After 18 hours, the volatile materials were removed under reduced pressure. The solid was extracted with hexane $(40 \mathrm{~mL})$, the red solution was filtered, and the filtrate was concentrated and cooled to $-20^{\circ} \mathrm{C}$. Red microcrystals were isolated by filtration and dried in $77 \%(0.41 \mathrm{~g})$ yield (based on cobalt). ${ }^{1} \mathrm{H}$ NMR $\left(\mathrm{C}_{6} \mathrm{D}_{6}\right.$, 
$\left.30^{\circ} \mathrm{C}\right):-10.16(3 \mathrm{H}), 5.14$ (2H), -1.50 (2F). IR: $2080 \mathrm{~m}, 1960 \mathrm{~s} v \mathrm{vr}, 1030 \mathrm{~m}, 855 \mathrm{~m}$, $780 \mathrm{~s}, 580$ s, 535 s, 509 s, 470 s, 430 s, $405 \mathrm{~m}, 355 \mathrm{w}, 335 \mathrm{w} \mathrm{cm}^{-1}$. The infrared spectrum was also obtained in $\mathrm{Et}_{2} \mathrm{O}$ solution; the absorbances between 2100 and $1800 \mathrm{~cm}^{-1}$ are as follows: $2080 \mathrm{w}, 2062 \mathrm{w}, 2058 \mathrm{w}, 2025$ s, $2017 \mathrm{~s}, 195 \mathrm{sm}$, $1927 \mathrm{~m}, 1899 \mathrm{~m}, 1869 \mathrm{w} \mathrm{cm}^{-1}$.

Method D: To $\left(\mathrm{McC} \mathrm{CH}_{4} \mathrm{H}_{3} \mathrm{UN} B \mathrm{Bu}(0.10 \mathrm{~g}, 0.18 \mathrm{mMol})\right.$ dissolved in $20 \mathrm{~mL}$ of hexane was added $\mathrm{CO}_{2}(\mathrm{CO})_{6}(0.06 \mathrm{~g}, 0.18 \mathrm{mM} \mathrm{Ml})$ diecolved in $20 \mathrm{~mL}$ of hexane. The solution slowly turned red and a red precipitate formed. After 24 hours, the dark red solution was filtered. The red precipitate that remained was extracted with $20 \mathrm{~mL}$ of hexane, the solution was filtered, and the two filtrates were combined. The filtrate was concentrated to ca. $50 \mathrm{~mL}$ and cooled to $-20^{\circ} \mathrm{C}$. Red crystals were isolated by filtration and dried, m.p. $130^{\circ} \mathrm{C}$ (dec.). ' $\mathrm{H}$ NMR spectoscopy showed that this material was identical to that produced in method $A$

\section{$\left.\mathrm{Cp}_{3} \mathrm{U}-\mu-\mathrm{OCCO}_{3}(\mathrm{CO})_{2}\right]$}

To Cp3UNSiMes $(0.62 \mathrm{~g}, 1.2 \mathrm{mMol})$ diseolved in $40 \mathrm{~mL}$ of ether was added $\mathrm{CO}_{2}(\mathrm{CO})_{8}(0.40 \mathrm{~g}, 1.2 \mathrm{mMol})$ dissolved in $30 \mathrm{~mL}$ of ether. A red precipitate slowly formed as the mixture was stirred over 20 hours. The volatile materials were removed under reduced pressure, the red solid was extracted with toluene $(40 \mathrm{~mL})$, the solution was filtered, and the filtrate was concentrated to ca. $30 \mathrm{~mL}$ and cooled to $-20^{\circ} \mathrm{C}$. Red plates were isolated by filtration and dried in $80 \%(0.57 \mathrm{~g})$ yield (based on cobalt). ${ }^{1} \mathrm{H} N \mathrm{NR}\left(\mathrm{C}_{6} \mathrm{D}_{6}\right.$ $28^{\circ} \mathrm{C}$ ): 3.32 . IR: $2080 \mathrm{~m}, 2020 \mathrm{~s}, 1968 \mathrm{~m}, 1260 \mathrm{w}, 1165 \mathrm{w}, 1018 \mathrm{w}, 1009 \mathrm{w}, 817 \mathrm{w}$, $795 \mathrm{~m}, 720 \mathrm{~m}, 588 \mathrm{~m}, 540 \mathrm{~m}, 510 \mathrm{~m}, 477 \mathrm{~m}, 436 \mathrm{~m}, 412 \mathrm{w} \mathrm{cm} \mathrm{cm}^{-1}$. 
$\left[\mathrm{MeC} \mathrm{H}_{4}\right)_{3} \mathrm{U}_{2}-\mu-\mathrm{PhNCO}$

A Fisher-Porter pressure apparatus containing $\left(\mathrm{MeC}_{5} \mathrm{H}_{4} \mathrm{U}_{3} \mathrm{NPh}(0.15 \mathrm{~g}\right.$, $0.27 \mathrm{mMdl}$ ) dissolved in $15 \mathrm{~mL}$ of $\mathrm{Et}_{2} \mathrm{O}$ was charged with 185 psi of carbon monoxide. After several hours, the color of the solution appeared to be lightening from deep red to pale red-orange. After 18 hours, the solution was cannulated from the ractor and the volatile materials were removed under reduced preasurs. The yellow-orange solid was extracted with ether ( $30 \mathrm{~mL}$ ), the solution was filtered, and the filtrate was concentrated to ce. $10 \mathrm{~mL}$ and cooled to $-20^{\circ} \mathrm{C}$. A small amount of olly material predpitated from the solution. The mother liquor was refiltered and cooled to $-80^{\circ} \mathrm{C}$, resulting in the formation of orange microcrystals, which were isolated and dried in $43 \%$ $0.07 \mathrm{~g})$ yield. ${ }^{1} \mathrm{H} N \mathrm{NR}\left(\mathrm{C}_{6} \mathrm{D}_{6}, 30^{\circ} \mathrm{C}\right):-3.42(9 \mathrm{H}),-21.74(9 \mathrm{H}), 12.64(6 \mathrm{H}), 4.39(6 \mathrm{H})$, $-7.87(6 \mathrm{H}),-18.71(6 \mathrm{H}),-25.00(2 \mathrm{H}), 3.0(2 \mathrm{H}), 6.4$ (1H). The spectrum was found to be identical to that obtained by Brennan. ${ }^{1}$

Reaction of $\left(\mathrm{MeC}_{3} \mathrm{H}_{4}\right)_{3} \mathrm{UNPh}_{\text {with }} \mathrm{Me}_{3} \mathrm{SnN}_{3}$

$\left(\mathrm{MeC}_{5} \mathrm{H}_{4}\right)_{3} \mathrm{UNPh}(0.15 \mathrm{~g}, 0.27 \mathrm{mMd})$ and $\mathrm{Me}_{3} \mathrm{SnN}_{3}(0.09 \mathrm{~g}, 0.4 \mathrm{mMol})$ were mixed in a Schlenk tube. Toluene $(10 \mathrm{~mL})$ was added and the solution was stirred for 24 hours. At the end of this time, the volatile materials were removed under reduced pressure and the green-brown residue was examined by ${ }^{1} \mathrm{H}$ NMR spectroscopy. The spectrum indicated the presence of both $\left(\mathrm{MeC}_{5} \mathrm{H}_{4}\right)_{3} \mathrm{UN}_{3}$ and $n=\mathrm{C}_{5} \mathrm{H}_{4} \mathrm{UNNh}_{3}$ in a ratio of ca. $95: 5$.

Reaction of (MeC, $\left.\mathrm{H}_{4}\right)_{3} \mathrm{UNPh}$ with $\mathrm{Me}_{3} \mathrm{SiN}_{3}$

To $\left(\mathrm{MeC}_{5} \mathrm{H}_{4}\right)_{3} \mathrm{UNPh}(0.15 \mathrm{~g}, 0.27 \mathrm{mMol})$ dissolved in $10 \mathrm{~mL}$ of toluene was added $\mathrm{Me}_{3} \mathrm{SiN}_{3}(0.06 \mathrm{~mL}, 0.46 \mathrm{mMol})$. The solution was stirred for 24 hours. At the end of this time, the volatile materials were removed under 
reduced pressure and the brown residue was examined by ${ }^{1} \mathrm{H}$ NMR spectroscopy. The spectrum indicated the presence of both $\left(\mathrm{MeC}_{5} \mathrm{H}_{4}\right)_{3} \mathrm{UNSiMej}_{\mathrm{g}}$ and $\left(\mathrm{MeC}_{5} \mathrm{H}_{4}\right)_{3} \mathrm{UN}_{3}$ in a ratio of ca. 85 : 15.

Reaction of (MeCg $\mathrm{H}_{4} \mathrm{UNSLM}_{3}$ with $\mathrm{Me}_{3} \mathrm{SnN}_{3}$

$\left(\mathrm{MeC}_{5} \mathrm{H}_{4}\right)_{3} \mathrm{UNSiM} \mathrm{g}_{3}(0.15 \mathrm{~g}, 0.27 \mathrm{mMOl})$ and $\mathrm{Meg}_{3} \mathrm{SrN}_{3}(0.09 \mathrm{~g}, 0.44$ mMol) were mixed in a Schlenk tube. Toluens (10 mL) was added and the solution was stirned for 24 hours. At the end of this time, the volatile materials were removed under reduced pressure and the green residue was examined by ${ }^{1} \mathrm{H}$ NMR spectroscopy. The spectrum indicated the presence of both $\left(\mathrm{MeC} \mathrm{H}_{4}\right)_{3} \mathrm{UN}_{3}$ and $\left(\mathrm{MeC}_{5} \mathrm{H}_{4}\right)_{3} \mathrm{UNSiMey}$ in a ratio of ca. $93: 7$.

Reaction of (MeCs $\mathrm{H}_{3} \mathrm{UNSiMe}_{3}$ with $\mathrm{Me}_{3} \mathrm{SiN}_{3}$

To $\left(\mathrm{MeC}_{5} \mathrm{H}_{4}\right)_{3} \mathrm{UNSiMe}_{3}(0.15 \mathrm{~g}, 0.27 \mathrm{mMol})$ dissolved in $10 \mathrm{~mL}$ of toluene was added $\mathrm{Me}_{3} \mathrm{SiN}_{3}(0.06 \mathrm{~mL}, 0.46 \mathrm{mMol})$. The solution was stirred for 24 hours. At the end of this time, the volatile materials were removed under reduced pressure and the brown residue was examined by ' $\mathrm{H}$ NMR spectroscopy. The spectrum indicated the presence of both $\left(\mathrm{MeC}_{5} \mathrm{H}_{4}\right)_{3} \mathrm{UNSiMe}_{3}$ and $\left(\mathrm{MeC}_{5} \mathrm{H}_{4} \mathrm{UN}_{3}\right.$ in a ratio of ca. $92: 8$.

Reaction of (MeC, $\left.\mathrm{H}_{4}\right)_{3} \mathrm{UNSLN}_{3}$ with $\mathrm{Ph}_{3} \mathrm{CN}_{3}$

To $\left(M e C_{5} \mathrm{H}_{4}\right)_{3} \mathrm{UNSiMe}_{3}(0.12 \mathrm{~g}, 0.21 \mathrm{mMol})$ was added $\mathrm{Ph}_{3} \mathrm{CN}_{3}(0.11 \mathrm{~g}$ $0.37 \mathrm{mMOl}$ ) dissolved in $10 \mathrm{~mL}$ of toluene. The solution was stirred for 24 hours. At the end of this time, the volatile materials were removed under reduced pressure and the brown residue was examined by ${ }^{1} \mathrm{H}$ NMR spectroscopy. The spectrum indicated the presence of both $\left(\mathrm{MeC}_{5} \mathrm{H}_{4}\right)_{3} \mathrm{UNSiMe}_{3}$ and $\left(\mathrm{MeC}_{5} \mathrm{H}_{4}\right)_{3} \mathrm{UN}_{3}$ in a ratio of $\mathrm{ca} .98$ : 2 . 
$\left(\mathrm{MeC} \mathrm{H}_{4}\right)_{3}$ UOMe

$\left.7 \mathrm{MeC} \mathrm{H}_{5}\right)_{3} \mathrm{UCl}$ was generated in situ as follows: $\mathrm{To}_{\mathrm{UC}}(0.80 \mathrm{~g}, 2.1$ mMol) discolved in $20 \mathrm{~mL}$ of thf was added $\mathrm{NaMeC}_{5} \mathrm{H}_{4}(5.0 \mathrm{~mL}$ of $\mathrm{a} 1.25 \mathrm{M}$ solution in thf, $6.25 \mathrm{mMal}$ ). The solution immediately turned red-brown, and a light precipitate formed. After one hour of stirring, the precipitate was allowed to settle and the colution of (McCgH $)_{3} \mathrm{UCl}$ was filtered onto NaOMe $(0.18 \mathrm{~g}, 3.3 \mathrm{mMol})$. The colution was stirred for 12 hours and the color changed from red to bright emerald green. The volatile materials vere removed under reduced preastire, and the green solid was extracted with hexane $(50 \mathrm{~mL})$. The green solution was filtered, the filtrate was concentrated to ca. $15 \mathrm{~mL}$ and cooled to $-20^{\circ} \mathrm{C}$. Green flakes were isolated and dried in $47 \%$ $\left(0.50 \mathrm{~g}\right.$ ) yield, m.p. $274275^{\circ} \mathrm{C}$ (the compound turns brown above $120^{\circ} \mathrm{C}$ ). ${ }^{1} \mathrm{H}$ $\operatorname{NMR}\left(C_{6} D_{G}, 30^{\circ} \mathrm{C}\right):-0.32(9 \mathrm{H}),-10.61(6 \mathrm{H}),-22.48(6 \mathrm{H}), 45.2(3 \mathrm{H})$. Anal. Calcd for $\mathrm{C}_{1} \mathrm{H}_{24} \mathrm{OU:} \mathrm{C}_{1}, 45.1 ; \mathrm{H}, 4.78$. Found: $\mathrm{C}_{1} 44.8 ; \mathrm{H}, 4.78$. Mass spectrum: 506 (100; 100), 507 (17; 21). IR: 1262 w, 1239 w, 1108 s, 1050m, $1030 \mathrm{~m}, 934$ w, $826 \mathrm{~m}$, $768 \mathrm{~s}, 632 \mathrm{w}, 494 \mathrm{wcm}^{-1}$.

Reaction of (MeC/H$)_{3}$ UNSiMe, with MeOH

To $\left(\mathrm{MeC}_{5} \mathrm{H}_{4}\right)_{3} \mathrm{UNSiMe}_{3}(0.37 \mathrm{~g}, 0.66 \mathrm{mMol})$ dissolved in $30 \mathrm{~mL}$ of toluene was added MeOH (1.34 mL of a $0.49 \mathrm{M}$ solution in ether). A reflux condenser topped with a gas inlet was placed on the flask and the solution was heated to reflux for 36 hours. At the end of this time, the solution was cooled and the volatile materials were removed under reduced pressure. The brown solid was extracted with hexane, the brown solution was filtered, and the filtrate was concentrated and cooled to $-80^{\circ} \mathrm{C}$. Brown bricks were isolated 
by filtration and dried $(0.12 \mathrm{~g}){ }^{1} \mathrm{H}$ NMR spectroscopy indicated that the product was a mixture of $\left(\mathrm{MeC}_{5} \mathrm{H}_{4}\right)_{3} \mathrm{UNSiMe}$ and $\left(\mathrm{MeC}_{5} \mathrm{H}_{4}\right)_{3}$ UOMe (ca. 1:1).

\section{Reection of (MeC, $\left.\mathrm{H}_{4}\right)_{3} \mathrm{UNSiMe}_{3}$ with PhOH}

To $\left(\mathrm{MeC}_{5} \mathrm{H}_{4}\right)_{3} \mathrm{UNSiMe}_{3}(0.37 \mathrm{~g}, 0.66 \mathrm{mMol})$ dissolved in $15 \mathrm{~mL}$ of ether was addad PhOH $(0.06 \mathrm{~g}, 0.6 \mathrm{mMLl})$ diseolved in $15 \mathrm{~mL}$ of ether. The mixture was stirred for 24 hours. The volatle materials were removed under reduced preasure. The brown solld was extracted with hexame $(25 \mathrm{~mL})$, the solution was filtered, and the filtrate was concentrated to ca. $5 \mathrm{~mL}$ and cooled to $-20^{\circ} \mathrm{C}$. Brown cystals were isolated by filtration and dried. 'H NMR spectroscopy indicated that the product was a mixture of $\left(\mathrm{MeC}_{5} \mathrm{H}_{4}\right)_{3} \mathrm{UNSiMe}_{3}$ and $\left(\mathrm{MeC}_{5} \mathrm{H}_{4}\right)_{3} \mathrm{UOPh}$. The major ' $\mathrm{H}$ NMR resonances of $\left(\mathrm{MeC} \mathrm{C}_{5} \mathrm{H}_{4}\right)_{3}$ UOPh are as follows: $-3.1 j(9 \mathrm{H}),-4.75(6 \mathrm{H}),-12.01(6 \mathrm{H})$. This compound was identified by comparison with an authentic sample prepared by Stults. ${ }^{19}$

Reaction of (MeC, $\mathrm{H}_{3}$ UNPh with 'BuNC

To $\left(\mathrm{MeC}_{5} \mathrm{H}_{4}\right)_{3} \mathrm{UNPh}(0.46 \mathrm{~g}, 0.81 \mathrm{mMol})$ dissolved in $20 \mathrm{~mL}$ of toluene was added t-butylisocyanide $(0.10 \mathrm{~mL}, 0.88 \mathrm{mMol})$. The solution was stirred for 8 days with no obvious color change, then the voistile materials were removed under reduced pressure and the residue was extracted with hexane $(50 \mathrm{~mL}$ ). The pale red solution (a lot of the material was not hexane soluble) was filtered and cooled to $-20^{\circ} \mathrm{C}$, resulting in the formation of pale red-orange needles. The ${ }^{1} H$ NMR spectrum $\left(C_{6} D_{j}\right)$ of these needles was complex, and the spectrum changed over time. And. Found: C, 54.3; H, 5.52; N, 7.39. IR: 2180 m, $1590 \mathrm{~m}, 1455$ s, $1290 \mathrm{~m}, 1263 \mathrm{~m}, 1235 \mathrm{~m}, 1218 \mathrm{~m}, 1167 \mathrm{w}, 1068 \mathrm{w}, 1030$ w, 948 $\mathrm{m}, 880 \mathrm{w}, 840 \mathrm{w}, 772 \mathrm{~m}, 751 \mathrm{~m}, 745 \mathrm{~m}, 690 \mathrm{~m} \mathrm{~cm}^{-1}$. Concentration and cooling of the remaining hexane solution yielded a dark solid; the ${ }^{1} \mathrm{H}$ NMR spectrum 
of this material showed it to be $\left(\mathrm{MeC}_{5} \mathrm{H}_{4}\right)_{4} \mathrm{U}$. The remaining hexane solution was filtered, and the volatile material removed under reduced pressure. The ${ }^{1} H$ NMR spectrum of the residue indicated that the primary material in this residue was $\left(\mathrm{MeC}_{5} \mathrm{H}_{4}\right)_{4} \mathrm{U}$, although resonances from $\left(\mathrm{MeC}_{5} \mathrm{H}_{4} \mathrm{~J}_{3} \mathrm{UNPh}\right.$ and $\left(\mathrm{MeC}_{5} \mathrm{H}_{4}\right)_{3} \mathrm{LNHPh}$ were also observed. 


\section{Section 4.2: Chapter 2 Experimental Details}

\section{$\left[\left(\mathrm{MeC} \mathrm{H}_{4}\right)_{3} \mathrm{U}_{5}\left[1-1, \mathrm{AN}_{2} \mathrm{C}_{3} \mathrm{H}_{4}\right]\right.$}

To $0.68 \mathrm{~g}$ of $\left(\mathrm{McC} \mathrm{CH}_{4} \mathrm{H}_{3} \mathrm{U}(\mathrm{th})(1.24 \mathrm{mMOl})\right.$ diseolved in $30 \mathrm{~mL}$ of diethyl ether was added 0.108 of 1,4dinzidobenzene $(0.62 \mathrm{mMOl})$ in $10 \mathrm{mi}$ of diethyl ther. Gas was immediately evolved, and the color of the solution changed from rad to dexp purple with formation of a dark predpitate. After stirring for 15 minutes, the volatile materials were renoved undar reduced pressure, leaving a dark solid. This solid was extracted into toluene $(60 \mathrm{~mL})$, the purple solution was filtered, and the filtrate was concentrated to $40-45 \mathrm{~mL}$ and cooled to $-20^{\circ} \mathrm{C}$. Purple-olack flakes were isolated by filtration and dried under reduced pressure, yielding $0.19 \mathrm{~g}$ of product. Concentrating the remaining solution to ce. $15 \mathrm{~mL}$ and cooling to $-20^{\circ} \mathrm{C}$ allowed isolation of an additional

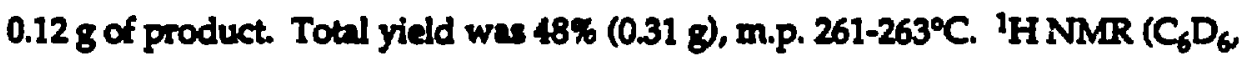
$\left.300^{\circ}\right): 4.69\left(9 \mathrm{H}, V_{1 / 2}=6 \mathrm{~Hz}\right),-2.46\left(6 \mathrm{H}, v_{1 / 2}=23 \mathrm{~Hz}\right),-9.01\left(6 \mathrm{H}, v_{1 / 2}=17 \mathrm{~Hz}\right)$, $15.11\left(4 \mathrm{H}, \mathrm{V}_{1 / 2}=14 \mathrm{H} 2\right.$ ). Anv1. Caled for $\mathrm{C}_{42} \mathrm{H}_{4} \mathrm{~N}_{2} \mathrm{U}_{2}: \mathrm{C}, 47.8 ; \mathrm{H}, 4.40 ; \mathrm{N}, 2.66$. Found: C, 48.1; H, 4.54; N, 2.64. Mass spectrum: 1054 (100; 100), 1055 (47; 36). . IR: 1578 w, $1493 \mathrm{~m}, 1283 \mathrm{~m}, 1260 \mathrm{~m}, 1090 \mathrm{w}, 1047$ w, $1032 \mathrm{~m}, 928 \mathrm{w}, 903$ w, 849 $\mathrm{m}, 833 \mathrm{~m}, 764 \mathrm{~s}, 610 \mathrm{~m}, 592 \mathrm{~m}, 538 \mathrm{w} \mathrm{cm}^{-1}$. Magnetic susceptibility (5 and $40 \mathrm{kG}$ fields): $H_{\text {eft }}=2.94$ B. M. $\left(140-280\right.$ K; $\theta=-147$ K; $\mu_{\text {eft }}=2.08$ B. M. per uranium). The compound is antiferromagnetic with $T_{N}=c a .18 \mathrm{~K}$ and $\mathrm{J}=c a .-19 \mathrm{~cm}^{-1}$.

\section{$\left[\left(\mathrm{MeC}, \mathrm{H}_{4}\right)_{3} \mathrm{U}_{3}\left[\mu-1,3-\mathrm{N}_{2} \mathrm{C}_{6} \mathrm{H}_{4}\right]\right.$}

To $0.47 \mathrm{~g}$ of $\left(\mathrm{MeC}_{5} \mathrm{H}_{4} \mathrm{U}(\mathrm{th})(0.86 \mathrm{mMO})\right.$ dissolved in $15 \mathrm{~mL}$ of diethyl ether was added $2.2 \mathrm{~mL}$ of $\mathbf{a} 0.03 \mathrm{~g} \mathrm{~mL}^{-1}$ solution of 1,3-diazidobenzene $\mathbf{0 . 0 6 6}$ g. $0.41 \mathrm{mMol})$ in toluene. Gas evolution occurred immediately, and the solution color darkened to deep red. The volatile materials were 
immediately removed under reduced pressure. The brown-red solid was extracted with $25 \mathrm{~mL}$ of hot toluene $\left(55-60^{\circ} \mathrm{C}\right)$, the solution was filtered, and the filtrate was concentrated to $\mathrm{ca} .10 \mathrm{~mL}$ and cooled to $-20^{\circ} \mathrm{C}$. Red-brown needles were isolated by filtration and dried in 37\% $(0.17 \mathrm{~g})$ yield, m.p. 213$215^{\circ} \mathrm{C}$. 1HNMR $\left(C_{6} \mathrm{D}_{6}, 59^{\circ} \mathrm{C}\right): 438\left(18 \mathrm{H}, \mathrm{V}_{1 / 2}=17 \mathrm{~Hz}\right),-227\left(12 \mathrm{H}, \mathrm{V}_{1 / 2}=62 \mathrm{~Hz}\right)$,

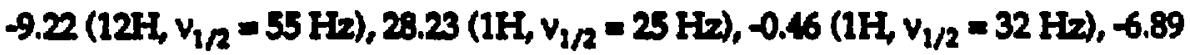
$\left(2 \mathrm{H}, \mathrm{V}_{1 / 2}=32 \mathrm{~Hz}\right.$ ). The $\mathrm{NMR}$ was recorded at $59^{\circ} \mathrm{C}$ because the peak at 0.46 Ppm was too broad to be obeerved at room temperature. Anvl. Calcd for $\mathrm{C}_{42} \mathrm{H}_{4} \mathrm{~N}_{2} \mathrm{U}_{2}: \mathrm{C}, 47.8 ; \mathrm{H} i, 4.40 ; \mathrm{N}, 2.66$. Found: $\mathrm{C}, 47.5 ; \mathrm{H}, 4.41 ; \mathrm{N}, 2.63$. Mass spectrum: 1054 (observed by FAB MS using 18-crown-6 and tetraglyme). IR: $1545 \mathrm{~m}, 1490$ w, 1292 w, $1250 \mathrm{~m}, 1200 \mathrm{~m}, 1148 \mathrm{~m}, 1048 \mathrm{w}, 1029 \mathrm{~m}, 990 \mathrm{~m}, 861$ w, $854 \mathrm{w}, 842 \mathrm{~m}, 797 \mathrm{~m}, 765 \mathrm{~s}, 682 \mathrm{~m}, 604 \mathrm{w}, 330 \mathrm{w} \mathrm{cm}-1$. Magnetic susceptibility (5 and $40 \mathrm{kG}$ fields): $\mu_{\text {eff }}=3.00$ B. M. $\left(140-280 K_{;} \theta=-134 K_{;} \mu_{\text {eff }}=2.12\right.$ B. M. per uranium), $\mu_{\text {eff }}=1.84$ B. M. $\left(5-40 \mathrm{~K} ; \theta=4.0 \mathrm{~K} \mu_{\text {eff }}=1.30\right.$ B. M. per uranium).

\section{$\left[\left(\mathrm{MeC} \mathrm{H}_{4}\right)_{3} \mathrm{U}_{9}\left[\mu-1,2-\left(4-\mathrm{NC}_{6} \mathrm{H}_{4}\right)_{2} \mathrm{C}_{2} \mathrm{H}_{2}\right]\right.$}

To $0.50 \mathrm{~g}$ of $\left(\mathrm{MeC}_{5} \mathrm{H}_{4} \mathrm{U}_{3} \mathrm{U}(\mathrm{th})(0.91 \mathrm{mMol})\right.$ dissolved in $10 \mathrm{~mL}$ of the was added $0.12 \mathrm{~g}$ of 4,4 -diazidostiltene $(0.46 \mathrm{mMol})$ in $10 \mathrm{~mL}$ thf. Gas evolution occurred immediately, and the solution color darkened to deep red. After 30 minutes, the volatile materials were removed under reduced pressure. The brown-red solid was extracted with $30 \mathrm{~mL}$ of toluene, the solution was filtered, and the filtrate was concentrated to $c a .25 \mathrm{~mL}$ and cooled to $-20^{\circ} \mathrm{C}$. Red-brown needles were isolated by filtration and dried in $64 \%(0.34 \mathrm{~g})$ yield, m.p. $241-245^{\circ} \mathrm{C}$. ${ }^{1} \mathrm{HNMR}\left(\mathrm{C}_{6} \mathrm{D}_{6}, 3^{\circ} \mathrm{C}\right): 3.99\left(18 \mathrm{H}, \mathrm{v}_{1 / 2}=22 \mathrm{~Hz}\right),-3.33\left(12 \mathrm{H}, \mathrm{v}_{1 / 2}=\right.$ $60 \mathrm{~Hz}),-10.68\left(12 \mathrm{H}, V_{1 / 2}=62 \mathrm{~Hz}\right), 19.40\left(4 \mathrm{H}, V_{1 / 2}=18 \mathrm{~Hz}\right), 9.48\left(2 \mathrm{H}, v_{1 / 2}=12 \mathrm{~Hz}\right)$. The peak from the ortho protons was not observed. Anal. Calcd for $\mathrm{C}_{50} \mathrm{H}_{52} \mathrm{~N}_{2} \mathrm{U}_{2}: \mathrm{C}, 51.9 ; \mathrm{H}, 4.53 ; \mathrm{N}, 2.42$. Found: $\mathrm{C}, 52.0 ; \mathrm{H}, 4.81 ; \mathrm{N}, 2.22$. Mass 
spectrum: 1157 (observed by FAB MS). Magnetic susceptibility (5 and 40 kG fields): $\mu_{\text {eff }}=2.73$ B. M. (140-220 K; $\theta=-48 \mathrm{~K} ; \mu_{\text {eff }}=1.93$ B. M. per uranium), $\mu_{\text {aff }}=1.94$ B.M. ( $5-40 \mathrm{~K} ; \theta=-6.3 K_{;} \mu_{\text {aff }}=1.37$ B.M. per uranium).

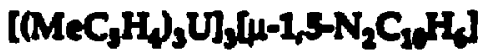

To $0.75 \mathrm{~g}$ of $\left(\mathrm{MeC} \mathrm{CH}_{4} \mathrm{U}(\mathrm{thn})(1.37 \mathrm{mMOl})\right.$ and $0.14 \mathrm{~g}$ of 1,5-divaddonapthalene $(0.67 \mathrm{mMol})$ wes added $10 \mathrm{~mL}$ thf and $30 \mathrm{~mL}$ ether. Gas evolution occurred immediately, and the solution color darkened to deep red-purple. After 10 minutes, the volatile materials were removed under reduced pressure. The brown-red solid was extracted with $75 \mathrm{~mL}$ of hot toluene $\left(50-60^{\circ} \mathrm{C}\right)$, the solution was filtered, and the filtrate was cooled to $-15^{\circ} \mathrm{C}$. Black-purple needles were isolated by filtration and dried in $18 \%(0.26$ g) yield. ${ }^{1} \mathrm{H}$ NMR (d, thf, $\left.30^{\circ} \mathrm{C}\right): 5.35\left(18 \mathrm{H}, \mathrm{v}_{1 / 2}=22 \mathrm{H} / 2\right),-5.18\left(12 \mathrm{H}, \mathrm{v}_{1 / 2}=65\right.$ $H z),-8.19\left(12 \mathrm{H}, V_{1 / 2}=49 \mathrm{H} z\right), 16.95\left(4 \mathrm{H}, V_{1 / 2}=18 \mathrm{Fz}\right), 9.48\left(2 \mathrm{H}, V_{1 / 2}=12 \mathrm{~Hz}\right)$. The other napthalene ring resonances were not observed. Magnetic susceptibility (5 and $40 \mathrm{kG}$ fields): $\mu_{\text {aff }}=2.00$ B.M. $\left(5-40 \mathrm{~K} ; \theta=-5.5 \mathrm{~K} ; \mu_{\text {eff }}=1.41\right.$ B.M. per uranium).

Reaction of $\left(\mathrm{MeC} \mathrm{H}_{4}\right)_{3} \mathrm{U}(\mathrm{th})$ with $\mathrm{Me}_{2} \mathrm{Si}_{\left(\mathrm{N}_{3}\right)_{2}}$

To $1.05 \mathrm{~g}\left(\mathrm{MeC} \mathrm{H}_{4}\right)_{3} \mathrm{U}(\mathrm{th})$ (1.92 mMol) dissolved in $30 \mathrm{~mL}$ of ether was added $0.12 \mathrm{~mL} \mathrm{Me} \mathrm{Si}_{2}\left(\mathrm{~N}_{3}\right)_{2}$ (0.90 mMol). A green-brown precipitate was observed immediately. The volatile materials were removed under reduced pressure. The green-brown solid was examined by 'H NMR spectroscopy and found to be primarily $\left(\mathrm{MeC}_{5} \mathrm{H}_{4} \mathrm{UNN}_{3}\right.$. This solid was extracted with $50 \mathrm{~mL}$ of hot toluene $\left(55-60^{\circ} \mathrm{C}\right)$, the solution was filtered, and the filtrate was concentrated to ce. 25 and then cooled to $-80^{\circ} \mathrm{C}$. Green microcrystals were 
isolated by filtration and dried in $58 \%(0.27 \mathrm{~g})$ yield [based on $\mathrm{Me}_{2} \mathrm{Si}_{(\mathrm{N}} \mathrm{N}_{2}$ ]. The ${ }^{1} \mathrm{H}$ NMR spectrum of this material indicated that it was pure $\left(\mathrm{MeC}_{5} \mathrm{H}_{4}\right)_{3} \mathrm{UN}_{3}$. 


\section{Section 4.3: Chapter 3 Experimental Details}

\section{$\left(\mathrm{MeC}_{5} \mathrm{H}_{4}\right)_{3} \mathrm{U}\left(\mathrm{NH}_{3}\right)$}

$\left(\mathrm{MeC}_{5} \mathrm{H}_{4}\right)_{3} \mathrm{U}(\mathrm{th})(0.45 \mathrm{~g}, 0.82 \mathrm{mmol})$ was dissolved in $30 \mathrm{~mL}$ of toluene, and the solution was frozen in a liquid nitrogen bath and the Schlenk tube evacuated. Into the vacuum line was expanded $9.4 \mathrm{~cm}$ of anhydrous ammonla (Volume $=0.32 \mathrm{Li} 9.4 \mathrm{~cm}=\mathrm{ca} .1 .6 \mathrm{mmol}$ ), and this gas was then condensed into the Schlenk tube. The tube was warmed to room temperature, filled with argon, and the reaction mixture was stirred for 24 hours. At the end of this time, the solution was warmed with a hot water bath to $55-60^{\circ} \mathrm{C}$, then filtered while hot. The dark red filtrate was then concentrated and cooled to $-20^{\circ} \mathrm{C}$. Red needles were isolated by filtration and dried in $57 \%(0.23 \mathrm{~g})$ yield, m.p. $206-210^{\circ} \mathrm{C}$ (with gas evolution and a color change from brown-red to brighter red). ${ }^{1} \mathrm{H} \mathrm{NMR}\left(\mathrm{C}_{6} \mathrm{D}_{6},{ }^{\circ}{ }^{\circ} \mathrm{C}\right):-15.48(9 \mathrm{H}$, $\left.v_{1 / 2}=6 \mathrm{H} 2\right),-9.28\left(6 \mathrm{H}, v_{1 / 2}=16 \mathrm{H} / 2\right),-18.71\left(6 \mathrm{H}, v_{1 / 2}=16 \mathrm{H} / 2\right),-137.25\left(3 \mathrm{H}, v_{1 / 2}=\right.$ $39 \mathrm{~Hz}$ ). Ans. Caled for $\mathrm{C}_{18} \mathrm{H}_{24} \mathrm{NU}$ : $\mathrm{C}, 43.9 ; \mathrm{H}, 4.91 ; \mathrm{N}, 2.84$. Found: $\mathrm{C}, 43.6 ; \mathrm{H}$, 4.78; N, 2.71. Mass spectrum: 492 (100; 100), 493 (32; 20), 494 (30; 2). IR: 3315 $\mathrm{m}, 3241 \mathrm{~m}, 1594 \mathrm{~m}, 1212 \mathrm{~s}, 1026 \mathrm{~m}, 930 \mathrm{w}, 830 \mathrm{~m}, 756 \mathrm{~s}, 617 \mathrm{w}, 577 \mathrm{w} \mathrm{cm}^{-2}$.

\section{$\left.\left(\mathrm{MeC}_{5} \mathrm{H}_{4}\right)_{3} \mathrm{U}^{\left({ }^{13}\right.} \mathrm{NH}_{3}\right)$}

$\left(\mathrm{MeC}_{5} \mathrm{H}_{4}\right)_{3} \mathrm{U}(\mathrm{th})(0.50 \mathrm{~g}, 0.91 \mathrm{mmol})$ was dissolved in $40 \mathrm{~mL}$ of toluene, and the solution was frozen in a liquid nitrogen bath and the Schlenk tube evacuated. Into the vacuum line was expanded $10.4 \mathrm{~cm}$ of ${ }^{15} \mathrm{NH}_{3}($ Volume = $0.32 \mathrm{~L} ; 10.4 \mathrm{~cm}=\mathrm{ca} .1 .8 \mathrm{mmol}$ ), and this gas was then condensed into the Schlenk tube. The tube was warmed to room temperature, filled with argon, and the reaction mixture was stirred for 24 hours. At the end of this time, the solution was filtered and the volatile materials were slowly removed under 
reduced presssure. Red-brown flakes were obtained. ${ }^{1} \mathrm{H} N M R\left(C_{6} D_{6}, 30^{\circ} \mathrm{C}\right)$ : $-15.43\left(9 \mathrm{H}, v_{1 / 2}=6 \mathrm{~Hz}\right),-9.22\left(6 \mathrm{H}, v_{1 / 2}=16 \mathrm{~Hz}\right),-18.73\left(6 \mathrm{H}, v_{1 / 2}=16 \mathrm{~Hz}\right),-135.94$ (3H, d, J = 60 Hz). IR: $3320 \mathrm{~m}, 3240 \mathrm{~m}, 1596 \mathrm{~m}, 1207 \mathrm{~s}, 1043 \mathrm{w}, 1025 \mathrm{w}, 973 \mathrm{w}$, $928 \mathrm{w}, 834 \mathrm{~m}, 812 \mathrm{~m}, 770 \mathrm{~s}, 751 \mathrm{~s}, 617 \mathrm{w} \mathrm{cm}^{-1}$.

\section{$\mathrm{MeC}_{3} \mathrm{H}_{3} \mathrm{U}\left(\mathrm{NH}_{2} \mathrm{Me}\right)$}

$\left(\mathrm{MaC}_{\mathrm{j}} \mathrm{H}_{4} \mathrm{U}\right.$ (th) $(0.60 \mathrm{~g}, 1.10 \mathrm{mmol})$ was diseolved in $25 \mathrm{~mL}$ of toluene and the solution was frozen uaing a liquid ritrogen bath. The Schlenk tube was then evacuated and $\mathrm{Ca} .2 .0 \mathrm{mmol}$ of $\mathrm{MeNH}_{2}$ from a constant volume bulb was condensed into the flask. The solution was warmed to room temperature, the tube filled with nitrogen, and the mixture was stirred for one hour. At the end of this time, the toluene was removed under reduced pressure to leave a red-brown solid. The solid was extracted with ether $(2 \times 30$ $m L)$, the red solution was filtered, and the filtrate was concentrated to ca. 50 $\mathrm{mL}$ and cooled to $-20^{\circ} \mathrm{C}$. Red/black flakes were isolated and dried. A second crop was obtained by concentrating the ether filtrate to 10-15 $\mathrm{mL}$ and cooling to $-78^{\circ} \mathrm{C}$. Overall yield was $70 \%(0.39 \mathrm{~g})$ The compound does not exhibit a clear melting point. When heated slowly in a sealed capillary, the material begins to "soften" at $\mathrm{Ca} .170-175^{\circ} \mathrm{C}$, continues softening to $\mathrm{Ca} .200^{\circ} \mathrm{C}$, then appears to begin to change color to a brighter red-green and finally melts at 237-238 ${ }^{\circ} \mathrm{C}$. ${ }^{1} \mathrm{H} N M R\left(C_{6} \mathrm{D}_{6}, 30^{\circ} \mathrm{C}\right):-17.13\left(9 \mathrm{H}, \mathrm{v}_{1 / 2}=8 \mathrm{~Hz}\right),-11.51\left(6 \mathrm{H}, v_{1 / 2}=19\right.$ $H z),-15.08\left(6 \mathrm{H}, v_{1 / 2}=17 \mathrm{~Hz}\right),-30.34(3 \mathrm{H}),-129\left(2 \mathrm{H}, V_{1 / 2}=70 \mathrm{~Hz}\right)$. Anal. Calcd for $\mathrm{C}_{1} \mathrm{H}_{26 \mathrm{NU}} \mathrm{C}, 45.1 ; \mathrm{H}, 5.17 ; \mathrm{N}, 2.77$. Found: $\mathrm{C}, 44.9 ; \mathrm{H}, 5.03 ; \mathrm{N}, 2.71$. The mass spectrum exhibited an M-1 peak at 505 . IR: $3290 \mathrm{~m}, 3245 \mathrm{~m}, 1588 \mathrm{~m}, 1234 \mathrm{w}$, $1200 \mathrm{w}, 1032 \mathrm{~m}, 987 \mathrm{~s}, 928 \mathrm{w}, 820 \mathrm{~s}, 758 \mathrm{~s}, 611 \mathrm{w}, 327 \mathrm{w} \mathrm{cm}^{-1}$. 
$\left(\mathrm{MeC}_{3} \mathrm{H}_{4}\right)_{3} \mathrm{U}\left(\mathrm{NH}_{2} \mathrm{Ph}\right)$

To $1.00 \mathrm{~g}$ of $\left(\mathrm{MeC} \mathrm{H}_{4} \mathrm{H}_{3} \mathrm{U}(\mathrm{th})(1.83 \mathrm{mmol})\right.$ dissolved in $20 \mathrm{~mL}$ of toluene was added $0.50 \mathrm{~mL}$ of aniline ( $8.5 \mathrm{mmol}$; an excess). The solution was stirred at room temperature for 18 hours, then the toluene removed under reduced preasure. The dark red-brown readue was hated to $50-60^{\circ} \mathrm{C}$ under vacuum to remove exceas aniline, then the reddue was extracted with toluene (55 $\mathrm{mL}$. The solution was flitered, and the toluene completely removed very slowly under reducad preasure. Dark red cryatals were isolated in $84 \%(0.87 \mathrm{~g})$ yield, m.p. 155-157 C (with gas evolution and a color change from brown to red). 'HNMR (C, $\left.\mathrm{C}_{6}, 27^{\circ} \mathrm{C}\right)$ : $-19.81(9 \mathrm{H}),-10.68,\left(6 \mathrm{H}, \mathrm{V}_{1 / 2}=16 \mathrm{~Hz}\right),-13.85(6 \mathrm{H}$, $\left.v_{1 / 2}=16 \mathrm{~Hz}\right), 2.16(t, 1 \mathrm{H}), 0.75(t, 2 \mathrm{H}),-15.26(2 \mathrm{H}),-121.45\left(2 \mathrm{H}, \mathrm{v}_{1 / 2}=115 \mathrm{~Hz}\right)$. Anul. Calcd for $\mathrm{C}_{24} \mathrm{H}_{20} \mathrm{NU}$ : $\mathrm{C}, 50.7 ; \mathrm{H}, 4.96 ; \mathrm{N}, 2.46$. Found: $\mathrm{C}, 49.0 ; \mathrm{H}, 4.88 ; \mathrm{N}$, 2.24. The mass spectrum exhibited an M-1 peak at 567 . IR: $3300 \mathrm{w}, 3215 \mathrm{~m}$, $1592 \mathrm{~m}, 1578 \mathrm{~m}, 1257 \mathrm{~m}, 1225 \mathrm{~m}, 1020$ s, 923 w, 821 s, 810 s, 795 s, 691 s, $608 \mathrm{w}$, $519 \mathrm{~m} \mathrm{~cm}^{-1}$.

\section{$\left(\mathrm{MeC} \mathrm{C}_{3} \mathrm{H}_{3} \mathrm{U}\left(\mathrm{p}-\mathrm{NH}_{2} \mathrm{C}_{6} \mathrm{H}_{4} \mathrm{Me}\right)\right.$}

To $0.52 \mathrm{~g}$ of $\left(\mathrm{MeC}_{5} \mathrm{H}_{4}\right)_{3} \mathrm{U}(\mathrm{th})(0.95 \mathrm{mmol})$ dissolved in $20 \mathrm{~mL}$ of toluene was added $0.11 \mathrm{~g}$ of p-toluidine (1.0 mmol) dissolved in $10 \mathrm{~mL}$ of toluene. No obvious color change was observed. After eight hours, the toluene was removed under reduced preasure, and the excess toluidine was sublimed from the flask using a warm water bath $\left(50-60^{\circ} \mathrm{C}\right)$. The brown solid was then extracted with toluene $(40 \mathrm{~mL})$, the solution was filtered, and the filtrate was concentrated to $\mathrm{ca} .20 \mathrm{~mL}$ and cooled to $-20^{\circ} \mathrm{C}$. Brown needles were isolated and dried in $69 \%(0.38 \mathrm{~g})$ yield, m.p. $166-169^{\circ} \mathrm{C}$ (with gas evolution and a color change from brown to red). ' $\mathrm{H} N M R\left(\mathrm{C}_{6} \mathrm{D}_{6}, 30^{\circ} \mathrm{C}\right)$ : $-19.64\left(9 \mathrm{H}, \mathrm{v}_{1 / 2}=6 \mathrm{~Hz}\right)$, $-10.57\left(6 \mathrm{H}, v_{1 / 2}=17 \mathrm{~Hz}\right),-13.70\left(6 \mathrm{H}, v_{1 / 2}=17 \mathrm{~Hz}\right), 0.59(2 \mathrm{H}, \mathrm{d}, \mathrm{J}=6.8 \mathrm{~Hz}),-15.09$ 
(2H), $-0.78(3 \mathrm{H}),-121\left(2 \mathrm{H}, \mathrm{V}_{1 / 2}=200 \mathrm{~Hz}\right)$. And. Calcd for $\mathrm{C}_{25} \mathrm{H}_{30} \mathrm{NU}: \mathrm{C}, 51.5 ; \mathrm{H}$, 5.19; N, 2.40. Found: C, 51.4; H, 5.11; N, 2.45. IR: 3324 w, $3221 \mathrm{~m}, 1616$ w, 1576 $w, 1514 \mathrm{~m}, 1233 \mathrm{w}, 1146 \mathrm{w}, 1036$ s, 972 w, $936 \mathrm{w}, 928 \mathrm{w}, 816 \mathrm{~m}, 760 \mathrm{~s}, 519 \mathrm{w} \mathrm{cm}^{-1}$.

\section{$\left(\mathrm{MeC}_{3} \mathrm{H}_{4}\right)_{3} \mathrm{UNH}_{2}$}

Method A: $\left(\mathrm{MCC}_{\mathrm{g}} \mathrm{H}_{4}\right)_{3} \mathrm{U}\left(\mathrm{NH}_{3}\right)(0.25 \mathrm{~g}, 0.51 \mathrm{mMol})$ was dissolved in 25 $\mathrm{mL}$ of xylense in a $100 \mathrm{~mL}$ round-bottomed Schlenk flask. A reflux condenser with a gas inlet was attached to the flask, and the solution heated to reflux for 1.5 hours. The color lightened to red-green over this time. The solution was allowed to cool slightly, then filtered. The volatile materials were removed under reduced preasure, and the residue was extracted with warm hexane (20 $\mathrm{mL}$ ). The solution was filtered and cooled to $-80^{\circ} \mathrm{C}$. Brown microcrystals were isolated by filtration and dried in $44 \%(0.11 \mathrm{~g})$ yield. The compound did not exhibit a clear melting point; the material darkened and "softened" at 170$175^{\circ} \mathrm{C}$, was very dark brown by $260^{\circ} \mathrm{C}$, and did not melt up to $310^{\circ} \mathrm{C}$. ${ }^{1} \mathrm{H}$ NMR $\left(C_{6} D_{6} 30^{\circ} \mathrm{C}\right): 0.39\left(9 \mathrm{H}_{1} \mathrm{v}_{1 / 2}=3 \mathrm{~Hz}\right),-5.73\left(6 \mathrm{H}, \mathrm{v}_{1 / 2}=8 \mathrm{~Hz}\right),-17.07\left(6 \mathrm{H}, \mathrm{v}_{1 / 2}=8\right.$ $\mathrm{H}(2),-135.4(2 \mathrm{H}, \mathrm{t}, \mathrm{J}=44 \mathrm{~Hz})$. Anv1. Calcd for $\mathrm{C}_{18} \mathrm{H}_{23} \mathrm{NU}$ : C, 44.0; H, 4.72; N, 285. Found: C, 42.6; H, 4.44; N, 2.44. Mass spectrum: 491 (100; 100), 492 (21; 20). IR: 3315 w, $1495 \mathrm{~m}, 1258$ w, 1235 w, 1150 w br, 1068 w, $1045 \mathrm{~m}, 1029 \mathrm{~m}, 970$ w, $929 \mathrm{w}, 830 \mathrm{~m} \mathrm{br}, 760 \mathrm{~s}, 720 \mathrm{~m}, 652 \mathrm{~m}, 601 \mathrm{~m}, 497 \mathrm{~m}, 450 \mathrm{~m}, 327 \mathrm{~m} \mathrm{~cm}^{-1}$.

Method B: Tn $\left(\mathrm{MeC}_{5} \mathrm{H}_{4}\right)_{3} \mathrm{U}_{\left(\mathrm{NH}_{3}\right)}(0.56 \mathrm{~g}, 1.1 \mathrm{mMol})$ was added $0.33 \mathrm{~g}$ $\left(\mathrm{Ph}_{3} \mathrm{Cl}_{2} \cdot \mathrm{PhMe}^{20}\right.$ (1.1 mMol of trityl monomer) dissolved in $30 \mathrm{~mL}$ of hexane. The solution immediately turned bright grcen-red. After three hours, the solution was filtered and the volatile materials were removed under reduced pressure. A cold finger was placed in in the flask and the solid heated to $100^{\circ} \mathrm{C}$ under reduced pressure for three hours. A green-white solid sublimed onto the coldfinger; this material was discarded. ${ }^{1} \mathrm{H}$ NMR spectroscopy 
showed that the remaining solid $(0.37 \mathrm{~g})$ was a mixture of $\left(\mathrm{MeC}_{5} \mathrm{H}_{4}\right)_{3} \mathrm{UNH}_{2}$ and $\mathrm{Ph}_{3} \mathrm{CH}$ (approximate molar ratio $1.0: 0.6$ ).

Method C. To (MeCjH $)_{3} U($ the $(0.50 \mathrm{~g}, 0.91 \mathrm{mMol})$ dissolved in $20 \mathrm{~mL}$ of the was added $28 \mu \mathrm{L}$ of anhydrous hydrazine. The solution was stirred for 18 hours, during which time the color turned light green. The volatile materials were removed under reducad presaure and the solid extracted with tolume (30 $\mathrm{mL}$ ), filtered, and the teluene remove under reduced pressure. To the green residue was addad $10 \mathrm{~mL}$ of hexame, and the solution was stirred for 30 minutes and then cooled to $-80^{\circ} \mathrm{C}$. Red-green microcrystals were isolated by filtration and dricj in $20 \%(0.09 \mathrm{~g})$ yield. The ' ${ }^{1} \mathrm{H}$ NMR spectrum of this material showed it to be $\left(\mathrm{MeC}_{5} \mathrm{Fi}_{4}\right)_{3} \mathrm{LNH}_{2}$.

\section{$\left(\mathrm{MeC}_{5} \mathrm{H}_{4}\right)_{3} \mathrm{U}^{13} \mathrm{NH}_{2}$}

$\left(\mathrm{MeC} \mathrm{H}_{4} \mathrm{~L}_{3}\left(\mathrm{~N}_{\mathrm{NH}}\right)(0.25 \mathrm{~g}, 0.51 \mathrm{mMOl})\right.$ and $\left(\mathrm{Ph}_{3} \mathrm{C}_{2}\right.$. $\mathrm{PhMe}(0.15 \mathrm{~g}, 0.50$ mMol of trityl monomer) were mixed and $6 \mathrm{~mL}$ of toluene was added. The solution was warmed to $60^{\circ} \mathrm{C}$ and stirred for 10 minutes. At the end of this time, the solution was filtered, allowed to cool to room temperature, then cooled to $-80^{\circ} \mathrm{C}$. $A$ tan solid was isolated by filtration and dried; ${ }^{1} \mathrm{H}$ NMR spectroscopy indicated that this was a mixture of $\mathrm{Ph}_{3} \mathrm{CH}$ and unreacted $\left(\mathrm{MeC}_{5} \mathrm{H}_{4}\right)_{3} \mathrm{U}\left({ }^{15} \mathrm{NH}_{3}\right)$. The volatile materials from the mother liquor were removed under reduced pressure to yield $\left(\mathrm{M} C_{5} \mathrm{H}_{\mathrm{S}_{3}} \mathrm{U}^{15} \mathrm{NH}_{2}\right.$ and additional $\mathrm{Ph}_{3} \mathrm{CH}$. ${ }^{1} \mathrm{H} N \mathrm{MR}\left(\mathrm{C}_{6} \mathrm{D}_{6}, 30^{\circ} \mathrm{C}\right): 0.39(9 \mathrm{H}),-5.74(6 \mathrm{H}),-17.03(6 \mathrm{H}),-134.86\left(2 \mathrm{H}, \mathrm{d}_{8} \mathrm{~J}\right.$ $=64 \mathrm{~Hz}$ ).

Reaction of $\left(\mathrm{MeC}_{9} \mathrm{H}_{4}\right)_{3} \mathrm{UNH}_{2}$ with $\mathrm{AMC}_{3}$

To $\left(\mathrm{MeC}_{5} \mathrm{H}_{4}\right)_{3} \mathrm{UNH}_{2}(0.24 \mathrm{~g}, 0.49 \mathrm{mMol})$ dissolved in $15 \mathrm{~mL}$ of toluene was added $\mathrm{AlMe}_{3}$ in hexane $(0.35 \mathrm{~mL}$ of a $1.38 \mathrm{M}$ solution, $0.48 \mathrm{mMol})$. The 
solution was stirred for four days, then the volatile materials were removed under reduced pressure. The green solid was extracted with toluene $(20 \mathrm{~mL})$, the solution was filtered, and the volatile materials were removed from the filtrate under reduced pressure. 'H NMR spectroscopy indicated that this material was primarily $\left(\mathrm{MCC}_{5} \mathrm{H}_{4}\right)_{3} \mathrm{UMe}$.

\section{$\left(\mathrm{MeC} \mathrm{H}_{4}\right)_{3} \mathrm{UNHMe}$}

$\left(\mathrm{MeC}_{5} \mathrm{H}_{4}\right)_{3} \mathrm{U}\left(\mathrm{NH}_{2} \mathrm{Me}\right)(0.15 \mathrm{~g} 0.30 \mathrm{mMol})$, in a Schlenk tube under $\mathrm{N}_{2}$ was immersed in an oil bath at $215-225^{\circ} \mathrm{C}$. The dark brown solid melted and turned red. After 20 minutes, the flask was cooled to room temperature, and the solid was extracted with warm tolvene $\left(50-60^{\circ} \mathrm{C}\right)$. The red-green solution was filtered and the toluene remove to give a green-red solid in $80 \%(0.12 \mathrm{~g})$

yield. $\left.{ }^{1} \mathrm{HNMR} \mathrm{C}_{6} \mathrm{D}_{6} 30^{\circ} \mathrm{C}\right): 1.44(9 \mathrm{H}),-10.71\left(6 \mathrm{H}, \mathrm{v}_{1 / 2}=7 \mathrm{~Hz}\right),-14.98\left(6 \mathrm{H}, \mathrm{v}_{1 / 2}=\right.$ $7 \mathrm{~Hz}), 7.29(3 \mathrm{H}, \mathrm{d}, \mathrm{J}=\mathrm{j} .9 \mathrm{~Hz}),-103 \mathrm{75}\left(1 \mathrm{H}, \mathrm{v}_{1 / 2}=50 \mathrm{~Hz}\right)$. Anal. Calcd for $\mathrm{C}_{1} \mathrm{H}_{2 \mathrm{~S}} \mathrm{NU}: \mathrm{C}, 45.2 ; \mathrm{H}, 490 ; \mathrm{N}, 2.77$. Found: $\mathrm{C}, 45.0 ; \mathrm{H}, 4.99 ; \mathrm{N}, 2.57$. Mass spectrum: 505 (100; 100), 506 (33; 21). IR: 1492 w, 1408 w, 1258 m, 1238 w, 1056 s, $1027 \mathrm{~s}, 930 \mathrm{w}, 840 \mathrm{~m}, 760 \mathrm{~s}, 606 \mathrm{~m}, 425 \mathrm{~m} \mathrm{br}, 329 \mathrm{~m} \mathrm{~cm}^{-1}$.

\section{$\left(\mathrm{MeC}_{3} \mathrm{H}_{4}\right)_{3} \mathrm{U}(\mathrm{NHPh})$}

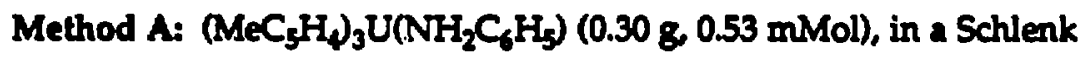
tube under $\mathrm{N}_{2}$, was immersed in an oil bath at $160^{\circ} \mathrm{C}$. The dark brown solid melted, turned red, and gas was evolved. After one hour at $160^{\circ} \mathrm{C}$, the flask was cooled to room temperature, and the solid was extracted with hexane (30;10 mL; the solution was warmed to dissolve the solid). The bright red solution was filtered, and the filtrate was concentrated and cooled to $-20^{\circ} \mathrm{C}$. Red bricks were isolated and dried in $53 \%(0.16 \mathrm{~g})$ yield, m.p. $128-129^{\circ} \mathrm{C}$. ${ }^{\mathrm{H}} \mathrm{H}$ $\operatorname{NMR}\left(C_{6} D_{6}, 30^{\circ} \mathrm{C}\right): 4.20(9 \mathrm{H}),-1.03\left(6 \mathrm{H}, v_{1 / 2}=8 \mathrm{~Hz}\right),-18.56\left(6 \mathrm{H}, v_{1 / 2}=9 \mathrm{~Hz}\right)$, 
$-2.10(t, 2 H),-5.18(t, 1 H D),-33.58(d, 2 H),-164.57\left(1 \mathrm{H}, v_{1 / 2}=24 \mathrm{~Hz}\right)$. Anal. Calcd for $\mathrm{C}_{24} \mathrm{H}_{22} \mathrm{NU}$ : $\mathrm{C}, 50.8 ; \mathrm{H}, 4.80 ; \mathrm{N}, 2.47$. Found: $\mathrm{C}, 50.8 ; \mathrm{H}, 4.84 ; \mathrm{N}, 2.66$. Mass spectrum: $567(100 ; 100), 566(27 ; 27)$. RR: $1582 \mathrm{~s}, 1347 \mathrm{~m}, 1253 \mathrm{~s}, 1210 \mathrm{~m}, 1168$ m, 1148 w, 1063 m, $1026 \mathrm{~m}, 989 \mathrm{~m}, 928 \mathrm{~m}, 899$ w, 840 s, 773 s, 747 s, 690 s, 607 m, $558 \mathrm{~s}, 543 \mathrm{w}, 490 \mathrm{~m}, 340 \mathrm{~s}, 325 \mathrm{~m}, 252 \mathrm{~m}, 236 \mathrm{~s} \mathrm{~cm}^{-1}$.

Method 8: in a $100 \mathrm{~mL}$ Schlenk flask, $0.52 \mathrm{~g}$ of (MCC, $\mathrm{H})_{3}$ UMe (1.1 mMol) was disuolved in $30 \mathrm{~mL}$ of hexane, and $0.20 \mathrm{~mL}$ of aniline (2.2 mMol) was addad. The flack was equipped with a reflux condenser topped with a gas inlet, and the solution was heated to reflux. The solution slowly turned from green-brown to red. After 60 hours, the flask was cooled and the condenser was removed. The bright red solution was filtered, and the filtrate was concentrated to $\mathrm{ca} .10 \mathrm{~mL}$ and cooled to $-20^{\circ} \mathrm{C}$. Red crystals were isolated by filtration and dried in $38 \%(0.23 \mathrm{~g})$ yield. 'H NMR showed this product to be (MeC $\mathrm{H}_{5} \mathrm{H}_{3} \mathrm{U}(\mathrm{NH}$ Ph).

\section{$\left(\mathrm{MeC}_{\text {gii }}\right)_{3} \mathrm{U}(\mathrm{NH}-\mathrm{p}-\mathrm{tolyl})$}

Method A: $\left(\mathrm{MeC}_{5} \mathrm{H}_{4}\right)_{3} \mathrm{U}\left(\mathrm{NH}_{2}-\mathrm{p}-\mathrm{tolyl}\right)\left(0.21_{\mathrm{g}}, 0.36 \mathrm{mMOl}\right)$, in a Schlenk tube under $\mathrm{N}_{2}$, was immersed in an oll bath at $160^{\circ} \mathrm{C}$. The dark brown solid melted, turned red, and gas was evolved. After 20 minutes at $160^{\circ} \mathrm{C}$, the flask was cooled to room temperature, and the solid was extracted with hexane (20 $m L_{i}$ the solution was warmed to dissolve the solid). The bright red solution was filtered, and the filtrate was concentrated to ca. $7 \mathrm{~mL}$ and cooled to $-20^{\circ} \mathrm{C}$. Red crystals were isolated and dried in $53 \%(0.11 \mathrm{~g})$ yield, m.p. $92-94^{\circ} \mathrm{C} .{ }^{1} \mathrm{H}$ $\operatorname{NMR}\left(\mathrm{C}_{6} \mathrm{D}_{6}, 30^{\circ} \mathrm{C}\right): 4.38\left(9 \mathrm{H}, \mathrm{v}_{1 / 2}=2 \mathrm{~Hz}\right),-1.91\left(6 \mathrm{H}, \mathrm{v}_{1 / 2}=7 \mathrm{~Hz}\right),-18.46\left(6 \mathrm{H}, \mathrm{v}_{1 / 2}\right.$ $=7 \mathrm{~Hz}), 1.04(3 \mathrm{H}),-1.80(2 \mathrm{H}),-32.78(2 \mathrm{H}, \mathrm{d}, \mathrm{J}=7.9 \mathrm{~Hz}),-158.78\left(1 \mathrm{H}, v_{1 / 2}=19 \mathrm{~Hz}\right)$. Anal. Calcd for $\mathrm{C}_{25} \mathrm{H}_{2 \mathrm{NU}} \mathrm{NU}$ :, $51.6 ; \mathrm{H}, 5.03 ; \mathrm{N}, 2.41$. Found: $\mathrm{C}, 51.5 ; \mathrm{H}, 4.94 ; \mathrm{N}$, 2.38. Mass spectrum: $581(100 ; 100), 582(24 ; 28), 583(2 ; 4)$. IR: $1603 \mathrm{~m}, 1501 \mathrm{~s}$, 
1252 s, $1208 \mathrm{~m}, 1175 \mathrm{~m}, 1102 \mathrm{w}, 1047 \mathrm{~m}, 1032 \mathrm{~m}, 932 \mathrm{w}, 889$ w, $851 \mathrm{~m}, 768$ s, 602 $w, 523 \mathrm{~m} \mathrm{~cm}^{-1}$.

Method B: To $0.35 \mathrm{~g}$ of $\left(\mathrm{MeC}_{5} \mathrm{H}_{4}\right)_{3} \mathrm{UNH}_{2}-\mathrm{p}$-tolyl) $(0.60 \mathrm{mMol})$ dissolved in $20 \mathrm{~mL}$ of toluene was added $0.35 \mathrm{~g}$ of $\left(\mathrm{McC}_{3} \mathrm{H}_{4}\right)_{3} \mathrm{UNC}_{6} \mathrm{H}_{4} \mathrm{CH}_{3}(0.60 \mathrm{mMol})$ i iseolved in $10 \mathrm{~mL}$ of toluene. The solution immediately turned bright red. After 90 minutes, the colvent was removed under reduced preasure to give a bright red solid. The solid was extracted with hexane $(60 \mathrm{~mL})$, the red solution was filtered, and the flitrate was concentrated to ca. $30 \mathrm{~mL}$ and cooled to $-20^{\circ} \mathrm{C}$. Red crystals were isolated by filtration and dried in $69 \%(0.48 \mathrm{~g})$ yield. ${ }^{2} \mathrm{H}$ NMR showed this product to be $\left(\mathrm{MeC}_{5} \mathrm{H}_{4} \mathrm{~J}_{3} \mathrm{U}(\mathrm{NH}-\mathrm{p}\right.$-tolyl).

\section{$\left(\mathrm{MeC}_{3} \mathrm{H}_{4}\right)_{3} \mathrm{UN}\left(\mathrm{NH}_{2}\right) \mathrm{Fh}$}

Method A: To $\left(\mathrm{MeC}_{5} \mathrm{H}_{4}\right)_{4} \mathrm{U}(0.27 \mathrm{~g}, 0.49 \mathrm{mMol})$ dissolved in $15 \mathrm{~mL}$ of toluene was added $45.5 \mu \mathrm{L}$ of phenylhydrazine $(0.46 \mathrm{mMol})$. The solution was stirred for 40 hours, during which time a color change from red to orange occurred. At the end of this time, the volatile materials were removed under reduced pressure and the red-orange oily solid was extracted with $20 \mathrm{~mL}$ of hexane and $5 \mathrm{~mL}$ of $\mathrm{Et}_{2} \mathrm{O}$. The orange solution was filtered, and the filtrate was concentrated to $\mathrm{ca} .15-20 \mathrm{~mL}$ and cooled to $-20^{\circ} \mathrm{C}$. Red bricks were isolated by filtration and dried in $46 \%(0.12 \mathrm{~g})$ yield, m.p. $81-87^{\circ} \mathrm{C}$. An additional amount (ca. $0.03 \mathrm{~g}$ ) was obtained by further concentration of the filtrate (7-10 $\mathrm{mL})$ and cooling to $-20^{\circ} \mathrm{C}$. The total yield was $56 \%$. ${ }^{1} \mathrm{H} \operatorname{NMR}\left(\mathrm{C}_{6} \mathrm{D}_{6}, 30^{\circ} \mathrm{C}\right)$ : $-0.03(9 \mathrm{H}),-5.73\left(6 \mathrm{H}, v_{1 / 2}=9 \mathrm{~Hz}\right),-18.32\left(6 \mathrm{H}, v_{1 / 2}=9 \mathrm{~Hz}\right), 10.90(2 \mathrm{H}, \mathrm{d}, \mathrm{J}=6.8 \mathrm{~Hz})$, $8.17(2 \mathrm{H}, \mathrm{m}),-9.24(2 \mathrm{H})$. The resonance from the para proton of the phenyl ring is buried under the solvent signal at room temperature, but can be observed in the variable temperature ${ }^{1} \mathrm{H}$ NMR spectrum. At $-12^{\circ} \mathrm{C}$, the following resonances were observed: $0.34(9 \mathrm{H}),-5.36(-\mathrm{H}),-23.29(6 \mathrm{H}), 10.01$ 
$(2 \mathrm{H}, \mathrm{d}, \mathrm{J}=7.7 \mathrm{~Hz}), 7.81(1 \mathrm{H}), 7.59(2 \mathrm{H}), 6.79 \mathrm{ppm}(2 \mathrm{H})$. Anal. Calcd for

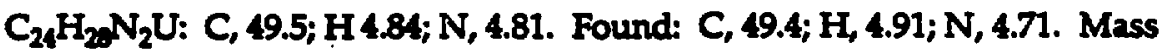
spectrum: 582 (100; 100), 583 (26; 27). IR: 3285 w, 3223 w, 1589 s, 1561 s, $1491 \mathrm{~s}$, $1298 \mathrm{~s}, 1260$ vs, $1184 \mathrm{w}, 1154 \mathrm{w}, 1047 \mathrm{~m}, 1030 \mathrm{~m}, 988 \mathrm{~m}, 849 \mathrm{~m}, 779$ vs br, $752 \mathrm{~s}$, $694 \mathrm{~m}, 633 \mathrm{~m}, 592 \mathrm{~m} \mathrm{~cm}^{-1}$.

Method 8: $\left(M C_{5} \mathrm{H}_{4}\right)_{3} \mathrm{U}(\mathrm{th})(0.50 \mathrm{~g}, 0.91 \mathrm{mMol})$ was dissolved in $20 \mathrm{~mL}$ $\alpha \mathrm{Et}_{2} \mathrm{O}$ and the solution was cooled to $0^{\circ} \mathrm{C}$. Phenylhydrazine $(0.10 \mathrm{~mL}, 1.0$ mMol) was added by syringe, and the solution inmediately turned red. After two minutes, the volatile materials were removed under reduced pressure while keeping the material at $0^{\circ} \mathrm{C}$. The brown solid was extracted with $40 \mathrm{~mL}$ of cold $\mathrm{Et}_{2} \mathrm{O}\left(0^{\circ} \mathrm{C}\right)$, and the solution was filtered into a pre-cooled flask and cooled to $-20^{\circ} \mathrm{C}$. Brown crystals were isolated and dried in $15 \%(0.07 \mathrm{~g})$ yield (based on uranium). 'H NMR spectroscopy indicated that this material was $\left(\mathrm{MeC}_{5} \mathrm{H}_{4}\right)_{3} \mathrm{U}\left(\mathrm{NH}_{3}\right)$. The mother liquor was concentrated to $c e .5 \mathrm{~mL}$ and cooled to $-80^{\circ} \mathrm{C}$. A very small amount of brown powder formed. The solution was again filtered, ca. $10 \mathrm{~mL}$ of hexane was added, and the solution was cooled to $-20^{\circ} \mathrm{C}$. Orange crystals were isolated by filtration and dried in $17 \%(0.09 \mathrm{~g})$ yield. ${ }^{1} \mathrm{H}$ NMR spectroscopy indicated that the material was $\left(\mathrm{MeC}_{5} \mathrm{H}_{4} \mathrm{UNN}_{3} \mathrm{UNH}\right)_{2} \mathrm{Ph}$.

Method C: To $\left(\mathrm{MeC}_{5} \mathrm{H}_{4} \mathrm{~J}_{3} \mathrm{U}^{+} \mathrm{Bu}(0.10 \mathrm{~g}, 0.19 \mathrm{mMol})\right.$ dissolved in $10 \mathrm{~mL}$ of $\mathrm{Et}_{2} \mathrm{O}$ was added $17.6 \mu \mathrm{L}$ of phenylhydrazine $(0.18 \mathrm{mMol})$. The solution was stirred for $11 / 4$ hours, during which time a color change from green to orange occurred. At the end of this time, the volatile materials were removed under reduced pressure and the red-orange oily solid was examined by ${ }^{1} \mathrm{H}$ NMR spectroscopy, indicating that the material was primarily $\left(\mathrm{MeC}_{5} \mathrm{H}_{4}\right)_{3}^{-} \mathrm{N}\left(\mathrm{NH}_{2}\right) \mathrm{Ph}$. 
Method D: To $\left(\mathrm{MeC}_{5} \mathrm{H}_{4}\right)_{3} \mathrm{LMe}(0.04 \mathrm{~g}, 0.08 \mathrm{mMol})$ dissolved in $10 \mathrm{~mL}$ of toluene was added $8.4 \mu \mathrm{L}$ of phenylhydrazine (0.09 mMol). The solution was heated to $70-75^{\circ} \mathrm{C}$ for 42 hours, during which time the color changed to orange. At the end of this time, the solution was cooled and filtered and the volatile materials were removed under reduced pressure. the red-orange oily solid was examined by ${ }^{1} \mathrm{H}$ NMR spectroscopy, indicating that the material was

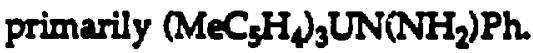

\section{$\left(\mathrm{MeC}_{5} \mathrm{H}_{4}\right)_{3} \mathrm{UN}\left({ }^{15} \mathrm{NH}_{2}\right) \mathrm{Ph}$}

To $\left(\mathrm{MeC}_{5} \mathrm{H}_{4}\right)_{4} \mathrm{U}(0.25 \mathrm{~g}, 0.45 \mathrm{mMol})$ diseolved in $15 \mathrm{~mL}$ of toluene was added $42.5 \mu \mathrm{L}$ of $\mathrm{PhNH}^{15} \mathrm{NH}_{2}(0.43 \mathrm{mMol})$. The solution was stirred for 18 hours, during which time a color change from red to orange occurred. At the end of this time, the volatile materials were removed under reduced pressure and the red-orange oily solid was extracted with $20 \mathrm{~mL}$ of hexane and $5 \mathrm{~mL}$ of $\mathrm{Et}_{2} \mathrm{O}$. The orange solution was filtered, and the filtrate was concentrated to $\mathrm{ca}$. $15-20 \mathrm{~mL}$ and cooled to $-20^{\circ} \mathrm{C}$. A red-orange powder were isolated by filtration and dried. ${ }^{1} \mathrm{H} N M R\left(\mathrm{C}_{6} \mathrm{D}_{6}, 30^{\circ} \mathrm{C}\right)$; $-0.03(9 \mathrm{H}),-5.74(6 \mathrm{H}),-18.30(6 \mathrm{H}), 10.86(2 \mathrm{H}$, d), $8.13(2 \mathrm{H}, \mathrm{m}),-9.24(2 \mathrm{H}, \mathrm{d}, \mathrm{J}=76 \mathrm{~Hz})$. IR: $3281 \mathrm{w}, 3225 \mathrm{w}, 1591 \mathrm{~s}, 1572 \mathrm{~m}, 1495$ m, 1296 w, 1254 s, 1186 m, 1152 w, 1044 m, 988 w, 868 e, 833 m, 818 s, 791 vs, 764 vs, $694 \mathrm{~m}, 635 \mathrm{~m} \mathrm{~cm}^{-1}$.

Thermolyses of $\left(\mathrm{MeC}_{5} \mathrm{H}_{4}\right)_{3} \mathrm{UN}\left(\mathrm{NH}_{2}\right) \mathrm{Ph}$ and $\left(\mathrm{MeC}_{5} \mathrm{H}_{4}\right)_{3} \mathrm{UN}\left({ }^{15} \mathrm{NH}_{2} \mathrm{Ph}\right)$

$\left(\mathrm{MeC}_{5} \mathrm{H}_{4}\right)_{3} \mathrm{UN}\left(\mathrm{NH}_{2}\right) \mathrm{Ph}$ was dissolved in $\mathrm{d}_{8}$-toluene. The ${ }^{1} \mathrm{H} \mathrm{NMR}$ spectrum was obtained, then the NMiR tube was heated in a constant temperature bath to $120^{\circ} \mathrm{C}$. Spectra were obtained over various time intervali:, and indicated the disappearance of the phenylhydrazide and the 
appearance of $\left(\mathrm{MeC}_{5} \mathrm{H}_{4}\right)_{3} \mathrm{UNHPh}$. For the labelled material, the ${ }^{1} \mathrm{H} \mathrm{NMR}$ spectrum showed a singlet for the $\mathrm{N}-\mathrm{H}$ resonance at $-162 \mathrm{ppm}$.

\section{$\left[\left(\mathrm{MeC} \mathrm{C}_{3} \mathrm{H}_{4}\right)_{3} \mathrm{U}_{2}\left[\mu-1,4-\left(\mathrm{H}_{2} \mathrm{~N}_{2} \mathrm{C}_{6} \mathrm{H}_{4}\right]\right.\right.$}

$\left(\mathrm{MeC}_{5} \mathrm{H}_{4}\right)_{3} \mathrm{U}(\mathrm{th})(0.65 \mathrm{~g}, 1.2 \mathrm{mMOl})$ was diecolved in $30 \mathrm{~mL}$ of $\mathrm{Et}_{2} \mathrm{O}$. This solution was filtered onto 0.0658 p-phenylenediamine $(0.60 \mathrm{mMol})$. A brown precipitate immediately began to form. The solution was stirred overnight, then flltered. The brown powder was dried under reduced pressure in $66 \%(0.42 \mathrm{~g})$ yield, m.p. 193-1970 C. The ${ }^{1} \mathrm{H}$ NMR spectrum could not be obtained due to the insolubility of the material. Ansl. Calcd for $\mathrm{C}_{42} \mathrm{H}_{50} \mathrm{~N}_{2} \mathrm{U}_{2}: \mathrm{C}, 47.6 ; \mathrm{H}, 4.76 ; \mathrm{N}, 2.65$. Found: $\mathrm{C}, 47.4 ; \mathrm{H}, 4.89 ; \mathrm{N}, 2.64$. IR: 3280 $m, 3230 \mathrm{~m}, 1588 \mathrm{~m}, 1489 \mathrm{~m}, 1375 \mathrm{~m}, 1347 \mathrm{w}, 1258 \mathrm{w}, 1235 \mathrm{~m}, 1217 \mathrm{w}, 1140 \mathrm{w}$, $1119 \mathrm{w}, 1025 \mathrm{~s}$ br, $935 \mathrm{w}, 927 \mathrm{w}, 815 \mathrm{~s}, 735$ s br, $610 \mathrm{w}, 541 \mathrm{~m}, 329 \mathrm{w} \mathrm{cm}^{-1}$. The material used for magnetic susceptibility measurements was made by an analogous procedure with toluene as solvent, an excess of $\left(\mathrm{MeC}_{5} \mathrm{H}_{4}\right)_{3} \mathrm{U}($ thf $)$ (2.5 molar equivalents), and sublimed, zone-refined p-phenylenediamine (Aldrich Chem. Co.). The brown, microcrystalline precipitate was washed with $10 \mathrm{~mL}$ of tolvene and $20 \mathrm{~mL}$ of $\mathrm{Et}_{2} \mathrm{O}$ prior to the measurement of its magnetism. 


\section{References}

1 Brennan, J. G. Ph.D. Thesis, Unioersity of Califormia, Berkeley 1985.

2 Eigenbrot, C. W.; Raymond, K. N. Polyhedron. 1982, 1, 417.

3 Pritzkow, V. W.; Timm, D. J. Prakt. Chem. 1966, 32, 178.

- Thayer, J. S.; Weat, R Inorg. Chem. 1964, 3, 889.

5 Thayer, J. S.; Weat, R Inorg. Chem. 1964, 3, 406.

- Arcus, C. C.; Mealey, P. J. J. Chem. Soc. 1933, 178, 181.

7 (a) Nölting. Chem. Ber. 1893, 26, 86. (b) Smith, P. A. S. Org. Syn. 1951, $31,14$.

- Ugi, I.; Perlinger, H.; Behringer, L. Chem. Ber. 1958, 91, 2330.

- Patel, D. I.; Smalley, R. K. J. Chem. Soc., Perkin Trans. I 1984, 2587.

10 Sundberg, R. J.; Suter, S. R.; Brenner, M. I Am. Chem. Soc. 1972, 94, 513.

11 Purvis, R; Smalley, R. K.; Suschitzky, H.; Alkhader, M. A. J. Chem. Soc., Perkin Trans. I 1984, 249.

12 The general procedures may be found in: (a) Smith, P. A. S.; Brown, B. B. J. Am. Chem. Soc. 1951, 73, 2435. (b) Smolinsky, G. J. Am. Chem. Soc. $1960,82,4717$.

13 Herring, D. L. J. Org. Chem. 1961, 26, 3998.

14 Forster, M. O.; Fierz, H. E. J. Chem. Soc. 1907, 91, 942.

13 Reiser, A.; Wagner, H. M.; Marley, R; Bowes, G. Trans. Faraday Soc. $1967,63,2403$.

16 Mikkelsen, R. B.; Wallach, D. F. H. J. Biol. Chem. 1976, 251, 7413.

17 Washburne, S. S.; Peterson, Jr., W. R. J. Organomet. Chem. 1971, 33, 153.

10 Audrieth, L. G.; Gibbs, C. F. Inors ?mth. 1, 78.

19 Stults, S. D. Ph.D. Thesis, Universtty of California, Berkeley 1988. 
20 A preparation of the trityl dimer may be found in: Hayes, J. Ph.D. Thesis, Harourd Unioersity 1984. The "molecular" silver needed for this preparation is deccribed in: Brauer, G. in Handbook of Preparative inorganic Chemistry, 2nd Edition, Volume 2, Riley, R. F. ed., Academic Prea, New York, 1963, p. 1623. 


\section{DISCLAIMER}

This document was prepared as an account of work sponsored 'by the United States Government. Neither the United Stales Government nor any axency thereof, nor The Reyents of the University of Californin, nor any of their employees, makes any warranty, express or implied, or assumes any lezal liability or responsibility for the eccuracy, compteteness, or usefulness of any information, apparatus, product, or process disciosed, or represents that its use would not infrine privately owned rights. Reference herein to any specific commercial products process, or iservice by its trade name, trademark, manufucturer, or other: wise. does not necessarily constilute or imply its endorsement, ' recommendation, or favorins by the United Sutes Government , or any ayency thereof, or The Reents of the University of Cali. , fornis. The views and opinions of authors expressed herein do ' not necessarily sute or reflect those of the United Sutes 'Government or any apency thereof or The Reyents of the - University of Californic and shall not be uxed for advertising or product endorsement purposes.

Lawrence Berkeley Laboratory is an equal opportunity employer.

inis 